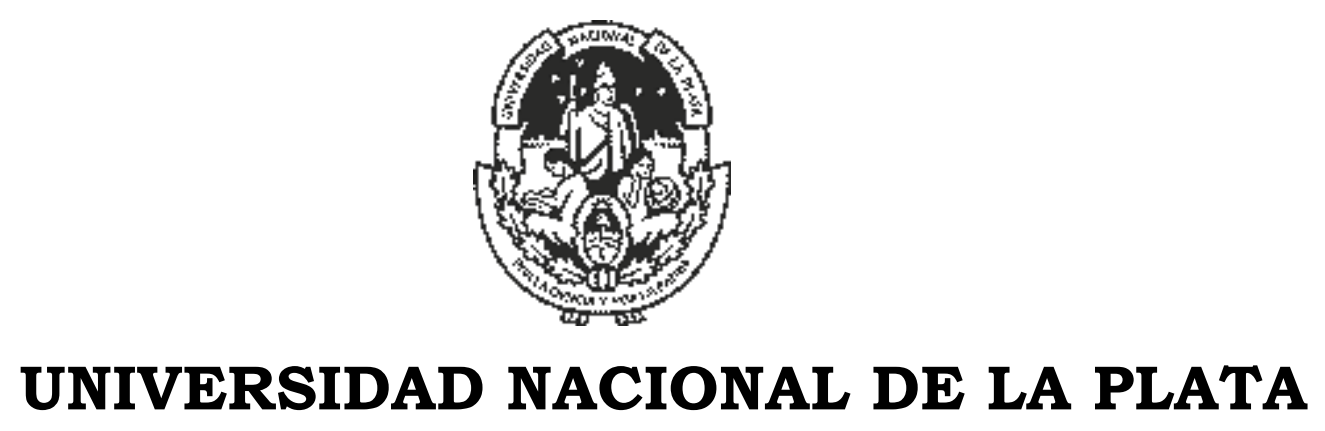

FACULTAD DE CIENCIAS EXACTAS

DEPARTAMENTO DE QUÍMICA

Trabajo de Tesis Doctoral:

Desarrollo de agentes de sostén cerámicos de baja densidad utilizados para la explotación de petróleo y gas no convencionales mediante ligas nanoestructuradas

Tesista: Ing. Anabella Mocciaro

Director: Dr. Alberto N. Scian

Codirectora: Dra. M. Bárbara Lombardi

Año 2018 
Tesis doctoral realizada en el

Centro de Tecnología de Recursos Minerales y Cerámica

para optar por el grado de

DOCTOR DE LA FACULTAD DE CIENCIAS EXACTAS

de la Universidad Nacional de La Plata

\title{
Desarrollo de agentes de sostén cerámicos de baja densidad utilizados para la explotación de petróleo y gas no convencionales mediante ligas nanoestructuradas
}

\author{
por \\ Anabella Mocciaro
}

Director:

Alberto N. Scian

Co-director:

M. Bárbara Lombardi

Defendida el 9 de Marzo de 2018

Frente al jurado conformado por:

Dra. Cristina Volzone

Dra. M. Andrea Camerucci

Dr. Arnaldo Vicentín 


\section{Agradecimientos}

A la Universidad Pública y Gratuita y en especial a la Universidad Nacional de La Plata y que a cien años de la reforma universitaria se reafirma el espíritu de pensar una Universidad inclusiva al servicio del pueblo.

Al CONICET y a YTEC por el financiamiento que me permitió realizar este trabajo y a las políticas científicas que promueven una ciencia soberana para el desarrollo de un país en el cual el Estado se apropia del conocimiento.

A mi director Tito por su generosidad al compartir su conocimiento y entender mis ansias de hacer y conocer que van más allá de este trabajo.

A mi codirectora Bárbara por su predisposición y porque construimos una relación de respeto mutuo.

A mis compañeras de oficina Sofi y Amalia que compartimos muchas horas de charla, mate y trabajo.

A mi segunda oficina Mane, Ernes y Marti por estar presentes para un mate, una palabra o simplemente escuchar.

A los Cetmiquianos por su disposición para colaborar con el compañero/a y que hacen del CETMIC que un lugar agradable en el cual me siento muy cómoda.

A mis amigas y amigos, compañeros y compañeras de la vida que ayudan a la deconstrucción y construcción de lo que soy como persona.

A mi familia por su cariño y por estar siempre acompañando incondicionalmente.

A mi mamá que es una luchadora de la vida de la que aprendí a no darse por vencida y que siempre va a haber una oportunidad.

A mi papá que está siempre en mi corazón. 


\section{Resumen}

La extracción de recursos de hidrocarburos no convencionales ha adquirido notable relevancia en los últimos años en la Argentina con el fin de aumentar la matriz energética del país.

La técnica de extracción de los hidrocarburos no convencionales, por las características de cómo se encuentran alojados en la roca, requiere la inyección de un líquido de fractura (compuesto por agua, aditivos y agentes de sostén) a elevada presión que rompe la roca y genera canales para que pueda fluir el hidrocarburo. La función de los agentes de sostén es "sostener" la fractura para que no se cierre y aumentar la conductividad del hidrocarburo a través del lecho poroso que generan en la fractura.

Los agentes de sostén que se utilizan son de origen cerámico, polimérico o arenas. Actualmente se busca desarrollar agentes de sostén cerámicos de baja densidad, es decir densidad similar a las arenas $(\sim 2,65$ 
$\left.\mathrm{g} / \mathrm{cm}^{3}\right)$, que posean elevada resistencia mecánica para poder disminuir los costos del bombeo del material, y a su vez baja densidad lo cual permite que el agente de sostén llegue lo más lejos posible dentro de la fractura y rellene con mayor eficiencia las cavidades generadas.

El objetivo de esta tesis es desarrollar agentes de sostén cerámicos de baja densidad a partir de materias primas minerales (arcilla y/o bauxita) con un precursor de liga cerámica. Para esto inicialmente se analizaron diferentes formulaciones y se determinaron las propiedades mecánicas y texturales de los materiales realizados por prensado uniaxial. El objetivo fue seleccionar aquellas formulaciones que condujeran a bajos valores de densidad y porosidad abierta con adecuados valores de resistencia mecánica.

Una vez seleccionadas las formulaciones se conformaron los agentes de sostén utilizando una mezcladora de alta energía para lo cual fue necesario desarrollar un programa de procesamiento del material. Los agentes de sostén cerámicos obtenidos, luego de calcinados, fueron caracterizados por medio de la norma API 19C (equivalente a la norma ISO 13503-2) y además, se analizó su microestructura, sus fases cristalinas y su distribución de porosidad abierta.

Se obtuvieron agentes de sostén con densidades menores a 2,65 g/cm 3 y algunas formulaciones presentaron valores del test crush (caracterización de la resistencia mecánica del material) dentro de los valores establecidos en la norma. A los agentes de sostén con mejores propiedades realizados en este trabajo se los comparó con las propiedades de agentes de sostén cerámico comerciales y los de una arena, dando como resultado los materiales desarrollados en este trabajo una performance superadora. ${ }^{1}$

1 Los resultados obtenidos en este desarrollo fueron presentados ante la Administración Nacional de Patentes INPI (Instituto Nacional de la Propiedad Industrial) con la solicitud de patente de invención $\mathrm{N}^{\circ} 20180101813$ 


\section{Índice}

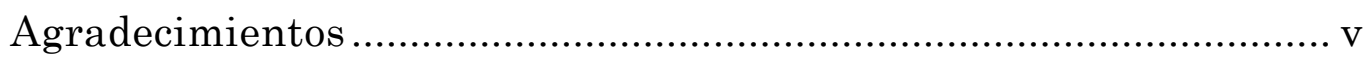

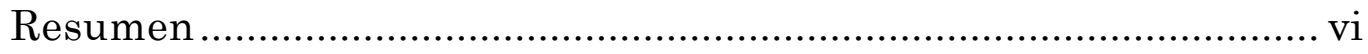

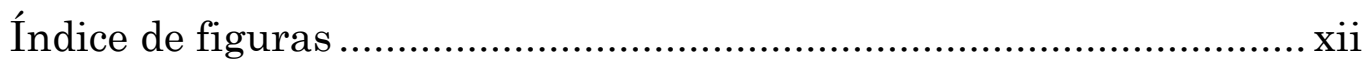

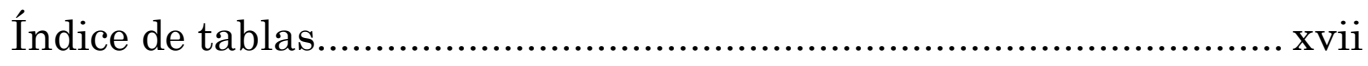

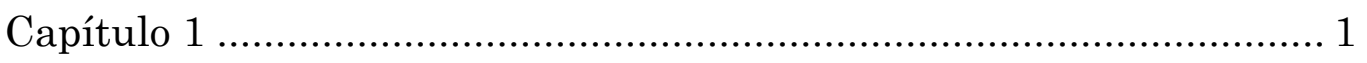

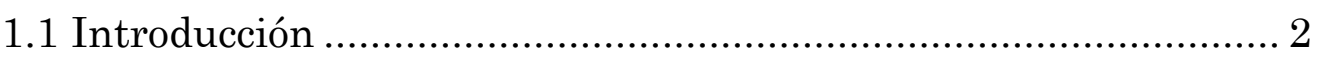

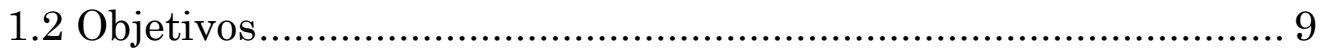

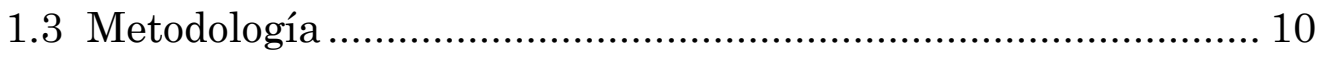

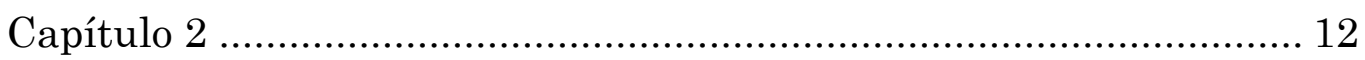

2.1 Materiales cerámicos de base mullita....................................... 15

2.2 Materiales cerámicos porosos.................................................. 19

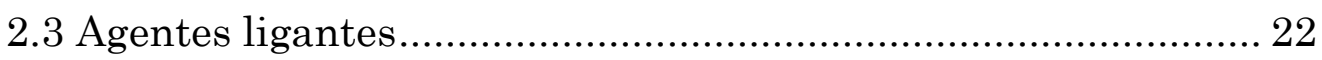

2.3.1 Fosfato de monoaluminio …………………..................... 22

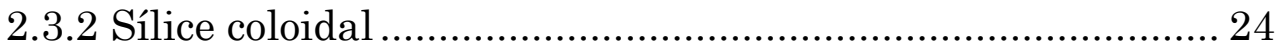

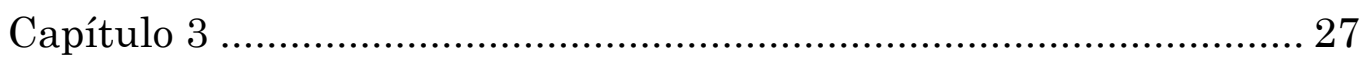

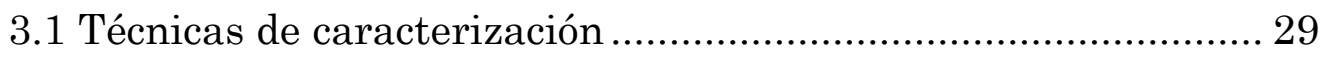

3.2 Materias primas minerales .................................................... 32

3.3 Síntesis del fosfato de monoaluminio......................................... 39

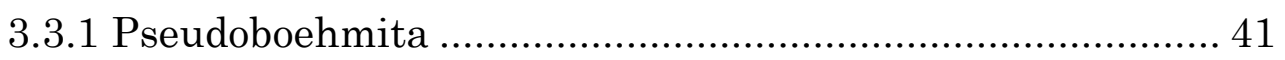




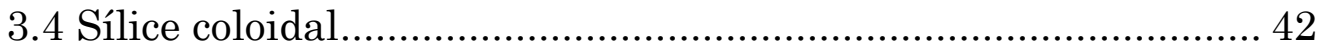

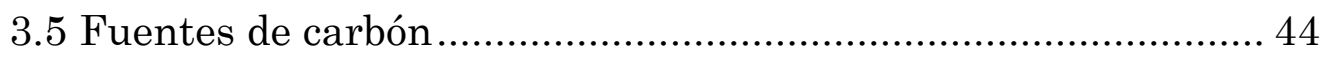

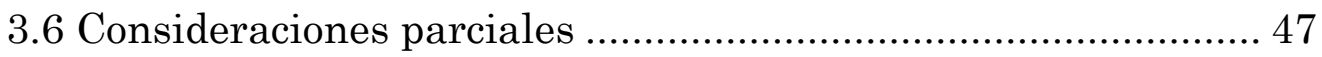

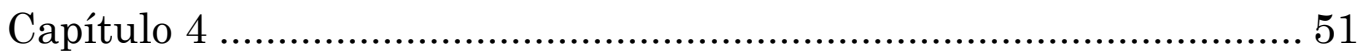

4.1 Análisis de las reacciones del MAP entre $110^{\circ} \mathrm{C}$ y $1400^{\circ} \mathrm{C}$........ 53

4.2 Análisis del sistema MAP-Tincar Super .................................... 56

4.3 Consideraciones parciales .......................................................... 61

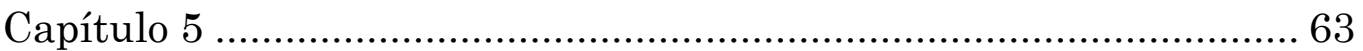

5.1 Técnicas de caracterización de los materiales cerámicos

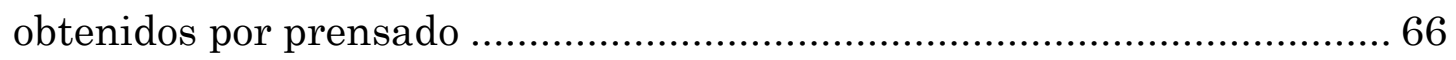

5.2 Materiales del sistema arcilla-MAP: selección de la arcilla...... 71

5.3 Materiales del sistema Tincar Super-MAP-carbón: evaluación

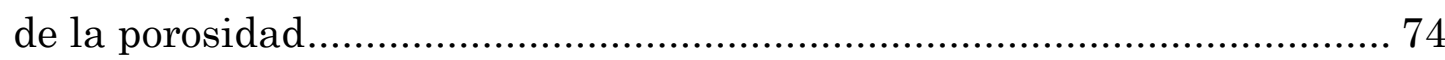

5.4 Evaluación de la utilización de liga fosfórica a alta temperatura 80

5.4.1 Sistema Tincar Super (activada y sin activar

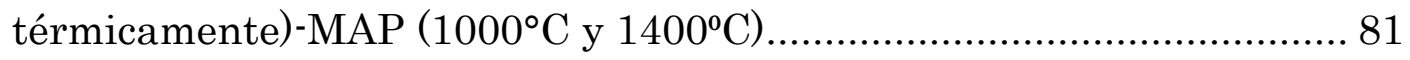

5.4.2 Sistema arcilla Tincar Super (activada y sin activar térmicamente) - MAP- bauxita $\left(1400^{\circ} \mathrm{C}\right.$ y $\left.1500^{\circ} \mathrm{C}\right)$................................ 85

5.5 Materiales del sistema Tincar Super-sílice coloidal.................. 88

5.6 Consideraciones parciales ......................................................... 92 
6.1 Conformado de los agentes de sostén y técnicas utilizadas para su caracterización 99

6.2 Estudio del efecto de la molienda de las materias primas en las propiedades de los agentes de sostén 108

6.3 Agentes de sostén del sistema Tincar Super- MAP- bauxita: estudio del efecto de utilización de arcilla activada térmicamente. 116

6.4 Agentes de sostén de Tincar Super con y sin MAP 126

6.5 Comparación de los agentes de sostén desarrollados con los comerciales 135

6.6 Consideraciones parciales 137

Capítulo 7

Referencias 147

Anexo I 159

Método de Rietveld 159

Método de Ohlberg. 161

Método del patrón externo. 162

Anexo II. 165

Anexo III 171

Publicaciones en revistas científicas 171

Publicaciones en actas de congresos 172

Informes técnicos 173 


\section{Índice de figuras}

Figura 1.1. Matriz energética Argentina del año 2015. Fuente: Elaboración propia en base a datos del Ministerio de Energía y Minería de Argentina.

Figura 1.2. Mapa de la Argentina con las potenciales cuencas de recursos de hidrocarburos no convencionales. Fuente elaboración propia..... 4

Figura 2.1. Estructura de la mullita. Estructura promedio (a) y desplazamientos atómicos alrededor de vacantes de oxígeno (b) (Duval et al., 2008).

Figura 2.2. Esquema de las rutas de procesamiento de materiales cerámicos porosos (Studart et al., 2006).

Figura 2.3. Mecanismo de gelificación de la sílice coloidal (NouriKhezrabad et al., 2013). 26

Figura 3.1. Diagrama de rayos X de la arcilla Tincar Super. 33

Figura 3.2. Diagrama de rayos X de la arcilla Blend....................... 33

Figura 3.3. Diagrama de rayos X de la bauxita. 34

Figura 3.4. Análisis térmico diferencial (ATD) y termo gravimétrico (TG) de la arcilla Tincar Super. 37

Figura 3.5. Análisis térmico diferencial (ATD) y termo gravimétrico (TG) de la arcilla Blend..... 38

Figura 3.6. Análisis térmico diferencial (ATD) y termo gravimétrico (TG) de la bauxita. 39

Figura 3.7. Diagrama de rayos $\mathrm{X}$ del fosfato de monoaluminio (MAP). 40

Figura 3.8. Diagrama de rayos X de la pseudoboehmita. 41

Figura 3.9. Diagrama de rayos $\mathrm{X}$ de la sílice coloidal a diferentes temperaturas. 43

Figura 3.10. Análisis térmico diferencial (ATD) y termo gravimétrico (TG) de la sílice coloidal. 
Figura 3.11. Diagrama de rayos X del carbón vegetal........................ 45

Figura 3.12. Diagrama de rayos X del carbón residual de petróleo. .. 45

Figura 3.13. Diagrama de rayos X del negro de humo. ....................... 46

Figura 3.14. Diagrama de rayos X de las cenizas del carbón vegetal. 47

Figura 4.1. Análisis térmico diferencial (ATD) y termo gravimétrico (TG) del MAP. 53

Figura 4.2. Diagrama de rayos $\mathrm{X}$ del MAP a diferentes temperaturas [m: $\left.\mathrm{Al}\left(\mathrm{H}_{2} \mathrm{PO}_{4}\right)_{3} ; \mathrm{T}: \mathrm{H}_{2} \mathrm{AlP}_{3} \mathrm{O}_{10} \cdot 2 \mathrm{H}_{2} \mathrm{O} ; \mathrm{C}: \mathrm{Al}_{2} \mathrm{P}_{6} \mathrm{O}_{18} ; \mathrm{M}: \mathrm{Al}\left(\mathrm{PO}_{3}\right)_{3} ; \mathrm{O}: \mathrm{Al}\left(\mathrm{PO}_{4}\right)\right] .55$

Figura 4.3. Curvas de ATD de Tincar Super y de Tincar Super-10\% MAP. 57

Figura 4.4. Curvas de TG de Tincar Super y de Tincar Super-10\% MAP. 58

Figura 4.5. Fotografía SEM/EDS de Tincar Super- MAP en la fase vítrea. 58

Figura 4.6. Fotografía SEM/EDS de Tincar Super- MAP en la fase cristalina. 59

Figura 4.7. Porcentaje de fase amorfa de la Tincar Super y de la Tincar Super -10\% MAP a diferentes temperaturas. 60

Figura 5.1. Distribución de tamaño de los macroporos de los materiales cerámicos realizados con las distintas fuentes de carbón. 78

Figura 5.2. Distribución de tamaño de los mesoporos de los materiales cerámicos realizados con las distintas fuentes de carbón. 78

Figura 5.3. Microtomografía de rayos x de los materiales cerámicos utilizando (a) Carbón Vegetal. (b) Negro de Humo y (c) Carbón Residual de Petróleo. 79

Figura 5.4. Fotografías SEM (27x) de los materiales cerámicos obtenidos utilizando (a) Carbón Vegetal, (b) Negro de Humo y (c) Carbón Residual de Petróleo. 79

Figura 5.5. Fotografías con microscopio óptico (40x) de los materiales cerámicos obtenidos utilizando (a) Carbón Vegetal, (b) Negro de Humo y (c) Carbón Residual de Petróleo. 79 
Figura 5.6. Distribución de tamaño de los mesoporos de los materiales: Tincar Super, Tincar Super activada térmicamente-MAP y Tincar Super-MAP sinterizados a $1000^{\circ} \mathrm{C}$. 83

Figura 5.7. Distribución de tamaño de los mesoporos de los materiales: Tincar Super, Tincar Super activada térmicamente-MAP y Tincar Super-MAP sinterizados a $1400^{\circ} \mathrm{C}$. 84

Figura 5.8. Distribución de tamaño de los mesoporos de los materiales: Tincar Super, Tincar Super activada térmicamente-bauxitaMAP y Tincar Super-bauxita-MAP sinterizados a $1400^{\circ} \mathrm{C}$. 85

Figura 5.9. Distribución de tamaño de los mesoporos de los materiales: Tincar Super, Tincar Super activada térmicamente-bauxitaMAP y Tincar Super-bauxita-MAP sinterizados a $1500^{\circ} \mathrm{C}$. 86

Figura 5.10. Distribución del tamaño de los mesoporos de los materiales Tincar Super- Sílice coloidal con y sin bauxita sinterizados a $1450^{\circ} \mathrm{C}$. 90

Figura 5.11. Distribución del tamaño de los mesoporos de los materiales Tincar Super- Sílice coloidal con y sin bauxita sinterizados a $1500^{\circ} \mathrm{C}$. 91

Figura 5.12. Diagrama de rayos $\mathrm{X}$ de los materiales Tincar SuperSílice coloidal con y sin bauxita sinterizados a 1450 y $1500^{\circ} \mathrm{C}$ 91

Figura 6.1. Vista y detalle del interior de la mezcladora de alta energía Erich. 100

Figura 6.2. Equipo para medir la densidad bulk de los agentes de sostén. 104

Figura 6.3. Celda utilizada en para el test crush. 106

Figura 6.4. Gráfico de redondez (eje X) y esfericidad (eje Y) (Krumbein W. C and Sloss L. L, 1963) 107

Figura 6.5. Distribución del tamaño de partícula de las materias primas minerales luego de la molienda. 109

Figura 6.6. Distribución de tamaño de los macroporos de los agentes de sostén AG1, AG2 y AG3. 110 
Figura 6.7. Distribución de tamaño de los mesoporos de los agentes de sostén AG1, AG2 y AG3.

Figura 6.8. Fotografías de los agentes de sostén AG1, AG2 y AG3 para medir redondez y esfericidad. 113

Figura 6.9. Diagrama de rayos $\mathrm{X}$ de los agentes de sostén AG1, AG2 y AG3.

Figura 6.10. Fotografías SEM x500 y x5000 de los agentes de sostén AG1 115

Figura 6.11. Fotografías SEM x500 y x5000 de los agentes de sostén AG2 116

Figura 6.12. Fotografías SEM x500 y x5000 de los agentes de sostén AG3. 116

Figura 6.13. Distribución del tamaño de partícula de las materias primas minerales luego de la molienda. 117

Figura 6.14. Distribución de tamaño de los macroporos de los agentes de sostén AG5 y AG4. 120

Figura 6.15. Distribución de tamaño de los mesoporos de los agentes de sostén AG5 y AG4.

Figura 6.16. Fotografías de los agentes de sostén AG4 y AG5 para medir esfericidad y redondez

Figura 6.17. Diagrama de rayos $\mathrm{X}$ de los agentes de sostén AG5 y AG4. 123

Figura 6.18. Fotografías SEM x500 y x5000 de los agentes de sostén AG4. 124

Figura 6.19. Fotografías SEM x500 y x5000 de los agentes de sostén AG5. 125

Figura 6.20. Potencial Zeta de las materias primas minerales de los AG5 en función del $\mathrm{pH}$. 126

Figura 6.21. Distribución del tamaño de partícula de la arcilla Tincar Super molida. 128

Figura 6.22. Distribución de tamaño de los macroporos de los agentes de sostén AG6 y AG7. 129 
Figura 6.23. Distribución de tamaño de los mesoporos de los agentes de sostén AG6 y AG7. 130

Figura 6.24. Fotografías de los agentes de sostén AG4 y AG5 para medir esfericidad y redondez 132

Figura 6.25. Diagrama de rayos $\mathrm{X}$ de los agentes de sostén AG6 y AG7. 133

Figura 6.26. Fotografías SEM x500 y x5000 de los agentes de sostén AG6. 134

Figura 6.27. Fotografías SEM x500 y x5000 de los agentes de sostén AG7. 134 


\section{Índice de tablas}

Tabla 3.1. Porcentajes de las fases cristalinas presentes en las materias primas minerales calculados por el método de Rietveld. 34

Tabla 3.2. Composición química de las materias primas minerales. . 35

Tabla 3.3. Valores de Cono Pirométrico Equivalente (CPE) de las arcillas. 36

Tabla 3.4. Diámetro efectivo de la sílice coloidal. 42

Tabla 5.1. Propiedades de los materiales cerámicos del sistema: Blend activada térmicamente-MAP-carbón vegetal sinterizados a $1350^{\circ} \mathrm{C}$ y $1450^{\circ} \mathrm{C}$.

Tabla 5.2. Propiedades de los materiales cerámicos del sistema Tincar Súper- MAP-carbón vegetal sinterizados a $1500^{\circ} \mathrm{C}$ y $1550^{\circ} \mathrm{C}$. 74

Tabla 5.3. Valores de densidad aparente y densidad aparente en agua para los materiales cerámicos realizados con las distintas fuentes de carbón.

Tabla 5.4. Porosidad abierta y cerrada de los materiales cerámicos realizados con las distintas fuentes de carbón determinadas por diferentes técnicas y resistencia mecánica (MOR)

Tabla 5.5. Propiedades de los materiales: Tincar Super, Tincar Super activada térmicamente-MAP y Tincar Super-MAP sinterizados a 1000 y $1400^{\circ} \mathrm{C}$

Tabla 5.6. Propiedades de los materiales: Tincar Super, Tincar Super activada térmicamente-bauxita-MAP y Tincar Super-bauxita-MA sinterizados a 1400 y $1500^{\circ} \mathrm{C}$ 87

Tabla 5.7. Propiedades de los materiales cerámicos del sistema Tincar Super-Sílice coloidal con y sin bauxita a 1450 y $1500^{\circ} \mathrm{C}$. 89

Tabla 6.1. Diámetro máximo $(\mu \mathrm{m})$ de partícula del $10 \%$, 50\% y $90 \%$. 108

Tabla 6.2. Densidades, solubilidad en ácido y porcentaje de finos del test crush de los agentes de sostén AG1, AG2 y AG3. 
Tabla 6.3. Redondez (X) y esfericidad (Y) de los agentes de sostén AG1, AG2 y AG3.

Tabla 6.4. Porcentaje de cada fase de los agentes AG1, AG2 y AG3 calculadas por el método de Rietvield y el método del patrón externo 115

Tabla 6.5. Diámetro máximo $(\mu \mathrm{m})$ de partícula del $10 \%, 50 \%$ y $90 \%$.

Tabla 6.6. Densidades, solubilidad en ácido y porcentaje de finos del test crush de los agentes de sostén AG4 y AG5. 119

Tabla 6.7. Medidas de redondez (X) y esfericidad (Y) de los agentes de sostén AG4 y AG5.

Tabla 6.8. Porcentaje de cada fase de los agentes AG4 y AG5 calculadas por el método de Rietvield y el método del patrón externo

Tabla 6.9. Diámetro máximo $(\mu \mathrm{m})$ de partícula del $10 \%, 50 \%$ y $90 \%$. 127

Tabla 6.10. Densidades, solubilidad en ácido y porcentaje de finos del test crush de los agentes de sostén AG6 y AG7.

Tabla 6.11. Medidas de redondez (X) y esfericidad (Y) de los agentes de sostén AG6 y AG7.

Tabla 6.12. Porcentaje de cada fase de los agentes AG6 y AG7 calculadas por el método de Rietvield y el método del patrón externo

Tabla 6.13. Propiedades de la arena y de los agentes de sostén Carboeconoprop, AG3 y AG5 según normas API 19C. 136 
Capítulo 1

Introducción, objetivos y metodología 


\subsection{Introducción}

La energía es uno de los pilares fundamentales del progreso humano, la gran mayoría de las actividades de la sociedad actual se basan en ella; desde la producción de alimentos, el transporte, la electricidad, la calefacción, las telecomunicaciones, etc. Es por esto que el desarrollo económico e industrial de un país depende estrechamente de la matriz energética que éste disponga.

Según datos del balance energético de la Argentina del 2015 del ministerio de Energía y Minería de la Argentina el gas natural y el petróleo representan el 85\% de las fuentes primarias de energía en el país (Figura 1.1). 


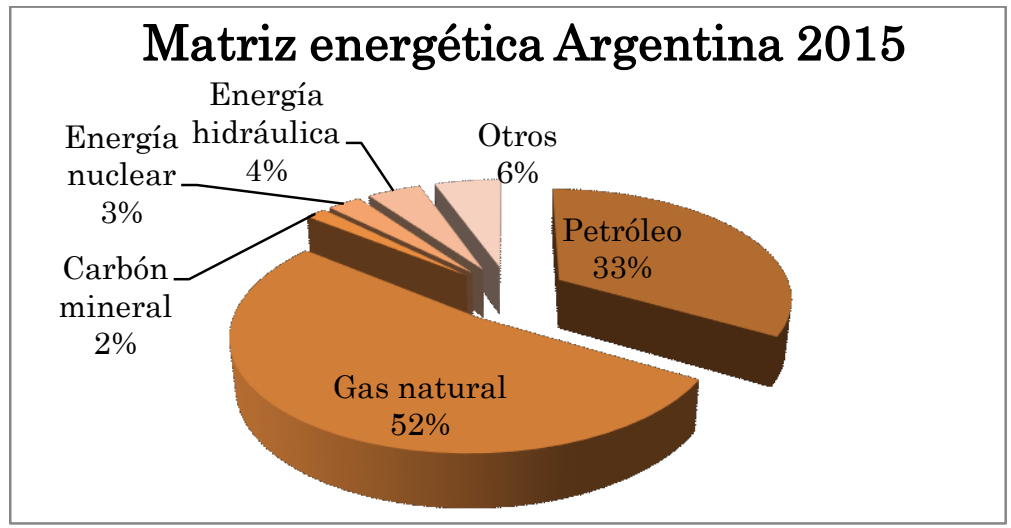

Figura 1.1. Matriz energética Argentina del año 2015. Fuente: Elaboración propia en base a datos del Ministerio de Energía y Minería de Argentina.

Con el objetivo de poder ampliar la matriz energética de la Argentina ha cobrado importancia la explotación de hidrocarburos no convencionales. Según estudios publicados por la Agencia de Información Energética de los EE. UU. (U.S. Energy Information Administration, 2013), se estima que la Argentina contaría con reservas técnicamente recuperables de hidrocarburos no convencionales que alcanzaría los 802 trillones de pies cúbicos (TCF) para el gas (21.654 miles de millones de $\mathrm{m}^{3}$ ) y los 26.9 millones de barriles para el petróleo (4.3 miles de millones de $\left.\mathrm{m}^{3}\right)$. Estos valores posicionan al país en el segundo lugar a nivel mundial en cuanto a recursos de gas no convencional y cuarto a nivel mundial en relación a recursos de petróleo no convencional.

En la Figura 1.2 se muestra en un mapa de la Argentina las zonas con potenciales recursos de hidrocarburos no convencionales, entre ellas se destaca en la provincia de Neuquén la formación geológica Vaca Muerta. Esta formación tiene una superficie de $30 \mathrm{mil} \mathrm{km}^{2}$ y se estima que tiene reservas de gas de 308 TCF y reservas de petróleo de 16,2 miles de millones de barriles, lo cual hace multiplicar por diez las reservas de hidrocarburos en la Argentina (U.S. Energy Information Administration, 2013). 


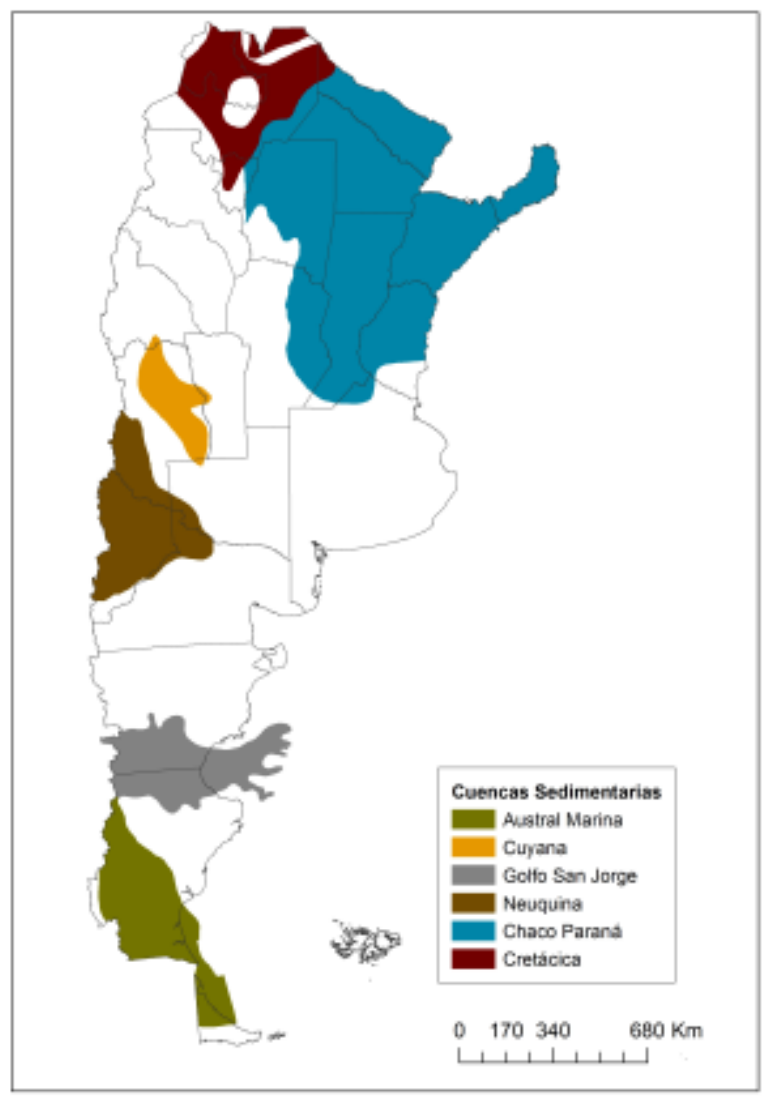

Figura 2.2. Mapa de la Argentina con las potenciales cuencas de recursos de hidrocarburos no convencionales. Fuente elaboración propia.

Las explotaciones de gas y petróleo no convencional tienen como característica principal que los hidrocarburos se encuentran distribuidos en millones de poros microscópicos los cuales no están interconectados entre sí, por lo que es necesario para su explotación generar vías para que pueda fluir el hidrocarburo hacia el pozo. Para eso, se utiliza una técnica denominada fractura hidráulica (en inglés denominada fracking) que consiste en inyectar a presión un fluido formado por agua, agentes de sostén y algunos aditivos químicos (López Anadón Ernesto et al., 2013).

La función principal del agente de sostén es garantizar que la fisura realizada en la roca por la presión del agua quede abierta, es por eso que el agente de sostén ingresa en la fisura y la apuntala generando una 
intrincada red porosa por la cual pueden fluir los hidrocarburos hacia el pozo para permitir su extracción.

La primera fractura hidráulica se realizó en 1947 en Kansas, Estados Unidos por la empresa Standard Oil and Gas Corporation con arena como agente de sostén y a partir de ahí ha evolucionado la técnica, la composición del líquido de fractura y los materiales que se utilizan como agentes de sostén.

La tecnología de perforación utiliza distintos tipos de agentes de sostén dependiendo tanto de las características de la roca del reservorio así como también de la viscosidad del líquido de fractura.

La velocidad de sedimentación de los agentes de sostén tiene una relación directa con su densidad y diámetro. De acuerdo con la ley de Stokes (ec. 1.1) la velocidad de sedimentación de los agentes de sostén $\left(\mathrm{V}_{\mathrm{s}}\right)$ es directamente proporcional al tamaño de los agentes de sostén y a la diferencia de densidad entre el agente de sostén y el líquido de fractura; y es inversamente proporcional a la viscosidad del fluido.

$$
\mathrm{V}_{\mathrm{s}}=\frac{\left(\rho-\rho^{\prime}\right) \mathrm{gr}^{2}}{9 \mu} \quad \text { ec. } 1.1
$$

Donde Vs es la velocidad de sedimentación de Stokes de una sola partícula; $\rho$ es la densidad de la partícula; $\rho^{\prime}$ es la densidad del fluido; g es la aceleración de la gravedad; $r$ el radio de la partícula y $\mu$ la viscosidad del fluido.

Entonces, a mayor tamaño y densidad del agente de sostén, mayor será la velocidad a la que sedimentará al ser inyectado en la fractura. Por este motivo, con el objetivo de disminuir la velocidad de sedimentación de los agentes de sostén y para que se distribuyan homogéneamente a lo largo 
de la fractura, es de interés desarrollar agentes de sostén de baja densidad. Si bien esta forma de la ley de Stokes tiene muchas simplificaciones, nos permite tener una idea general de la relación entre la densidad del fluido y la densidad de los agentes de sostén necesaria para que la velocidad de sedimentación de los agentes de sostén sea la menor posible.

Otra ventaja adicional que implica el uso de agentes de sostén de baja densidad es la disminución en la energía de bombeo necesaria para hacer fluir el fluido de fractura más los agentes de sostén a través del pozo (Neto et al., 2012).

Los fluidos que se utilizan en la fractura hidráulica generalmente están compuestos por 99,5\% de agua y 0,5\% de aditivos químicos. Entre los aditivos se encuentran bactericidas, gelificantes, reductores de fricción, etc. por lo que la densidad del líquido de fractura es cercana a la del agua $(\approx 1$ g/cm³) (López Anadón Ernesto et al., 2013); de manera que la densidad ideal del agente de sostén debería ser lo más cercana posible a este valor.

Además de las propiedades ya mencionadas como la baja densidad y la gran resistencia mecánica para sostener la fractura, los agentes de sostén deben ser compatibles químicamente con el líquido de fractura, ser térmicamente estables, resistentes a la corrosión, poseer ciertas características de tamaño y forma (esfericidad y redondez) para poder crear canales de alta conductividad del hidrocarburo, tener amplia disponibilidad (se utilizan alrededor de 2 mil toneladas por pozo) y ser de bajo costo (Petrotecnia, 2012).

Otra característica importante a considerar en los agentes de sostén es la porosidad abierta del material. Si la porosidad abierta es elevada, en el momento de bombear los agentes de sostén, por más baja que sea su densidad el agua penetrará en los poros con lo cual el material se comportará con una mayor densidad. Por lo que se requerirá mayor energía (es decir, mayor costo) para transportar los agentes de sostén. 
A su vez una vez dentro de la fractura los agentes de sostén con porosidad abierta elevada disminuyen la conductividad del hidrocarburo, debido a que este ingresará dentro del material en lugar de fluir a través de los canales que se forman entre los agentes de sostén.

En la actualidad se pueden dividir los agentes comerciales en tres grandes clases: arenas, agentes de sostén cerámicos y agentes de sostén poliméricos (Pangilinan et al., 2016; Tang et al., 2017).

Las arenas se utilizan tradicionalmente en la fractura hidráulica por su bajo costo, su alta resistencia a la solubilidad en ácido por ser materiales monocristalinos y por su baja densidad. Sin embargo la resistencia mecánica de este material no es elevada y poseen baja esfericidad lo cual produce una disminución conductividad del hidrocarburo dentro de la fractura (Liu et al., 2016; Wu et al., 2015). Por este motivo para mejorar la resistencia mecánica de las arenas se las recubre con resinas poliméricas (Almond et al., 1995; Dewprashad et al., 1993; Liu et al., 2015; Zhang et al., 2017; Zoveidavianpoor and Gharibi, 2015).

Los agentes de sostén cerámicos disponibles en el mercado se dividen en tres tipos según su densidad y éste valor se relaciona directamente con el contenido de alúmina en el material. Los cerámicos livianos (Light Weight ceramics, LWC) poseen un contenido 45-50\% de alúmina y una densidad aparente en el rango de 2,55-2,71 $\mathrm{g} / \mathrm{cm}^{3}$; los cerámicos de densidad intermedia (Intermediate Density Ceramics, IDC) poseen entre 70-75\% de alúmina con densidades de aproximadamente $3,27 \mathrm{~g} / \mathrm{cm}^{3}$ y los cerámicos de alta densidad (Hight Density Ceramics, HDC) que contienen entre 80-85\% de alúmina y una densidad de alrededor de 3,50 g/cm³ (Liang et al., 2016).

Para los agentes de sostén cerámicos de nueva generación (Kulkarni and Ochoa, 2012; Sergey Shmotev and Sergey Pliner, 2009) que están siendo desarrollados actualmente se buscan densidades cercanas a los valores de densidad de las arenas $\left(\sim 2,65 \mathrm{~g} / \mathrm{cm}^{3}\right)$. Como se mencionó anteriormente, se requiere de una densidad baja para que los agentes de sostén puedan ser 
arrastrados más eficientemente por la corriente acuosa utilizada en la fractura hidráulica y llegar a la mayor distancia posible del canal de perforación, rellenando así con mayor eficiencia las cavidades generadas por la fractura hidráulica (Cannan and Palamara, 2006; Lunghofer, 1992).

En la Argentina no existen plantas de producción de agentes de sostén cerámicos, actualmente en el mercado existen agentes de sostén cerámicos producidos por empresas multinacionales como CARBO, SaintGobain, etc.; todos materiales importados en su mayoría desde Estados Unidos, China y Brasil. Además, como se mencionó anteriormente los volúmenes de material que se necesitan son elevados y el transporte del mismo es marítimo, por lo cual la disponibilidad del material tiene una demora de entre 3 a 4 meses; esto hace que los agentes de sostén cerámicos tengan un costo elevado.

Para reducir costos en la extracción de los hidrocarburos no convencionales se utilizan arenas provenientes de canteras Argentinas y en algunos casos para mejorar la resistencia mecánica se utilizan estas arenas recubiertas con resina. La empresa YPF (Yacimientos Petrolíferos Fiscales S.A.) instaló en Neuquén una planta de resinado para mejorar la resistencia mecánica de los materiales. Si bien el uso de estas arenas resinadas produce una diminución en los costos de explotación, las propiedades de estos materiales no superan a las propiedades de los materiales cerámicos.

Al ser los hidrocarburos no convencionales una fuente de recursos importante para ampliar la matriz energética Argentina, es conveniente tener el conocimiento y la capacidad de poder desarrollar los insumos requeridos para dicha explotación. En este caso, poder desarrollar agentes de sostén a partir de materias primas nacionales que cumplan los requisitos de las normas internacionales (API 19C) y que a su vez estos materiales puedan llegar a ser competitivos por sus propiedades (densidad, resistencia mecánica, etc.) respecto a los disponibles en el mercado. 


\subsection{Objetivos}

\section{Objetivo general}

Investigar materiales y métodos para producción de agentes de sostén cerámicos de baja densidad utilizando sistemas de liga nanoestructurados para la extracción de gas y petróleo no convencional.

\section{Objetivos específicos}

- Encontrar vías sencillas y económicas en cuanto operaciones y procesos para producir agentes de sostén de materiales cerámicos de baja densidad $\left(\leq 2.65 \mathrm{~g} / \mathrm{cm}^{3}\right)$, que puedan ser utilizados en la industria del petróleo.

- Obtener agentes de sostén cerámicos de baja densidad que soporten presiones, en el test crush, mayores y/o iguales a 5000 psi $(\sim 34.5 \mathrm{MPa})$.

- Utilizar técnicas de liga cerámica donde estén involucrados sistemas nano (sol-gel, coloides, etc.) que puedan conducir a materiales parcial o totalmente nanoestructurados.

- Estudiar las transformaciones térmicas del fosfato de monoaluminio, precursor de liga nanoestructurada, y su interacción con una arcilla caolinítica. 
- Utilizar diferentes agentes formadores de poro para disminuir la densidad de los materiales cerámicos y analizar cómo varían las propiedades finales de los materiales.

- Analizar diferentes formulaciones y seleccionar aquellas que conduzcan a materiales con menor densidad y mayor resistencia mecánica.

- Producir agentes de sostén de las formulaciones seleccionadas que cumplan con las exigencias de los ensayos bajo norma API 19C para ser utilizados en técnicas de extracción de gas y petróleo no convencional.

- Comparar las propiedades de los agentes se sostén cerámicos de baja densidad desarrollados y producidos en este trabajo con los agentes de sostén cerámicos comerciales y las arenas que se utilizan en la actualidad.

\subsection{Metodología}

Para desarrollar los agentes de sostén cerámicos de baja densidad primero se caracterizaron las materias primas por diferentes técnicas como difracción de rayos $\mathrm{X}$, análisis térmico diferencial y térmico gravimétrico, análisis químico, etc. Como el material desarrollado tiene gran potencialidad para su fabricación a nivel industrial se eligieron materias primas nacionales y commodities ${ }^{2}$ para facilitar el escalado de la producción del material.

2 Commodities: bienes de consumo generales que están disponibles en grandes cantidades en el mercado mundial, poseen un valor o utilidad y un bajo nivel de diferenciación. 
Dentro de las materias primas utilizadas se encuentran dos precursores de liga nanoestructurada el fosfato de monoaluminio (MAP) y la sílice coloidal. Al MAP también se lo estudió termoquímicamente para poder comprender las transformaciones químicas a diferentes temperaturas y conocer los compuestos intermedios que se forman hasta llegar al fosfato de aluminio. También se estudió la interacción que tiene el MAP con la arcilla Tincar Super.

Además, se evaluó la posibilidad de utilizar agentes formadores de poro (carbón vegetal, carbón residual de petróleo y negro de humo) con el objetivo de formar una matriz porosa y de esta manera, disminuir la densidad de los materiales cerámicos.

Se formularon diferentes mezclas de las materias primas y se estudiaron inicialmente las propiedades de los materiales en forma de barras prismáticas por prensado uniaxial en seco. Si bien este tipo de conformación no se extrapola al conformado de los agentes de sostén útil para tener una aproximación acerca de las propiedades finales de los materiales.

De todos los materiales obtenidos en forma de barras se eligieron formulaciones y temperaturas de sinterizado que conducen a materiales de baja densidad y resistencia mecánica adecuada. Las propiedades que se midieron en las barras prensadas fueron densidad y porosidad por el método de Arquímedes, distribución de la porosidad por medio de intrusión de mercurio, resistencia mecánica a la flexión en tres puntos (MOR), variación lineal permanente por calentamiento y determinación de las fases cristalinas por difracción de rayos $\mathrm{X}$.

Una vez analizadas las diferentes formulaciones se eligieron algunas de ellas para obtener los agentes de sostén. El conformado de los mismos requirió el desarrollo de un programa de elaboración de los agentes de sostén, para lo cual se utilizó una mezcladora de alta energía. El programa involucra la cantidad de agua adicionada, la necesidad o no de agregar otros 
aditivos que mejoren la plasticidad de las materias primas, el tiempo de conformado y los programas de velocidad con los que van a trabajar los distintos componentes de la mezcladora.

Los agentes de sostén, luego de tratamiento térmico, fueron ensayados bajo la norma API 19C correspondiente al tipo de material y su aplicación. En esta norma se analizan características texturales y mecánicas de los agentes de sostén como la densidad bulk, densidad aparente, solubilidad en ácido, test crush, esfericidad y redondez. Además, se realizaron otros ensayos tendientes a conocer su microestructura $\mathrm{y}$ composición final como son porosimetría de mercurio, difracción de rayos $\mathrm{X}$ y con microscopía electrónica de barrido.

Por último, se compararon los agentes de sostén cerámicos desarrollados en el laboratorio con agentes de sostén cerámicos denominados livianos disponibles en el mercado y arenas utilizadas en la actualidad en la explotación de pozos de hidrocarburos no convencionales de la Argentina. 
Capítulo 2 
Los agentes de sostén cerámicos realizados en el marco de este trabajo son de mullita, fase cristalina del sistema $\mathrm{Si}_{2} \mathrm{O}-\mathrm{Al}_{2} \mathrm{O}_{3}$, y con un precursor de liga nanoestructurada. En este capítulo se mencionan las propiedades fisicoquímicas de la mullita, se describen los procesos de obtención y en particular la vía elegida en este trabajo. Además se detallan las características de los materiales cerámicos porosos siendo el objetivo, en este trabajo, la utilización de los mismos para la obtención de materiales con una baja densidad aparente.

Por último, se presentan los dos precursores de liga nanoestructurada que se utilizaron en este trabajo: fosfato de monoaluminio y sílice coloidal y se mencionan características particulares de cada uno de ellos. 


\subsection{Materiales cerámicos de base mullita}

Los materiales cerámicos tienen infinidad de usos tanto en la vida cotidiana de las personas (ollas, vajilla, azulejos, pisos, etc.) como en la industria. Este tipo de materiales han reemplazado en muchos casos la utilización de metales o polímeros por sus propiedades que permiten estabilidad química y resistencia a altas temperaturas. En las actividades industriales constituyen en muchos casos insumos básicos de las industrias como en la siderúrgica, química, electrónica, petroquímica, etc; como por ejemplo el revestimiento de hornos de altas temperaturas (Bruni et al., 2016), cerámicos refractarios resistentes a la corrosión (Rendtorff et al., 2009), cementos de alto contenido de alúmina (Scian and Pereira, 1994), entre otros. Otros usos de los materiales cerámicos son los denominados de avanzada que tienen ciertas características específicas como son los biocerámicos (Stabile, 2016), los materiales con propiedades ópticas (AbdelBaki and El-Diasty, 2011), eléctricas (Kazlauskas et al., 2017) y/o magnéticas (Marghussian, 2015).

Dentro de los materiales cerámicos lo que poseen mullita en su composición son ampliamente estudiados y de gran interés tecnológico por sus propiedades fisicoquímicas tanto para el desarrollo de materiales tradicionales como de avanzada.

La mullita es el único silicoaluminato del sistema $\mathrm{Al}_{2} \mathrm{O}_{3}-\mathrm{SiO}_{2}$ que es estable a presión atmosférica y a altas temperaturas. Su fórmula química es $\mathrm{Al}_{4+2 \mathrm{x}} \mathrm{Si}_{2-2 \mathrm{x}} \mathrm{O}_{10-\mathrm{x}}$, con valores de $\mathrm{x}$ entre $0,2-0,9$, con $\mathrm{x}=0,25$ se obtiene una mullita de relación $\mathrm{Al}_{2} \mathrm{O}_{3}: \mathrm{SiO}_{2}$ de 3:2. (Schneider et al., 2008).

La estructura cristalina de la mullita consiste en cadenas octaédricas de Al-O paralelas al eje c entrecruzadas con cadenas dobles tetraédricas de Si y Al. Como la relación Al:Si tetraédrica no es 1:1 a medida que aumenta el contenido de alúmina en la composición, cationes de $\mathrm{Si}^{+4}$ son reemplazados por cationes de $\mathrm{Al}^{+3}$ y se crean sitios vacantes de oxígeno para 
mantener la neutralidad de las cargas (Angel et al., 1991; Duval et al., 2008). En la Figura 2.1 se muestra la unidad de la mullita.

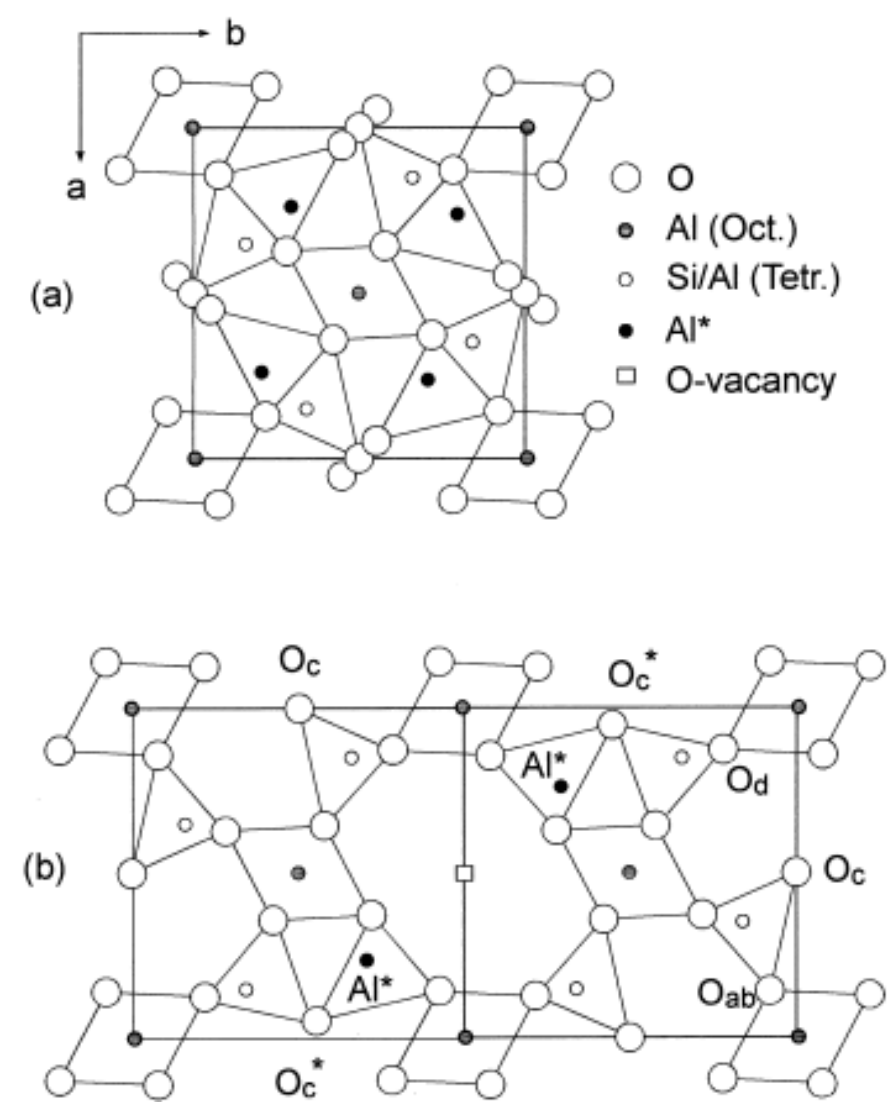

Figura 2.1. Estructura de la mullita. Estructura promedio (a) y desplazamientos atómicos alrededor de vacantes de oxígeno (b) (Duval et al., 2008).

La mullita presenta una densidad teórica de $3,17 \mathrm{~g} / \mathrm{cm} 3$, alto punto de fusión $\left(\sim 1830^{\circ} \mathrm{C}\right)$, buena resistencia mecánica (resistencia a la compresión $\sim 200 \mathrm{MPa}$ ), estabilidad química, buena resistencia al choque térmico, resistencia a la abrasión, resistencia al ataque de metales fundidos y a cierto tipo de escorias, baja constante dieléctrica ( $\varepsilon \sim 7)$, bajo coeficiente de expansión térmica $\left(\sim 4.5 \times 10-6^{\circ} \mathrm{C}-1\right)$ y baja conductividad térmica $(\sim 6 \mathrm{Kcalm}$ 1h-1K-1) (Ananthakumar et al., 2006; Jain, 1996; Schneider et al., 2008).

Estas propiedades de la mullita hacen que sea un material ampliamente utilizado en la fabricación de materiales refractarios 
(Bartonickova et al., 2015; de Sousa et al., 2017; Juettner et al., 2007; Luz et al., 2013; Ribero et al., 2009), materiales estructurales (Xu et al., 2013), soportes de catalizadores (Uchisawa et al., 2008; Zhao et al., 2010), filtros (Ahmad et al., 2016; Schaafhausen et al., 2013), membranas (Cao et al., 2014; Guo et al., 2016), dispositivos eléctricos y ópticos (Aksay et al., 1991; Camerucci et al., 2001; Roy et al., 2013; Viswabaskaran et al., 2004), etc

En la bibliografía se describen tres grandes vías para la síntesis de la mullita: mullita sinterizada, mullita electrofundida y mullita química (Schneider et al., 2008). El nivel de pureza, de homogeneidad, el tamaño de grano y el costo de producción de la mullita depende estrechamente de cuál fue el método de fabricación de la misma.

La mullita sinterizada se obtiene a partir de reacciones de estado sólido de mezclas de minerales de alto contenido de alúmina y sílice durante tratamiento térmico a alta temperatura. Entre los minerales más utilizados se encuentra la caolinita, hidróxidos de aluminio (boehmita, gibbsita, etc.), bauxita, cuarzo, sílice amorfa, etc. (Chen et al., 2000; Lee et al., 2008; Liu et al., 1994)

La vía de obtención de la denominada mullita electrofundida se basa en la preparación de mezclas de alúmina y sílice que se funden por electrofusión y luego durante el enfriamiento cristalizan en la fase mullita (Srivastava et al., 2014).

Por último, la mullita química se obtiene a través del método de solgel o síntesis química, el cual se parte de precursores que se nuclean y cristalizan bajo la estructura de la mullita mediante un tratamiento térmico en el rango de temperatura de $850-1350^{\circ} \mathrm{C}$. Por esta vía se obtienen materiales de alta pureza y gran homogeneidad (Campos et al., 2002; Cividanes et al., 2010). Diferentes fuentes de aluminio y silicio se utilizan en este método de síntesis, generalmente los precursores son una sal inorgánica del aluminio (nitrato, acetato, sulfato, etc.) (Chen and Gu, 2009a; 
Jayasankar et al., 2011; Liu et al., 2013; Ren et al., 2015) con especies orgánicas como los alcóxidos del silicio (Chen and Gu, 2009b; Sen and Thiagarajan, 1988).

Para los fines de este estudio en el cual se pretende desarrollar agentes de sostén cerámicos, los cuales se utilizan en grandes volúmenes en la explotación de hidrocarburos no convencionales, por lo que el costo de producción y las posibilidades de escalado del proceso de fabricación de los materiales son factores importantes a considerar durante todo el desarrollo, se eligió desarrollar materiales de base mullita a partir del sinterizado de materias primas minerales (arcillas caoliníticas y bauxita) las cuales se encuentran en gran disponibilidad en la corteza terrestre.

Las materias primas utilizadas en este trabajo fueron arcillas caoliníticas $\left(\mathrm{Al}_{2} \mathrm{O}_{3} 2 \mathrm{SiO}_{2} 2 \mathrm{H}_{2} \mathrm{O}\right)$, las cuales existen en grandes yacimientos en la Argentina (Domínguez et al., 2016; Vallés Jorge M., 2011) y en algunos casos dónde se buscó generar mayor porcentaje de mullia se utilizó bauxita como fuente de alúmina.

Las reacciones que tienen lugar durante el tratamiento térmico de la caolinita han sido reportadas en numerosas publicaciones (da Silva et al., 2016; Ptáček et al., 2010) y se describen en las siguientes ecuaciones:

$$
\begin{aligned}
& \mathrm{Al}_{2} \mathrm{O}_{3} \cdot 2 \mathrm{SiO}_{2} \cdot 2 \mathrm{H}_{2} \mathrm{O} \rightarrow \mathrm{Al}_{2} \mathrm{O}_{3} \cdot 2 \mathrm{SiO}_{2}+2 \mathrm{H}_{2} \mathrm{O} \\
& 2\left(\mathrm{Al}_{2} \mathrm{O}_{.3} 2 \mathrm{SiO}_{2}\right) \rightarrow 2 \mathrm{Al}_{2} \mathrm{O}_{3} \cdot 3 \mathrm{SiO}_{2}+\mathrm{SiO}_{2} \\
& 3\left(2 \mathrm{Al}_{2} \mathrm{O}_{3} \cdot 3 \mathrm{SiO}_{2}\right) \rightarrow 2\left(3 \mathrm{Al}_{2} \mathrm{O}_{3} \cdot 2 \mathrm{SiO}_{2}\right)+5 \mathrm{SiO}_{2} \\
& \mathrm{SiO}_{2} \text { (amorfo) } \rightarrow \mathrm{SiO}_{2} \text { (cristobalita) }
\end{aligned}
$$

La primera reacción (ec. 2.1) se debe al proceso de deshidroxilación (pérdida de agua estructural) de la arcilla, que normalmente ocurre en el rango entre $450-600^{\circ} \mathrm{C}$ para dar lugar a una fase desordenada denominada 
metacaolín $\left(\mathrm{Al}_{2} \mathrm{O}_{3} 2 \mathrm{SiO}_{2}\right)$. El metacaolín se convierte en espinela y sílice amorfa entre $925-1050^{\circ} \mathrm{C}$ (ec. 2.2) y a temperaturas superiores de $1050^{\circ} \mathrm{C}$ la espinela comienza a cristalizar en forma de mullita (ec. 2.3). Estos cristales de mullita (mullita primaria) se encuentran inmersos en sílice amorfa que está en estado líquido. La cristalización de la sílice amorfa en cristobalita comienza a suceder temperaturas mayores a $1200^{\circ} \mathrm{C}$ (ec. 2.4).

El contenido de sílice en las arcillas caoliníticas es mayor que en la mullita, por lo que el exceso de sílice más las impurezas en la arcillas forman fase amorfa y cristobalita. La cantidad de fase amorfa y de cristobalita puede disminuirse con el agregado de alguna fuente de alúmina como gibbsita, boehmita, bauxita, etc. al sistema. La reacción entre la cantidad extra de alúmina y la sílice proveniente de la fase vítrea y la cristobalita generan mullita secundaria (Chen et al., 2000; Liu et al., 1994; Sahraoui et al., 2016).

\subsection{Materiales cerámicos porosos}

Los materiales porosos poseen diversas propiedades como baja densidad, baja conductividad térmica, baja constante dieléctrica, alta permeabilidad, alta resistencia al choque térmico, alta superficie específica, entre otras; que hacen que estos materiales sean de gran interés para diferentes aplicaciones (Liu and Chen, 2014; Studart et al., 2006).

Dentro de las aplicaciones típicas de los materiales cerámicos porosos se pueden mencionar: soporte de catalizadores (Quan et al., 2017; Yuan et al., 2018), filtros (Taslicukur et al., 2007), membranas (Bouzerara et al., 2009; Cao et al., 2014), sensores de gases (An et al., 2014), electrodos de baterías (Wu et al., 2011; Yang et al., 2007), aislantes térmicos, amortiguadores acústicos (Han et al., 2017; Takahara, 1994), etc. 
Existen diversas rutas de procesamiento de materiales cerámicos porosos en las cuales se emplean una gran variedad de materias primas de distinta naturaleza y morfología. Según la literatura (Colombo, 2006; Studart et al., 2006) las técnicas de procesamiento podría agruparse en tres grandes grupos: a) réplica por medio de una plantilla; b) agregado de un material de sacrificio y c) espumado directo. En la Figura 2.2 se muestra un esquema de las posibles rutas de procesamiento de materiales cerámicos porosos.

a) Réplica por medio de una plantilla: este método se basa en el uso de una estructura (plantilla) que puede ser sintética o natural la cual se la impregna de una solución cerámica, luego el sistema se seca y la plantilla se quema para dar lugar a un material poroso de igual morfología que la estructura base (Figura 2.2 a). Las plantillas en general son de poliuretano, poliestireno, celulosa, látex, policloruro de vinilo (PVC), etc.

b) Agregado de un material de sacrificio: consiste en adicionar a la mezcla de precursores cerámicos una fase de sacrificio (agentes formadores de poro) que durante el tratamiento térmico se descomponen dejando huecos en la matriz cerámica (Figura 2.2 b). Gran variedad de agentes formadores de poro se utilizan incluyendo tanto de origen natural como sintéticos como por ejemplo almidón, carbón, aserrín, nylon, resinas, gelatina, etc. El porcentaje de porosidad (abierta y/o cerrada), distribución, tamaño y forma del poro está relacionado con la naturaleza, tamaño y morfología del agente formador. 


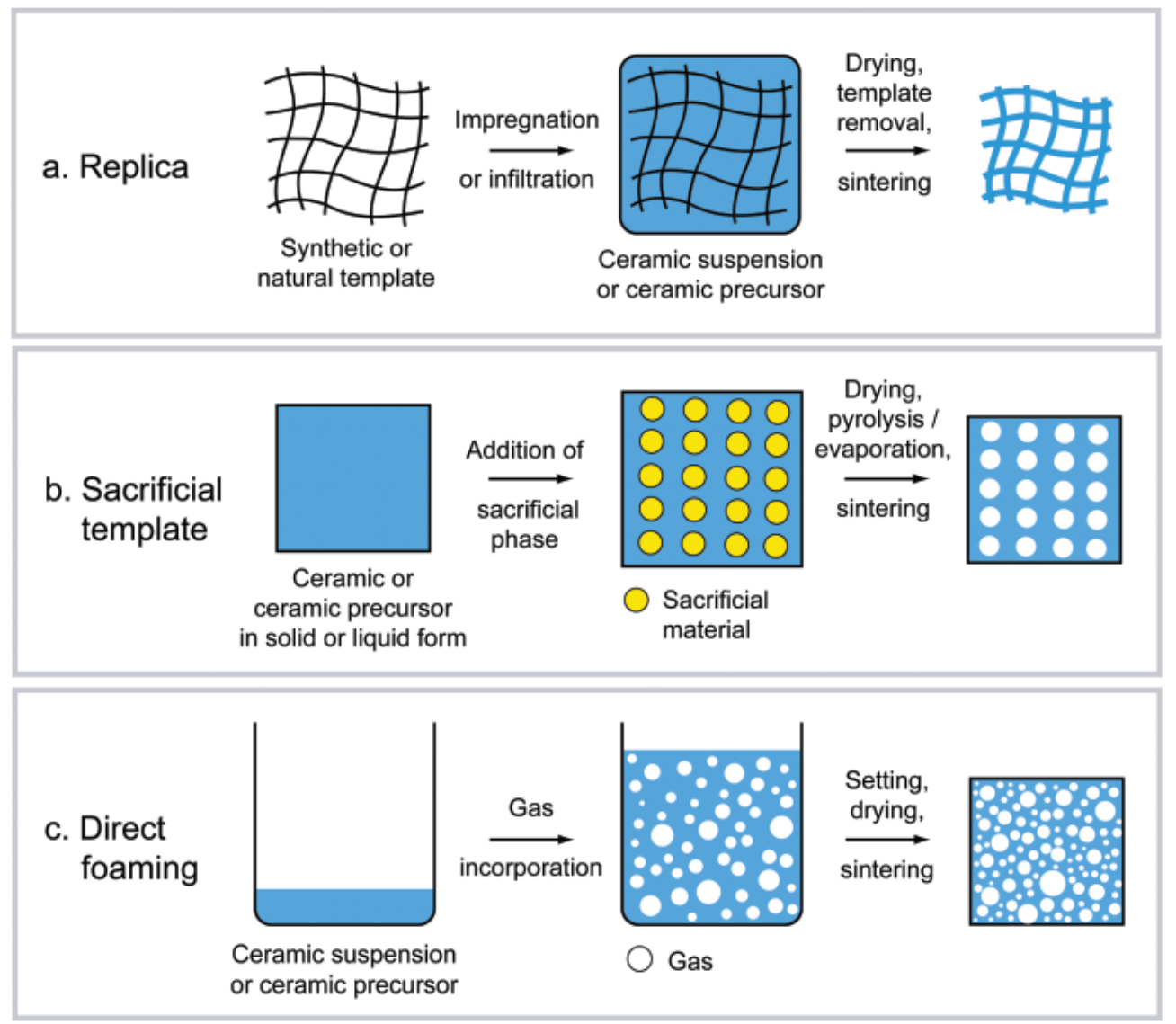

Figura 2.2. Esquema de las rutas de procesamiento de materiales cerámicos porosos (Studart et al., 2006).

c) Espumado directo (Figura 2.2 c): en esta técnica los materiales porosos se producen por la generación de burbujas adentro de una suspensión liquida de polvos cerámicos que se estabiliza para mantener la estructura porosa generada. Luego a las suspensiones se las somete a un tratamiento térmico para obtener las características propias de los materiales cerámicos. La porosidad total de los materiales obtenidos con este método es directamente proporcional a la cantidad de gas incorporado a la suspensión, y el tamaño de poro está determinado por la estabilidad de la espuma previa al sinterizado. 
En este trabajo se estudió la posibilidad de generar una matriz porosa para disminuir la densidad del material. Para generar porosidad se utilizó el método de agregar un material de sacrificio, para ello se usaron tres fuentes de carbón: carbón vegetal, carbón residual de petróleo y negro de humo.

El carbón vegetal se produce por calentamiento de madera y residuos vegetales en ausencia de oxígeno a temperaturas entre $400^{\circ} \mathrm{C} \mathrm{y} 700{ }^{\circ} \mathrm{C}$. El carbón residual de petróleo (también conocido como Coque) es un producto que proviene del proceso de refinación de petróleo, y el negro de humo que se obtiene a partir de la combustión incompleta en ausencia de oxígeno de gas, aceite, grasa, etc.

\subsection{Agentes ligantes}

En la fabricación de cerámicos se utilizan gran variedad de agentes ligantes tanto para la liga de la matriz cerámica como así también como recubrimiento (Chung, 2003). Ligantes poliméricos como el polivinil alcohol (PVA) se usan para aumentar la resistencia de los materiales entre temperatura ambiente y aproximadamente $200^{\circ} \mathrm{C}$, debido a que temperaturas superiores a ésta el PVA se descompone. Otros ligantes como el silicato de sodio, oxicloruros, oxisulfatos y cementos hidráulicos tienen alta resistencia mecánica a temperatura ambiente y se comienzan a desintegran entre los $200-300^{\circ} \mathrm{C}$. Para los cerámicos refractarios se utilizan agentes ligantes de alta resistencia a altas temperaturas como los nitruros, los fosfatos y la sílice que tienen temperaturas de descomposición superiores a $1000^{\circ} \mathrm{C}$ (Chen et al., 2003; Chiou and Chung, 1993).

En este trabajo se estudia la incorporación de dos precursores de ligas nanoestructuradas: el fosfato de monoaluminio y la sílice coloidal.

\subsubsection{Fosfato de monoaluminio}


Numerosos tipos de agentes ligantes de base fosfórica se utilizan en la industria cerámica como por ejemplo los fosfatos de zinc, de magnesio, zirconia, aluminio, calcio, ácido fosfórico, entre otros (Kingery, 1950).

Kingery estudió las distintas reacciones entre los óxidos metálicos y el ácido fosfórico. Concluyó que los óxidos ácidos o inertes no reaccionan con ácido fosfórico; los óxidos básicos reaccionan violentamente con el ácido fosfórico dando lugar una estructura porosa por lo que no es posible ningún tipo de cohesión; y que los óxidos de naturaleza básica débil o anfótera reaccionan con el ácido fosfórico pero no todos los productos de la reacción tienen características ligantes. También llegó a la conclusión que el radio iónico del catión influye en las características ligantes de los productos de la reacción siendo los cationes con menor radio los que presentaron productos de reacción con mejores propiedades ligantes.

Dentro del grupo de óxidos de naturaleza básica débil se ha evidenciado que los fosfatos provenientes de los óxidos de hierro, magnesio y aluminio tienen propiedades cohesivas (Hipedinger et al., 2002; Wagh, 2016; Wagh and Jeong, 2003).

Las propiedades ligantes de los fosfatos provienen de la polimerización de éstos luego de un tratamiento térmico con pérdida de agua, la cual genera porosidad en el material (Giskow et al., 2004).

Muchas publicaciones estudiaron las ligas de fosfatos de aluminio a partir de distintas fuentes de alúmina (Chen et al., 2003; Gonzalez and Halloran, 1980; Han and Kim, 2003; Kumar et al., 2013; Luz et al., 2015; Morris et al., 1977; Vippola et al., 2000; Wagh, 2013). En el sistema $\mathrm{Al}_{2} \mathrm{O}_{3}$ $\mathrm{P}_{2} \mathrm{O}_{5}$ existen distintos tipos compuestos con variaciones en sus estequiometrias, estructuras y propiedades que se basan en las relaciones molares entre los dos óxidos (Morris et al., 1977).

El fosfato de monoaluminio ( $\mathrm{MAP}$ o $\left.\mathrm{Al}\left(\mathrm{H}_{2} \mathrm{PO}_{4}\right)_{3}\right)$ es un compuesto formado a partir de la relación 1:3 $\left(\mathrm{Al}_{2} \mathrm{O}_{3}: \mathrm{P}_{2} \mathrm{O}_{5}\right)$. A sido reportado como uno 
de los precursores de liga fosfórica más eficaces debido a su alta resistencia mecánica en verde, alta solubilidad en agua, resistencia abrasiva y corrosiva (Giskow et al., 2004, 2004, Luz et al., 2016, 2016, Morris et al., 1976, 1977).

Las propiedades químicas del MAP varían con el método de obtención las cuales se pueden dividir en tres vías i) por la adición de ácido fosfórico a una mezcla refractaria con alúmina reactiva en su composición, ii) a partir de la mezcla de $\mathrm{Al}_{2} \mathrm{O}_{3}$ y/o $\mathrm{Al}(\mathrm{OH})_{3}$ con ácido fosfórico, o iii) utilizando alúmina parcialmente hidratada para mejorar la interacción con el ácido fosfórico (Luz et al., 2015).

En el mercado se venden soluciones comerciales de MAP con una concentración entre 40-60\%. En este trabajo se estudió la utilización de MAP como agente ligante de los materiales cerámicos. El MAP se sintetizó partir de psuedoboehmita $(\mathrm{AlO}(\mathrm{OH}) \cdot \mathrm{xH} 2 \mathrm{O})$ y ácido fosfórico y luego se adicionó agua hasta alcanzar una concentración del 40\% y así obtener una solución similar a las comerciales.

\subsubsection{Sílice coloidal}

La sílice coloidal es una suspensión de nanopartículas amorfas de sílice cuyo tamaño oscila entre 5-100 nm, son insolubles en agua y poseen alta superficie específica. Las partículas se encuentran dispersas en agua con cargas negativas en su superficie lo que impide la aglomeración (Bergna, 1994).

Las partículas de sílice en la suspensión coloidal se disponen en una estructura interna conformada por una red de siloxanos (-Si-O-Si-) con una capa superficial de grupos silanol (-SiOH) y grupos hidroxilos (dos Anjos et al., 2008; Nouri-Khezrabad et al., 2013). 
El rol principal de los coloides utilizados como agentes ligantes se encuentra relacionado con el proceso de fraguado. Las suspensiones acuosas de nanopartículas se combinan entre sí para dar lugar a cadenas ramificadas mediante un proceso conocido como gelificación (NouriKhezrabad et al., 2013).

Las partículas de sílice coloidal se vinculan mediantes distintos mecanismos de fraguado como es la gelificación proporcionando al sistema cerámico, en la cual es incorporada la suspensión, cierta resistencia mecánica. En la Figura 2.3 se esquematiza el mecanismo de gelificación que tiene lugar cuando se obtienen grupos siloxanos en la interfaz de las partículas a expensas de grupos silanoles por medio de la siguiente reacción (ec. 2.5) (Xiong et al., 2012):

a

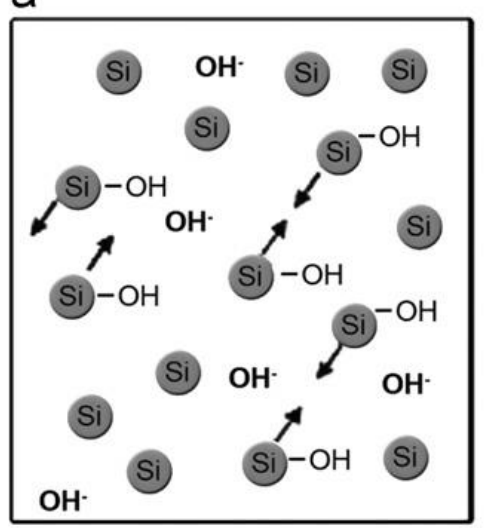

Si $=$ Silicon

C

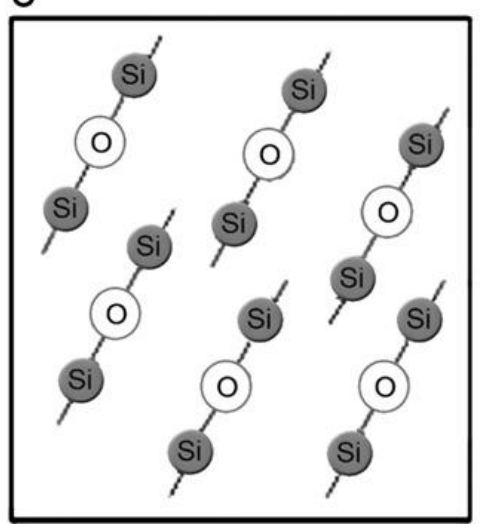

b

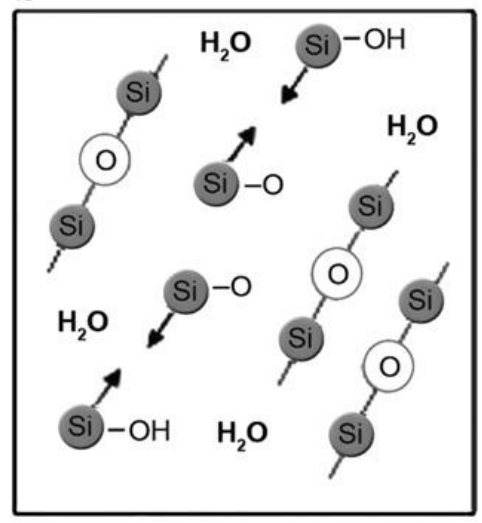

(O) = oxygen

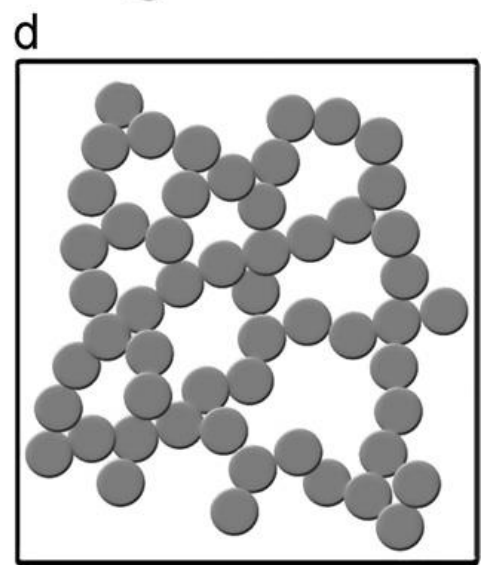

Figura 2.3. Mecanismo de gelificación de la súlice coloidal (NouriKhezrabad et al., 2013) 


$$
-\mathrm{SiOH}+\mathrm{HOSI}-\rightarrow-\mathrm{SiOSi}-+\mathrm{H}_{2} \mathrm{O} \quad \text { ec. } 2.5
$$

El proceso de fraguado comienza cuando se desestabiliza la suspensión, lo que permite que las partículas se pongan en contacto. Esto puede ocurrir por diferentes vías que incluyen cambios de $\mathrm{pH}$, agregado de agentes de fraguado, secado, sinterizado, etc. (Nouri-Khezrabad et al., 2013).

Por esta propiedad de formación de geles, la sílice coloidal se utiliza como agente ligante en hormigones refractarios (dos Anjos et al., 2008; Ismael et al., 2006). Para el desarrollo de agentes de sostén cerámicos de baja densidad primero se caracterizó una sílice comercial, que luego se utilizó como agente ligante de los materiales cerámicos a los que se le evaluaron sus propiedades texturales y mecánicas. 
Capítulo 3

Selección y caracterización de las materias primas 
Para la obtención de materiales de base mullita se utilizaron dos arcillas Argentinas: Blend (Neuquén) y Tincar Super (Santa Cruz) y también se agregó, en algunos sistemas bauxita (proveniente de Brasil) como fuente de alúmina.

El fosfato de monoaluminio sintetizado a partir de pseudoboehmita y ácido fosfórico y la sílice coloidal fueron los agentes ligantes empleados en este trabajo. Además con el objetivo generar porosidad y así disminuir la densidad final de los materiales se adicionaron tres fuentes de carbón carbón vegetal, carbón residual de petróleo y negro de humo- como agentes formadores de poro.

Conocer la composición química, el comportamiento térmico, las fases cristalinas, etc. de las materias primas nos permite realizar un mejor análisis de las características de los materiales finales. Con ese fin, dependiendo del caso, se analizaron las materias primas por difracción de 
rayos $\mathrm{X}$, análisis térmico diferencial y térmico gravimétrico, análisis químico, cono pirométrico equivalente y tamaño medio de partícula.

\subsection{Técnicas de caracterización}

Para la caracterización de las materias primas minerales y sintéticas que se utilizaron en este trabajo se aplicaron las siguientes técnicas descriptas a continuación.

\section{Difracción de rayos $X$}

Para conocer las fases cristalinas presentes en las materias primas se utilizó la técnica de Difracción por Rayos X (DRX), esta técnica es ampliamente utilizada para la identificación de sólidos cristalinos y se basa en la comparación de patrones reportados en la literatura. Consiste en hacer incidir un haz monocromático de rayos $\mathrm{X}$ sobre una muestra, con un ángulo de incidencia variable, y medir la intensidad de haz que ha sido difractado de acuerdo a la ley de Bragg (ec. 3.1).

$$
\mathrm{n} \lambda=2 \mathrm{~d} \sin \theta \quad \text { ec. } 3.1
$$

Donde $\lambda$ es la longitud de onda del rayo, $\mathrm{d}$ es la distancia entre planos cristalinos y $\theta$ es el ángulo de incidencia. Dependiendo de las condiciones de interferencia cada plano de átomos produce una serie de $\mathrm{n}$ reflexiones, a partir de los cuales puede calcularse la distancia interatómica empleando la ecuación de Bragg. Cada compuesto tiene su conjunto característico de valores de distancia entre planos cristalinos (d) e intensidades, las cuales son utilizadas para su identificación.

En el presente trabajo la determinación de los espectros de difracción de los materiales se realizó con un equipo Philips PW-3710 con radiación 
$\mathrm{Cu}-\mathrm{Ka}(\lambda=0,154)$ con filtro de níquel a $40 \mathrm{kV}$ y $35 \mathrm{~mA}$. Los barridos se realizaron en todos los casos con pasos de $0,02^{\circ}(2 \theta)$ y 1 un segundo por paso, en el intervalo de $2 \theta$ desde $5^{\circ}$ a $70^{\circ}$. Para la identificación de las fases cristalinas se utilizó el X'Pert High Score Plus y la base de datos de la ICDD (Internacional Center of Diffraction Data).

Además se cuantificaron las fases cristalinas mediante el método de Rietveld que se basa en los diagramas obtenidos por DRX y se encuentra explicado en el Anexo I.

\section{Análisis químico}

Se determinó la composición química de las materias primas minerales con la técnica fluorescencia de rayos X (FRX). Con esta técnica la composición de una muestra definida se cuantifica por los óxidos, a partir del bombardeo de la muestra mediante el empleo de una fuente de haz de rayos $\mathrm{X}$, que genera la emisión de fluorescencia de los electrones excitados, los cuales poseen una determinada longitud de onda característica del elemento al que pertenecen, dando además la posibilidad de cuantificar el elemento a partir de la intensidad de la emisión.

\section{Cono pirométrico equivalente}

Se estableció el punto de ablandamiento de las materias primas minerales por medio del ensayo de Cono Pirométrico Equivalente (CPE) bajo lineamiento de la norma IRAM 12.507. Este ensayo nos brinda información de la refractariedad de los materiales y del rango de temperaturas en el cual el material se ablanda.

Para medir el CPE de las materias primas y de las mezclas formuladas se utilizó un horno con las especificaciones que se mencionan en 
la norma, y se elaboraron conos de las muestras a caracterizar que se colocaron junto a conos de referencia Orton en un soporte. El punto de ablandamiento del material es aquel en el cual la punta del cono toca el soporte, entonces considerando los conos de referencia se determina la temperatura de ablandamiento.

\section{Análisis térmico diferencial y termo gra vimétrico}

Se caracterizaron las materias primas por análisis térmico diferencial (ATD) y termo gravimétrico (TG). El ATD es una técnica que compara la temperatura de la muestra con la temperatura de un material de referencia (que no experimenta cambios entálpicos en el rango de temperaturas de trabajo) mientras ambas están siendo sometidas a un cambio de temperatura a velocidad controlada. La temperatura de la muestra y la de la referencia se mantienen iguales hasta que la muestra experimenta un cambio entálpico que se asocia con una fusión, descomposición, cambio de estructura del cristal, etc; el cual hace que la temperatura de la muestra sea mayor o menor que la temperatura de referencia.

En este mismo programa de calentamiento controlado se estudia la evolución de la masa de la muestra (análisis termo gravimétrico) y se lo compara con la masa del material de referencia, que no sufre ningún cambio durante el calentamiento. Los cambios entálpicos mencionados anteriormente muchas veces llevan asociados ganancias o pérdidas de peso por lo que la combinación de las dos técnicas (ATD y TG) sirven para explicar los comportamientos térmicos de los materiales.

El ATD-TG de las muestras se realizó en un equipo Rigaku Evo plus II desde temperatura ambiente hasta $1300-1450^{\circ} \mathrm{C}$ (según la materia prima analizada), con una velocidad de calentamiento de $10^{\circ} \mathrm{C} / \mathrm{min}$ en atmósfera de aire y utilizando alúmina como material de referencia. 
Tamaño medio de partícula en suspensiones coloidales

Se midió el tamaño medio de partícula de la sílice coloidal con un Particle Size Analyzer 90 (Brookhaven Instruments Corporation) que mide el tamaño de partícula en el rango de $2 \mathrm{~nm}-3000 \mathrm{~nm}$. El equipo opera a $\lambda=$ $635 \mathrm{~nm}$ y emplea un láser de estado sólido a $15 \mathrm{~mW}$, con un ángulo de dispersión de $90^{\circ}$ y a una temperatura de $25^{\circ} \mathrm{C}$.

El principio de funcionamiento del equipo se basa en la diferencia entre el índice de refracción del medio líquido y del material sólido que sufre un haz de luz cuando se hace pasar a éste a través de una suspensión coloidal; de esta manera, se forma el llamado haz Tyndall que es proporcional al tamaño de las partículas. Este método supone partículas esféricas por lo que la determinación otorga un valor de diámetro aparente de la esfera equivalente a partir de un cálculo estadístico que el equipo realiza en cada barrido.

\subsection{Materias primas minerales}

En la Figura 3.1 se muestra el diagrama de rayos $\mathrm{X}$ de la arcilla Tincar Súper, se identificó la presencia de cuarzo $\left(\mathrm{SiO}_{2}\right)$ y caolinita $\left(\mathrm{Al}_{2} \mathrm{O}_{3} \cdot 2 \mathrm{SiO}_{2} \cdot 2 \mathrm{H}_{2} \mathrm{O}\right)$ como minerales principales. En el DRX de la arcilla Blend (Figura 3.2) también se evidenciaron estos dos compuestos, variando la intensidad de sus picos característicos de acuerdo a la naturaleza de cada materia prima y por ende la cantidad relativa de estos dos minerales. Además en la arcilla Blend se observan otros minerales como son muscovita $\left(\mathrm{KAl}_{2}\left(\mathrm{AlSi}_{3} \mathrm{O}_{10}\right)(\mathrm{OH})_{2}\right)$ y rutilo $\left(\mathrm{TiO}_{2}\right)$ (Moore and Reynolds, 1997; Żbik et al., 2010). 


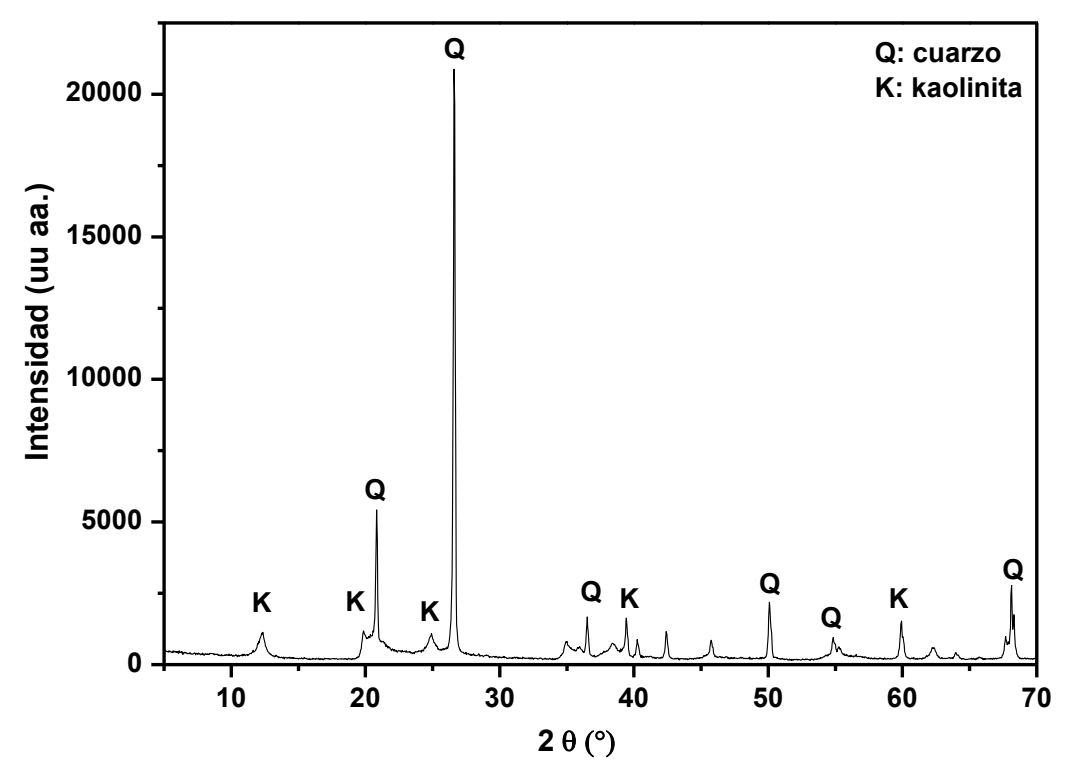

Figura 3.1. Diagrama de rayos X de la arcilla Tincar Super.

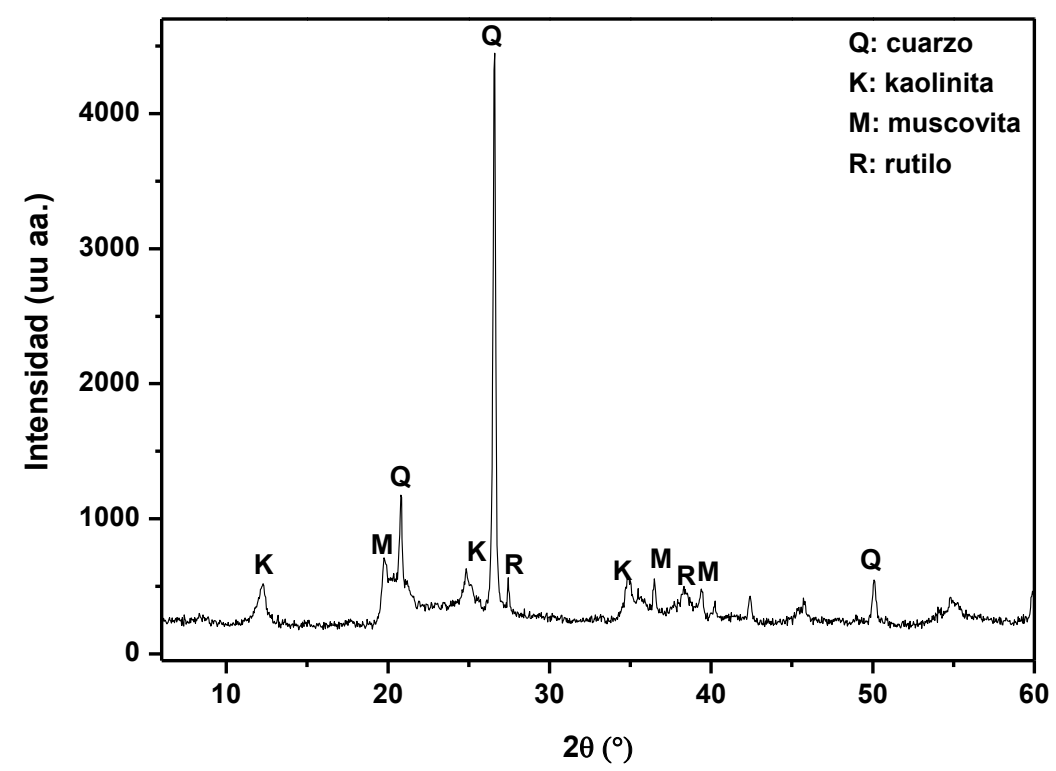

Figura 3.2. Diagrama de rayos X de la arcilla Blend.

En el DRX de la bauxita (Figura 3.3) se observaron picos asociados con la gibbsita $\left(\mathrm{Al}(\mathrm{OH})_{3}\right)$ y la boehmita $(\mathrm{AlO}(\mathrm{OH}))$ como las principales 
fuentes de alúmina. También se evidenciaron fases cristalinas de caolinita, anatasa $\left(\mathrm{Ti}_{2} \mathrm{O}\right)$ y goethita $\left(\mathrm{Fe}_{2} \mathrm{O}_{3} \cdot \mathrm{H}_{2} \mathrm{O}\right)$.

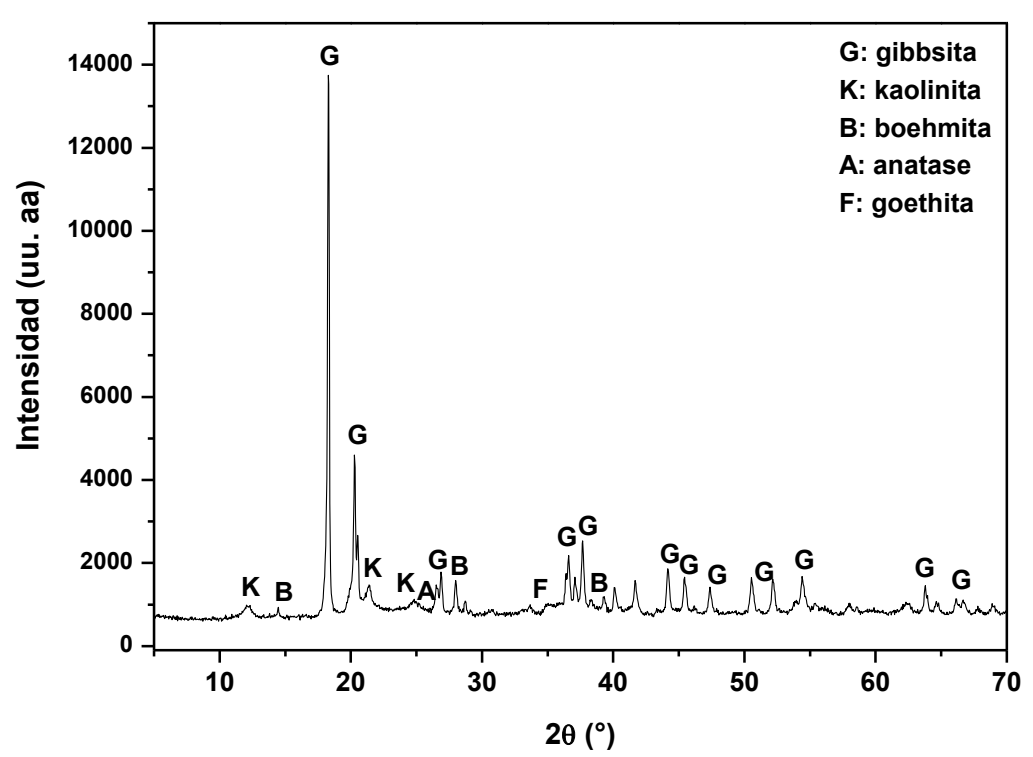

Figura 3.3. Diagrama de rayos X de la bauxita.

La cuantificación de las fases cristalinas por el método Rietveld de las materias primas minerales se muestra en la Tabla 3.1. Ambas arcillas presentaron alto contenido de caolinita (superando el 50\%), y en el caso de la arcilla Tincar Super tuvo mayor contenido de cuarzo (50,72\%) que la arcilla Blend (32,08\%).

La mayor fuente de alúmina de la bauxita fue la gibbsita $(71,06 \%)$ y en mucho menor proporción la boehmita (1,28\%). También presentó un porcentaje cercano al $20 \%$ de caolinita y un aporte de óxido de hierro como goethita $(5,50 \%)$ que le confiere un color rojizo a la bauxita. 
Tabla 3.1. Porcentajes de las fases cristalinas presentes en las materias primas minerales calculados por el método de Rietveld.

\begin{tabular}{c|ccc}
\multicolumn{1}{c}{ Tincar Super } & Blend & Bauxita \\
\hline Cuarzo & $50,72(3,44)$ & $32,08(1,44)$ & - \\
Caolinita & $49,28(5,21)$ & $64,17(3,36)$ & $21,84(0.2)$ \\
Muscovita & - & $3,03(0,13)$ & - \\
Rutilo/ Anatasa & - & $0,72(0,05)$ & $0,33(0,03)$ \\
Gibbsita & - & - & $71,06(0,26)$ \\
Boehmita & - & - & $1,28(0,06)$ \\
Goethita & - & - & $5,50(0,09)$
\end{tabular}

En la Tabla 3.2 se muestran las composiciones químicas de las materias primas minerales, donde se comprueba lo identificado por DRX. Los componentes principales de las arcillas fueron el óxido de sílice y el óxido de aluminio, estando presentes otros óxidos en menor proporción.

Tabla 3.2. Composición química de las materias primas minerales.

\begin{tabular}{r|ccccccccc}
\multicolumn{2}{c}{$\mathrm{SiO}_{2}$} & $\mathrm{Al}_{2} \mathrm{O}_{3}$ & $\mathrm{Fe}_{2} \mathrm{O}_{3}$ & $\mathrm{MgO}$ & $\mathrm{K}_{2} \mathrm{O}$ & $\mathrm{TiO}_{2}$ & $\mathrm{CaO}$ & Otros & $\begin{array}{c}\mathrm{PPC} \\
\left(1000^{\circ} \mathrm{C}\right)\end{array}$ \\
\hline $\begin{array}{r}\text { Tincar } \\
\text { Súper }\end{array}$ & 61,82 & 27,55 & 0,79 & 0,66 & 0,76 & 0,39 & 0,28 & 2,92 & 7,63 \\
Blend & 55,04 & 28,59 & 4,13 & 0,72 & 2,27 & 0,81 & 0,21 & - & 8,10 \\
Bauxita & 13,38 & 53,91 & 6,20 & 0,48 & 0,22 & 0,72 & - & 0,77 & 24,33
\end{tabular}


Además, en la Tabla 3.2 se presentan los porcentajes de pérdida de peso debido a la calcinación a $1000^{\circ} \mathrm{C}(\mathrm{PPC})$. En el caso de la bauxita se observó que el porcentaje presente de alúmina supera a penas el 50\% con lo cual se la podría considerar como una fuente del denominado tenor medio de alúmina (Liu et al., 2016; Ma et al., 2016).

Los valores obtenidos en el análisis de CPE se presentan en la Tabla 3.3. La arcilla Tincar Súper tuvo mayor refractariedad (mayor punto de ablandamiento) que la arcilla Blend debido al menor porcentaje de impurezas observado en su composición química (Tabla 3.2) y en el DRX (Figura 3.1). La temperatura de ablandamiento de la bauxita fue mayor a $1646^{\circ} \mathrm{C}$ y la de la mezcla Tincar Súper con $20 \%$ de bauxita dio en el rango de $1605-1621^{\circ} \mathrm{C}$. Si bien al incorporar alúmina al sistema se esperaría que el punto de ablandamiento sea mayor de la mezcla que el de la arcilla sola, la fuente de hierro que contiene la bauxita produciría esta disminución en la temperatura de ablandamiento.

Tabla 3.3. Valores de Cono Pirométrico Equivalente (CPE) de las arcillas.

\begin{tabular}{c|cc} 
Muestra & CPE & Temperatura $\left({ }^{\circ} \mathrm{C}\right)$ \\
\hline Tincar Súper & $31 \frac{1 / 2-32}{}$ & $1669-1717$ \\
Blend & $23-26$ & $1605-1621$ \\
Bauxita & $>28$ & $>1646$ \\
Tincar Super - 20\% Bauxita & $23-26$ & $1605-1621$
\end{tabular}

La Figura 3.4 muestra las curvas de ATD-TG de la arcilla Tincar Super. Se observaron en la curva TG dos variaciones de masa, una de $1,94 \%$ entre $21-200^{\circ} \mathrm{C}$ debido a la pérdida de agua adsorbida superficialmente en el mineral y otra de $7,08 \%$ entre $200-1000^{\circ} \mathrm{C}$ que se encuentra asociada a la pérdida de agua de la estructura de la caolinita. 
Por otro lado, en el ATD se observaron cuatro efectos térmicos: el primer efecto a temperaturas menores a $200^{\circ} \mathrm{C}$ relacionado con la pérdida de agua adsorbida, el segundo efecto, un pico endotérmico a $511,1^{\circ} \mathrm{C}$ que pertenece a la deshidroxilación de la caolinita y solapado a esta transformación se encuentra el cambio de fase reversible $a \rightarrow b$ del cuarzo (este último es de muy baja intensidad comparado con la deshidroxilación). El tercer efecto un pico exotérmico a $977,6^{\circ} \mathrm{C}$ correspondiente a la formación de espinela (Lee et al., 1999; Saikia et al., 2003) y el ultimo efecto a $1218,8^{\circ} \mathrm{C}$ la transformación de espinel a mullita que se evidencia con un pico exotérmico.

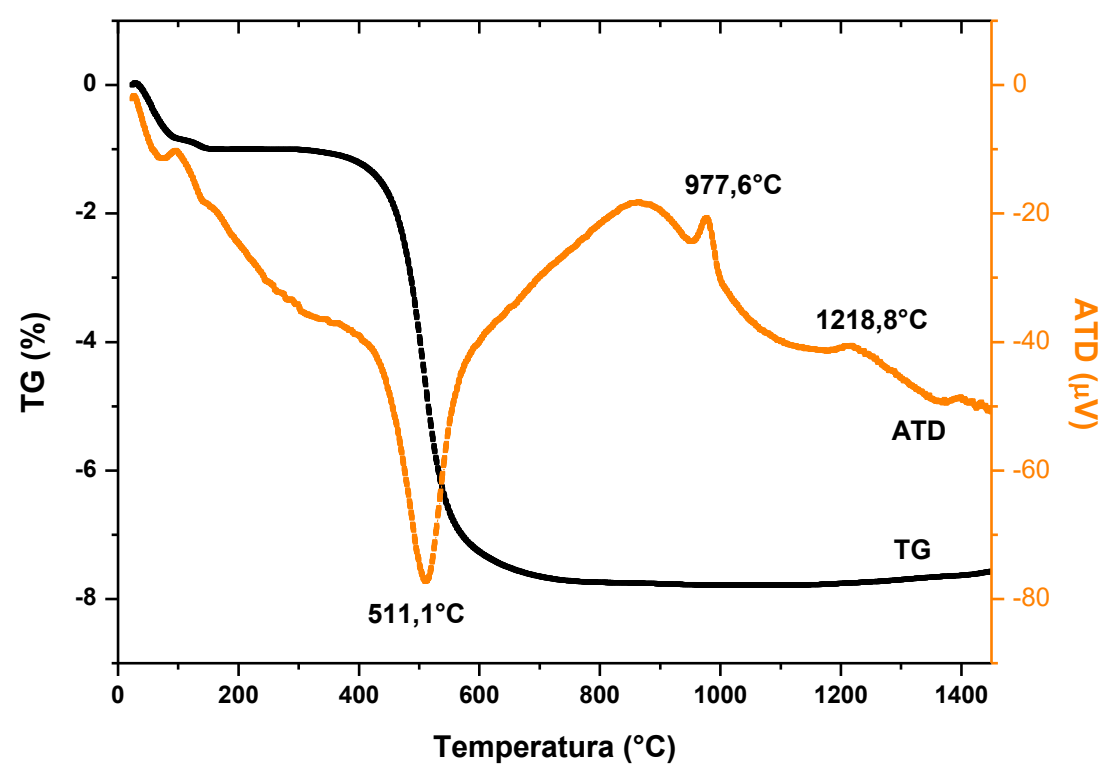

Figura 3.4. Análisis térmico diferencial (ATD) y termo gravimétrico (TG) de la arcilla Tincar Super.

En la Figura 3.5 se observaron tanto en la curva ATD como en la curva de TG de la arcilla Blend las mismas variaciones de masa y los mismos procesos térmicos que en la arcilla Tincar Super con pequeñas 
diferencias, en cuanto a la temperatura e intensidad de los picos, por la presencia de hierro que se observó en el análisis químico (4,13\%).

En este caso el pico endotérmico debido a la deshidroxilación de la caolinita y junto a este el cambio $a \rightarrow B$ del cuarzo se presenté a $495,3^{\circ} \mathrm{C}$. La pérdida de agua estructural de la transformación de la arcilla en el TG fue de $-8,18 \%$. El pico exotérmico relacionado con la formación de la espinela se identificó a los $948,4^{\circ} \mathrm{C}$.

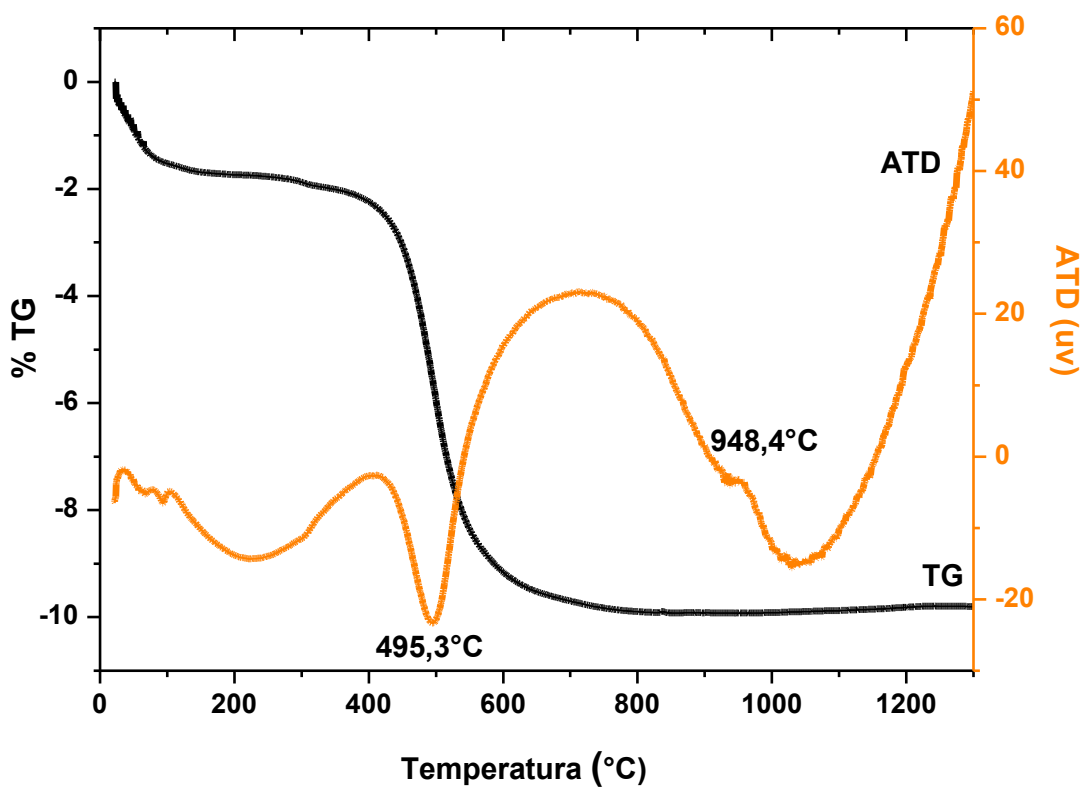

Figura 3.5. Análisis térmico diferencial (ATD) y termo gravimétrico (TG) de la arcilla Blend.

Dos picos endotérmicos se observaron en la curva de ATD de la bauxita (Figura 3.6). El primer pico endotérmico a $298,9^{\circ} \mathrm{C}$ se debe a la deshidroxilación de $\mathrm{Al}(\mathrm{OH})_{3}$ a $\mathrm{AlO}(\mathrm{OH})$; el segundo pico a $480^{\circ} \mathrm{C}$ es producido por la deshidroxilación de $\mathrm{AlO}(\mathrm{OH})$ a la fase amorfa de $\mathrm{Al}_{2} \mathrm{O}_{3} \mathrm{y}$ solapado a esta transformación se encuentra también la deshidroxilación de la caolinita. En la curva de TG se evidenciaron dos pérdidas de masa. La primera en el rango de temperatura de $200-380^{\circ} \mathrm{C}$, con una pérdida de $22 \%$, 
se relaciona con la deshidroxilación de la gibbsita. En el rango de temperatura de $400-650^{\circ} \mathrm{C}$ una segunda pérdida de masa de $5 \%$ es causada por la deshidroxilación de la boehmita (Laskou et al., 2006; Zhu et al., 2010). Además en este rango de temperatura se presentó la deshidroxilación de la caolinita, por lo que la pérdida de masa del 5\% en el TG y el pico endotérmico a $480,0^{\circ} \mathrm{C}$ en el ATD también contempla esta transformación.

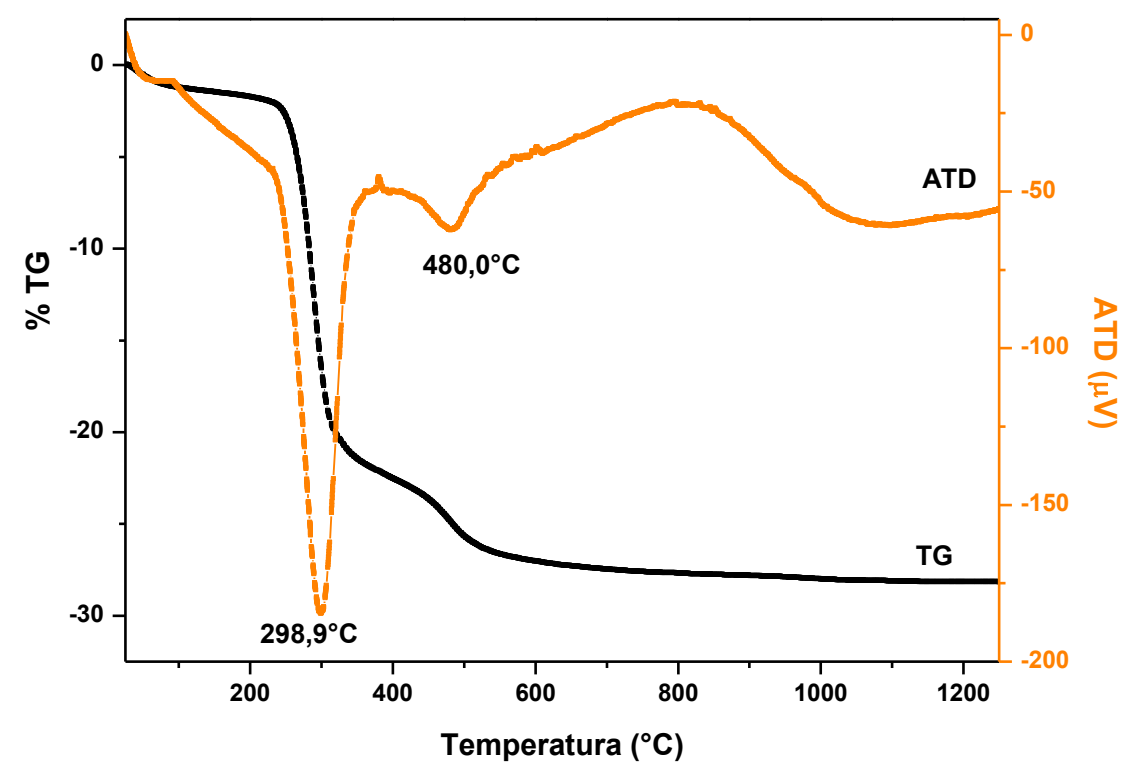

Figura 3.6. Análisis térmico diferencial (ATD) y termo gravimétrico (TG) de la bauxita.

\subsection{Síntesis del fosfato de monoaluminio}

Para este estudio se obtuvo MAP a partir de la reacción de pseudoboehmita $(\mathrm{AlO}(\mathrm{OH}) \times \mathrm{xH} 2 \mathrm{O})$, como fuente de alúmina, y ácido fosfórico $\left(\mathrm{H}_{3} \mathrm{PO}_{4}\right)$ al $85 \% \mathrm{p} / \mathrm{p}$, los cuales se mezclaron de forma estequiométrica ${ }^{3}$ para

${ }^{3}$ Los cálculos estequiométricos se realizaron considerando el $85 \%$ de pureza del ácido y la cantidad de agua de la pseudoboehmita calculada a partir de la pérdida de masa por calcinación. 
obtener fosfato de monoaluminio $\left(\mathrm{Al}\left(\mathrm{H}_{2} \mathrm{PO}_{4}\right)_{3}\right)$ según la ec. 3.1. Además, se adicionó agua destilada para llegar a una concentración del 40\% como se presentan las soluciones comerciales del MAP (Giskow et al., 2004). La solución se mantuvo con agitación a $80^{\circ} \mathrm{C}$ sobre una platina calefactora durante 40 minutos hasta obtener un sistema sol-gel.

$$
6 \mathrm{H}_{3} \mathrm{PO}_{4}+\mathrm{Al}_{2} \mathrm{O}_{3} \rightarrow 2 \mathrm{Al}\left(\mathrm{H}_{2} \mathrm{PO}_{4}\right)_{3}+3 \mathrm{H}_{2} \mathrm{O}
$$

Para caracterizar la solución sintetizada en el laboratorio se le realizó un DRX (Figura 3.7). Como el MAP está en un sistema sol-gel, previo a realizar el ensayo la muestra se secó en estufa a $110^{\circ} \mathrm{C}$; en el DRX se observó que la fase cristalina presente es MAP.

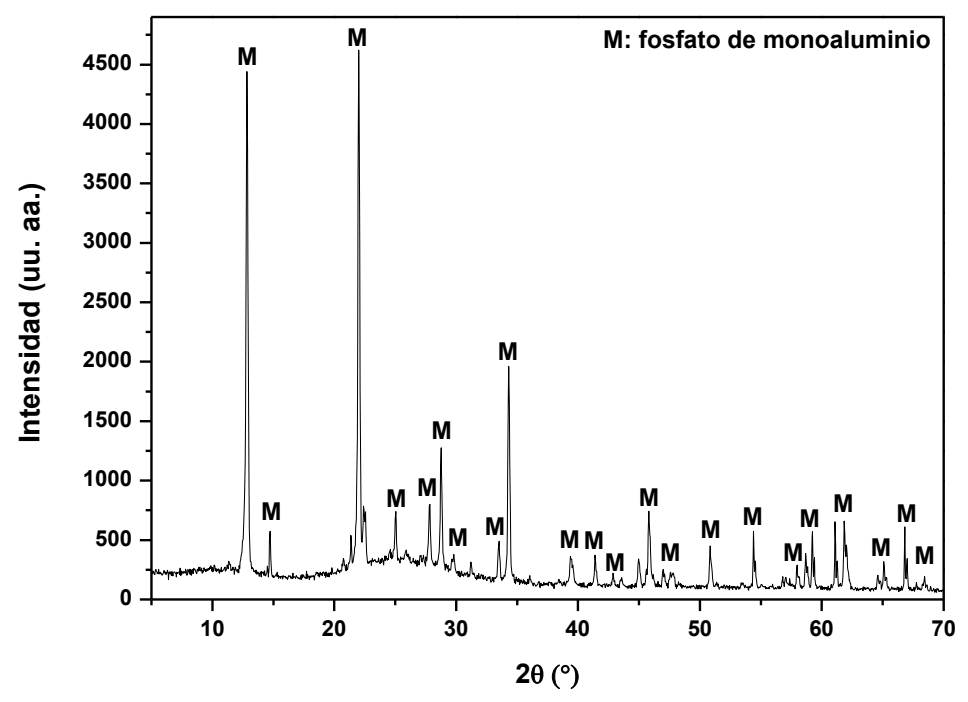

Figura 3.7. Diagrama de rayos $\mathrm{X}$ del fosfato de monoaluminio (MAP). 


\subsubsection{Pseudoboehmita}

El DRX de la pseudoboehmita (la muestra se secó a $110^{\circ} \mathrm{C}$ previo al ensayo) utilizada en la síntesis del MAP se muestra en la Figura 3.8. En el difractograma se observó la fase cristalina boehmita con los picos desplazados ligeramente hacia valores de $2 \theta$ menores. Esta posición de los picos se debe al mayor contenido de agua en el hidróxido ( $\mathrm{AlO}(\mathrm{OH}) \times \mathrm{xH} 2 \mathrm{O})$.

Para estimar la cantidad de agua presente en la estructura de la pseudoboehmita, se calcinó la muestra secada en estufa a $110^{\circ} \mathrm{C}$ a $1000^{\circ} \mathrm{C}$ durante una hora en horno eléctrico. La pérdida de masa evaluada por calcinación de la muestra fue de 18,30\%.

La boehmita $(\mathrm{AlO}(\mathrm{OH}))$ contiene un porcentaje teórico de agua de estructura de 15,00\%, entonces considerando la pérdida de masa de la pseudoboehmita determinada anteriormente $(18,30 \%)$ se estimó la cantidad de agua extra que tiene la muestra en comparación de la boehmita, es decir, el valor de $\mathrm{x}$ en la fórmula $\mathrm{AlO}(\mathrm{OH}) \times \mathrm{xH} 2 \mathrm{O}$. Se obtuvo un valor de $\mathrm{x}=0,13$ para la pesudoboehmita.

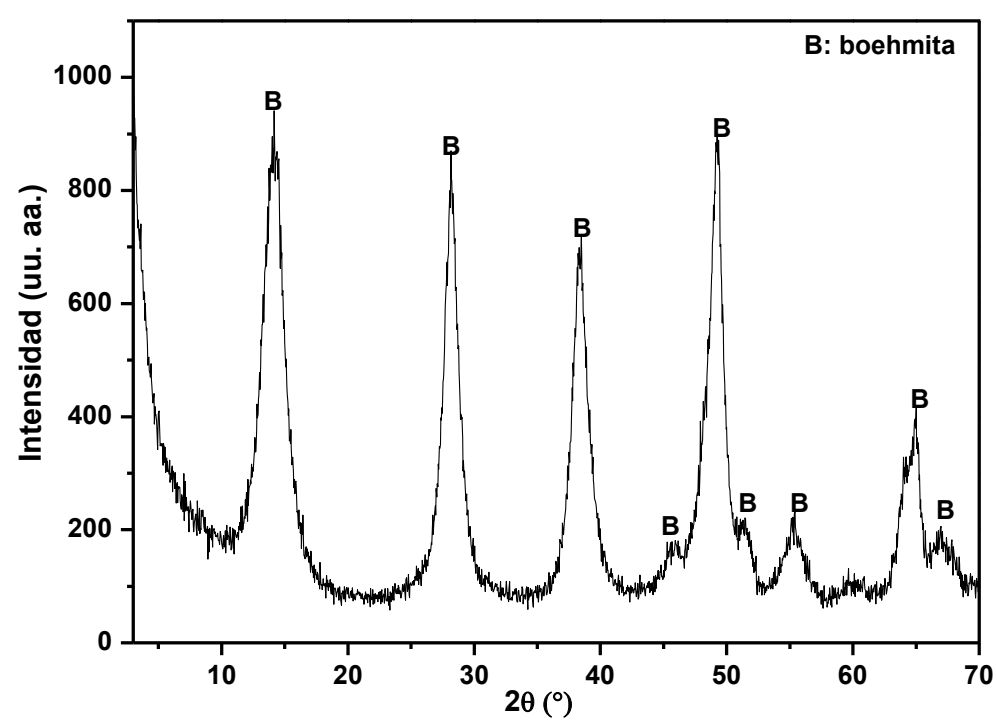

Figura 3.8. Diagrama de rayos X de la pseudoboehmita. 


\subsection{Sílice coloidal}

La sílice coloidal es una solución coloidal de alta hidratación molecular, en la cual la sílice se encuentra en finas partículas dispersas en agua. Se realizaron ensayos de caracterización de la sílice coloidal utilizada en este trabajo (Kaowool rigidizer, Morgan Thermal Ceramics) para corroborar la ficha técnica del producto comercial.

Se realizó el ensayo de pérdida por calcinación a $700^{\circ} \mathrm{C}$ durante una hora para determinar la concentración de súlice coloidal en la solución. El resultado fue de $29 \%$, siendo éste valor similar al informado en la ficha técnica $(28-29 \%)$.

Se midió el tamaño de partícula medio de la súlice coloidal con un analizador de diámetro medio de las partículas en suspensiones coloidales. La Tabla 3.4 muestra los valores obtenidos de las diez medidas realizadas, el promedio y el error estándar en las medidas. El tamaño medio de la sílice coloidal fue de $25,6 \mathrm{~nm}( \pm 0,4)$, lo que comprueba que la solución contiene nanosílice.

Tabla 3.4. Diámetro efectivo de la sílice coloidal.

\begin{tabular}{c|llllllllllll} 
Medida & 1 & 2 & 3 & 4 & 5 & 6 & 7 & 8 & $\mathbf{9}$ & 10 & Promedio & $\begin{array}{c}\text { Error } \\
\text { std }\end{array}$ \\
\hline $\begin{array}{c}\text { Diámetro } \\
\text { efectivo } \\
(\mathrm{nm})\end{array}$ & 28,2 & 26,4 & 26,8 & 25,1 & 25,1 & 24,1 & 24,3 & 25,7 & 24,8 & 25,9 & 25,6 & 0,4 \\
& & & & & & & & & & & &
\end{tabular}

En la Figura 3.9 se muestran los DRX de la sílice coloidal a diferentes temperaturas. Se observó que a $110^{\circ} \mathrm{C}$ la sílice coloidal tiene una banda centrada en $22^{\circ}$ de $2 \Theta$, lo cual evidencia la presencia de óxido en fase amorfa. A mayor temperatura $600^{\circ} \mathrm{C}$, se sigue identificando esta banda con 
otros picos de la fase óxido de silicio $\left(\mathrm{SiO}_{2}\right)$ más definidos, lo que evidencia el inicio de la cristalización de la muestra con el aumento de temperatura.

En el DRX a $800^{\circ} \mathrm{C}$ se comenzó a observarse dos picos correspondientes a la fase tridimita del óxido de silicio y a $1100^{\circ} \mathrm{C}$ estos picos adquirieron mayor intensidad. Además a ésta temperatura, se identificó la presencia de cristobalita, otra fase cristalina del $\mathrm{SiO}_{2}$. Hasta $1450^{\circ} \mathrm{C}$ se continuó identificando cristobalita y tridimita como las fases cristalinas presentes en la muestra.

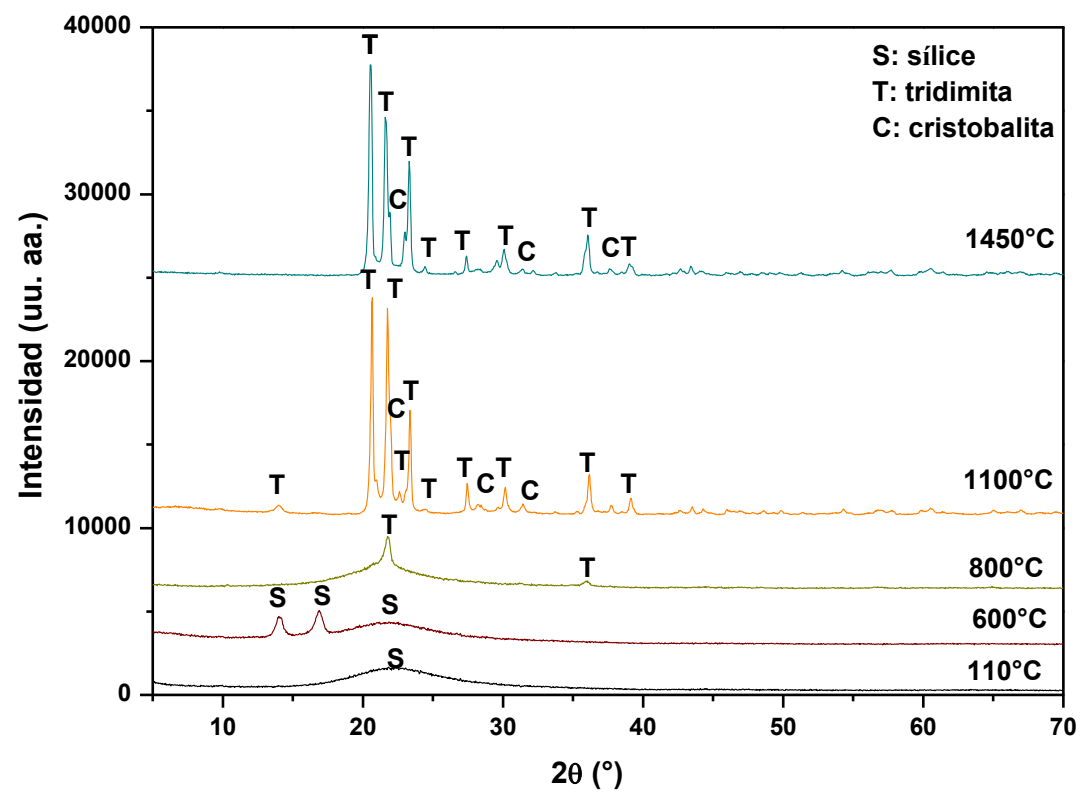

Figura 3.9. Diagrama de rayos $\mathrm{X}$ de la sílice coloidal a diferentes temperaturas.

En la Figura 3.10 se muestran las curvas de ATD y TG de la sílice coloidal. Se observó una pérdida de masa en la curva de TG hasta los $600^{\circ} \mathrm{C}$, de aproximadamente $5 \%$, la cual se asocia a la liberación de agua del sistema. En la curva de ATD se vio una banda exotérmica a $459^{\circ} \mathrm{C}$ que puede relacionarse con la cristalización del óxido de silicio como se observó en el DRX a $600^{\circ} \mathrm{C}$. Además, en la curva de ATD se identificó otro pico 
exotérmico a $925,5^{\circ} \mathrm{C}$ que se asocia con la transformación de la fase tridimita a la fase cristobalita (Gupta and Jean, 1994; Pagliari et al., 2013).

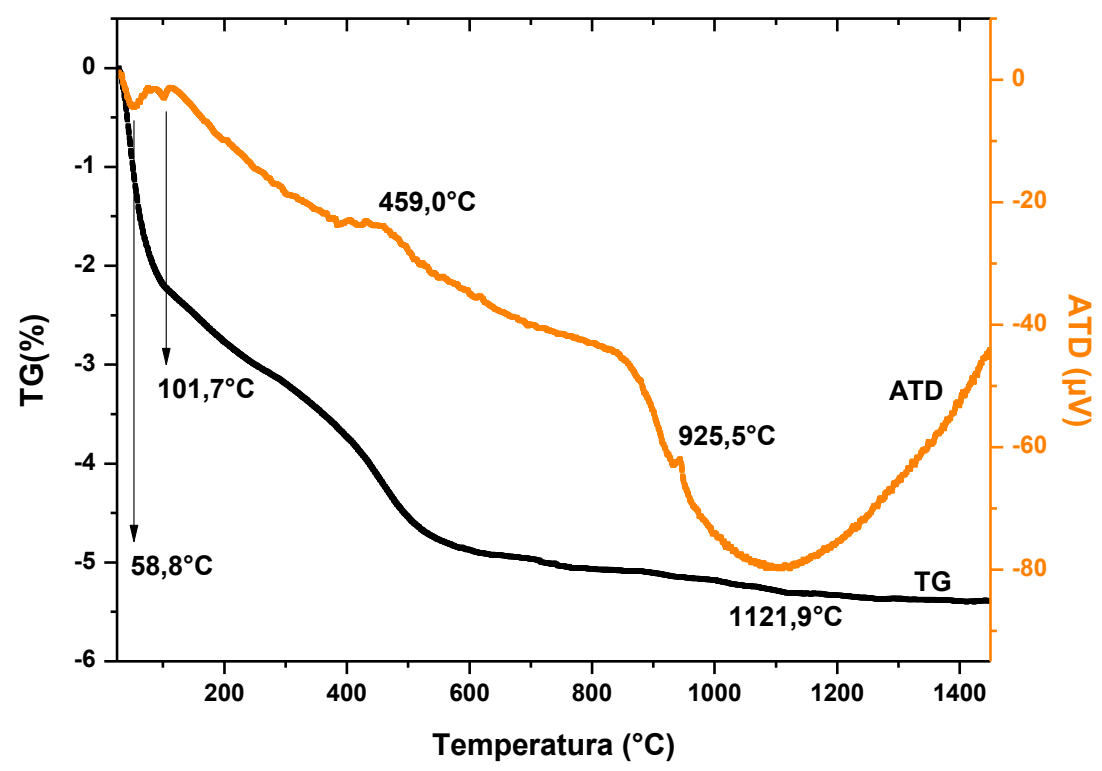

Figura 3.10. Análisis térmico diferencial (ATD) y termo gravimétrico (TG) de la sílice coloidal.

\subsection{Fuentes de carbón}

Los diagramas de rayos $\mathrm{X}$ de las diferentes fuentes de carbón: carbón vegetal, carbón residual de petróleo y negro de humo se muestran en las Figuras 3.11, 3.12 y 3.13 respectivamente. Se observaron en las mismas, las estructuras cristalinas asociadas con el grafito con bandas anchas y un poco desplazadas, debido a la baja cristalinidad de las muestras. Además, en el carbón vegetal se observaron fases cristalinas de carbonato de calcio, carbonato de magnesio y dolomita (carbonato doble de calcio y magnesio). 


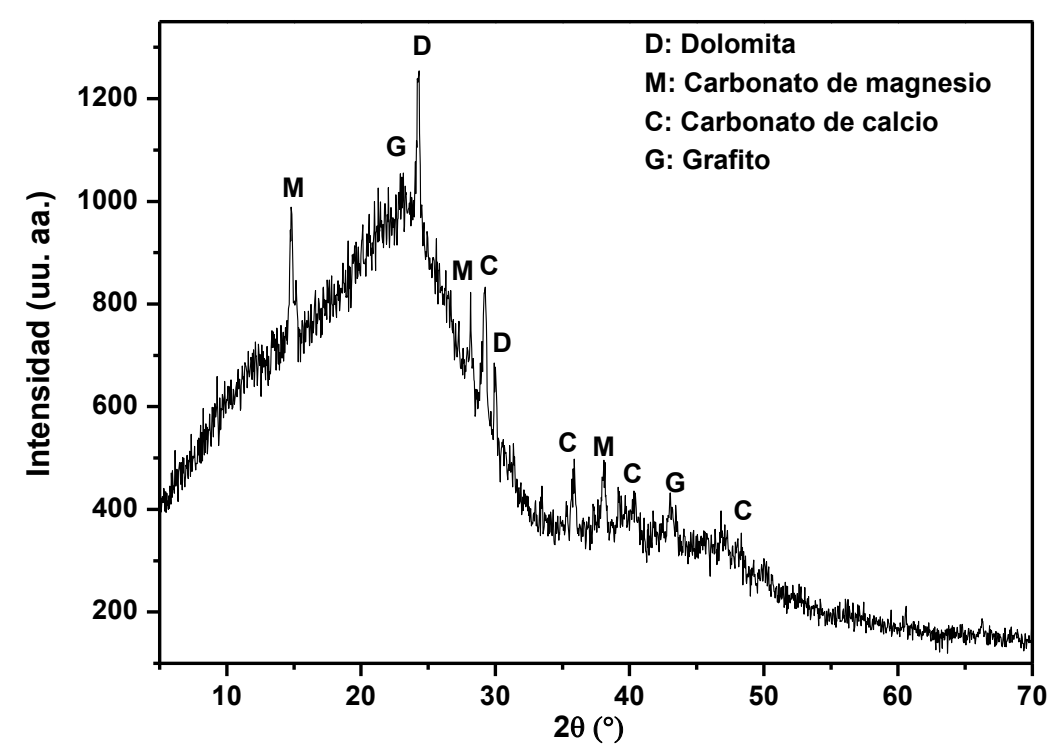

Figura 3.11. Diagrama de rayos X del carbón vegetal.

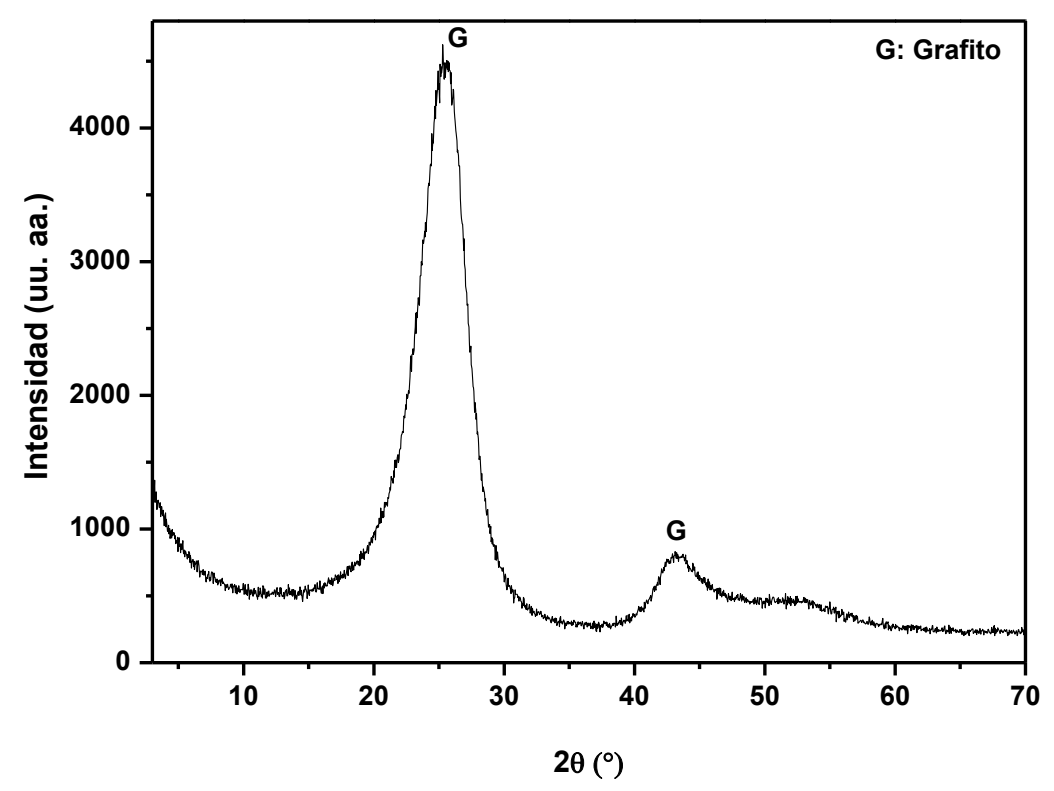

Figura 3.12. Diagrama de rayos X del carbón residual de petróleo. 


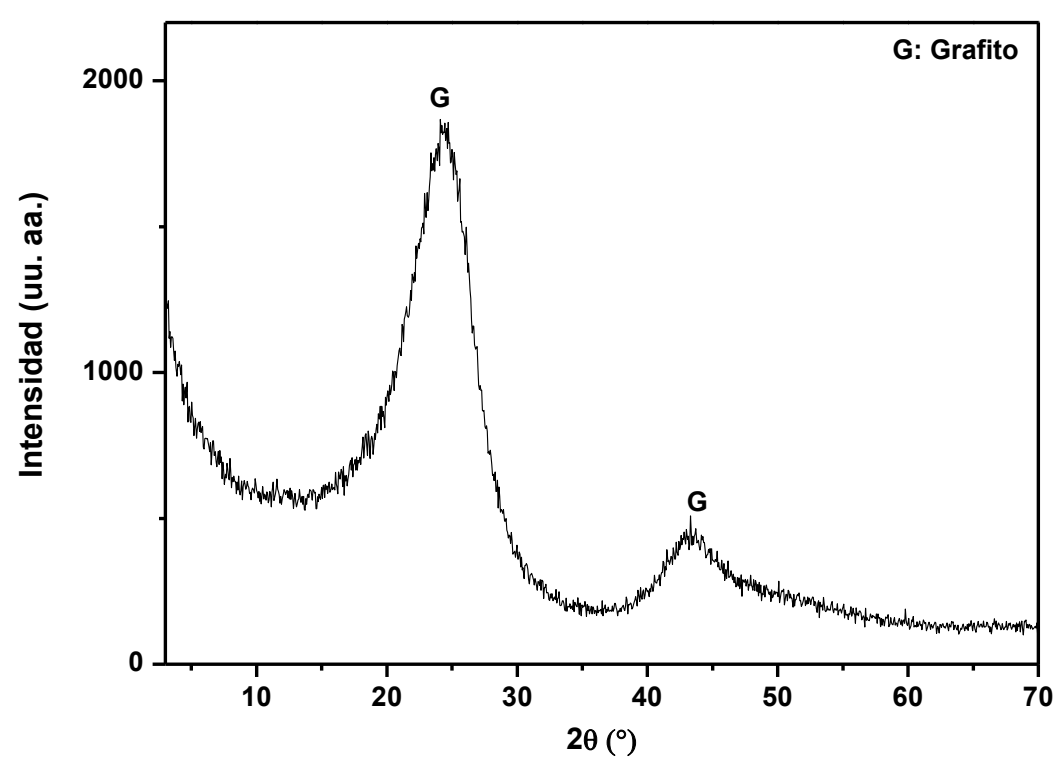

Figura 3.13. Diagrama de rayos X del negro de humo.

El negro de humo y el carbón residual de petróleo presentaron una pérdida por calcinación de $100 \%$, en cambio el carbón vegetal tuvo una pérdida por calcinación de 98,56\%. En la Figura 3.14 se muestra el diagrama de DRX de las cenizas de carbón vegetal, los componentes principales de las cenizas fueron óxido de calcio y magnesio. Esto se corresponde con los carbonatos de calcio, magnesio y dolomita observados en el diagrama de rayos $\mathrm{X}$ del material sin calcinar (Figura 3.11). 


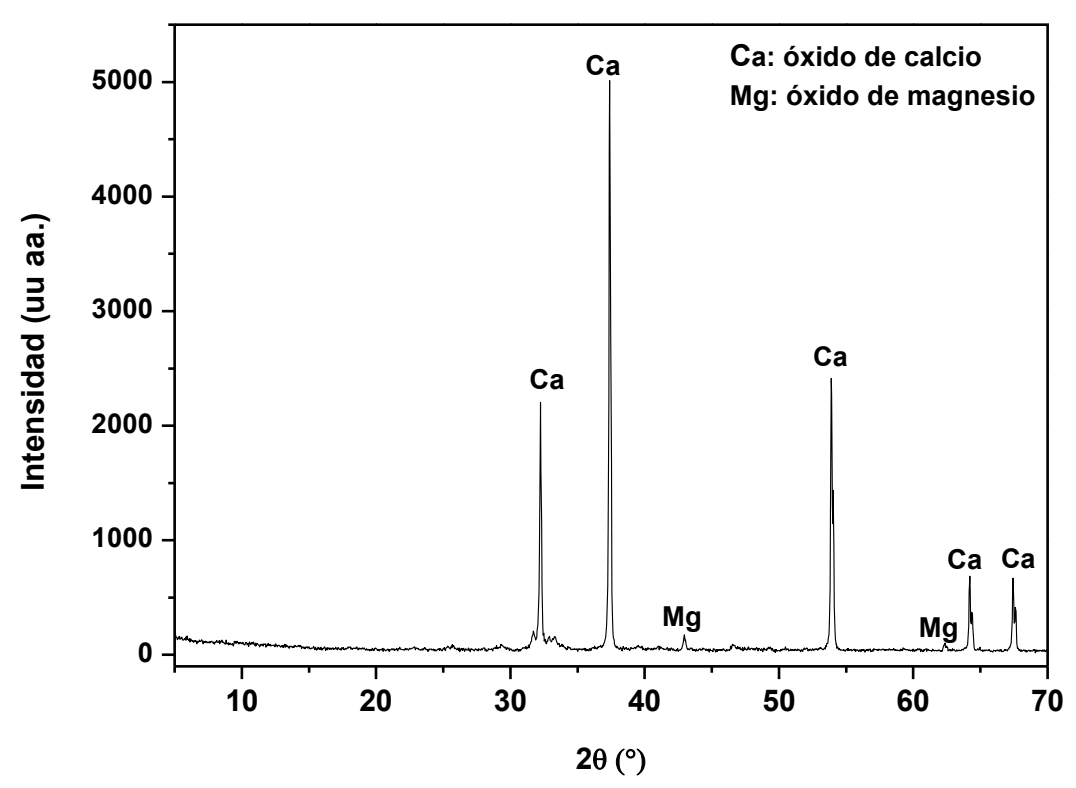

Figura 3.14. Diagrama de rayos X de las cenizas del carbón vegetal.

\subsection{Consideraciones parciales}

Se caracterizaron dos arcillas caoliníticas Argentinas (Tincar Super y Blend) y una bauxita proveniente de Brasil como materias primas minerales. Por difracción de rayos X (DRX) se observó que ambas arcillas contienen caolinita y cuarzo como las fases cristalinas mayoritarias en su composición. Además, la arcilla Blend presentó fases cristalinas correspondientes a rutilo (óxido de titanio) y muscovita (silicoaluminato de potasio). Con el método de Rietvield se cuantificaron las fases cristalinas de las arcilla Blend y la arcilla Tincar Super; siendo la primera arcilla la que presentó mayor cantidad de caolinita $(64,17 \%)$.

Los análisis químicos de las arcillas corroboraron lo observado en los DRX, siendo ambas arcillas de alto contenido de sílice y alúmina por lo que presentan un gran potencial para la obtención de mullita por reacciones de estado sólido a alta temperatura. 
La caracterización de la bauxita por análisis químico determinó que el porcentaje de alúmina es de 53,91\% por lo que se la puede denominar como una fuente de "tenor medio de alúmina"(Ma et al., 2016). Las fases cristalinas identificadas por DRX como hidratos de aluminio fueron gibbsita y boehmita y la cuantificación de las mismas por el método de Rietvield dio como resultado que la gibbsita se encuentra en mayor porcentaje $(71,06 \%)$ que la boehmita $(1,28 \%)$.

El ensayo de Cono Pirométrico Equivalente de las materias primas minerales permitió definir la temperatura de ablandamiento de las mismas, siendo el valor de la arcilla Tincar Super mayor que el de la arcilla Blend, por contener esta última arcilla impurezas que producen la disminución de la temperatura de ablandamiento.

Se caracterizó la pseudoboehmita, fuente hidratada de alúmina, que se utilizó para la síntesis de fosfato de monoaluminio (agente ligante estudiado en este trabajo). El DRX de la pseudoboehmita presentó un difractograma similar al de la boehmita con los picos desplazados debido al mayor contenido de agua. El valor calculado de agua estructural de la pseudoboehmita a partir de la pérdida por calcinación de la misma fue de 18,30\%. En base a la cantidad de agua estructural teórica de la boehmita se determinó la siguiente fórmula para la pseudoboehmita utilizada $\mathrm{AlO}(\mathrm{OH}) \cdot 0,13 \mathrm{H}_{2} \mathrm{O}$.

El fosfato de monoaluminio (MAP) se sintetizó en el laboratorio a partir de la pseudoboehmita caracterizada y ácido fosfórico. Al resultado de la reacción entre estos dos compuestos se le adicionó agua para que la concentración del MAP sea del 40\% (en peso,) como se presentan las soluciones de MAP comerciales.

Otro agente ligante utilizado en este trabajo fue la sílice coloidal, la cual se midió el tamaño medio de partícula en solución siendo el mismo de 25,6 $( \pm 0,4)$ nm. También se caracterizó la sílice coloidal por ATD-TG y DRX 
a distintas temperaturas. El DRX de la sílice coloidal a $110^{\circ} \mathrm{C}$ presentó una banda a valores de $2 \theta$ de $22^{\circ}$, lo que evidenció la presencia de fase amorfa. A medida que la sílice fue tratada térmicamente se fueron identificando fases cristalinas, siendo a $1450^{\circ} \mathrm{C}$ la cristobalita y la tridimita las dos fases cristalinas presentes en la muestra.

En la curva de ATD de la sílice coloidal se observó una banda exotérmica a $459^{\circ} \mathrm{C}$ que se puede relacionar con el proceso de cristalización observado y otro pico exotérmico a $\operatorname{los} 925,5^{\circ} \mathrm{C}$ asociado a la transformación de tridimita a cristobalita. La curva de TG presentó una pérdida de masa hasta aproximadamente $5 \%$ hasta $\operatorname{los} 600^{\circ} \mathrm{C}$ la que se relaciona con la liberación de agua del sistema coloidal.

También se caracterizaron tres fuentes formadoras de poro: carbón vegetal, carbón residual de petróleo y negro de humo. En los DRX de los carbones se observaron fases cristalinas asociadas con el grafito con bandas anchas y desplazadas de sus posiciones debido a la baja cristalinidad de las muestras. La pérdida por calcinación del negro de humo y del carbón residual de petróleo fue del 100\% y para el carbón vegetal de 98,56\%. En el DRX de las cenizas de esta última fuente de carbón se identificaron fases cristalinas correspondientes a óxidos de calcio y de magnesio. 


\section{Capítulo 4}

Transformaciones térmicas del fosfato de monoaluminio para su utilización como ligante químico 
El fosfato de monoaluminio (MAP) es un precursor de liga química cuya acción ligante es la formación de polímeros como resultado de la deshidratación (Morris et al., 1977). Como se mencionó en la sección 2.3.1, el MAP es ampliamente usado en la industria para el fraguado rápido de hormigones y materiales refractarios. Existen diversas investigaciones con resultados contradictorios acerca de las reacciones intermedias entre el MAP y el ortofosfato de aluminio $\left(\mathrm{AlPO}_{4}\right)$, por lo que se decidió estudiar las transformaciones térmicas que presenta el mismo en el rango de temperaturas de $110^{\circ} \mathrm{C}-1400^{\circ} \mathrm{C}$. Además se analizó la interacción del MAP en este rango de temperaturas con la arcilla Tincar Super. 


\subsection{Análisis de las reacciones del MAP entre $110^{\circ} \mathrm{C}$ y $1400^{\circ} \mathrm{C}$}

Para analizar el comportamiento del MAP a distintas temperaturas se realizó un análisis térmico diferencial y termo gravimétrico (ATD-TG) desde temperatura ambiente hasta $1450^{\circ} \mathrm{C}$ y se determinaron por DRX las fases cristalinas que se forman en el rango de temperatura estudiado (Ambos ensayos se realizaron en iguales condiciones que las descriptas en la sección 3.1).

El ATD-TG obtenido para el MAP secado en una estufa a $110^{\circ} \mathrm{C}$ durante 24 horas se muestra en la Figura 4.1.

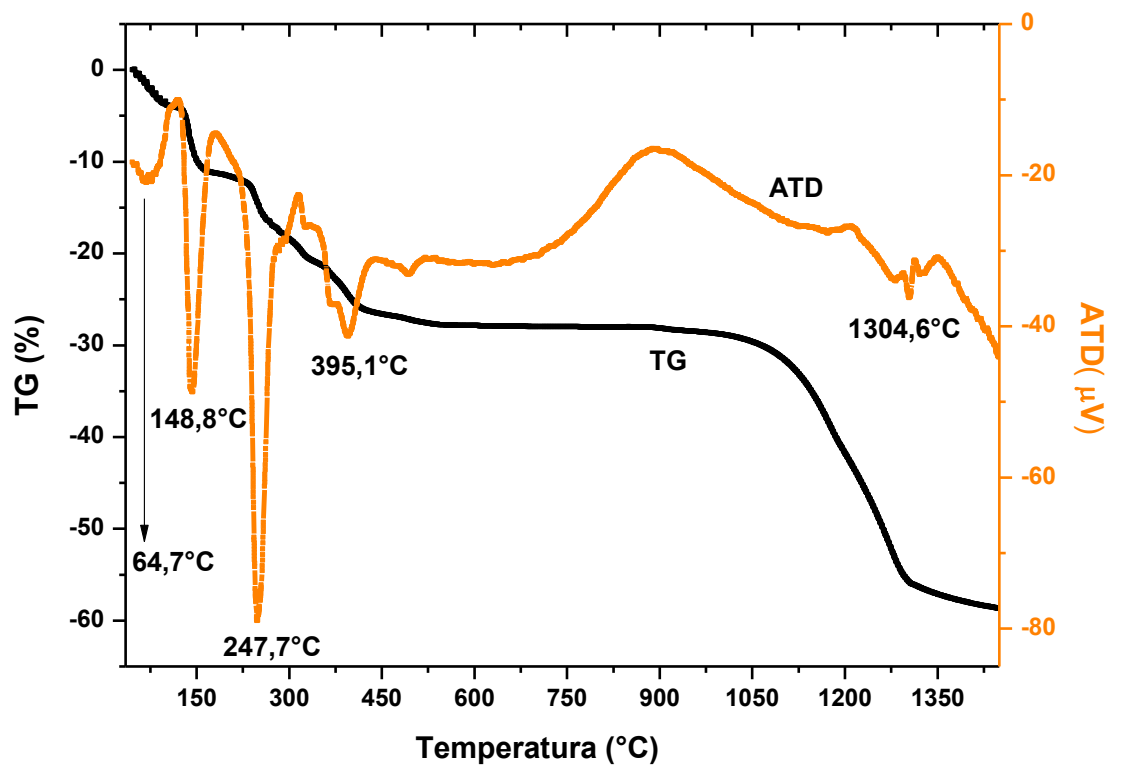

Figura 4.1. Análisis térmico diferencial (ATD) y termo gravimétrico (TG) del MAP.

En la curva de ATD se observaron dos picos endotérmicos a $64,7^{\circ} \mathrm{C}$ y a $148,8^{\circ} \mathrm{C}$ los cuales se deben a la pérdida de agua que tiene el sistema por provenir de un sistema sol-gel y ser altamente higroscópico. Esta agua adsorbida se une al MAP a través de uniones con distinta energía por lo cual 
se visualizan los dos picos mencionados anteriormente. En la curva de TG se ven reflejadas estas pérdidas de agua como pérdidas de masa de $-3,9 \%$ y $7,2 \%$ respectivamente.

En el rango de temperatura de $250-300^{\circ} \mathrm{C}$ se observó una pérdida de masa de $-8 \%$ en la curva de TG y un pico endotérmico en el ATD. Estas variaciones se asocian al pasaje de fosfato de monoaluminio a tripolifosfato de aluminio $\left(\mathrm{H}_{2} \mathrm{AlP}_{3} \mathrm{O}_{10}\right)$ con pérdida de agua (ec. 4.1).

En el diagrama de rayos $\mathrm{X}$ a $300^{\circ} \mathrm{C}$ (Figura 4.2) se identificó el $\mathrm{H}_{2} \mathrm{AlP}_{3} \mathrm{O}_{10} \cdot \mathrm{H}_{2} \mathrm{O}(\mathrm{T})$, esto se debe a que son compuestos higroscópicos y al momento del ensayo de DRX la muestra adsorbió humedad del ambiente.

Otra banda endotérmica también asociada con pérdida de masa ($8,33 \%$ ) se observó en el rango $300-450^{\circ} \mathrm{C}$. Estos cambios en las curvas se deben a la reacción de transformación de tripolifosfato de aluminio a ciclohexafosfato de aluminio (C) $\left(\mathrm{Al}_{2} \mathrm{P}_{6} \mathrm{O}_{18}\right)$ (ec. 4.2) (Vippola et al., 2000) con liberación de agua y la posterior transformación de $\mathrm{Al}_{2} \mathrm{P}_{6} \mathrm{O}_{18}$ a metafosfato de aluminio $\left(\mathrm{Al}\left(\mathrm{PO}_{3}\right)_{3}\right)$ (ec. 4.3). Esto se corrobora en el DRX a $450^{\circ} \mathrm{C}$, en el cual se presentó la fase $\mathrm{Al}\left(\mathrm{PO}_{3}\right)_{3}$ y la fase $\mathrm{Al}_{2} \mathrm{P}_{6} \mathrm{O}_{18}$, mientras que en el difractograma a $850^{\circ} \mathrm{C}$ sólo se observó la fase de metafosfato.

El abrupto descenso de la curva TG (pérdida de masa de 30,86\%) y su pico endotérmico asociado en la curva de ATD por encima de $1000^{\circ} \mathrm{C}$ se debió a la descomposición del metafosfato de aluminio a ortofosfato de aluminio (O) $\left(\mathrm{AlPO}_{4}\right)$ con pérdida de óxido fosfórico $\left(\mathrm{P}_{2} \mathrm{O}_{5}\right)$ (ec. 4.4) (Chiou and Chung, 1993). 


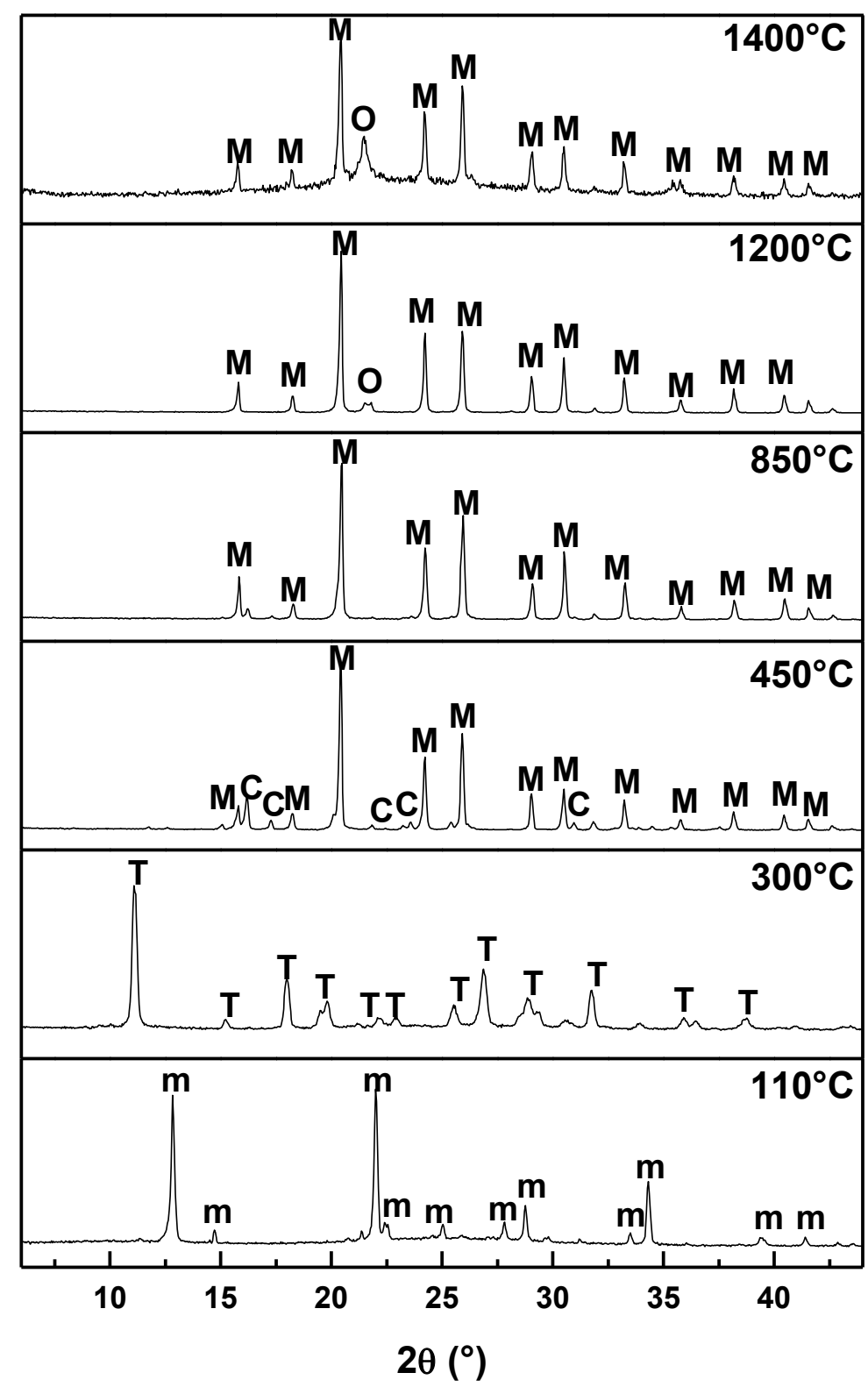

Figura 4.2. Diagrama de rayos $\mathrm{X}$ del MAP a diferentes temperaturas $\left[\mathrm{m}: \mathrm{Al}\left(\mathrm{H}_{2} \mathrm{PO}_{4}\right)_{3}\right.$; T: $\left.\mathrm{H}_{2} \mathrm{AlP}_{3} \mathrm{O}_{10} \cdot 2 \mathrm{H}_{2} \mathrm{O} ; \mathbf{C}: \mathrm{Al}_{2} \mathrm{P}_{6} \mathrm{O}_{18} ; \mathbf{M}: \mathrm{Al}\left(\mathrm{PO}_{3}\right)_{3} ; \mathbf{O}: \mathrm{Al}\left(\mathrm{PO}_{4}\right)\right]$.

En base a los resultados experimentales se determinó para el MAP la siguiente secuencia de ecuaciones de transformación térmica en el rango de temperatura de $110^{\circ} \mathrm{C}$ a $1400^{\circ} \mathrm{C}$. 


$$
\begin{aligned}
& \mathrm{Al}\left(\mathrm{H}_{2} \mathrm{PO}_{4}\right)_{3} \rightarrow \mathrm{H}_{2} \mathrm{AlP}_{3} \mathrm{O}_{10}+2 \mathrm{H}_{2} \mathrm{O} \\
& 2 \mathrm{H}_{2} \mathrm{AlP}_{3} \mathrm{O}_{10} \rightarrow \mathrm{Al}_{2} \mathrm{P}_{6} \mathrm{O}_{18}+2 \mathrm{H}_{2} \mathrm{O} \\
& \mathrm{Al}_{2} \mathrm{P}_{6} \mathrm{O}_{18} \rightarrow 2 \mathrm{Al}\left(\mathrm{PO}_{3}\right)_{3} \\
& \mathrm{Al}\left(\mathrm{PO}_{3}\right)_{3} \rightarrow \mathrm{Al}\left(\mathrm{PO}_{4}\right)+\mathrm{P}_{2} \mathrm{O}_{5} \uparrow
\end{aligned}
$$

\subsection{Análisis del sistema MAP-Tincar Super}

Para analizar la interacción del MAP con la arcilla Tincar Súper (caracterizada en la sección 3.2) y 10\% de MAP sintetizado en el laboratorio (sección 3.3.1). Se realizó ATD-TG bajo las mismas condiciones mencionadas en la sección 3.1.

En las Figuras 4.3 y 4.4 se muestran las curvas de ATD y TG de la arcilla y de la mezcla arcilla-10\% de MAP. Al igual que en la Figura 4.1, se observaron los picos a $124,3^{\circ} \mathrm{C}$ y $223,3^{\circ} \mathrm{C}$ en la muestra con MAP asociados con la pérdida de agua del sistema sol-gel y con la reacción descripta en las ec. 4.1 pero desplazadas a menor temperatura.

En las dos curvas de ATD se identificó un pico endotérmico alrededor de $\operatorname{los} 500^{\circ} \mathrm{C}$ que se debe a la deshidroxilación de la caolinita y a la transformación $\alpha \rightarrow B$ del cuarzo que se encuentra presente en la arcilla. En la curva de TG (Figura 4.4) se observó una pérdida de masa de -6,76\% para la arcilla y de $-4,56 \%$ para la mezcla Tincar Super-10\% MAP entre los 300$800^{\circ} \mathrm{C}$. Esta pérdida de masa se relaciona con la deshidroxilación de la arcilla y se ve que fue menor en presencia de MAP; es decir, la deshidroxilación de la arcilla no es completa porque ocurren reacciones que involucran a los fosfatos con la alúmina y la sílice proveniente de la caolinita. Esto conduce a formación de fases sólidas no cristalinas ya que no se observaron por DRX (Sahnoun and Bouaziz, 2012). 


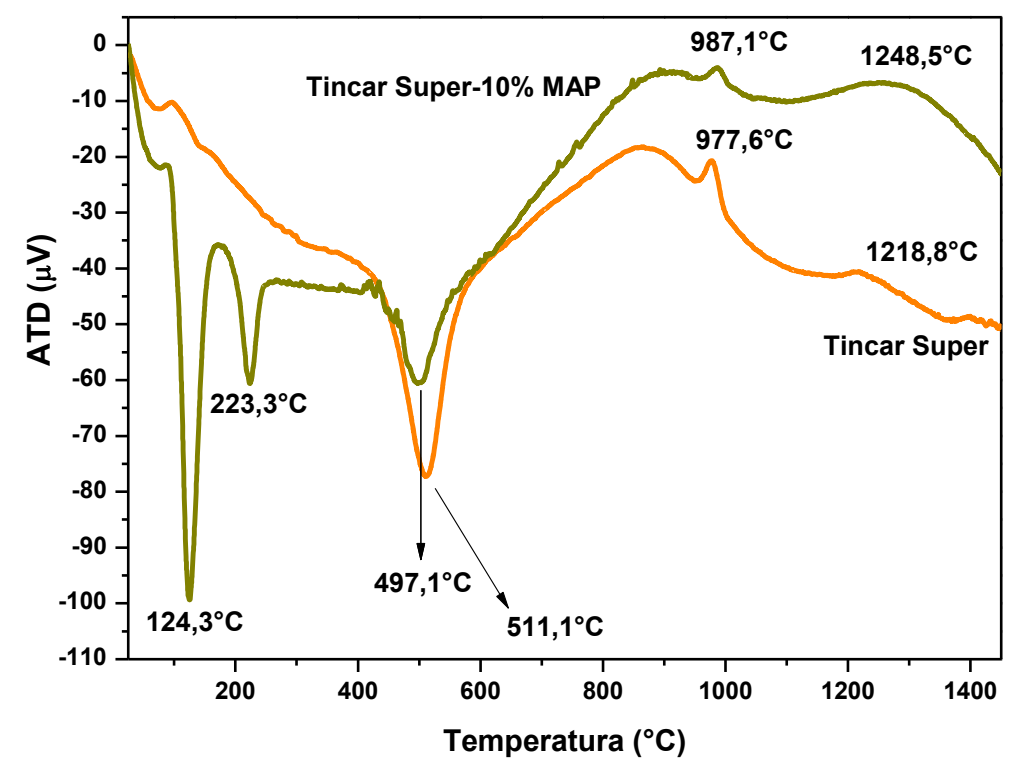

Figura 4.3. Curvas de ATD de Tincar Super y de Tincar Super-10\% MAP.

La pérdida de masa observada por encima de $\operatorname{los} 1000^{\circ} \mathrm{C}$ en la Figura 4.1 debida a la liberación de óxido fosfórico no se observó en la curva TG de la mezcla Tincar Super-10\% MAP. Esto se debe a la presencia de sílice $\left(\mathrm{SiO}_{2}\right)$ y alúmina provenientes de la descomposición de la caolinita que reacciona con el óxido fosfórico $\left(\mathrm{P}_{2} \mathrm{O}_{5}\right)$ formando fase vítrea debido a que la sílice y el óxido fosfórico son óxidos formadores de vidrio.

También se observó tanto en el ATD de la arcilla y como en el ATD de la mezcla Tincar Super-10\% MAP un pico exotérmico alrededor de $970^{\circ} \mathrm{C}$ correspondiente a la transformación de metacaolín $\left(\mathrm{Al}_{2} \mathrm{O}_{3} \cdot 2 \mathrm{SiO}_{2}\right)$ y otro pico exotérmico alrededor de $1200^{\circ} \mathrm{C}$ asociado a la formación de cristobalita (fase cristalina del $\mathrm{SiO}_{2}$ ) y nucleación de mullita. Ambos picos exotérmicos fueron más notorios en la muestra de Tincar Super que en la muestra de Tincar Super-10\%MAP, por las reacciones entre el $\mathrm{P}_{2} \mathrm{O}_{5}$ y los óxidos $\mathrm{SiO}_{2}$ y $\mathrm{Al}_{2} \mathrm{O}_{3}$ reactivos de la caolinita lo que disminuye la formación de metacaolín y posterior formación de mullita. 


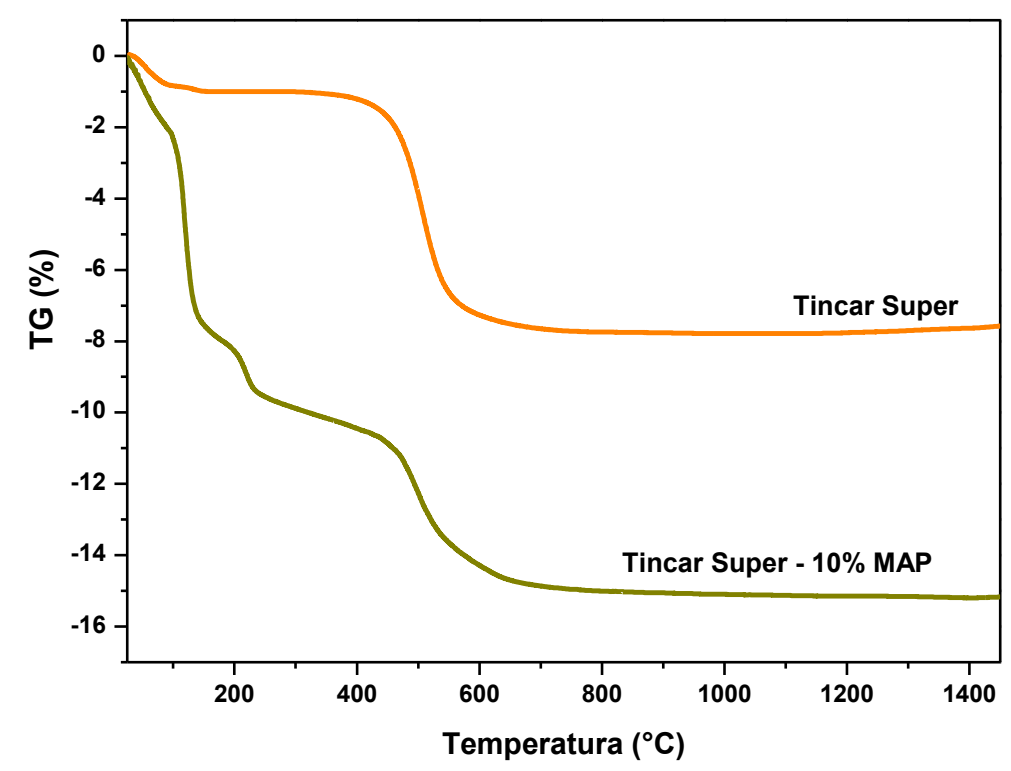

Figura 4.4. Curvas de TG de Tincar Super y de Tincar Super-10\% MAP.

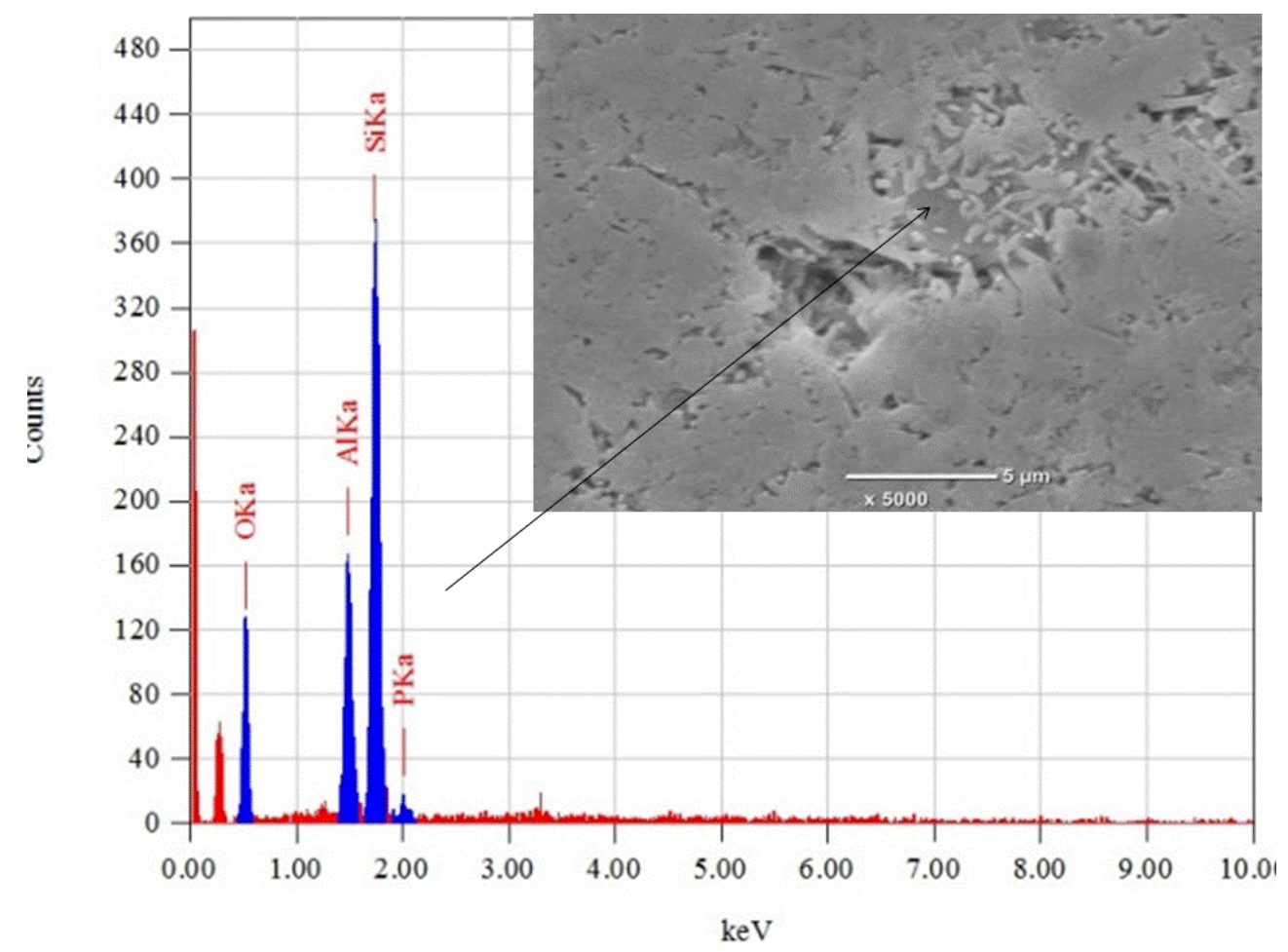

Figura 4.5. Fotografía SEM/EDS de Tincar Super- MAP en la fase vítrea. 


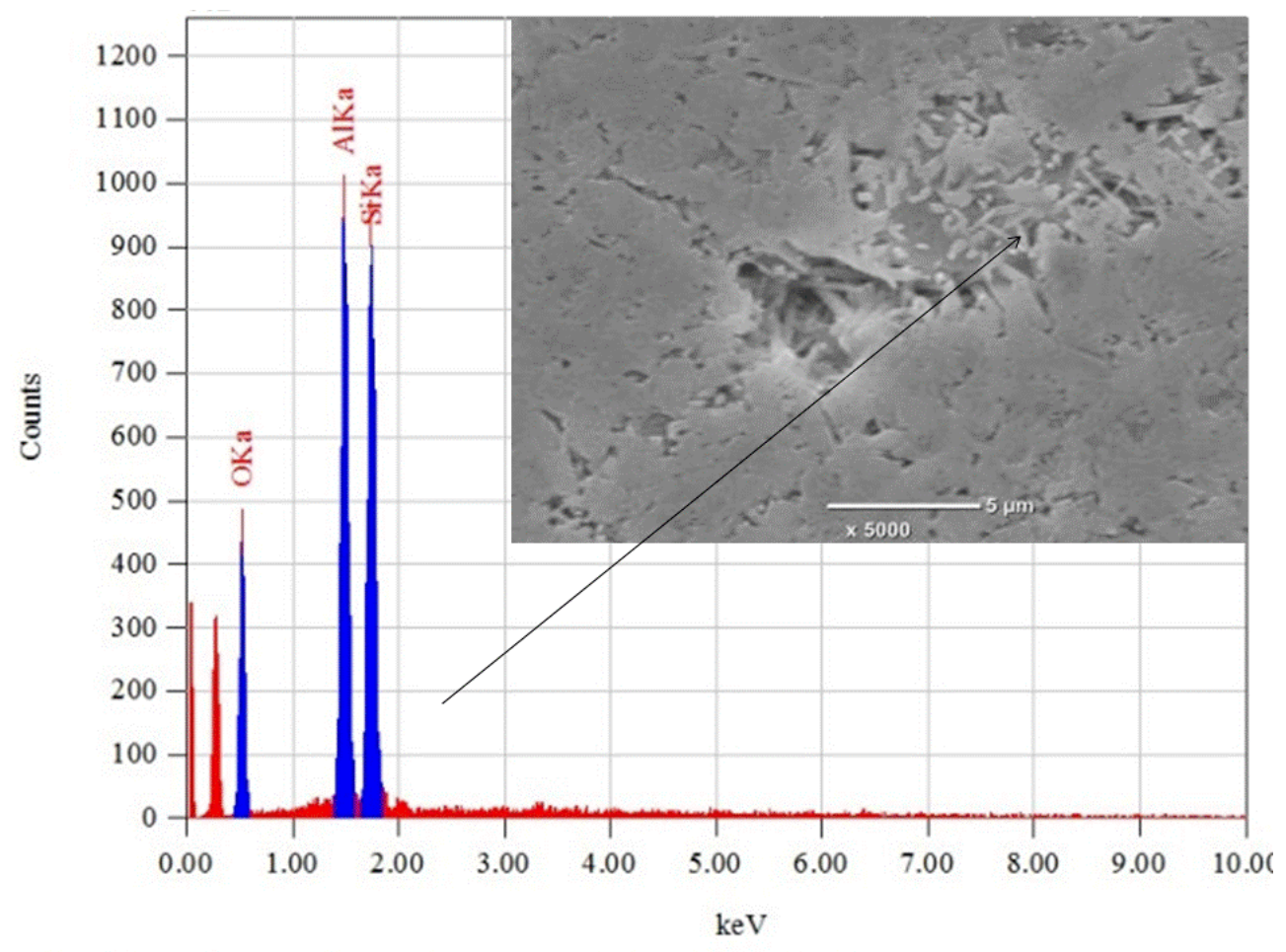

Figura 4.6. Fotografía SEM/EDS de Tincar Super- MAP en la fase cristalina.

Para verificar que el $\mathrm{P}_{2} \mathrm{O}_{5}$ liberado en la ec 4.4 esté presente en la fase vítrea se realizó un análisis de la microestructura y su composición en una muestra de Tincar Super-MAP sinterizada a $1500^{\circ} \mathrm{C}$ con microscopía electrónica de barrido (SEM) y con un detector de espectroscopia de dispersión de energía de rayos X (EDS) con un equipo JEOL JCM-6000 Neo Scope. En las Figuras 4.5 se observa que en la zona más obscura del material que corresponde a la fase vítrea se detectó la presencia de fósforo. En cambio en las zonas más claras que se asocian a la fase cristalina no se encontró fósforo en su composición (Figura 4.6).

También se semicuantificó el porcentaje de fase no cristalina de la mezcla arcilla-10\%MAP y de la arcilla a diferentes temperaturas (1000$1500^{\circ} \mathrm{C}$ ). esta determinación se hizo en base a los DRX de las muestras y la redefinición de la ecuación de Ohlberg (ec. 4.5) (Conconi et al., 2011; Ohlberg and Strickler, 1962) (Anexo I). 


$$
\% N C=100 \times\left(\frac{\left(I_{m}-I_{c}\right)}{\left(\left(I_{v}-I_{c}\right)\right.}\right)(\text { ec. 4.5) }
$$

Donde $I_{v}, I_{m}$ y $I_{c}$ son las intensidades sacadas del difractograma a $2 \theta=22,5^{\circ} \mathrm{C}$ correspondientes a la muestra $100 \%$ vítrea (sílice amorfa), parcialmente cristalina (muestra problema) y la muestra 100\% cristalina (cuarzo) respectivamente.

En la Figura 4.7 se muestran los porcentajes de fase amorfa calculados según el método de Ohlberg modificado a $1000^{\circ} \mathrm{C}, 1400^{\circ} \mathrm{C}$ y $1500^{\circ} \mathrm{C}$. Se observó que la mezcla de Tincar Super-10\% MAP posee un mayor porcentaje de fase amorfa para todas las temperaturas, esto se relaciona con lo descripto en las curvas de ATD-TG sobre la mayor reactividad de esa mezcla para formar fase vítrea.

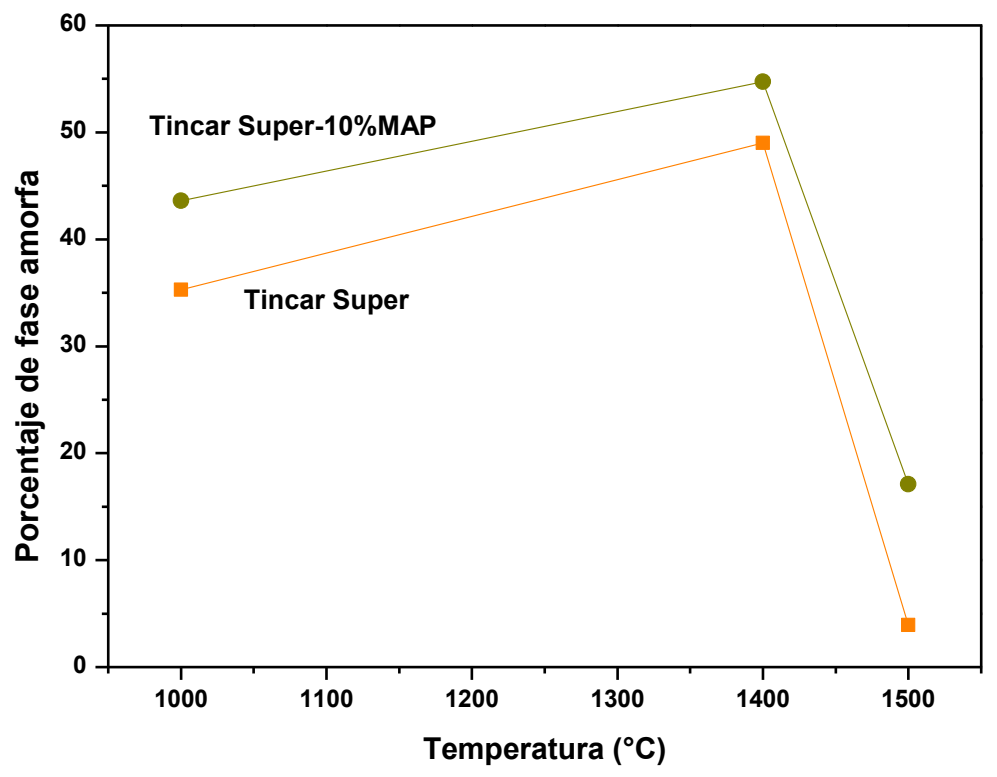

Figura 4.7. Porcentaje de fase amorfa de la Tincar Super y de la Tincar Super - $10 \%$ MAP a diferentes temperaturas. 
A $1500^{\circ} \mathrm{C}$ se observó para los dos sistemas que la fase amorfa disminuye por el incremento en la formación de fases cristalinas estables (mullita y cristobalita).

\subsection{Consideraciones parciales}

Se estudió las transformaciones térmicas que tiene el MAP en el rango de temperatura de $110-1400^{\circ} \mathrm{C}$ y se observó, en este rango, una continua transformación de fases con liberación de agua y de $\mathrm{P}_{2} \mathrm{O}_{5}$. Por debajo de $300^{\circ} \mathrm{C}$ el sistema es higroscópico por lo que es inestable y adsorbe humedad ambiente.

Se obtuvieron como fases cristalinas intermedias entre el MAP y el ortofosfato de aluminio tres compuestos distintos: tripolifosfato de aluminio $\left(\mathrm{H}_{2} \mathrm{AlP}_{3} \mathrm{O}_{10}\right)$, ciclohexafosfato de aluminio $\left(\mathrm{Al}_{2} \mathrm{P}_{6} \mathrm{O}_{18}\right)$ y metafosfato de aluminio $\left(\mathrm{Al}\left(\mathrm{PO}_{3}\right)_{3}\right)$. El MAP por encima de $1000^{\circ} \mathrm{C}$ se descompone para dar ortofosfato de aluminio $\left(\mathrm{AlPO}_{4}\right)$ con liberación de $\mathrm{P}_{2} \mathrm{O}_{5}$.

Cuando se analizó la interacción entre el MAP y la arcilla Tincar Super no se observó en el ATD pérdida de masa a temperaturas superiores de $1000^{\circ} \mathrm{C}$. Esto se debe a que el $\mathrm{P}_{2} \mathrm{O}_{5}$ y el $\mathrm{SiO}_{2}$ (proveniente de la descomposición de la arcilla) son óxidos formadores de vidrio entonces ambos compuestos contribuyen a la fase amorfa del sistema. A su vez por medio de la técnica SEM/EDS se corroboró que el fósforo sólo se encuentra presente en esta fase.

En la curva de ATD de la mezcla Tincar Super-MAP se vio que la presencia del MAP en la arcilla disminuye la formación de metacaolín, cristobalita y mullita a alta temperatura, debido a reacciones entre la alúmina y la sílice, provenientes de la arcilla, con el $\mathrm{P}_{2} \mathrm{O}_{5}$ procedente del MAP. 
Transformaciones térmicas del fosfato de monoaluminio para su utilización como ligante químico 


\section{Capítulo 5}

Obtención y evaluación de las propiedades de materiales cerámicos obtenidos por prensado 
En este capítulo se estudiaron diferentes formulaciones de las materias primas, caracterizadas en el capítulo 3, y las propiedades de dichos materiales con el objetivo de seleccionar formulaciones para el desarrollo de agentes de sostén cerámicos de baja densidad.

Se decidió utilizar un $10 \%$ en peso de MAP en las formulaciones, debido a que en la industria de los materiales refractarios los porcentajes habitualmente usados por las ligas fosfóricas se encuentran entre un 10-20\% (Kumar et al., 2013); en base a estos valores se decidió elegir el porcentaje más conservador para no generar grandes cantidades de fase amorfa, durante el tratamiento térmico a alta temperatura, la cual influye en la resistencia mecánica final del material.

En primer lugar se analizaron los materiales obtenidos a partir de las dos arcillas caoliníticas para elegir con cuál de ellas se desarrollarán los 
agentes de sostén. Luego en la sección 5.3, se estudió la porosidad lograda a partir de las distintas fuentes de carbón evaluándose las propiedades de los materiales obtenidos. El objetivo de usar una fuente de carbón fue el de generar una matriz porosa cerrada para disminuir la densidad del material cerámico.

En estas dos primeras secciones se utilizó MAP como precursor de liga nanoestructurada por lo cual en la sección 5.4 se evalúo el comportamiento de esta liga en el rango de temperatura $\left(1000-1500^{\circ} \mathrm{C}\right)$.

Por último, se investigaron las propiedades de los materiales cerámicos obtenidos a partir de otro agente ligante, como precursor de liga nanoestructurada, la sílice coloidal (sección 5.5).

Para evaluar las distintas formulaciones se optó por preparar probetas a partir de un proceso conocido, como es el prensado, y así obtener las propiedades de los materiales cerámicos. Para esto las mezclas se prensaron uniaxialmente a $40 \mathrm{MPa}$ en forma de barras prismáticas. Por cada mezcla se prensaron barras de $7 \times 7 \times 50 \mathrm{~mm}$ de aproximadamente $5,00 \mathrm{~g}$ por quintuplicado.

Luego se calcinaron en horno eléctrico en atmosfera de aire con una velocidad de calentamiento de $5^{\circ} \mathrm{C} / \mathrm{min}$ y una hora de permanencia a la temperatura final que fue en el rango de temperatura de $1350^{\circ} \mathrm{C}-1550^{\circ} \mathrm{C}$. La selección de la temperatura final de calcinación dependió de las características de las materias primas. Luego de la calcinación se evaluaron las propiedades texturales y mecánicas ${ }^{4}$ que se describen en la siguiente sección.

${ }^{4}$ Los valores de las propiedades caracterizadas en este trabajo se presentan con su correspondiente desviación estándar $(n=5)$. 


\subsection{Técnicas de caracterización de los materiales cerámicos obtenidos por prensado}

Resistencia a la flexión en tres puntos

La resistencia a la flexión también denominada módulo de rotura a la flexión en tres puntos (MOR) es una técnica utilizada para caracterizar la resistencia mecánica de los materiales. El ensayo se realizó bajo lineamiento de norma IRAM 12511 en una máquina de ensayos mecánicos universal Instron 5985, con una velocidad de avance de la carga de $0,5 \mathrm{~mm} / \mathrm{min}$ y se calculó el valor de MOR a partir de la ec. 5.3.

$$
\sigma_{f}=\frac{3 Q l}{2 w e^{2}} \quad \text { ec. } 5.3
$$

Donde of es el valor de MOR expresado en MPa, Q es la carga máxima al momento de la rotura en Newton, w es el ancho de la probeta, e el espesor de la misma y 1 la luz entre los dos puntos de apoyo.

\section{Variación lineal permanente}

La variación lineal permanente por calentamiento (bajo lineamiento de norma IRAM 12516) permite determinar la contracción lineal o expansión de un material después de ser sometida a un tratamiento térmico. Se calcula el porcentaje de variación lineal (VL) a partir de la ec. 5.4. Dónde $l_{f}$ longitud final y lo longitud inicial de la probeta.

$$
V L=\frac{l_{f}-l_{o}}{l_{o}} \times 100 \% \quad \text { ec. } 5.4
$$




\section{Distribución del tamaño de poros por intrusión de mercurio}

Se determinó la distribución de tamaño de los macro y mesoporos abiertos con la técnica de intrusión de mercurio. Para esto se utiliza un líquido no reactivo ni humectante, como el mercurio, al que se le aplica presión para que penetre en los poros del material a analizar y así se vencen las fuerzas capilares asociadas a la tensión superficial. A medida que la presión aplicada aumenta el mercurio va penetrando en poros cada vez más estrechos. Se utiliza la ecuación de Washburn para obtener la curva de distribución de los poros en función del radio (ec. 5.5). Se utilizó para ésta técnica un Porosímetro PascalThermo Fisher 440 y 140.

$$
r=\frac{-2 \sigma \cos \theta}{P}
$$

r: radio de poro; $\sigma$ tensión superficial del mercurio; $\theta$ ángulo de contacto entre el sólido y el líquido; $\mathrm{P}$ presión aplicada.

\section{Difracción de rayos $X$ y semicuantificación de la fase amorfa}

Se determinaron las fases cristalinas presentes en los distintos materiales por medio de difracción de rayos X (DRX) bajo las mismas condiciones descriptas en la sección 3.1, y con el método de Ohlberg modificado (Anexo I) se semicuantificó el porcentaje de fase amorfa como en la sección 4.2 con el método de Ohlberg5.

${ }^{5}$ El método de Ohlberh por ser una técnica en la cual se semicuantifica el porcentaje de fase amorfa en base al difractograma de la muestra en comparación con otros difractogramas no es posible asignarle una desviación estándar debido a que se realiza a una única muestra. 


\section{Densidad y porosidad por el método de Arquímedes}

Se midió el porcentaje de porosidad abierta, el porcentaje de porosidad cerrada (únicamente en la sección 4.3) y la densidad aparente por medio del método de Arquímedes por inmersión en agua (bajo lineamiento de norma IRAM 12510). Para los cálculos se consideró que la densidad del agua es de 1 $\mathrm{g} / \mathrm{cm}^{3}$.

La densidad aparente, en esta técnica, es la relación entre el peso de la muestra seca $\left(\mathrm{P}_{\mathrm{sec}}\right)$ y el volumen aparente $\left(\mathrm{V}_{\mathrm{ap}}\right)$ de la misma incluyendo los poros, como se muestra en la ec. 5.1 y se expresa en $\mathrm{g} / \mathrm{cm}^{3}$.

$$
\delta_{a p}=\frac{P_{s e c}}{V_{a p}}=\frac{P_{s e c}}{\frac{P_{s a t}-P_{s u m}}{\delta_{l}}} \quad \text { ec. } 5.1
$$

$\mathrm{P}_{\text {sat }}$ es el peso de la probeta saturada en agua y $\mathrm{P}_{\text {sum }}$ es el peso de la probeta sumergida en agua y $\delta_{1}$ es la densidad del líquido.

El porcentaje de porosidad abierta de la muestra es el cociente entre el volumen de los poros abiertos $\left(\mathrm{V}_{\mathrm{pa}}\right)$ y el volumen del material $\left(\mathrm{V}_{\mathrm{m}}\right)$ (ec. 5.2).

$$
\% P=\frac{V_{p a}}{V_{m}}=\frac{\frac{P_{s a t}-P_{\text {sec }}}{\delta_{l}}}{\frac{P_{\text {sec }}-P_{\text {sum }}}{\delta_{l}}} \times 100 \% \quad \text { ec. } 5.2
$$

El porcentaje de porosidad total calculado en la sección 4.3 se estableció a partir de la suma entre el porcentaje de porosidad abierta determinada por el método de Arquímedes y el porcentaje de porosidad cerrada estimado considerando la ec. 5.7 .

$$
\% P_{\text {cer }}=\frac{\delta_{\text {real }}-\delta_{\text {apen } a g u a}}{\delta_{\text {real }}} \times 100 \%
$$




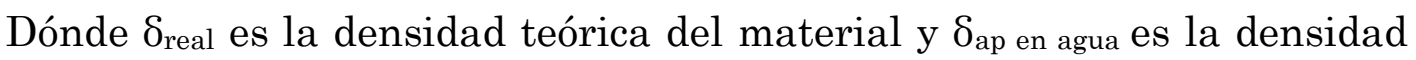
aparente en agua que incluye los poros cerrados pero no los abiertos (ec. 5.8).

$$
\delta_{\text {ap en agua }}=\frac{P_{\text {sec }}}{\frac{P_{\text {sec }}-P_{\text {sum }}}{\delta_{l}}} \quad \text { ec. } 5.8
$$

En la sección 5.3 la densidad teórica del material se determinó por dos vías: una a partir de la densidad por picnometría y otra por el método de la mezcla de las fases.

\section{Densidad por picnometría}

Se determinó la densidad de los materiales por la técnica de picnometría utilizando kerosén como líquido de inmersión (en base a la norma IRAM 12517). Esta medida se determina a partir de la relación entre la masa de la muestra y el volumen del picnómetro (ec. 5.9). Para esta medida el material se molió en un molino Herzog hasta llegar a un tamaño de partícula $<45 \mu \mathrm{m}$ (pasante malla 325).

$$
\delta_{\text {pic }}=\frac{P \times S}{(K+P-F)} \quad \text { ec. } 5.9
$$

Dónde $\mathrm{P}$ es el peso del picnómetro, $\mathrm{S}$ es la densidad del kerosén, $\mathrm{K}$ es el peso del picnómetro lleno de kerosén y $\mathrm{F}$ es el peso del picnómetro con la muestra molida lleno del líquido. 
También se calculó la densidad del material por el método de mezcla de las fases. Este se basa en calcular la densidad de un material como la suma de las densidades de cada fase que lo componen por el porcentaje de cada una de ellas (ec. 5.10). Para esto se determinó la cantidad el porcentaje presente de cada fase a partir de DRX y con el método de Rietveld y DRX (Anexo I).

$$
\delta_{m f}=\sum_{i=0}^{n} \delta_{i} x_{i}
$$

Dónde $\delta_{\mathrm{i}}$ es la densidad de cada fase $\mathrm{y} \mathrm{x}_{\mathrm{i}}$ es el porcentaje de la fase presente en la mezcla.

\section{Microtomografía de rayos $X$}

La técnica de microtomografía de rayos $\mathrm{X}$ permite construir representaciones en 3 dimensiones de los materiales. Para obtener esto, se requiere obtener imágenes de un escaneo angular de la absorción parcial de rayos X por parte del material. Esta absorción parcial permite además distinguir materiales de distinta densidad dentro del material. La configuración del equipo utilizado (Bruker Skyscan 1173) es fuente-muestradetector y la muestra es la que rota durante el escaneo. En este tipo de configuración la resolución espacial varía según la posición de la muestra, siendo la máxima resolución del orden de los $6 \mu \mathrm{m}$.

El resultado que surge del análisis consiste en una imagen digital que constituye una representación tridimensional de la muestra escaneada y la información que podemos obtener a partir de ésta es:

- Representación tridimensional de las muestras. Permite observar la constitución de los materiales, homogeneidad, microtextura y microestructura interna, entre otras cosas. 
- Cuantificación volumétrica de los materiales con distinta densidad. Las imágenes obtenidas tienen asociado un histograma, el cual se puede separar en distintas zonas y cuantificar volumétricamente cada una de las zonas diferenciadas. También se pueden contar objetos, obtener distribuciones de tamaño y determinar parámetros de forma sobre los mismos.

- Cálculo de la porosidad de los materiales. La diferenciación de densidades permite también identificar y cuantificar la porosidad presente en las muestras.

En este trabajo se utilizó en la sección 5.3 la microtomografía de rayos X para realizar imágenes de la textura porosa de los materiales y calcular el porcentaje de porosidad total de los mismos.

\section{Microscopía electrónica de barrido}

Se analizaron las microestructuras por medio de microscopía electrónica de barrido (SEM) con un equipo JEOL JCM-6000 Neo Scope. Para poder observar los materiales con microscopio las muestras se pulieron y luego se recubrieron con una capa conductora de oro.

\section{Microscopio óptico}

También se observó la morfología a nivel de superficial de los materiales porosos con un microscopio óptico por reflexión marca Olympus BX 60.

\subsection{Materiales del sistema arcilla-MAP: selección de la arcilla}

Inicialmente se estudiaron las propiedades de los materiales cerámicos elaborados a partir de la arcilla Blend y la arcilla Tincar Super con el objetivo 
de seleccionar la arcilla para el desarrollo de los agentes de sostén. A partir de las materias primas mencionadas anteriormente, se confeccionaron barras prismáticas de arcilla, 10\% MAP y 25\% carbón vegetal (porcentajes sobre el peso de arcilla).

También se analizó la influencia de la activación térmica inicial de la arcilla (para este análisis se utilizó la arcilla Tincar Super) en las propiedades finales del material cerámico, y si es que existen diferencias, si son significativas como para adicionar una etapa más al procesamiento del material con su correspondiente incidencia económica.

La activación térmica de las arcillas consistió en una calcinación durante una hora a $700^{\circ} \mathrm{C}$, el objetivo es destruir la estructura de la caolinita y que los amorfos formados se encuentren con mayor disponibilidad para la unión con el MAP.

En la Tabla 5.1 se muestran los valores obtenidos para los ensayos de caracterización de las barras realizadas a partir de la mezcla arcilla Blend activada térmicamente, $10 \%$ de MAP y $25 \%$ de carbón vegetal sinterizadas a $1350^{\circ} \mathrm{C}$ y $1450^{\circ} \mathrm{C}$. La elección de estas temperaturas se basó en los valores de CPE obtenidos en la sección 3.2, los cuales indicaron que la temperatura de ablandamiento de la arcilla Blend está en el rango de $1605-1621^{\circ} \mathrm{C}$.

Se observó que a mayor temperatura el material se encuentra en un mayor grado de sinterización por lo que la densidad y la resistencia mecánica son mayores y la porosidad del material menor. Como el objetivo es el utilizar estos materiales como agentes de sostén para la explotación de hidrocarburos no convencionales, y para ello se requiere que el porcentaje porosidad abierta sea el menor posible, los porcentajes de porosidad abierta de los materiales deberían ser menores que los logrados. 
Tabla 5.1. Propiedades de los materiales cerámicos del sistema: Blend activada térmicamente-MAP-carbón vegetal sinterizados a $1350^{\circ} \mathrm{C}$ y $1450^{\circ} \mathrm{C}$.

\begin{tabular}{c|cc} 
& $1350^{\circ} \mathrm{C}$ & $1450^{\circ} \mathbf{C}$ \\
\hline Porosidad abierta (\%) & $22,1(0,9)$ & $4(1)$ \\
Densidad aparente (g/cm $)$ & $1,7(0,9)$ & $1,96(0,03)$ \\
VL (\%) & $-12,1(0,1)$ & $-15,5(0,3)$ \\
MOR (MPa) & $18(3)$ & $27(4)$
\end{tabular}

Las mezclas con arcilla Tincar Super (con y sin activación térmica), 10\% de MAP y $25 \%$ de carbón vegetal se sinterizaron a mayores temperaturas (1500 y $1550^{\circ} \mathrm{C}$ ) considerando lo visibilizado en el ensayo de CPE (sección 3.2). Los resultados se muestran en la Tabla 5.2.

Los materiales con arcilla activada térmicamente alcanzaron a $1500^{\circ} \mathrm{C}$ una menor porosidad $(4,5 \%)$ que aquellos con arcilla sin activar $(21,8 \%)$ y en ambos casos a $1550^{\circ} \mathrm{C}$ el porcentaje de porosidad disminuyó a valores cercanos al 1\%; siendo el menor porcentaje de porosidad abierta para los materiales realizados con arcilla Tincar Super activada térmicamente.

Los valores de MOR para los materiales con la arcilla activada no presentaron diferencias significativas a las distintas temperaturas, en cambio para los materiales con la arcilla sin activar se observó que a mayor temperatura mayor fue el valor del MOR. En todos los materiales estudiados en la Tabla 5.2 las densidades obtenidas presentaron valores $\leq 2,00 \mathrm{~g} / \mathrm{cm}^{3}$. 
Tabla 5.2. Propiedades de los materiales cerámicos del sistema Tincar Súper- MAPcarbón vegetal sinterizados a $1500^{\circ} \mathrm{C}$ y $1550^{\circ} \mathrm{C}$.

\begin{tabular}{c|c|c|c|c} 
& \multicolumn{2}{|c|}{$\begin{array}{r}\text { Tincar Súper con activación } \\
\text { térmica }\end{array}$} & \multicolumn{2}{|c}{$\begin{array}{r}\text { Tincar Súper sin activación } \\
\text { térmica }\end{array}$} \\
\cline { 2 - 4 } & $1500^{\circ} \mathbf{C}$ & $1550^{\circ} \mathbf{C}$ & $1500^{\circ} \mathbf{C}$ & $1550^{\circ} \mathbf{C}$ \\
\hline $\begin{array}{c}\text { Porosidad } \\
\text { abierta (\%) }\end{array}$ & $4,5(0,9)$ & $0,8(0,3)$ & $21,8(0,4)$ & $1,1(0,3)$ \\
$\begin{array}{c}\text { Densidad } \\
\text { aparente } \\
(\text { g/cm }\end{array}$ & $1,96(0,05)$ & $2,00(0,04)$ & $1,89(0,01)$ & $2,00(0,01)$ \\
VL (\%) & $-18,34(0,01)$ & $-16.96(0,01)$ & $-17,93(0,3)$ & $-15,09(0,01)$ \\
MOR & $22(1)$ & $21(6)$ & $23(3)$ & $22(4)$ \\
$(\mathbf{M P a})$ & & &
\end{tabular}

En base a la alta porosidad abierta obtenida con la arcilla Blend, y considerando que la arcilla Tincar Super posee mayor disponibilidad en el mercado se decidió utilizar esta última en las siguientes formulaciones.

\subsection{Materiales del sistema Tincar Super-MAP-carbón: evaluación de la porosidad}

En esta sección se analizó cómo influyen tres distintos tipos de carbón en la textura porosa de un cerámico obtenido a partir de una mezcla de Tincar Super, $10 \%$ de MAP y 25\% de la fuente de carbón (carbón vegetal, carbón residual de petróleo y negro de humo). La arcilla utilizada en este caso no tenía ningún tratamiento térmico previo. 
Las fuentes de carbón se molieron en un molino de martillo hasta un tamaño de partícula entre 76-106 $\mu \mathrm{m}$, excepto el negro de humo que se presentaba como un material fino aglomerado.

El proceso de sinterización se realizó a $1550^{\circ} \mathrm{C}$ (en base a los resultados obtenidos de porcentaje de porosidad abierta y MOR en la sección 5.2) y luego se determinaron las propiedades mecánicas y texturales de los materiales (resistencia a la flexión en tres puntos, densidad aparente, densidad aparente en agua, porosidad tanto abierta como cerrada).

Tabla 5.3. Valores de densidad aparente y densidad aparente en agua para los materiales cerámicos realizados con las distintas fuentes de carbón.

\begin{tabular}{c|cc} 
Muestra & $\begin{array}{c}\text { Densidad aparente }\left(\mathbf{g} / \mathrm{cm}^{3}\right) \\
\text { Densidad aparente en } \\
\text { agua }\left(\mathbf{g} / \mathbf{c m}^{3}\right)\end{array}$ \\
\hline Carbón vegetal & $2,00(0,01)$ & $2,01(0,01)$ \\
Negro de humo & $1,9(0,2)$ & $2,1(0,3)$ \\
Carbón residual de \\
petróleo
\end{tabular}

Las densidades aparentes y aparentes en agua obtenidas en los cerámicos realizados a partir de la mezcla de arcilla, MAP y las fuentes de carbón se muestran en la Tabla 5.3. Los valores de densidades son cercanos a $\operatorname{los} 2 \mathrm{~g} / \mathrm{cm}^{3}$ y no presentaron diferencias significativas entre las distintas fuentes de carbón utilizadas.

Para determinar la porosidad cerrada de los materiales con la ec. 5.7 se calculó por dos vías la densidad real del material, una por picnometría (ec. 5.9) y otra por mezcla de fases (ec. 5.10). La densidad real del material determinada por picnometría $\left(\delta_{\text {pic }}\right)$ presentó un valor de $2,40 \mathrm{~g} / \mathrm{cm}^{3}$. 
Para el cálculo de la densidad por mezcla de fases los porcentajes de las fases presentes en el material determinados por DRX y el método de Rietveld (Anexo I) fueron: $35 \%$ de cristobalita, $24 \%$ de mullita y $41 \%$ de fase amorfa. A partir de estos porcentajes y las densidades teóricas de cada fase sacadas de bibliografía (se aproximó que la densidad de la fase amorfa corresponde a la densidad de un vidrio de sílice) se calculó la densidad real teórica ( $\left.\delta_{\text {teórica }}\right)$ del material por el método de las fases, siendo la misma de $2,46 \mathrm{~g} / \mathrm{cm}^{3}$.

En la Tabla 5.4 se muestran los porcentajes de porosidad abierta determinada por el método de Arquímedes, las porosidades cerradas calculadas con las densidades reales descriptas anteriormente y la porosidad total obtenida por la microtomografía de rayos X. El microtomógrafo tiene una resolución mínima de $6 \mu \mathrm{m}$, por lo que el porcentaje de porosidad calculado con esta técnica se ve limitado a este valor.

Tabla 5.4. Porosidad abierta y cerrada de los materiales cerámicos realizados con las distintas fuentes de carbón determinadas por diferentes técnicas y resistencia mecánica $(\mathrm{MOR})^{6}$.

\begin{tabular}{c|ccccc}
$\begin{array}{c}\text { Materiales } \\
\text { carbonosos }\end{array}$ & $\begin{array}{c}\text { Porosidad } \\
\text { abierta (\%) }\end{array}$ & $\begin{array}{c}\text { Porosidad } \\
\text { cerrada }\left(\delta_{\text {pic }}\right)\end{array}$ & $\begin{array}{c}\text { Porosidad } \\
\text { cerrada } \\
(\%)\end{array}$ & $\begin{array}{c}\text { Porosidad total } \\
(\text { microtomogra- } \\
\text { fía de rayos X) }\end{array}$ & $\begin{array}{c}\text { MOR } \\
(\mathbf{M P a})\end{array}$ \\
\hline $\begin{array}{c}\text { Carbón } \\
\text { vegetal }\end{array}$ & $0,8(0,3)$ & $16,5(0,3)$ & $15,4(0,2)$ & 16,42 & $23(2)$ \\
$\begin{array}{c}\text { Negro de } \\
\text { humo }\end{array}$ & $13,41(0,09)$ & $9,2(0,8)$ & $11,4(0,3)$ & 20,45 & $16(0,7)$ \\
$\begin{array}{c}\text { Carbón } \\
\text { residual de } \\
\text { petróleo }\end{array}$ & $0,6(0,1)$ & $16,2(0,5)$ & $19,1(0,4)$ & 15,78 & $22(3)$
\end{tabular}

${ }^{6}$ La medida de la porosidad total por microtomografía de rayos $\mathrm{X}$ al no ser una medida estadística, la porosidad se mide en una sola medida, no se calcula el error estándar sino se informa la resolución mínima de $6 \mu \mathrm{m}$. 
Se observó que la porosidad total cuando se utiliza negro de humo es mayor en comparación de las otras fuentes de carbón presentando la mayor diferencia en la porosidad abierta del material. Siendo el porcentaje de porosidad abierta para los materiales con negro de humo de $13,41 \%$ y para los otros materiales menor al 1\%.

Existen diferencias entre los porcentajes de porosidad cerrada estimados con la densidad por picnometría y con la densidad obtenida con la mezcla de las fases en el rango de $\pm 1,1-2,9$. Estas diferencias pueden deberse a errores en el ensayo de picnometría al no tener la muestra completamente pulverizada por lo que podría existir poros cerrados dentro de las partículas y/o a la suposición en la determinación de la densidad por mezcla de fases que la fase amorfa posee una densidad igual a la densidad de un vidrio de sílice.

La distribución de tamaños de los macroporos (>10000 nm), obtenidos por la técnica por intrusión de mercurio, para las distintas fuentes de carbón se muestra en las Figura 5.1. La distribución de los macroporos de los materiales con negro de humo presentó una distribución bimodal con un volumen total mayor a $12 \mathrm{~mm} 3 / \mathrm{g}$, siendo este volumen de poro el mayor entre las tres distintas fuentes de carbón. La distribución de macroporos de las muestras con carbón vegetal y con carbón residual de petróleo fue amplia presentando el primero el menor volumen de poro $(2,3 \mathrm{~mm} 3 / \mathrm{g})$ entre las tres porosimetrías.

En las Figura 5.2 se muestra la distribución del tamaño de los mesoporos abiertos de los materiales obtenidos. Cuando se utilizó negro de humo la distribución fue estrecha en el rango de 400-800 nm y como en el caso de los macroporos presentó el mayor volumen de poro $\left(100 \mathrm{~mm}^{3} / \mathrm{g}\right)$.

El carbón vegetal presentó una distribución no tan estrecha de poros en un rango de 40-400 $\mathrm{nm}$ siendo menor a $1 \mathrm{~mm}^{3 /} \mathrm{g}$ el volumen de poro presente en el cerámico. En contraste, el carbón residual de petróleo exhibió una 
distribución más amplia que en los casos anteriores en un rango de 10-1000 $\mathrm{nm}$ con un volumen de poro acumulado de $7 \mathrm{~mm}^{3} / \mathrm{g}$.

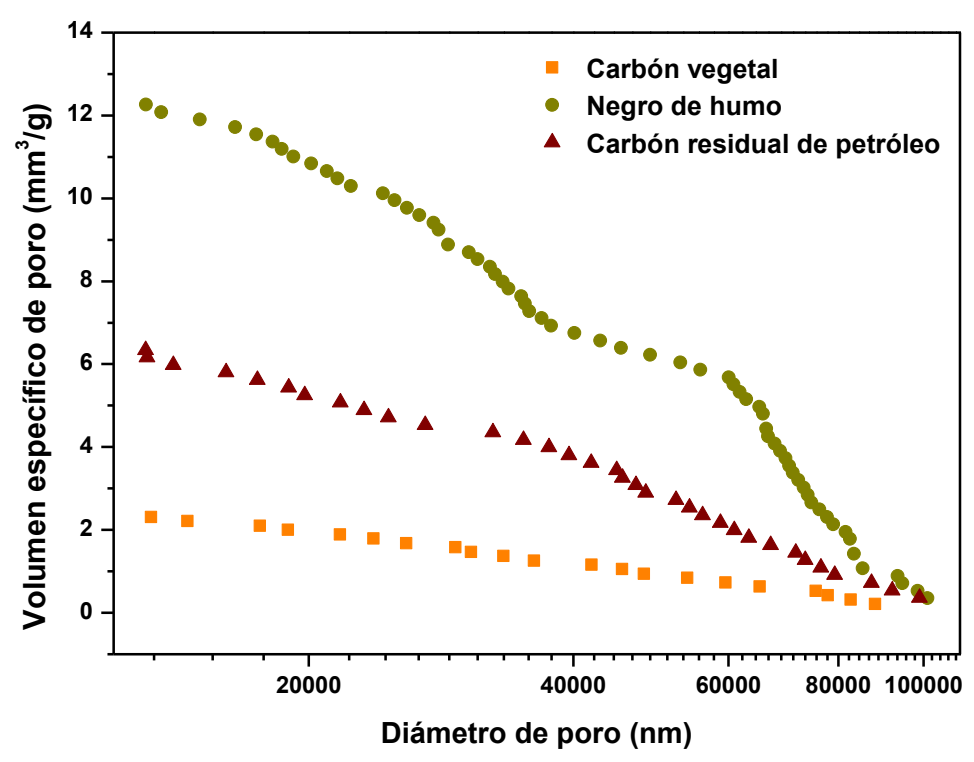

Figura 5.1. Distribución de tamaño de los macroporos de los materiales cerámicos realizados con las distintas fuentes de carbón.

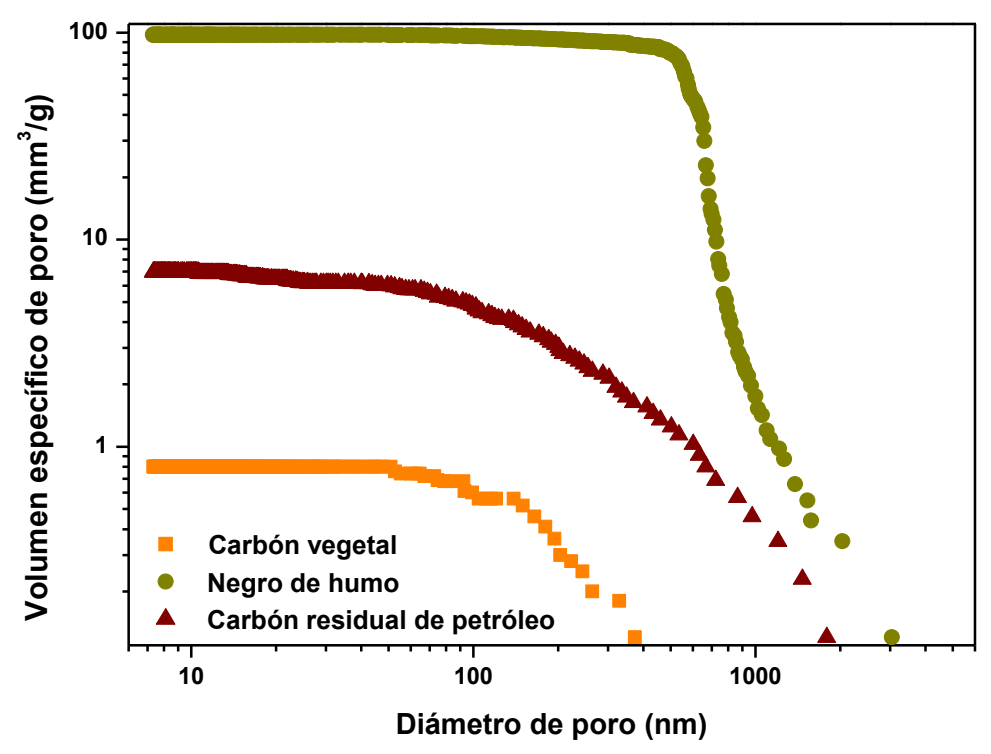

Figura 5.2. Distribución de tamaño de los mesoporos de los materiales cerámicos realizados con las distintas fuentes de carbón. 
La microestructura de los materiales observada por microtomografía de rayos $\mathrm{X}$, por microscopía electrónica de barrido y por microscopía óptica se muestra en las Figuras 5.3, 5.4 y 5.5 respectivamente. Estas técnicas nos permiten analizar la distribución de los poros.

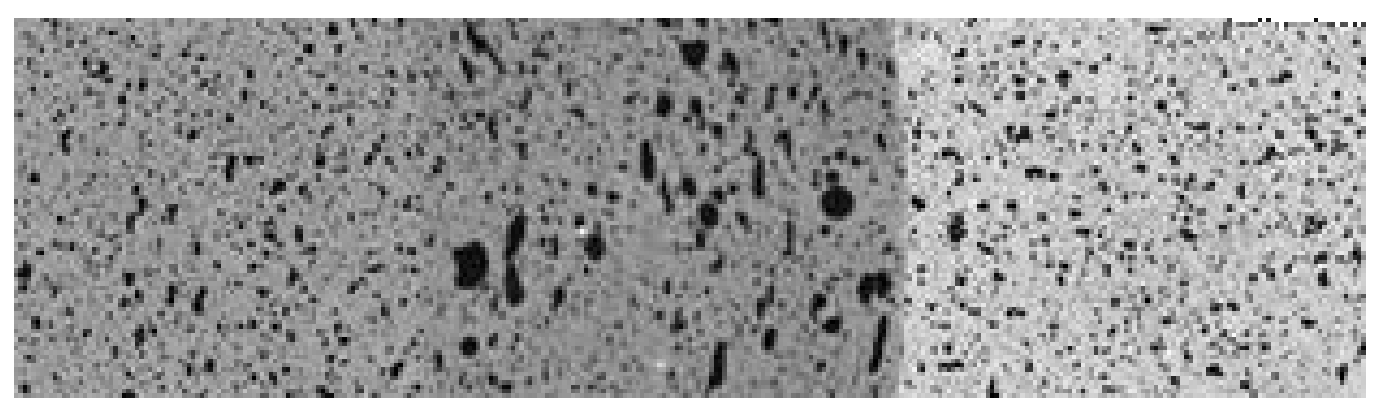

Figura 5.3. Microtomografía de rayos $x$ de los materiales cerámicos utilizando (a) Carbón Vegetal. (b) Negro de Humo y (c) Carbón Residual de Petróleo.

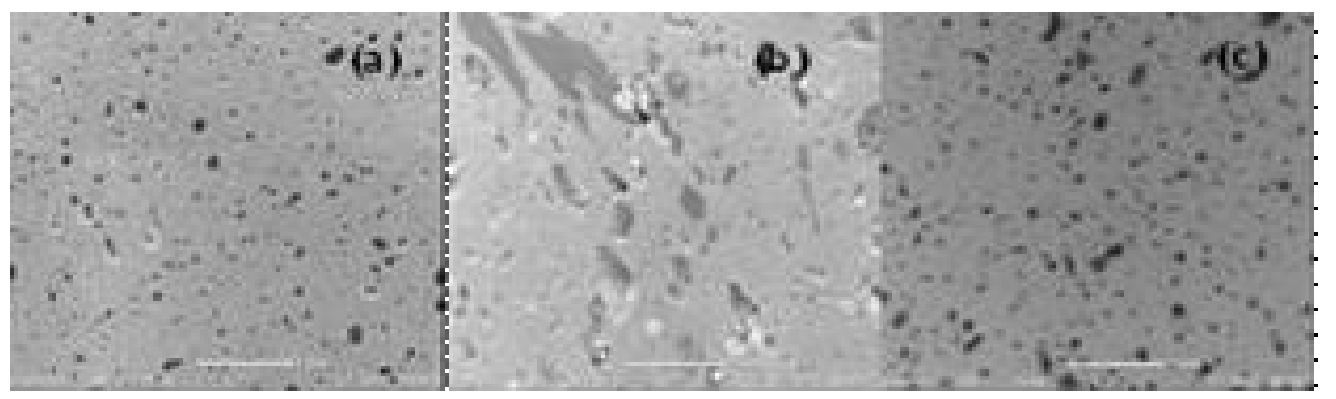

Figura 5.4. Fotografías SEM (27x) de los materiales cerámicos obtenidos utilizando (a) Carbón Vegetal, (b) Negro de Humo y (c) Carbón Residual de Petróleo.

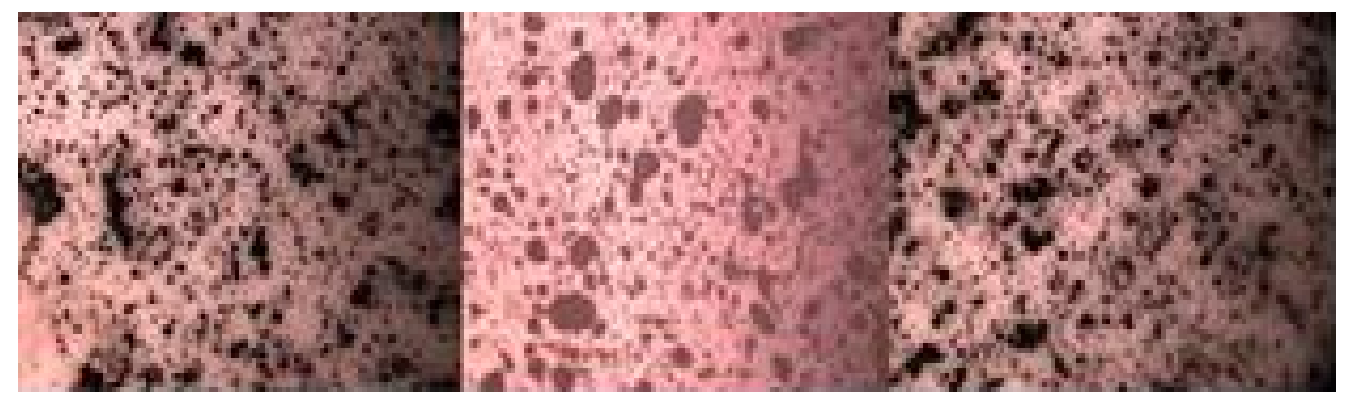

Figura 5.5. Fotografías con microscopio óptico (40x) de los materiales cerámicos obtenidos utilizando (a) Carbón Vegetal, (b) Negro de Humo y (c) Carbón Residual de Petróleo. 
Se observó que cuando se adiciona negro de humo como agente formador de poros se obtienen poros de gran tamaño y variada forma, en cambio con los otros dos tipos de carbón se observó una microtextura con un tamaño menor de poros y homogénea. Esto puede deberse al tamaño de partícula del negro de humo $(<50 \mathrm{~nm})$ que contribuye a la generación de aglomerados que no permite una distribución homogénea del carbón en la mezcla.

En base a los resultados obtenidos si se opta por la utilización de un agente formador de poros para disminuir la densidad de los materiales el carbón residual de petróleo sería el indicado. Esto se justifica en que los materiales con esta fuente de carbón, entre las tres fuentes analizadas en este trabajo, condujo a los menores valores de porcentaje de porosidad abierta; que como se mencionó en la introducción (sección 1.1) es un factor importante para la utilización del material cerámico como agente de sostén. Además, el carbón residual de petróleo es un producto del proceso de refinación del petróleo lo que lo hace un material de fácil acceso por la industria de los hidrocaburos.

\subsection{Evaluación de la utilización de liga fosfórica a alta temperatura}

En esta sección se estudiaron las propiedades de los materiales cerámicos y de la liga fosfórica cuando ésta se la utiliza a elevada temperatura.

Primero (sección 5.4.1) se analizaron materiales que se realizaron a partir de arcilla Tincar Super (activada y sin activar térmicamente)-10\% de MAP (en base a la cantidad de arcilla) y materiales cerámicos obtenidos a partir de arcilla únicamente para su comparación. En el caso de la arcilla activada se adicionó un 10\% de polivinil alcohol al 6\% p/p para mejorar la resistencia en verde de las probetas prensadas. Las diferentes mezclas se trataron térmicamente a $1000^{\circ} \mathrm{C}$, y $1400^{\circ} \mathrm{C}$ durante una hora. 
Después (sección 5.4.2) se evaluó la utilización de MAP en materiales cerámicos y como varían sus propiedades mecánicas y texturales cuando se los sinteriza a $1400^{\circ} \mathrm{C}$ y $1500^{\circ} \mathrm{C}$. Los sistemas estudiados fueron Tincar Super (activada térmicamente y sin activar), 10\% de MAP y $20 \%$ de bauxita; también en este caso, se utilizó únicamente arcilla para comparar las propiedades de los materiales cerámicos obtenidos.

Se adicionó bauxita a los sistemas a mayor temperatura para favorecer la formación de mullita secundaria entre la alúmina proveniente de la bauxita y la sílice que se encuentra en forma de cristobalita y/o en la fase amorfa, ambas provenientes de la arcilla (Liu et al., 1994).

\subsubsection{Sistema Tincar Super (activada y sin activar térmicamente)-MAP $\left(1000^{\circ} \mathrm{C}\right.$ y $\left.1400^{\circ} \mathrm{C}\right)$}

El porcentaje de porosidad abierta, la densidad aparente, los valores de MOR,la variación lineal (VL) y el porcentaje de fase amorfa calculado por el método de Ohlberg modificado de los materiales sinterizados a $1000^{\circ} \mathrm{C} \mathrm{y}$ $1400^{\circ} \mathrm{C}$ se muestran en la Tabla 5.5.

Se observó que los porcentajes de porosidad a $1400^{\circ} \mathrm{C}$ son menores que a $1000^{\circ} \mathrm{C}$, esto se debe al grado de densificación del material siendo mayor a mayor temperatura de sinterizado, disminuyendo entonces su porosidad. A su vez, a una dada temperatura los materiales realizados a partir de arcilla activada térmicamente y MAP presentaron mayor porosidad que los materiales obtenidos con arcilla sin activación térmica.

A $1000^{\circ} \mathrm{C}$ entre los materiales realizados con MAP, el sistema Tincar Super-MAP presentó mayor resistencia mecánica pero a $1400^{\circ} \mathrm{C}$ los materiales que tienen solo arcilla, como materia prima en su composición, tuvieron mayores valores de MOR que aquellos a los que se les adicionó MAP. 
Tabla 5.5. Propiedades de los materiales: Tincar Super, Tincar Super activada térmicamente-MAP y Tincar Super-MAP sinterizados a 1000 y $1400^{\circ} \mathrm{C}$.

\begin{tabular}{|c|c|c|c|c|c|c|}
\hline & \multicolumn{2}{|c|}{ Tincar Super } & \multicolumn{2}{|c|}{$\begin{array}{c}\text { Tincar Super activada } \\
\text { térmicamente- MAP }\end{array}$} & \multicolumn{2}{|c|}{$\begin{array}{c}\text { Tincar Super sin } \\
\text { activar } \\
\text { térmicamente - } \\
\text { MAP }\end{array}$} \\
\hline & $1000^{\circ} \mathrm{C}$ & $1400^{\circ} \mathrm{C}$ & $1000^{\circ} \mathrm{C}$ & $1400^{\circ} \mathrm{C}$ & $1000^{\circ} \mathrm{C}$ & $1400^{\circ} \mathrm{C}$ \\
\hline $\begin{array}{l}\text { Densidad } \\
\text { aparente } \\
\left(\mathrm{g} / \mathrm{cm}^{3}\right)\end{array}$ & $\begin{array}{l}1,76 \\
(0,02)\end{array}$ & $\begin{array}{c}1,68 \\
(0,02)\end{array}$ & $1,57(0,04)$ & $\begin{array}{c}1,78 \\
(0,03)\end{array}$ & $\begin{array}{c}1,8 \\
(0,1)\end{array}$ & $\begin{array}{c}2,09 \\
(0,03)\end{array}$ \\
\hline $\begin{array}{l}\text { Porosidad } \\
\text { (\%) }\end{array}$ & $33(1)$ & $\begin{array}{l}15,8 \\
(0,2)\end{array}$ & $43(2)$ & $\begin{array}{l}25,7 \\
(0,2)\end{array}$ & $28(4)$ & $10(1)$ \\
\hline MOR (MPa) & $11(2)$ & $46(2)$ & $4(3)$ & $29(1)$ & $14(2)$ & $34(2)$ \\
\hline VL (\%) & $\begin{array}{l}-2,00 \\
(0,01)\end{array}$ & $\begin{array}{l}-6,00 \\
(0,01)\end{array}$ & $\begin{array}{l}-2,7 \\
(0,2)\end{array}$ & $\begin{array}{l}-9,0 \\
(0,1)\end{array}$ & $\begin{array}{l}-2,5 \\
(0,1)\end{array}$ & $\begin{array}{l}-6,80 \\
(0,01)\end{array}$ \\
\hline $\begin{array}{c}\text { Fase amorfa } \\
(\%)\end{array}$ & 35,29 & 49,02 & 41,33 & 48,78 & 43,61 & 54,75 \\
\hline
\end{tabular}

En base a los resultados obtenidos de porcentaje de fase amorfa, se observó que en los procesos de sinterizado se produce mayor vitrificación a temperaturas más bajas cuando está presente el MAP (el $\mathrm{P}_{2} \mathrm{O}_{5}$ es formador de vidrio al igual que el $\mathrm{SiO}_{2}$ (Bengisu, 2001)). A las temperaturas de sinterizado se obtuvieron valores de densidad menores o cercanos a $2 \mathrm{~g} / \mathrm{cm}^{3}$.

En las Figuras 5.6 y 5.7 se muestran las curvas de distribución de tamaño de mesoporos de los materiales a $1000^{\circ} \mathrm{C}$ y $1400^{\circ} \mathrm{C}$ respectivamente. A ambas temperaturas el mayor volumen de poro, para este rango, se presentó cuándo se utilizó la Tincar Super activada térmicamente. Todos los materiales 
sinterizados a $1000^{\circ} \mathrm{C}$ mostraron curvas, de distribución de tamaño de poro, continuas y amplias.

A $1000^{\circ} \mathrm{C}$ se observó que el menor volumen de poro total fue el del sistema Tincar Super-MAP, esto se correlaciona con el menor porcentaje de porosidad abierta total obtenido con el método de Arquímedes y con el mayor valor de resistencia mecánica (Tabla 5.5).

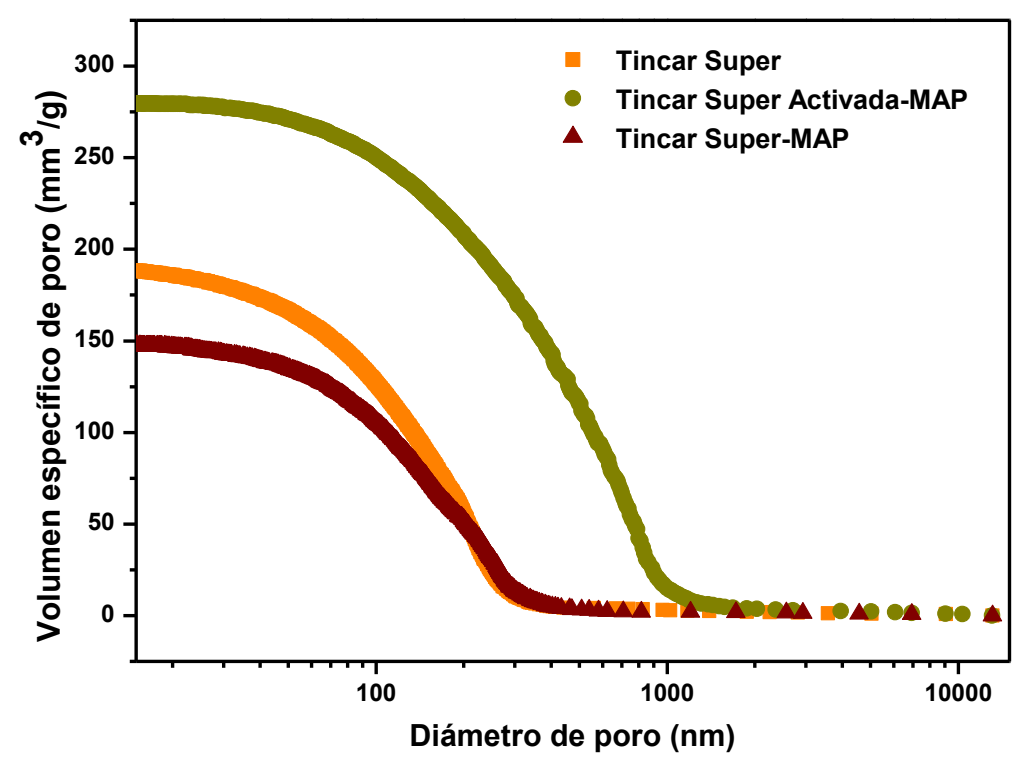

Figura 5.6. Distribución de tamaño de los mesoporos de los materiales: Tincar Super, Tincar Super activada térmicamente-MAP y Tincar Super-MAP sinterizados a $1000^{\circ} \mathrm{C}$.

Las curvas de distribución de tamaño de los mesoporos de los materiales sinterizados a $1400^{\circ} \mathrm{C}$ (Figura 5.7) muestran distinto comportamiento que las curvas de los materiales sinterizados a $1000^{\circ} \mathrm{C}$. A mayor temperatura las curvas son estrechas en distribución, con tamaños promedio mayores que a menor temperatura y con menores volúmenes totales de poro. Lo observado mostró que los poros de menor tamaño vistos a $1000^{\circ} \mathrm{C}$ se unieron para formar 
poros de mayor tamaño pero con un menor volumen total; y además posiblemente muchos de los poros abiertos al aumentar la temperatura se transformaron en poros cerrados, por lo que no fueron detectados en este ensayo.

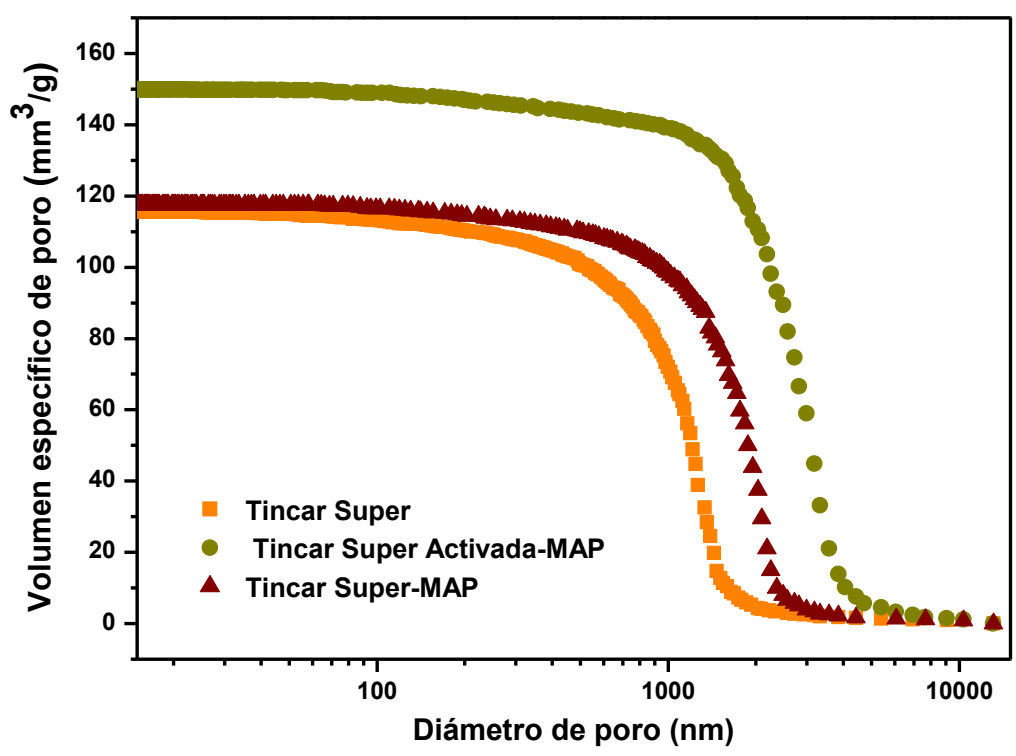

Figura 5.7. Distribución de tamaño de los mesoporos de los materiales: Tincar Super, Tincar Super activada térmicamente-MAP y Tincar Super-MAP sinterizados a $1400^{\circ} \mathrm{C}$.

Según lo observado en la Tabla 5.5 y comparando con las curvas de distribución de tamaño de poro (Figuras 5.6 y 5.7) se ve relación entre los resultados obtenidos por diferentes técnicas de caracterización, siendo que para todos los casos una menor porosidad y un menor tamaño de poro conducen a una mayor resistencia mecánica si se compara entre materiales sinterizados a la misma temperatura. 
Con los resultados obtenidos en estos sistemas se observó la necesidad de sinterizar los materiales a mayor temperatura para obtener menor porcentaje de porosidad abierta.

\subsubsection{Sistema arcilla Tincar Super (activada y sin activar térmicamente) - MAP- bauxita $\left(1400^{\circ} \mathrm{C}\right.$ y $\left.1500^{\circ} \mathrm{C}\right)$}

Los materiales del sistema Tincar Super- MAP- bauxita sinterizados a $1500^{\circ} \mathrm{C}$ presentaron un alto grado de vitrificación por lo que no se evaluaron sus propiedades.

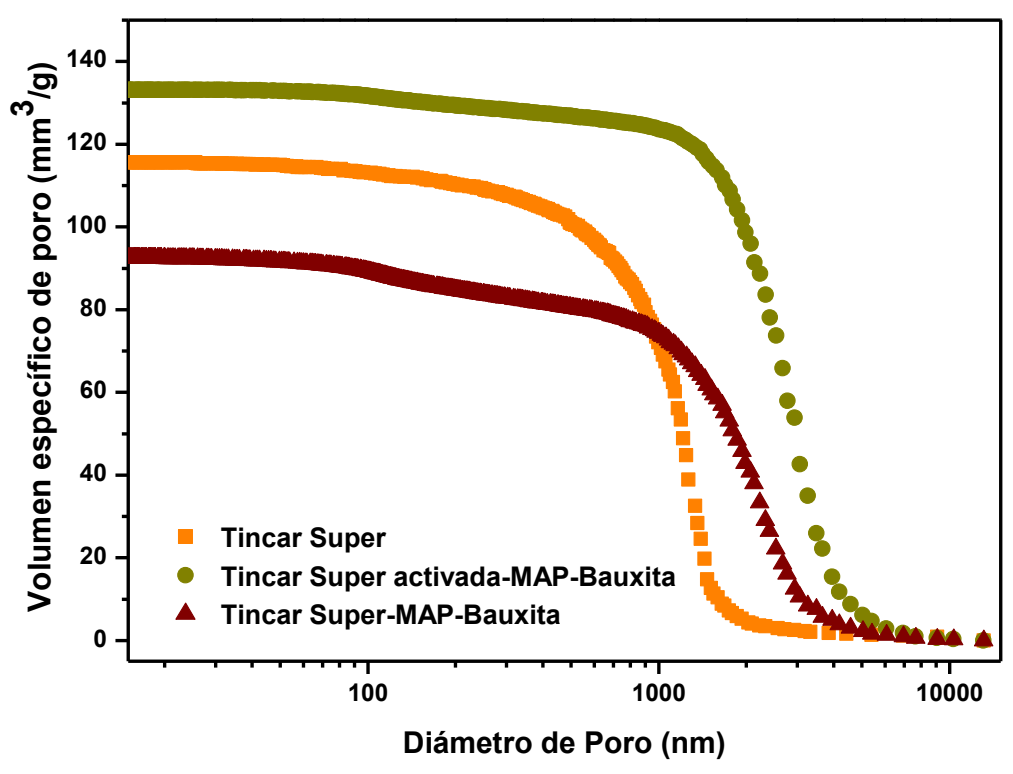

Figura 5.8. Distribución de tamaño de los mesoporos de los materiales: Tincar Super,

Tincar Super activada térmicamente-bauxita-MAP y Tincar Super-bauxita-MAP sinterizados a $1400^{\circ} \mathrm{C}$.

En la Figura 5.8 se muestra la distribución de los mesoporos de los materiales cerámicos sinterizados a $1400^{\circ} \mathrm{C}$, se observó que en todos los materiales obtenidos la distribución de la porosidad es estrecha. El mayor 
volumen total de poros abiertos se obtuvo cuando se utilizó arcilla Tincar Super activada térmicamente.

Las curvas de distribución de porosidad abierta de los materiales cerámicos sinterizados $1500^{\circ} \mathrm{C}$ (Figura 5.9) presentaron menor volumen total de poro que las sinterizadas a $1400^{\circ} \mathrm{C}$. Los materiales del sistema Tincar Super activada térmicamente-MAP-bauxita presentaron mayor resistencia mecánica y menor densidad que las barras de arcilla sola.

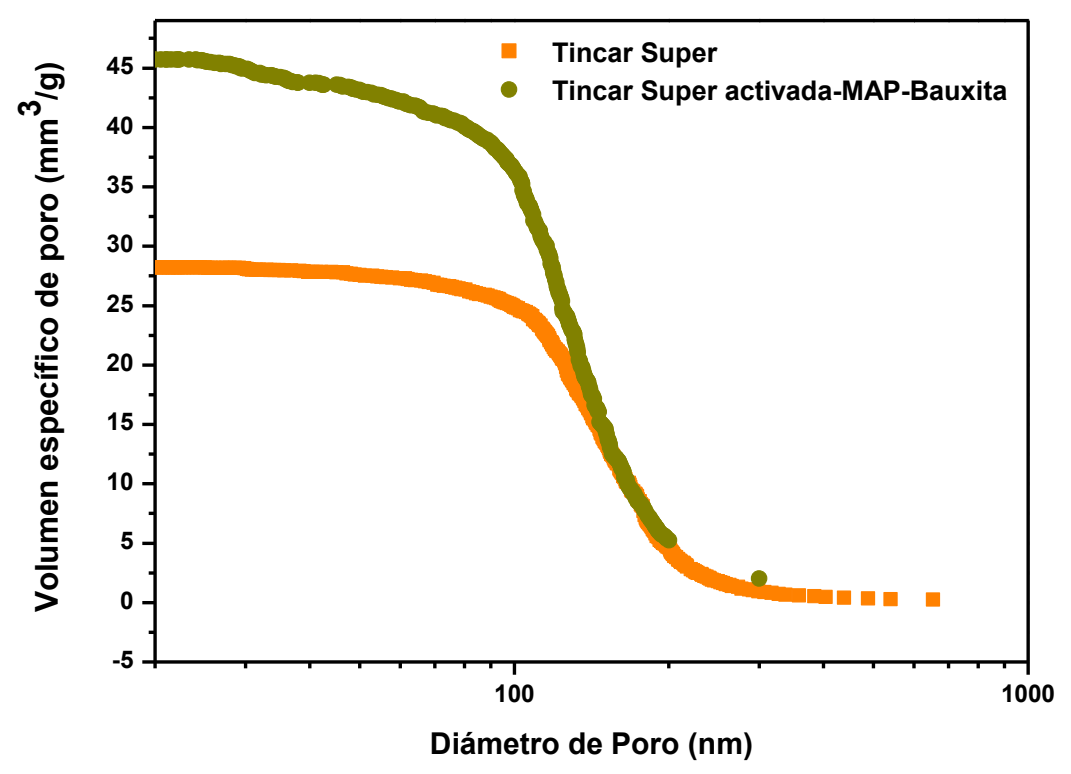

Figura 5.9. Distribución de tamaño de los mesoporos de los materiales: Tincar Super,

Tincar Super activada térmicamente-bauxita-MAP y Tincar Super-bauxita-MAP sinterizados a $1500^{\circ} \mathrm{C}$.

En la Tabla 5.6 se presentan la densidad, el porcentaje de porosidad, el porcentaje de variación lineal (VL), los valores de MOR y el porcentaje de fase amorfa de los materiales sinterizados a $1400^{\circ} \mathrm{C}$ y $1500^{\circ} \mathrm{C}$. Se observó que el porcentaje de porosidad abierta disminuyó con la temperatura para todos los 
materiales. Como se mencionó en la sección anterior, esto se debe a que a mayor temperatura mayor es la densificación del material, por lo cual disminuye la porosidad. A $1400^{\circ} \mathrm{C}$ los materiales cerámicos del sistema Tincar Super activada térmicamente-MAP-bauxita presentaron un porcentaje de porosidad abierta elevada $(27,19 \%)$ en comparación con los otros materiales.

Tabla 5.6. Propiedades de los materiales: Tincar Super, Tincar Super activada térmicamente-bauxita-MAP y Tincar Super-bauxita-MA sinterizados a 1400 y $1500^{\circ} \mathrm{C}$.

\begin{tabular}{|c|c|c|c|c|c|}
\hline & \multicolumn{2}{|c|}{ Tincar Super } & \multicolumn{2}{|c|}{$\begin{array}{l}\text { Tincar Super activada } \\
\text { térmicamente- MAP - } \\
\text { bauxita }\end{array}$} & \multirow{2}{*}{$\begin{array}{c}\text { Tincar Super sin } \\
\text { activar } \\
\text { térmicamente- } \\
\text { MAP -bauxita } \\
1400^{\circ} \mathrm{C}\end{array}$} \\
\hline & $1400^{\circ} \mathrm{C}$ & $1500^{\circ} \mathrm{C}$ & $1400^{\circ} \mathrm{C}$ & $1500^{\circ} \mathrm{C}$ & \\
\hline $\begin{array}{l}\text { Densidad } \\
\left(\mathrm{g} / \mathrm{cm}^{3}\right)\end{array}$ & $\begin{array}{c}1,68 \\
(0,02)\end{array}$ & $\begin{array}{l}2,31 \\
(0,01)\end{array}$ & $\begin{array}{c}1,86 \\
(0,02)\end{array}$ & $2,24(0,02)$ & $1,22(0,04)$ \\
\hline $\begin{array}{l}\text { Porosidad } \\
\text { (\%) }\end{array}$ & $\begin{array}{l}15,8 \\
(0,2)\end{array}$ & $1,4(0,1)$ & $27(1)$ & $1,50(0,1)$ & $14(1)$ \\
\hline MOR (MPa) & $46(3)$ & $41(2)$ & $28(2)$ & $48(2)$ & $20(3)$ \\
\hline $\mathrm{VL}(\%)$ & $\begin{array}{l}-6,00 \\
(0,01)\end{array}$ & $\begin{array}{r}-10,2 \\
(0,2)\end{array}$ & $-9,6(0,2)$ & $-15,2(0,3)$ & $-6,5(0,2)$ \\
\hline $\begin{array}{c}\text { Fase amorfa } \\
\text { (\%) }\end{array}$ & 49,02 & 3,92 & 48,71 & 50,98 & 54,90 \\
\hline
\end{tabular}

A mayor temperatura $\left(1500^{\circ} \mathrm{C}\right)$ se observó que la densidad de los aumentó debido a la densificación de los materiales con la temperatura. También se vio que el sistema Tincar Super sin activar térmicamente-MAPbauxita mostró la menor densidad a dicha temperatura $\left(2,24 \mathrm{~g} / \mathrm{cm}^{3}\right)$. 
Los materiales de arcilla Tincar Super sinterizados a $1500^{\circ} \mathrm{C}$ mostraron una notable disminución del porcentaje de fase amorfa en comparación con los materiales que tienen MAP en el sistema. Como se mencionó en la sección anterior esto se basa en el hecho que el $\mathrm{P}_{2} \mathrm{O}_{5}$ es un óxido formador de vidrio, que en combinación con el $\mathrm{SiO}_{2}$ (otro óxido formador de vidrio), forman una importante cantidad de fase amorfa.

\subsection{Materiales del sistema Tincar Super-sílice coloidal}

Se analizó la utilización de súlice coloidal como precursor de liga nanoestructurada en lugar del MAP. Para seguir la misma relación utilizada con el MAP se decidió adicionar un 10\% de sílice coloidal a la arcilla.

Se estudiaron dos sistemas: Tincar Super-sílice coloidal y Tincar Supersílice coloidal-bauxita. Como en la sección anterior el porcentaje de bauxita fue del $20 \%$. Las temperaturas de sinteriozado fueron $1450^{\circ} \mathrm{C}$ y $1500^{\circ} \mathrm{C}$.

En la Tabla 5.7 se muestran los valores de densidad aparente, porcentaje de porosidad, variación lineal (VL), MOR y porcentaje de fase amorfa de los materiales sinterizados a las dos temperaturas estudiadas.

En ambos casos el porcentaje de porosidad disminuyó con la temperatura de sinterizado. En el sistema Tincar Super- sílice coloidal no se observaron diferencias significativas en cuanto a los valores de MOR y de densidad aparente a distinta temperatura.

En el sistema Tincar Super- sílice coloidal- bauxita aparece la formación de mullita secundaria debido a la reacción entre la alúmina proveniente de la bauxita y la sílice libre. Este es un proceso expansivo por lo cual disminuye la densidad y la resistencia mecánica de los materiales con la temperatura, por este motivo se observó una contracción menor a $1500^{\circ} \mathrm{C}$ que $1450^{\circ} \mathrm{C}$. 
Tabla 5.7. Propiedades de los materiales cerámicos del sistema Tincar Super-Sílice coloidal con y sin bauxita a 1450 y $1500^{\circ} \mathrm{C}$.

\begin{tabular}{|c|c|c|c|c|}
\hline & \multicolumn{2}{|c|}{$\begin{array}{c}\text { Tincar Super - sílice } \\
\text { coloidal }\end{array}$} & \multicolumn{2}{|c|}{$\begin{array}{c}\text { Tincar Super - sílice coloidal - } \\
\text { bauxita }\end{array}$} \\
\hline & $1450^{\circ} \mathrm{C}$ & $1500^{\circ} \mathrm{C}$ & $1450^{\circ} \mathrm{C}$ & $1500^{\circ} \mathrm{C}$ \\
\hline $\begin{array}{c}\text { Densidad } \\
\text { aparente }\left(\mathrm{g} / \mathrm{cm}^{3}\right)\end{array}$ & $2,22(0,09)$ & $2,25(0,01)$ & $2,33(0,02)$ & $2,26(0)$ \\
\hline Porosidad (\%) & $8,0(0,7)$ & $1,68(0,04)$ & $5,9(0,3)$ & $2,4(0,3)$ \\
\hline MOR (MPa) & $32(2)$ & $31(1)$ & $31(3)$ & $28(2)$ \\
\hline VL (\%) & $-8,4(0,3)$ & $-9,8(0,5)$ & $-11,2(0,3)$ & $-10(1)$ \\
\hline Fase amorfa (\%) & 54,27 & 50,35 & 52,63 & 49,02 \\
\hline
\end{tabular}

Posiblemente si a estos materiales se los hubiera calcinado durante mayor tiempo y/o a mayor temperatura el efecto de sinterización hubiera adquirido mayor importancia y los valores de MOR serían mayores.

En los porcentajes de fase amorfa que se muestran en la Tabla 5.7 se observó que los porcentajes disminuyeron con la temperatura debido al proceso de cristalización de la mullita y la cristobalita. La relación entre el porcentaje de fase amorfa a las dos temperaturas fue mayor para el sistema Tincar Supersílice coloidal debido a que el agregado de bauxita (fuenet de alúmina) junto con la sílice libre proveniente de la arcilla contribuye a la formación de mullita secundaria.

En las Figuras 5.10 y 5.11 se muestra la distribución de tamaño de los mesoporos de los materiales a las dos temperaturas de trabajo. A $1450^{\circ} \mathrm{C}$ el volumen total de poros para los dos sistemas fue similar (aproximadamente 43 $\mathrm{mm}^{3} / \mathrm{g}$ ), aunque presentaron distinta distribución. Esto se relaciona con los valores de MOR obtenidos, siendo que ambos materiales tuvieron valores similares. 


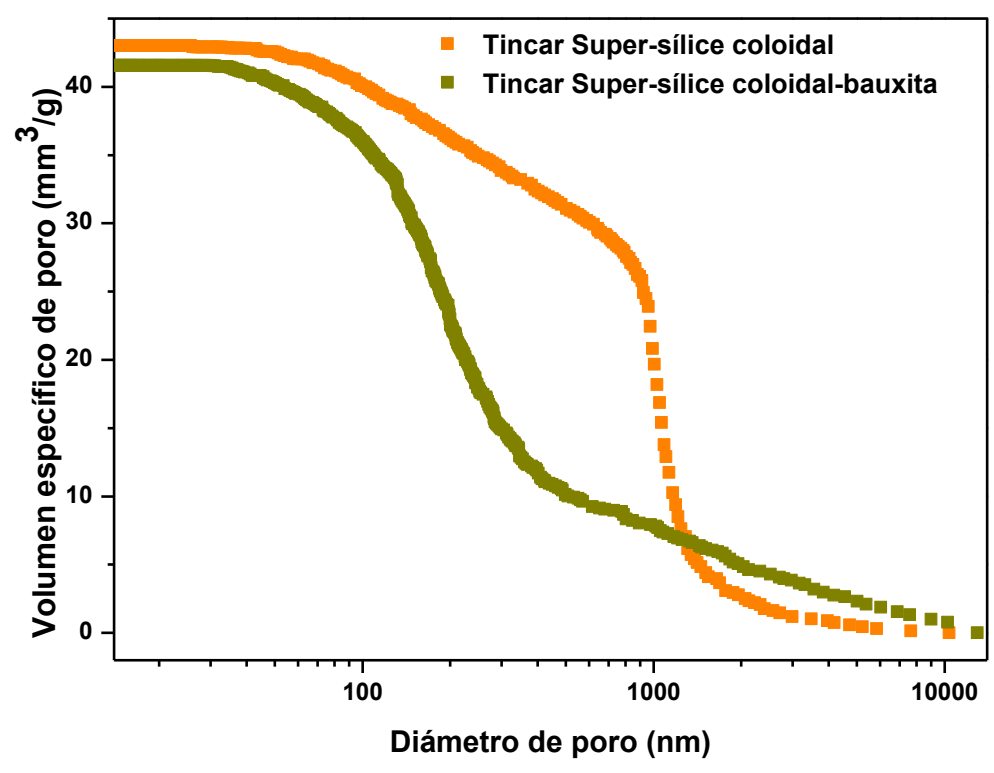

Figura 5.10. Distribución del tamaño de los mesoporos de los materiales Tincar SuperSílice coloidal con y sin bauxita sinterizados a $1450^{\circ} \mathrm{C}$.

A $1500^{\circ} \mathrm{C}$ (Figura 5.11) ambos sistemas presentaron igual tamaño medio de poro pero los materiales con bauxita como materia prima exhibieron mayor volumen total debido al proceso expansivo mencionado anteriormente. Esto se correlaciona con la menor resistencia mecánica del material a $1500^{\circ} \mathrm{C}$ (Tabla 5.7) y el efecto del proceso de generación de mullita secundaria explicado anteriormente. 


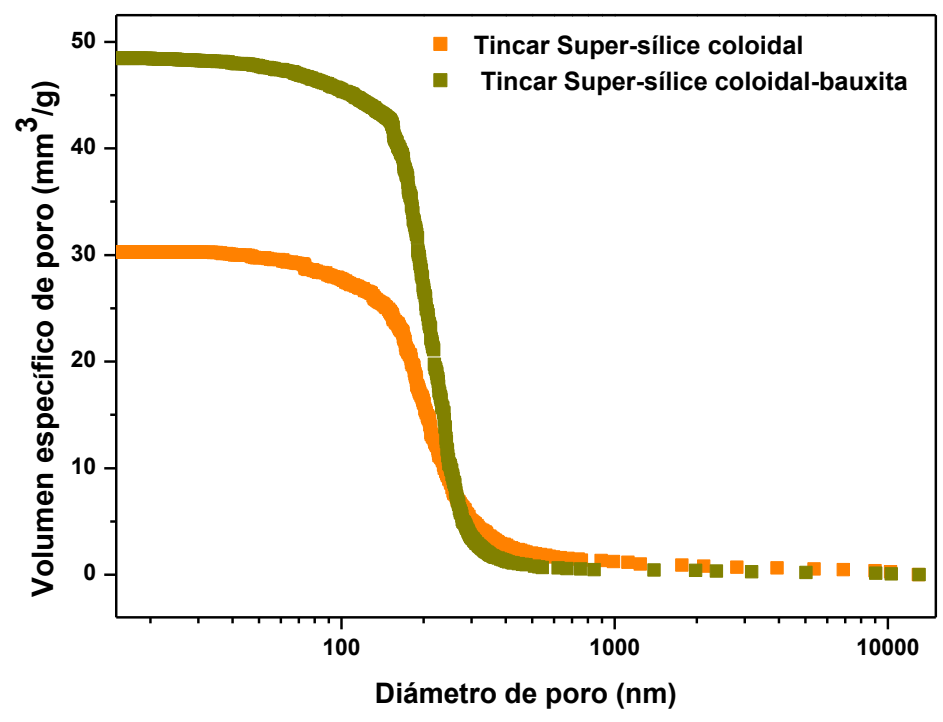

Figura 5.11. Distribución del tamaño de los mesoporos de los materiales Tincar SuperSílice coloidal con y sin bauxita sinterizados a $1500^{\circ} \mathrm{C}$.
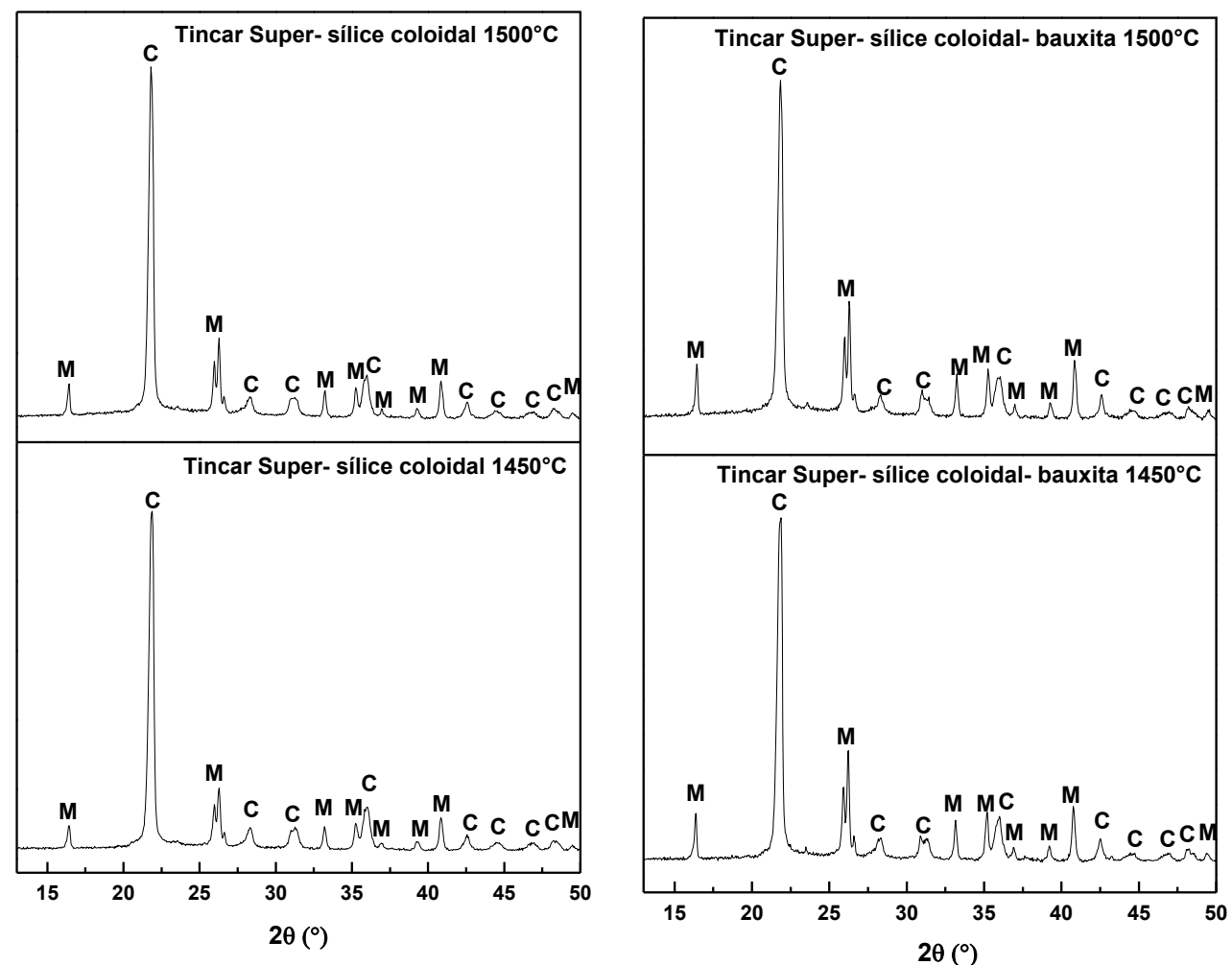

Figura 5.12. Diagrama de rayos X de los materiales Tincar Super- Sílice coloidal con y sin bauxita sinterizados a 1450 y $1500^{\circ} \mathrm{C}$. 
En la Figura 5.12 se muestran los diagramas de rayos $\mathrm{X}$ de los materiales sinterizados a $1450^{\circ} \mathrm{C}$ y $1500^{\circ} \mathrm{C}$. Se observó en los diagramas mayor intensidad de los picos $26,17^{\circ}(210)$ y el de $16,4^{\circ}$ (110) de la mullita en los materiales del sistema Tincar Super-sílice coloidal-bauxita. Esto corrobora la mayor formación de mullita por la presencia de una fuente de alúmina extra.

En ninguno de los dos sistemas bajo estudio se identificó tridimita como una fase cristalina de la sílice. En cambio, el DRX de la sílice coloidal mostrado en la sección 3.4 se identificó a alta temperatura $\left(1450^{\circ} \mathrm{C}\right)$ la presencia de tridimita y cristobalita. Esto se debe a que la presencia de otros compuestos distintos al óxido de silicio favorece la cristalización del mismo bajo la fase cristobalita y no la de tridimita.

\subsection{Consideraciones parciales}

Se obtuvieron materiales cerámicos con distintos valores densidad, en algunos casos cercanos a $2 \mathrm{~g} / \mathrm{cm}^{3}$, y variada resistencia mecánica. Se observó que en general, al incrementar la temperatura de sinterización aumentaba la densidad final del material y la resistencia a la flexión, acompañado de una disminución de la porosidad abierta.

Se analizaron materiales formulados con las dos arcillas caracterizadas en el capítulo 3 (Tincar Super y Blend) dando mejores resultados en cuanto al porcentaje de porosidad los sistemas con arcilla Tincar Super.

También se evaluaron tres agentes formadores de poro -carbón vegetal, carbón residual de petróleo y negro de humo- con el propósito de generar materiales con una matriz porosa y así disminuir la porosidad de los mismos. Tanto el uso de carbón vegetal como el uso de carbón residual de petróleo no evidenciaron diferencias significativas en la mayoría de las propiedades, pero éste último presenta menor porcentaje de porosidad y además considerando la 
aplicación final de este material y por lo tanto su producción en gran escala al ser un producto de la refinación de sería de fácil disponibilidad.

Cuando se utilizó negro de humo como agente formador de poro, el material presentó un gran volumen de mesoporos y una baja resistencia a la flexión en comparación con los cerámicos obtenidos cuando se usaron las otras fuentes de carbón. Esto podría deberse al tamaño de partícula del negro de humo que contribuye a la formación de aglomerados e impide una distribución homogénea del carbón en la mezcla.

Cuando se estudió la liga fosfórica a alta temperatura se vio que a $1000^{\circ} \mathrm{C}$ la presencia del MAP produjo un aumento de la resistencia mecánica del material en comparación con materiales sinterizados a igual temperatura sin ningún precursor de liga cerámica. En cambio a $1400^{\circ} \mathrm{C}$, los materiales que no tienen MAP presentaron los mayores valores de MOR. A las dos temperaturas estudiadas inicialmente $\left(1000^{\circ} \mathrm{C}\right.$ y $\left.1400^{\circ} \mathrm{C}\right)$ la utilización de arcilla activada térmicamente produjo un aumento en la porosidad abierta de los materiales cerámicos.

La porosidad obtenida en los materiales tratados a $1400^{\circ} \mathrm{C}$, comparada con la de los materiales a $1000^{\circ} \mathrm{C}$ disminuye en volumen total de poros, pero aumenta el tamaño promedio de poro y las curvas de distribución de tamaño de poro se estrechan.

En cuanto al estudio de la liga fosfórica a $1400^{\circ} \mathrm{C}$ y $1500^{\circ} \mathrm{C}$ en sistemas con Tincar Super y bauxita se obtuvieron densidades mayores a mayor temperatura de sinterizado por el proceso de sinterizado y el proceso de mullitización de la arcilla y la bauxita. Se observó que el sistema Tincar SuperMAP-bauxita a $1500^{\circ} \mathrm{C}$ presentó la mejor performance de resistencia mecánica junto con bajos valores de densidad y bajo porcentaje de porosidad abierta.

Se observó que la presencia de MAP a cualquier temperatura $\left(1000^{\circ} \mathrm{C}\right.$, $1400^{\circ} \mathrm{C}$ y $1500^{\circ} \mathrm{C}$ ) aumenta el porcentaje de fase amorfa en el sistema. Esto se 
debe a que tanto el $\mathrm{SiO}_{2}$ como el $\mathrm{P}_{2} \mathrm{O}_{5}$ son óxidos formadores de vidrio por lo que la combinación de estos producen una importante formación de fase vítrea.

Se evaluó la utilización de otro agente ligante (sílice coloidal) a dos temperaturas $\left(1450\right.$ y $\left.1500^{\circ} \mathrm{C}\right)$ en un sistema sólo con arcilla Tincar Super y en otro de Tincar Super con bauxita. El sistema Tincar Super-sílice coloidal no presentó variación en los valores de MOR a las dos temperaturas estudiadas; mientras que el sistema Tincar Super-sílice coloidal-bauxita disminuyó el valor de MOR con el aumento de la temperatura de sinterización. Esto último se debe a que al adicionar una fuente de alúmina (bauxita) es necesario sinterizar el material durante mayor tiempo o a una mayor temperatura para permitir la formación de mullita secundaria.

Para ambos sistemas con sílice se observó que la porosidad disminuyó con la temperatura y que a $1500^{\circ} \mathrm{C}$ por el proceso expansivo de generación de mullita secundaria el sistema con bauxita presentó mayor volumen de poros en la distribución de mesoporos por intrusión de mercurio.

Entre las distintas formulaciones estudiadas en este capítulo se decidió optar por la utilización del MAP como precursor de liga nanoestructurada en vez de la sílice coloidal, por haber conducido a mejores valores de resistencia mecánica.

Entre la arcilla Tincar Super y la Blend se decidió elegir la primera por tener mayor disponibilidad en el mercado.

Se decidió desarrollar por un lado agentes de sostén cerámicos de menor resistencia mecánica con Tincar Super y con Tincar Super-MAP y por otro lado agentes de sostén de mayor resistencia mecánica con el sistema Tincar SuperMAP-bauxita, con la arcilla activada térmicamente y sin activar.

Se decidió no utilizar agentes formadores de poro para aumentar la resistencia y disminuir así la densidad debido a que produjo una disminución considerable de la resistencia mecánica de los materiales cerámicos y elevados valores de porosidad abierta. 
Las formulaciones elegidas para el desarrollo de agentes de sostén fueron estudiadas en este capítulo en forma de barras prensadas uniaxialmente, pero se decidió volver a analizar estas formulaciones en desarrollo de los agentes de sostén. Esto se debe a que el procesamiento y conformado del material influye en las propiedades finales del mismo. Además, considerando la forma, tamaño y aplicación de los agentes de sostén no se puede realizar una extrapolación directa entre las propiedades mecánicas y texturales de las barras con las propiedades que tendrán los agentes de sostén. 
Obtención y evaluación de las propiedades de materiales cerámicos obtenidos por prensado 


\section{Capítulo 6}

Desarrollo de agentes de sostén cerámicos de baja densidad 
A partir de las formulaciones estudiadas en el capítulo 5 se decidió desarrollar agentes de sostén bajo dos sistemas Tincar Super-MAP y Tincar Super-bauxita-MAP.

En la literatura (Liu et al., 2016; Wu et al., 2017; Zhao et al., 2015) se hace mención a un proceso de molienda de las materias primas, previo al esferizado del material, pero no se especifica el tamaño final de las partículas. También algunas patentes (Fitzgibbon, J.J and Lafayette, L., n.d.; Khaund, A., 1987) recomiendan un tamaño promedio de partícula de las materias primas menor a $15 \mu \mathrm{m}$, preferentemente menor a $10 \mu \mathrm{m}$ y más preferentemente menor a $5 \mu \mathrm{m}$. En base a esto se decidió primero estudiar el efecto de la molienda de las materias primas minerales en las propiedades de los agentes de sostén.

Luego se analizó cómo influye la activación térmica previa de la arcilla Tincar en los materiales finales y en la siguiente sección se estudian 
las propiedades de los agentes de sostén obtenidos a partir de Tincar Super con y sin el agregado de MAP como agente ligante.

Si bien en estas últimas dos secciones se estudian sistemas ya analizados en el capítulo 5, el proceso de conformado del material influye en las propiedades finales del mismo por lo que no son directamente extrapolables las propiedades que tiene el material conformado por prensado que por esferizado. Así como también por las características geométricas y por la aplicación de los agentes de sostén las propiedades mecánicas y texturales se evalúan con diferentes técnicas.

En la última sección se hace una pequeña comparación entre los agentes de sostén cerámicos de baja densidad desarrollados en este trabajo con algunos agentes de sostén cerámicos de baja densidad disponibles en el mercado y con arenas utilizadas con el mismo fin.

\subsection{Conformado de los agentes de sostén y técnicas utilizadas para su caracterización}

Las materias primas minerales utilizadas para el desarrollo de agentes de sostén en todos los casos estudiados se molieron en molino de bolas de porcelana con un tercio de material sólido, un tercio de un arreglo de bolas de diferentes tamaños y un tercio de agua. Luego de la molienda las suspensiones obtenidas se secaron a $110^{\circ} \mathrm{C}$ en estufa y después, los aglomerados secos se disgregaron con un molino de martillo (Raymond) con salida de polvo.

Para conformar los agentes de sostén se utilizó una mezcladora de alta energía (R20E, Erich Industrial Ltda, Brazil) que se muestra en la Figura 6.1. Los parámetros que se pueden modificar son: el tiempo de procesamiento, la velocidad de la cuba (permite dos velocidades: alta de 88 
rpm y baja de $44 \mathrm{rpm}$ ), la velocidad del agitador (siendo la velocidad máxima 4500 rpm) y la cantidad de agua adicionada.
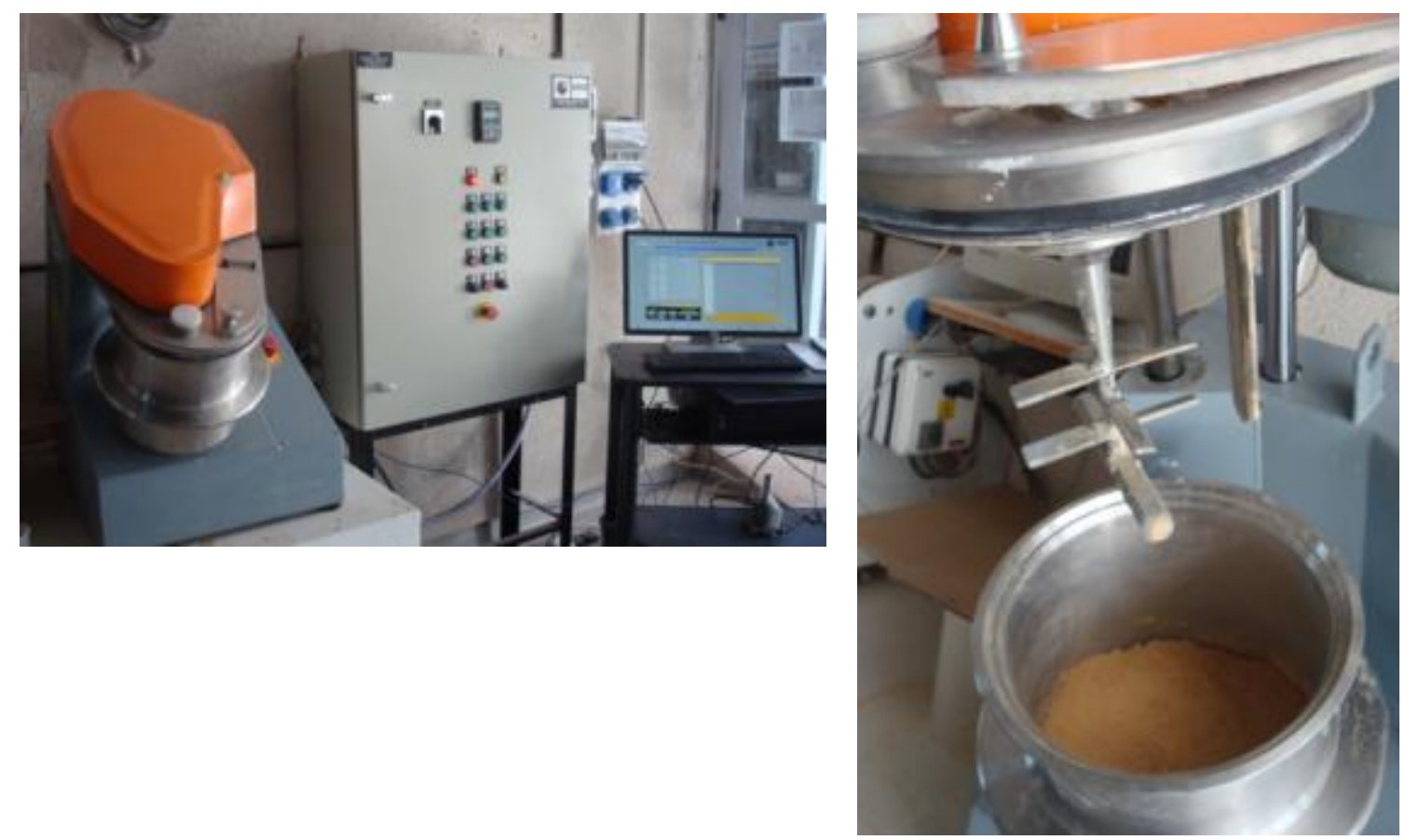

Figura 6.1. Vista y detalle del interior de la mezcladora de alta energía Erich.

A partir de los parámetros mencionados anteriormente se diseñó un programa de procesamiento el material el cual se desarrolló a partir de ensayos empíricos que se realizaron con la mezcladora de alta energía hasta obtener un conformado del material adecuado para su uso como agentes de sostén. El programa desarrollado consta de las siguientes etapas:

1. Se adiciona manualmente el material sólido en la cuba.

2. Se baja la tapa de la cuba.

3. Se mezcla el material sólido durante 20 segundos con una velocidad del agitador del $100 \%$ y velocidad de la cuba alta.

4. Se adiciona el agua y el MAP (en el caso que sea parte de las materias primas) con una velocidad de la cuba baja y una velocidad del agitador de 40\% durante 60 segundos. El porcentaje adicionado de 
agua se varió dependiendo de las características de las materias primas.

5. Agitación de alta energía para rotura de los aglomerados. Se realizó con una velocidad del agitador del 100\% de su capacidad y una velocidad de la cuba alta durante 300 segundos.

6. Se adicionó material seco (10\% del material sólido inicial) para facilitar la siguiente etapa de redondeo. El material se agregó con la velocidad de la cuba baja y una velocidad del agitador del $40 \%$ durante 60 segundos.

7. La última etapa consistió en el redondeo de los materiales, la cual se realizó con una velocidad del agitador del 40\% y una velocidad de la cuba alta durante 200 segundos.

Los agentes de sostén desarrollados en la mezcladora de alta energía se calcinaron en batch a $1450^{\circ} \mathrm{C}$ y $1500^{\circ} \mathrm{C}$ en horno eléctrico con una velocidad de calentamiento de $5^{\circ} \mathrm{C} / \mathrm{min}$ y una hora de permanencia a la temperatura seleccionada. La temperatura de calcinación dependió de las materias primas utilizadas, para los sistemas Tincar Super-bauxita la temperatura fue de $1450^{\circ} \mathrm{C}$ y para los sistemas sólo de Tincar Super la temperatura de calcinado fue de $1500^{\circ} \mathrm{C}$. Esta elección de la temperatura se basa en los valores de CPE determinados en la sección 3.2 y en los resultados del capítulo 5. Luego de calcinados los agentes de sostén se tamizaron entre las mallas $30-50 \quad(595-297 \mu \mathrm{m})$. Las técnicas de caracterización utilizadas para estudiar las materias primas y los agentes de sostén se describen a continuación.

\section{Distribución del tamaño de partícula de las materias primas}

Este método se fundamenta en el principio físico de la dispersión de las ondas electromagnéticas monocromáticas frente a la presencia de 
partículas. Cuando un haz de luz láser incide sobre un conjunto de partículas suspendidas en un medio transparente, el haz es en parte dispersado, en parte absorbido y en parte transmitido. Las partículas dispersan luz en todas las direcciones con un patrón de intensidad que depende de su tamaño y del ángulo de observación. Las partículas grandes dispersan la luz en ángulos pequeños en relación con el rayo láser, y las partículas pequeñas dispersan la luz en ángulos grandes. A partir de la distribución de la intensidad de la luz dispersada es posible calcular la distribución de tamaño de partícula. Como resultado se obtiene un diámetro de partícula correspondiente a la difracción láser de una partícula esférica con un diámetro equivalente a la partícula objeto de estudio

Esta técnica se utilizó para determinar la distribución de tamaño de partículas de las mezclas luego de molidas, procediendo a dispersarlas en suspensiones acuosas diluidas con aplicación de ultrasonido. El equipo utilizado fue un Mastersizer 2000 Malvern Instrument que permite medir tamaños de partícula desde 0,02 hasta $2000 \mu \mathrm{m}$.

\section{Distribución de tamaño de poro por intrusión de mercurio}

Se determinó la distribución de tamaño de los macro y mesoporos abiertos con la técnica de intrusión de mercurio de los agentes de sostén desarrollados. La técnica y el equipo utilizado se describieron en la sección 5.1 .

\section{Difracción de rayos $X$ y cuantificación de las fases}

Con la técnica de difracción de rayos $\mathrm{X}$ se identificaron las fases cristalinas presentes en los materiales cerámicos, el equipo utilizado y las condiciones del ensayo fueron las mismas que las explicadas en la sección 3.1. La cuantificación de las fases cristalinas y no cristalinas se realizó con el método de Rietvield y el método del patrón externo (Anexo I). 


\section{Microscopía electrónica de barrido}

Se obtuvieron imágenes de los agentes de sostén para observar su microestructura con con un equipo JEOL JCM-6000 Neo Scope. Para poder observar los materiales con el microscopio las muestras se pulieron, se revelaron los granos de mullita a través de un etching químico que fue hecho por contacto con ácido fluorhídrico (HF) al 5\% durante cinco minutos (Elssner G et al., 1999) y luego se recubrieron con una capa conductora de oro.

Para evaluar las propiedades de los agentes de sostén existen normas internacionales (API 19C y su equivalente ISO 13503-2), en las cuales se indican las propiedades necesarias para el control de calidad de los materiales para la utilización como agentes de sostén en la fractura hidráulica y cómo medirlas. Las propiedades que se estudiaron en este trabajo fueron: densidad bulk, densidad aparente, esfericidad, redondez, determinación de la solubilidad en ácido y test crush.

\section{Densidad bulk y densidad aparente}

La densidad bulk describe la masa de agentes de sostén que llena una unidad de volumen determinado e incluye tanto los agentes de sostén como los espacios que se generan entre ellos, en la Figura 6.2, se muestra el equipo que se utilizó para medir la densidad bulk.

Para medir la densidad se colocan en el embudo superior del equipo los agentes de sostén y se abre la perilla para que el material caiga en el recipiente que está debajo. Una vez lleno el recipiente, se enraza y se pesa; la densidad bulk en g/cm3 se calcula según la ec. 6.1. El volumen del cilindro es $\mathrm{Vc}$ y mf es la masa de agentes de sostén dentro del recipiente. 


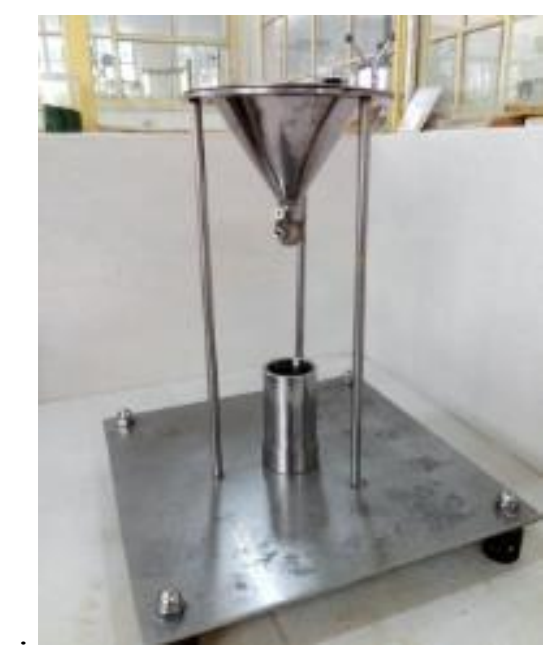

Figura 6.2. Equipo para medir la densidad bulk de los agentes de sostén.

$$
\delta_{b u l k}=\frac{m_{f}}{V_{c}} \quad \text { ec. } 6.1
$$

La densidad aparente se mide por picnometría y evalúa la masa de los agentes de sostén por unidad de volumen incluyendo la porosidad interna de los mismos.

Para medir la densidad se utilizó agua como líquido de inmersión y cómo se explicó en la sección 5.1 la técnica determina la densidad a partir de la relación de la masa de la muestra y el volumen del picnometro (ec. 6.2).

$$
\delta_{a p}=\frac{m_{m} \times \delta_{l}}{\left(m_{p}+m_{m}-m_{m p}\right)} \quad \text { ec. } 6.2
$$

Dónde $\mathrm{m}_{\mathrm{m}}$ es la masa de muestra, $\mathrm{m}_{\mathrm{p}}$ es la masa del picnómetro lleno de agua, $\delta_{1}$ es la densidad del agua y $m_{m p}$ es la masa del picnómetro con la muestra lleno de agua. 
Determinación de la solubilidad en ácido de agentes de sostén

La solubilidad en la solución ácida, es un indicador de la cantidad de materiales solubles (carbonatos, óxidos de hierro, arcillas, etc.) presentes en los agentes de sostén, y permite evaluar la posibilidad de que éstos materiales se utilicen en aplicaciones donde se encuentren en contacto con ácidos.

Para ello se pesan aproximadamente $5 \mathrm{~g}$ de agentes de sostén (secos a $110^{\circ} \mathrm{C}$ hasta peso constante y luego enfriados a temperatura ambiente) y se les adiciona, en un vaso precipitado, $100 \mathrm{ml}$ de una solución de ácido $\mathrm{HCl}$ : HF 12:3 (preparada a partir de ácido clorhídrico $(\mathrm{HCl})$ y bifloruro de amonio $\left(\mathrm{NH}_{4} \mathrm{~F}_{2}\right)$ ). Luego, el vaso se coloca en un baño de agua a $66^{\circ} \mathrm{C}$ durante media hora y transcurrido este tiempo los agentes de sostén se lavan para que no queden rastros de la solución ácida, se secan en estufa a $110^{\circ} \mathrm{C}$ hasta peso constante y se pesan.

El cálculo de la solubilidad en ácido (S) expresada en porciento de masa se muestra en la ec. 6.3.

$$
S=\frac{m_{s}-m_{f}}{m_{s}} \times 100 \% \quad \text { ec. } 6.3
$$

Dónde $\mathrm{m}_{\mathrm{s}}$ es el peso inicial de los agentes de sostén y $\mathrm{m}_{\mathrm{f}}$ es el peso de los agentes de sostén limpios y secos luego de ser sometidos a la solución ácida. Según la norma para agentes de sostén cerámicos el porcentaje de solubilidad en ácido no debe superar el 7\%.

\section{Test crush}

El test crush es una medida de la resistencia mecánica de los agentes de sostén. La celda (Figura 6.4) en la cual se mide esta propiedad y la prensa utilizada están estrictamente descriptas en la norma API 19C. El 
objetivo es determinar la cantidad de agentes de sostén que se rompen, porcentaje de finos, con un tamaño menor a la menor malla de la fracción utilizada (en este caso malla 50) a una determinada presión.

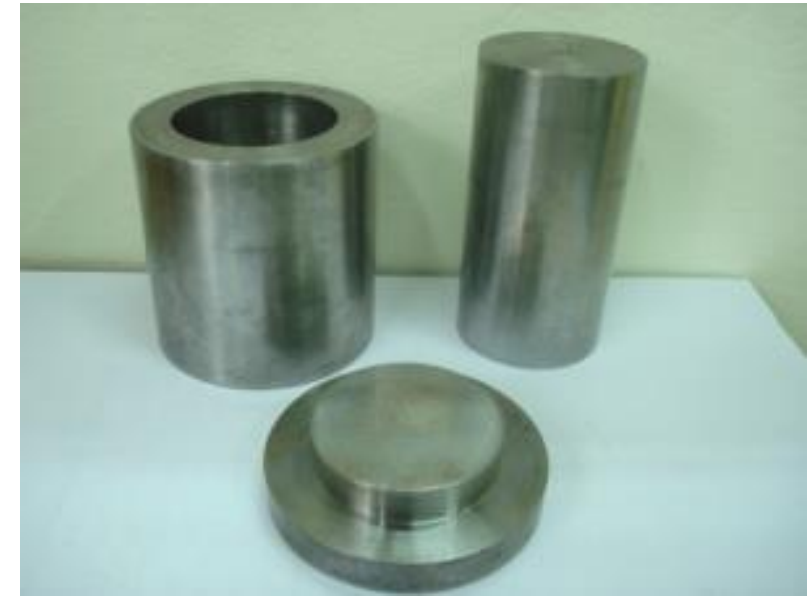

Figura 6.3. Celda utilizada en para el test crush.

El porcentaje de finos se calcula con la ec. 6.2, dónde $\mathrm{W}_{\mathrm{o}}$ es el peso de los agentes de sostén antes del ensayo y $\mathrm{W}_{\mathrm{c}}$ es el peso de los agentes de sostén de tamaño menor a la menor malla de la fracción (malla 50) luego de haber sido sometidos a presión.

$$
\eta=\frac{w_{c}}{w_{o}} \times 100 \% \quad \text { ec. } 6.2
$$

La norma API 19C requiere un valor de $\eta \leq 10 \%$ para que sean utilizados en la fractura hidráulica y se informa la máxima presión a la cual la muestra cumple la norma.

\section{Esfericidad y redondez}

La esfericidad es la medida de cuanto un agente de sostén se acerca a la forma de una esfera y la redondez es una medida relativa de que los 
vértices-aristas bordes de los agentes de sostén sean redondeados y no angulosos. La norma API 19C determina para los agentes de sostén cerámicos que la esfericidad y redondez promedio debe ser cada una igual o mayor a 0,7. Para realizar este ensayo se saca una foto de una muestra de los agentes de sostén con una lupa y se los califica por comparación con la Figura 6.3 con un valor de esfericidad (Y) y otro de redondez (X).

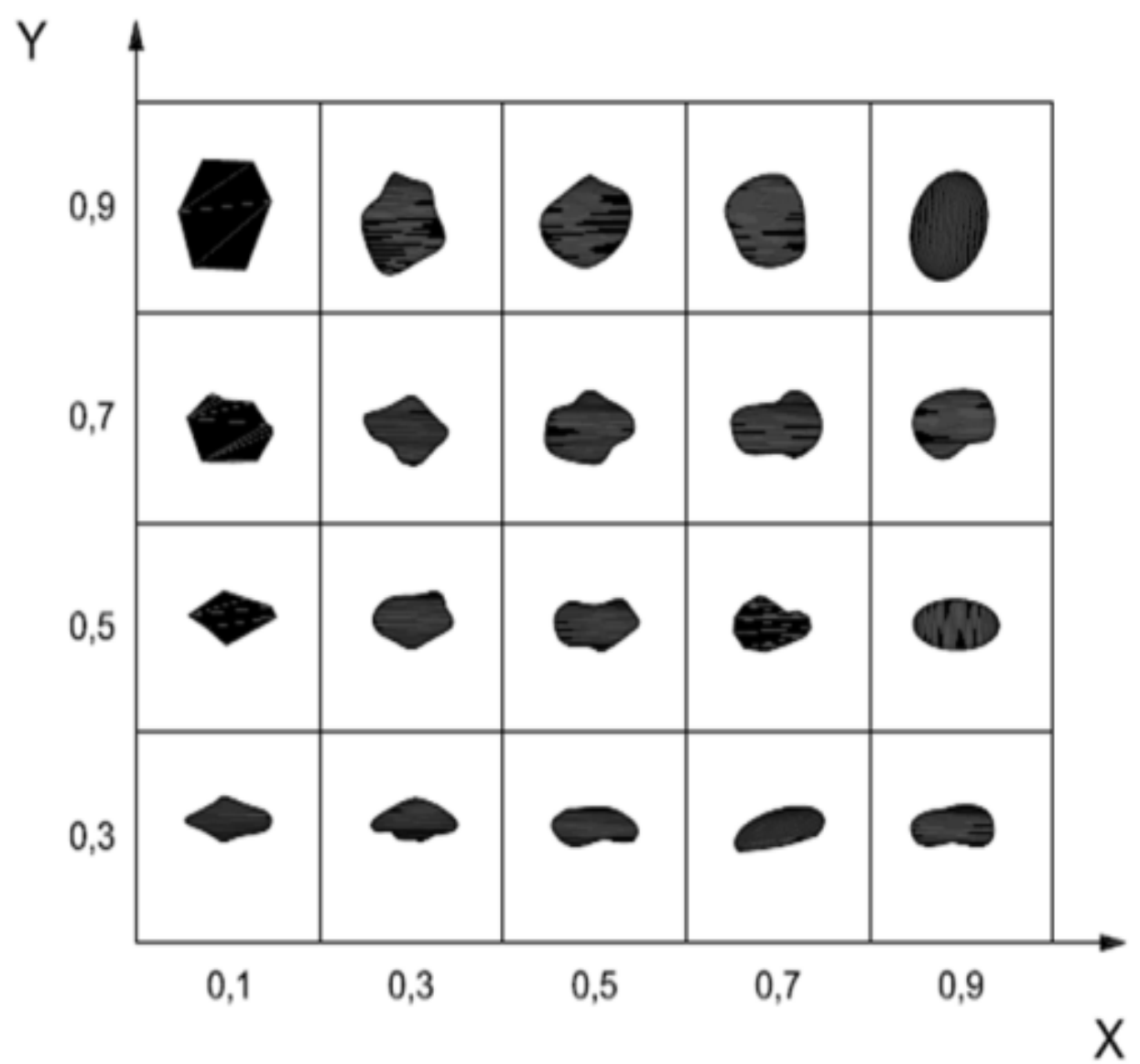

Figura 6.4. Gráfico de redondez (eje X) y esfericidad (eje Y) (Krumbein W. C and Sloss L. L, 1963). 
6.2 Estudio del efecto de la molienda de las materias primas en las propiedades de los agentes de sostén

Para estudiar el efecto de la molienda de las materias primas en las propiedades de los agentes de sostén se utilizó el sistema Tincar Super-10\% bauxita- $10 \%$ MAP.

La arcilla y la bauxita se molieron durante 48 y 72 horas sin adición de dispersante y 48 horas con la adición de dispersante (poliacrilato de sodio). Se denominaron estas moliendas como AG1, AG2 y AG3 respectivamente. El proceso de molienda en húmedo y posterior secado de las suspensiones fue descripto en la sección 6.1.

Los agentes de sostén se conformaron en la esferizadora a partir de las materias primas molidas secas, $10 \%$ de MAP y $12 \%$ de agua utilizando el programa explicado en la sección anterior (sección 6.1).

En la Figura 6.5 se muestra la distribución del tamaño de partícula de las diferentes moliendas y en la Tabla 6.1 se expresan los diámetros máximos de $10 \%, 50 \%$ y $90 \%\left(\mathrm{~d}_{0,1}, \mathrm{~d}_{0,5}\right.$ and $\mathrm{d}_{0,9}$ respectivamente $)$ de cada muestra.

Tabla 6.1. Diámetro máximo $(\mu \mathrm{m})$ de partícula del 10\%, 50\% y 90\%.

\begin{tabular}{c|ccc} 
& AG1 & AG2 & AG3 \\
\hline $\mathbf{d}(\mathbf{0 , 1})$ & 1,44 & 1,44 & 1,31 \\
$\mathbf{d}(\mathbf{0 , 5 )}$ & 4,49 & 4,44 & 3,08 \\
$\mathbf{d}(\mathbf{0 , 9 )}$ & 12,79 & 13,01 & 7,34
\end{tabular}




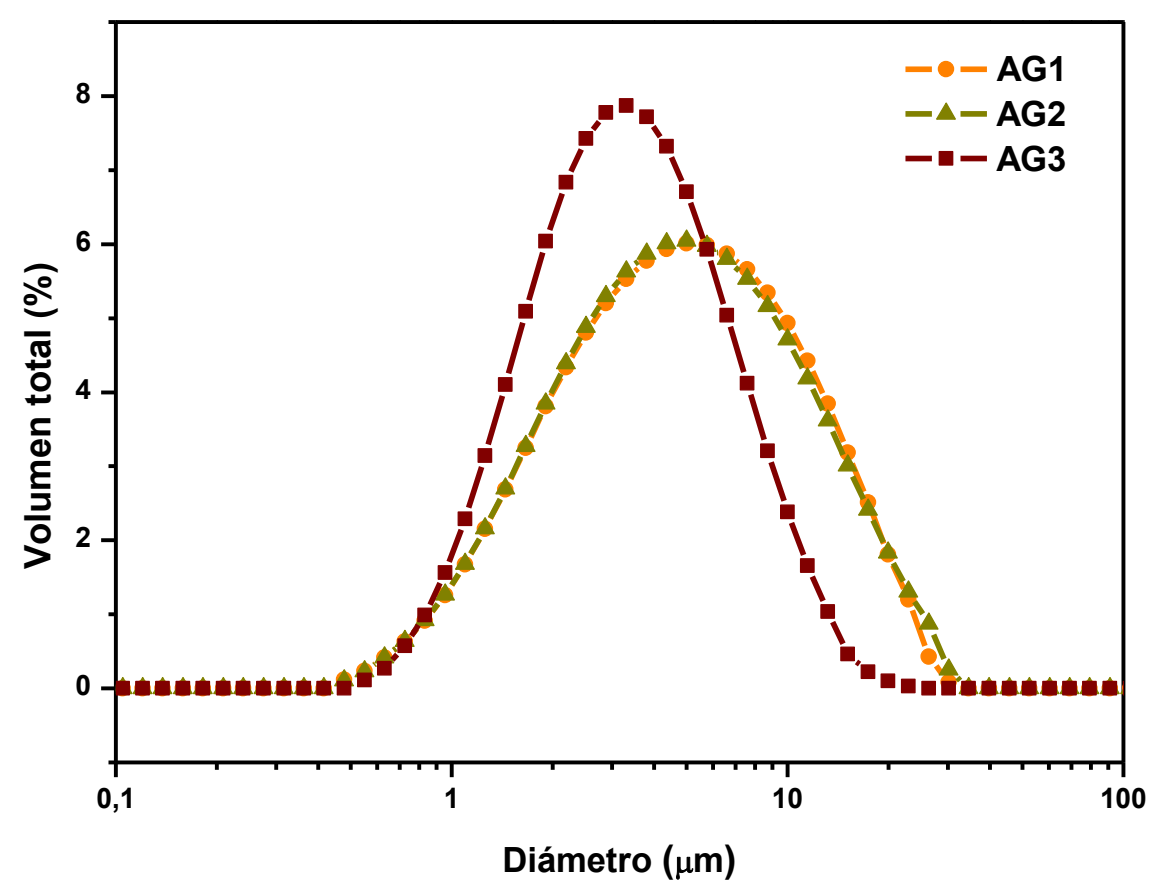

Figura 6.5. Distribución del tamaño de partícula de las materias primas minerales luego de la molienda.

No se observaron cambios significativos entre las moliendas AG1 y AG2 respecto a la distribución del tamaño de partícula. Sin embargo, la molienda AG3 presentó una distribución más estrecha con menor tamaño de partícula y el valor de $\mathrm{d}_{0.9}$ disminuyó notablemente. Estos resultados nos permiten concluir que el tamaño de partícula en la molienda se vio influenciado en mayor proporción debido a la adición de dispersante que al tiempo de molienda; esto puede deberse a que el dispersante colabora con una distribución homogénea de los materiales sólidos y previene la aglomeración.

La distribución de los macroporos y mesoporos de los agentes de sostén AG1, AG2 y AG3 luego de calcinados a $1450^{\circ} \mathrm{C}$ se muestra en la Figura 6.6 y 6.7, respectivamente. Se observó que la molienda de las materias primas afectó la porosidad abierta de los materiales finales 
obteniéndose el menor volumen total de poros con la muestra AG3, es decir los agentes de sostén realizados a partir de las materias primas con menor tamaño de partícula.

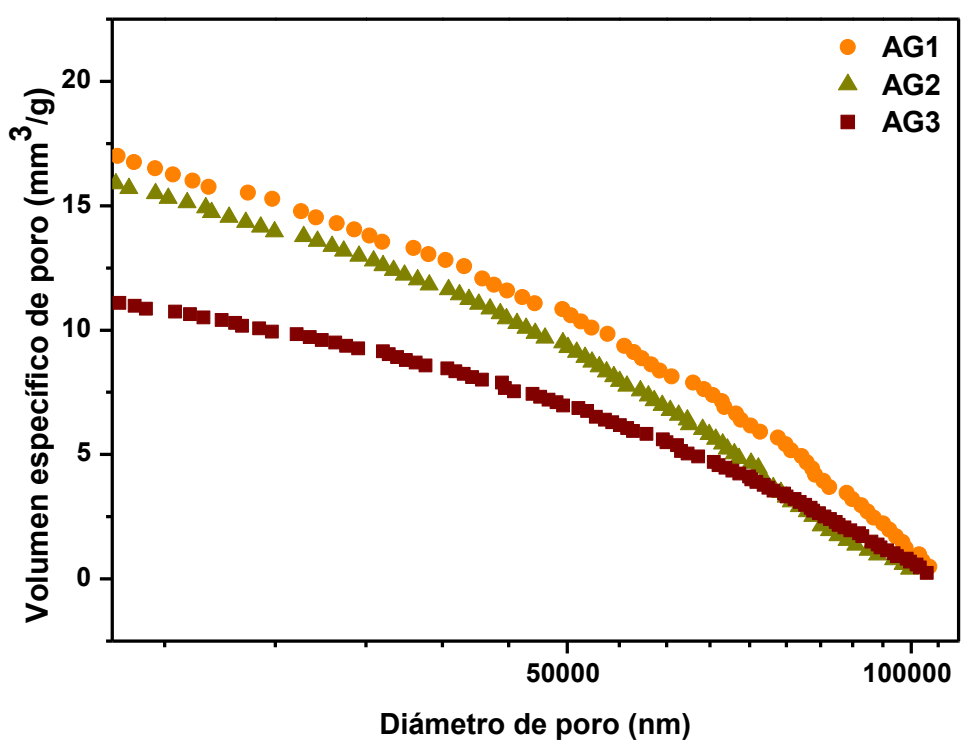

Figura 6.6. Distribución de tamaño de los macroporos de los agentes de sostén AG1, AG2 y AG3.

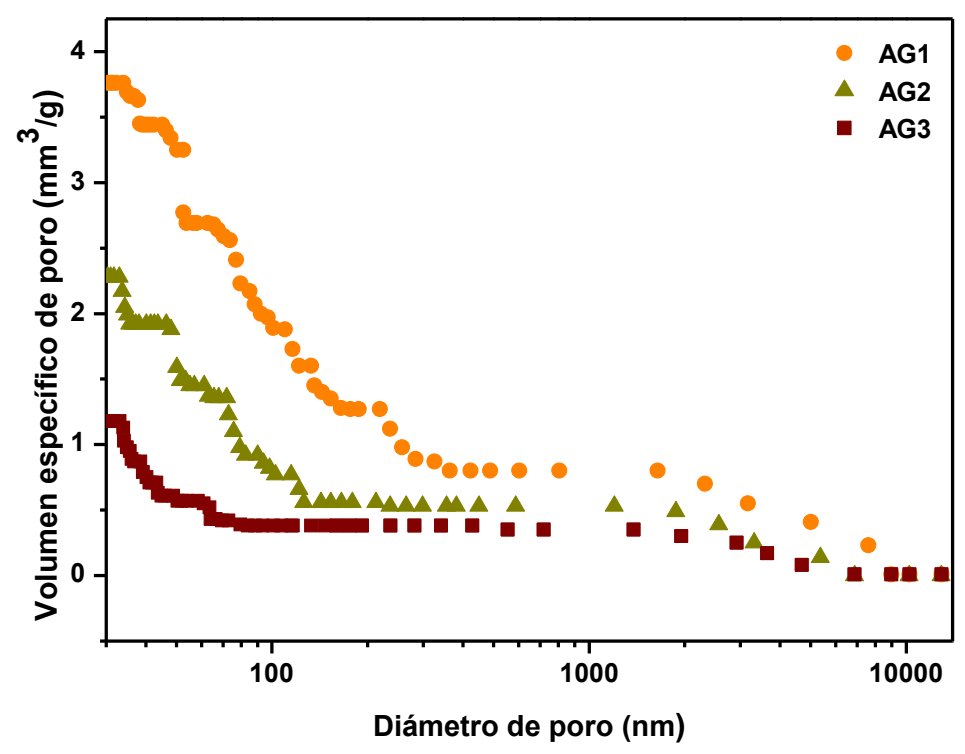

Figura 6.7. Distribución de tamaño de los mesoporos de los agentes de sostén AG1, AG2 y AG3. 
Tabla 6.2. Densidades, solubilidad en ácido y porcentaje de finos del test crush de los agentes de sostén AG1, AG2 y AG3.

\begin{tabular}{c|cccc} 
Muestra & $\begin{array}{c}\text { Densidad } \\
\text { bulk }\left(\mathbf{g} / \mathrm{cm}^{3}\right)\end{array}$ & $\begin{array}{c}\text { Densidad } \\
\text { aparente }\left(\mathrm{g} / \mathrm{cm}^{3}\right)\end{array}$ & $\begin{array}{c}\text { Solubidad en } \\
\text { ácido (\%) }\end{array}$ & $\begin{array}{c}\text { \% de finos (64 } \\
\mathrm{MPa})\end{array}$ \\
\hline AG1 & 1,33 & 2,32 & 7,53 & 12,36 \\
AG2 & 1,34 & 2,35 & 7,01 & 10,73 \\
AG3 & 1,33 & 2,40 & 8,47 & 9,61
\end{tabular}

La Tabla 6.2 muestra los resultados de la caracterización de los agentes de sostén bajo la norma API 19C. El test crush en este caso se evaluó a $64 \mathrm{MPa}$ ( 9000 psi). El porcentaje de finos obtenidos para cada muestra varió según el tamaño de partícula de las materias primas.

La densidad aparente de los agentes de sostén aumentó a medida que disminuyó el tamaño de partícula de las materias primas y la porosidad abierta de los materiales. Los materiales AG3 obtuvieron la mejor performance en el test crush $(9,61 \%)$ manteniendo un valor de densidad bajo $\left(2,40 \mathrm{~g} / \mathrm{cm}^{3}\right)$.

Para las muestras AG1 y AG3 el porcentaje de solubilidad en ácido fue mayor que el valor límite especificado en la norma $(\leq 7 \%)$. En cambio la muestra AG2 presentó este valor límite con lo cual cumple con los requerimientos de la norma API 19C para esta propiedad.

Como se ha mencionado en la introducción los agentes de sostén de baja densidad para su utilización en la fractura hidráulica requieren de baja porosidad abierta para tener una buena conductividad del hidrocarburo en el reservorio; y una alta porosidad cerrada con el objetivo de disminuir la densidad aparente del material sin sacrificar la resistencia mecánica del mismo. Por este motivo entre los tres materiales estudiados en esta sección los AG3 presentaron la mejor performance con un valor adecuado del test crush y valores bajos de volumen total de poros (Figura 6.6 y Figura 6.7). 
En la Tabla 6.3 se muestran los valores de redondez (X) esfericidad (Y) de los agentes de sostén mostrados en la Figura 6.8. Se observó que la esfericidad, redondez y la densidad bulk de los agentes de sostén es independiente del tamaño de partícula de las materias primas utilizadas.

Tabla 6.3. Redondez (X) y esfericidad (Y) de los agentes de sostén AG1, AG2 y AG3.

AG1

AG2

AG3

\begin{tabular}{|c|c|c|c|c|c|c|c|c|}
\hline Número & $\mathbf{X}$ & $\mathrm{Y}$ & Número & $\mathbf{X}$ & $\mathrm{Y}$ & Número & $\mathrm{X}$ & $\mathrm{Y}$ \\
\hline 1 & 0,7 & 0,9 & 1 & 0,7 & 0,9 & 1 & 0,7 & 0,9 \\
\hline 2 & 0,9 & 0,7 & 2 & 0,8 & 0,7 & 2 & 0,8 & 0,7 \\
\hline 3 & 0,5 & 0,9 & 3 & 0,5 & 0,7 & 3 & 0,5 & 0,8 \\
\hline 4 & 0,6 & 0,9 & 4 & 0,4 & 0,9 & 4 & 0,6 & 0,9 \\
\hline 5 & 0,7 & 0,8 & 5 & 0,3 & 0,9 & 5 & 0,8 & 0,9 \\
\hline 6 & 0,5 & 0,8 & 6 & 0,7 & 0,9 & 6 & 0,4 & 0,9 \\
\hline 7 & 0,7 & 0,7 & 7 & 0,6 & 0,7 & 7 & 0,5 & 0,9 \\
\hline 8 & 0,7 & 0,9 & 8 & 0,8 & 0,9 & 8 & 0,7 & 0,9 \\
\hline 9 & 0,5 & 0,7 & 9 & 0,4 & 0,9 & 9 & 0,3 & 0,9 \\
\hline 10 & 0,5 & 0,9 & 10 & 0,3 & 0,9 & 10 & 0,7 & 0,9 \\
\hline 11 & 0,7 & 0,5 & 11 & 0,6 & 0,7 & 11 & 0,7 & 0,9 \\
\hline 12 & 0,7 & 0,9 & 12 & 0,7 & 0,9 & 12 & 0,7 & 0,9 \\
\hline 13 & 0,9 & 0,8 & 13 & 0,7 & 0,9 & 13 & 0,8 & 0,9 \\
\hline 14 & 0,8 & 0,9 & 14 & 0,8 & 0,9 & 14 & 0,4 & 0,9 \\
\hline 15 & 0,9 & 0,8 & 15 & 0,7 & 0,9 & 15 & 0,6 & 0,9 \\
\hline 16 & 0,6 & 0,9 & 16 & 0,6 & 0,9 & 16 & 0,7 & 0,9 \\
\hline 17 & 0,5 & 0,7 & 17 & 0,7 & 0,9 & 17 & 0,6 & 0,7 \\
\hline 18 & 0,6 & 0,9 & 18 & 0,7 & 0,9 & 18 & 0,5 & 0,9 \\
\hline 19 & 0,7 & 0,8 & 19 & 0,8 & 0,9 & 19 & 0,6 & 0,9 \\
\hline 20 & 0,7 & 0,9 & 20 & 0,5 & 0,9 & 20 & 0,7 & 0,9 \\
\hline Promedio & 0,7 & 0,8 & Promedio & 0,6 & 0,9 & Promedio & 0,6 & 0,9 \\
\hline
\end{tabular}



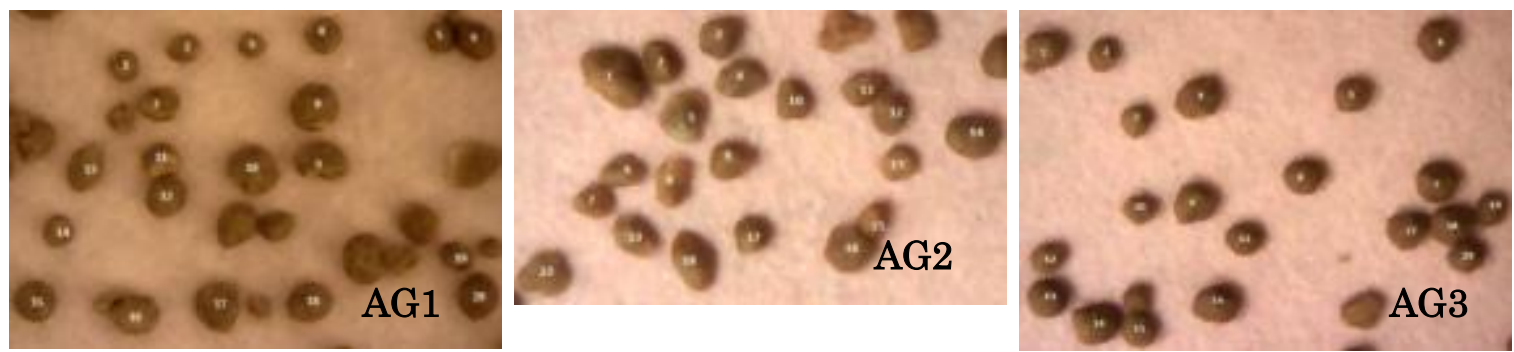

Figura 6.8. Fotografías de los agentes de sostén AG1, AG2 y AG3 para medir redondez y esfericidad.

Los valores de esfericidad fueron acordes con los valores exigidos por la norma pero en el caso de los valores de redondez de los agentes de sostén AG2 y AG3 no llegaron a los exigidos por la norma $(\geq 0,7)$. Estos bajos valores de redondez podrían deberse a que en el proceso de calcinación se utilizó un horno tipo batch pero en la producción industrial de estos materiales se realiza el sinterizado del material en un horno rotatorio, esto permite continuar el proceso de redondeado y esferizado de los agentes de sostén durante el tratamiento térmico.

En la Figura 6.9 se muestran los diagramas de rayos X de los agentes de sostén desarrollados con las distintas moliendas. Las fases cristalinas presentes fueron mullita y cristobalita. A $1450^{\circ} \mathrm{C}$ la cantidad de mullita en el sistema se debe a la transformación térmica de la caolinita (mullita primaria) más la mullita secundaria proveniente de la reacción entre la alúmina de la bauxita con la sílice libre de la arcilla (Chen et al., 2000; Liu et al., 1994). Como se observó en los DRX no existe variación de las fases cristalinas entre los distintos agentes de sostén. 


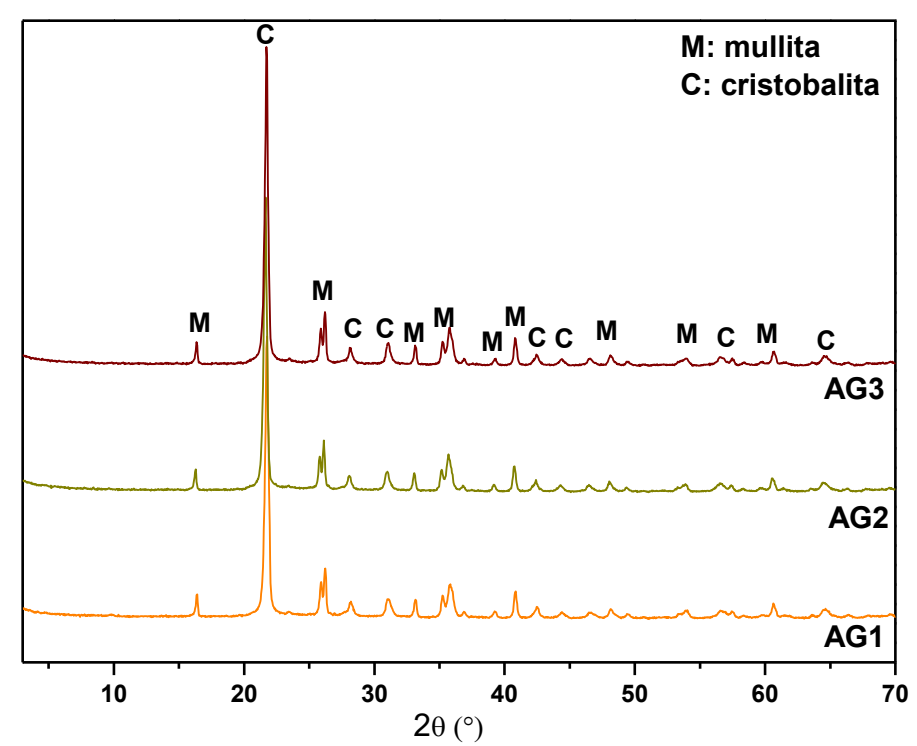

Figura 6.9. Diagrama de rayos $\mathrm{X}$ de los agentes de sostén AG1, AG2 y AG3.

La cuantificación por el método de Rietvield y el método del patrón externo de los agentes de sostén se muestra en la Tabla 6.4. En los tres materiales el porcentaje de fase amorfa no pudo ser determinado debido a que el error del método se encuentra en el rango del 5\% al igual que el porcentaje de fase amorfa por lo que no se puedo cuantificar correctamente.

El porcentaje de mullita obtenido por la cuantificación se lo comparó con el porcentaje de mullita calculado a partir de la cantidad de alúmina agregada al sistema, teniendo en cuenta los análisis químicos de la bauxita y la arcilla Tincar Super presentados en la sección 3.2. Suponiendo que toda la alúmina adicionada contribuyó a la formación de la fase mullita, el porcentaje de esta fase tendría que ser de $38,27 \%$. Entonces, teniendo en cuenta los errores del método de Rietvield los resultados de porcentaje de fase mullita en los agentes de sostén AG1, AG2 y AG3 fueron adecuados para el contenido de alúmina adicionado. 
Tabla 6.4. Porcentaje de cada fase de los agentes AG1, AG2 y AG3 calculadas por el método de Rietvield y el método del patrón externo.

\begin{tabular}{c|ccc} 
Muestra & \% Mullita & \% Cristobalita & \% Fase amorfa \\
\hline AG1 & 41,90 & 58,10 & $<5$ \\
AG2 & 42,03 & 57,97 & $<5$ \\
AG3 & 40,94 & 59,06 & $<5$
\end{tabular}

Las fotografías SEM de las microestructuras de los agentes de sostén desarrollados con las mezclas AG1, AG2 y AG3 se presentan en la Figura 6.10, 6.11 y 6.12 respectivamente. En todos los materiales se observaron las agujas características de la fase mullita con cierta fase líquida (fase amorfa) generada por la alta temperatura de calcinación de los materiales cerámicos (Santana et al., 2017).

La microestructura de los agentes de sostén AG3 mostró mayor cantidad de macroporos que los otros agentes de sostén (Figura 6.12), lo que confirma que estos macroporos observados serían cerrados porque este material presentó la menor porosidad abierta (Figura 6.6 y 6.7).
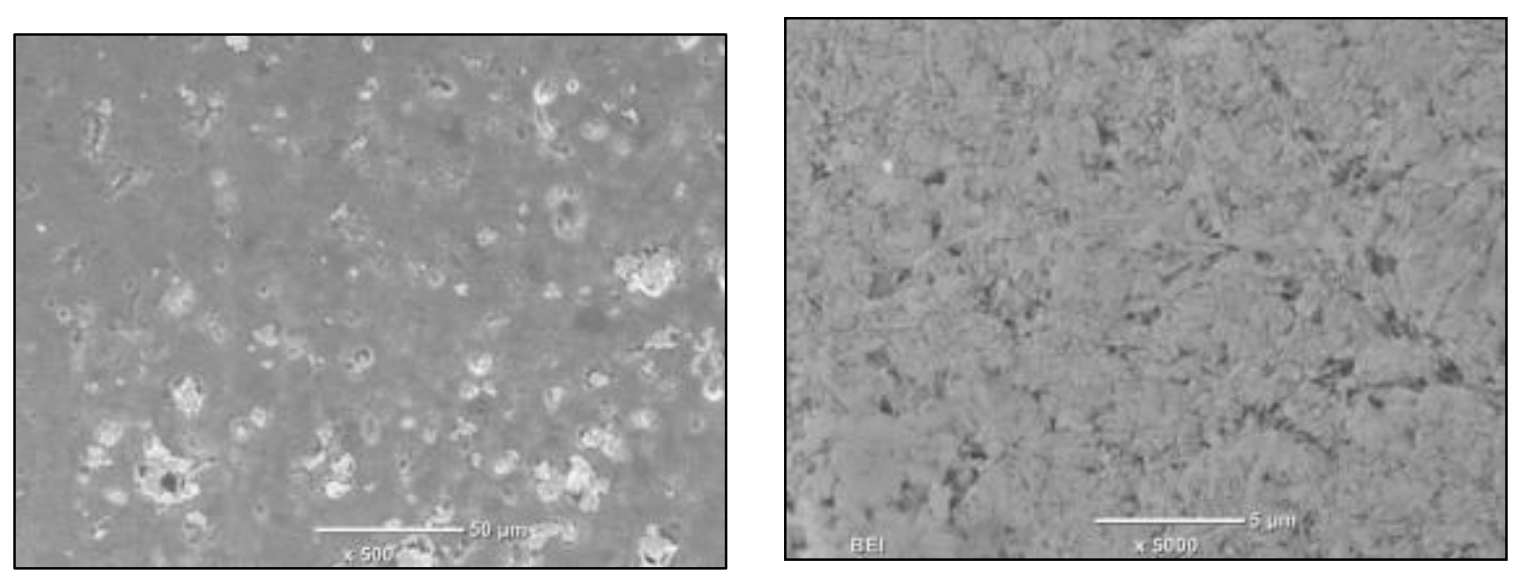

Figura 6.10. Fotografías SEM x500 y x5000 de los agentes de sostén AG1. 

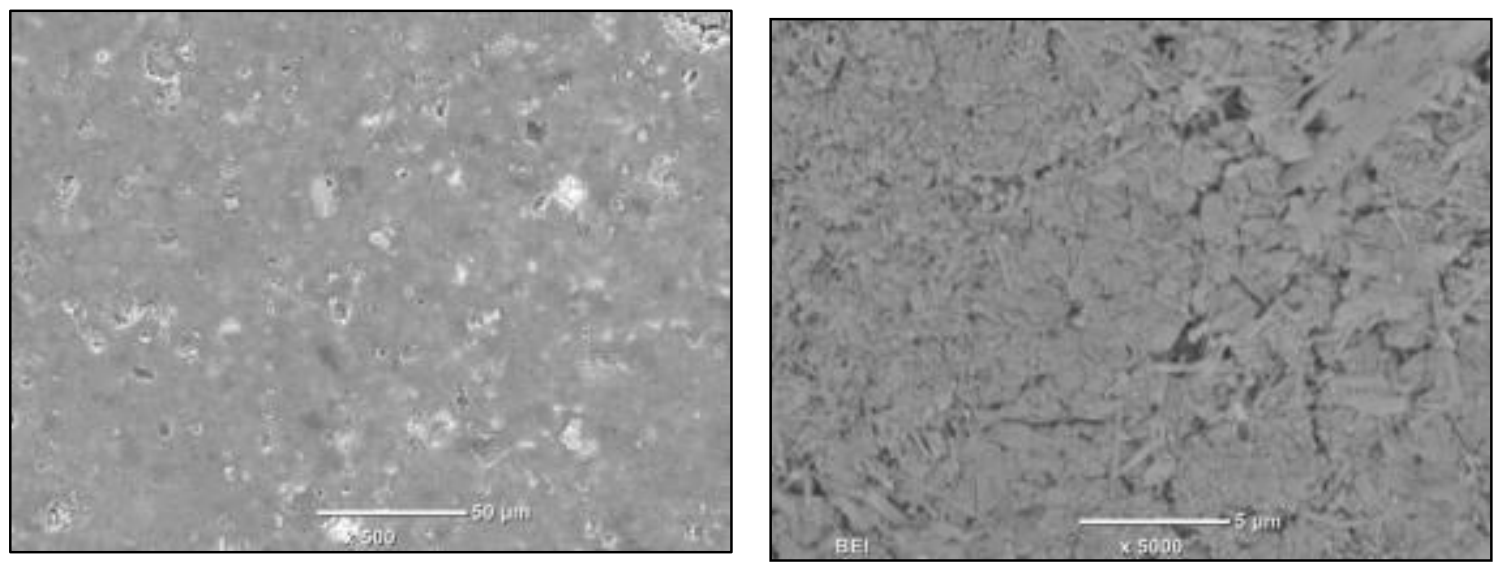

Figura 6.11. Fotografías SEM x500 y x5000 de los agentes de sostén AG2.
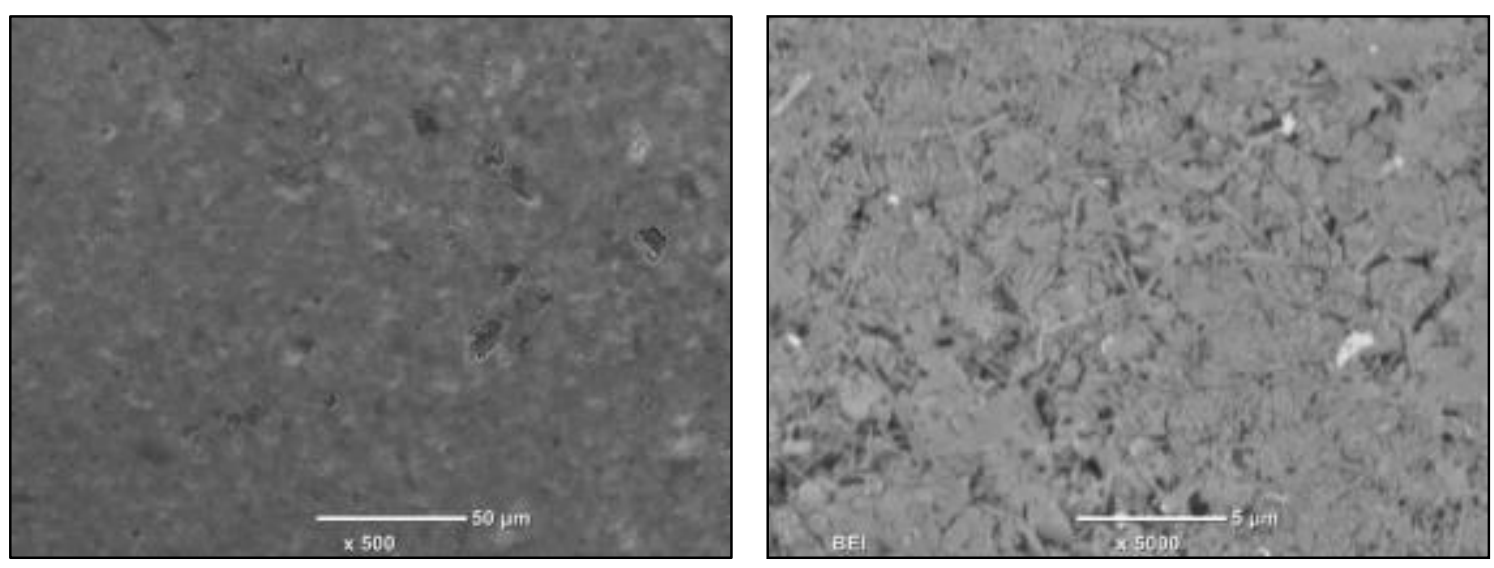

Figura 6.12. Fotografías SEM x500 y x5000 de los agentes de sostén AG3.

\subsection{Agentes de sostén del sistema Tincar Super- MAP- bauxita: estudio del} efecto de utilización de arcilla activada térmicamente

En base a lo estudiado en la sección 5.4.1 en el cual se utilizó la arcilla activada térmicamente y los materiales sinterizados a alta temperatura $\left(1500^{\circ} \mathrm{C}\right)$ presentaron un volumen total de poros abierto bajo con una buena resistencia mecánica se decidió evaluar la utilización de arcilla activada térmicamente en el conformado de agentes de sostén. La arcilla Tincar Super fue activada térmicamente como se hizo en el capítulo 5 (arcilla calcianda a $700^{\circ} \mathrm{C}$ durante una hora en horno eléctrico). 
También se consideraron los resultados obtenidos en la sección anterior (sección 6.2) sobre cómo la molienda de las materias primas incide en las propiedades finales de los agentes de sostén. Por lo que las materias primas sólidas (arcillas y bauxita) se molieron 48 horas en molino de bolas de porcelana con el agregado de poliacrilato de sodio como dispersante. Las mezclas molidas fueron arcilla Tincar Super y $20 \%$ bauxita (AG4) y arcilla Tincar Super activada térmicamente y $20 \%$ de bauxita (AG5).

Se decidió aumentar la cantidad de bauxita en comparación con la sección anterior que se utilizó $10 \%$ para aumentar el porcentaje de la fase mullita en los agentes de sostén para mejorar la resistencia mecánica y así obtener en el test crush menor porcentajes de finos.

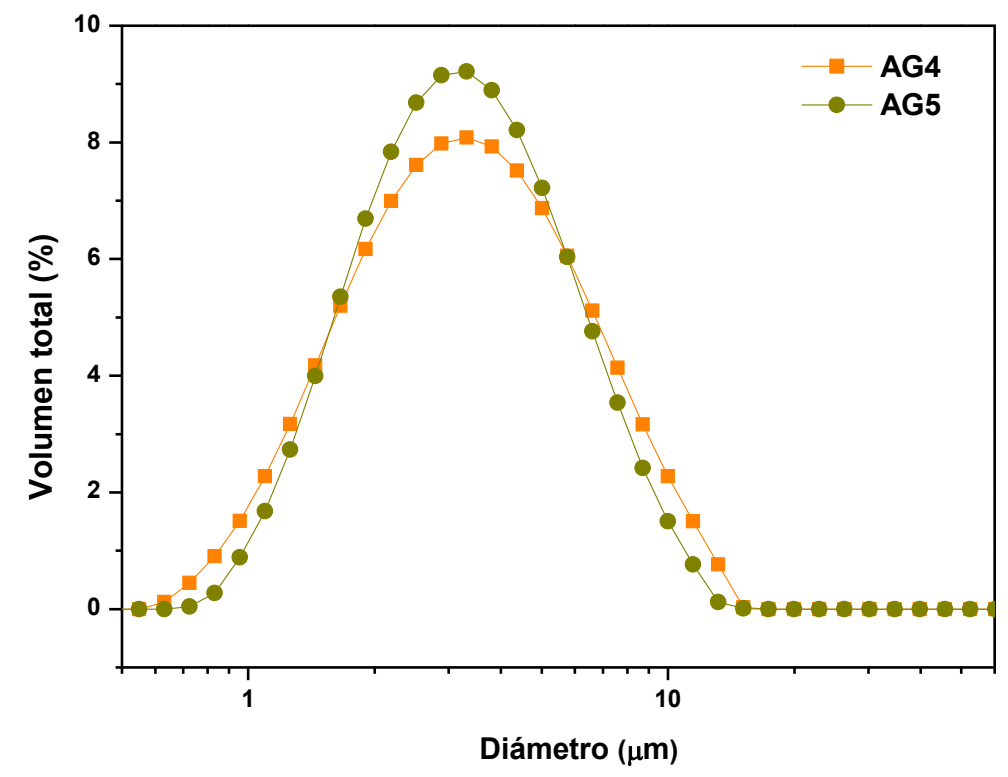

Figura 6.13. Distribución del tamaño de partícula de las materias primas minerales luego de la molienda. 
Tabla 6.5. Diámetro máximo $(\mu \mathrm{m})$ de partícula del 10\%, 50\% y 90\%.

\begin{tabular}{c|cc} 
& AG4 & AG5 \\
\hline $\mathbf{d}(\mathbf{0 , 1})$ & 1,33 & 1,46 \\
$\mathbf{d}(\mathbf{0 , 5 )}$ & 3,06 & 3,00 \\
$\mathbf{d}(\mathbf{0 , 9 )}$ & 7,01 & 6,27
\end{tabular}

En la Figura 6.13 se muestra la distribución de tamaño de partícula de las mezclas AG4 y AG5, y en la Tabla 6.5 se muestran los valores de $\mathrm{d}_{0,1}$, $\mathrm{d}_{0,5}$ y $\mathrm{d}_{0,9}$. Se observó que para ambas mezclas los valores de $\mathrm{d}_{50}$ son muy parecidos pero se diferenciaron en los valores sobre todo de $d_{90}$, presentando mayor tamaño de partícula para la mezcla AG4. Esto también se evidenció en la forma de las curvas de distribución de tamaño de partícula en la que se ve que la mezcla AG5 presentó una campana más angosta que la mezcla AG4.

Se desarrollaron los agentes de sostén de las mezclas AG4 y AG5 según el programa descripto en la sección 6.1, con 10\% de MAP (porcentaje en base de la cantidad de arcilla) y $12 \%$ de agua para la mezcla AG4 y 13,5\% de agua para la mezcla AG5. Como las materias primas de la mezcla AG5 presentaron poca plasticidad (áridas) para el conformado de los agentes de sostén al agua se le adicionó vinagre de alcohol comercial (ácido acético en una solución al 5\%) con el objetivo de mejorar la plasticidad de la pasta.

Luego los agentes de sostén se calcinaron a $1450^{\circ} \mathrm{C}$ y se caracterizaron con las normas API 19C; en la Tabla 6.6 se muestran los resultados de la densidad bulk, densidad aparente, el porcentaje de solubilidad en ácido y el porcentaje de finos que se obtuvieron en el test crush que se realizó a $64 \mathrm{MPa}$ ( 9000 psi). Se observa que la densidad tanto aparente como bulk fue menor para la muestra AG4 pero estos agentes de sostén presentaron un porcentaje de finos en el test crush de 11,30\%, el cual no cumple con el valor 
límite establecido por norma. En cambio, para los agentes de sostén AG5 el porcentaje de finos generados $(6,22 \%)$ fue menor que el porcentaje de finos máximo permitido en la norma.

Tabla 6.6. Densidades, solubilidad en ácido y porcentaje de finos del test crush de los agentes de sostén AG4 y AG5.

\begin{tabular}{c|cccc} 
Muestra & $\begin{array}{c}\text { Densidad } \\
\text { bulk }\left(\mathrm{g} / \mathrm{cm}^{3}\right)\end{array}$ & $\begin{array}{c}\text { Densidad } \\
\text { aparente }\left(\mathrm{g} / \mathrm{cm}^{3}\right)\end{array}$ & $\begin{array}{c}\text { Solubilidad en } \\
\text { ácido (\%) }\end{array}$ & $\begin{array}{c}\text { \% de finos } \\
(\mathbf{6 4} \mathbf{~ M P a})\end{array}$ \\
\hline AG4 & 1,34 & 2,13 & 8,42 & 11,30 \\
AG5 & 1,40 & 2,50 & 7,83 & 6,22
\end{tabular}

La solubilidad en ácido para las dos muestras AG4 y AG5, dio porcentajes de $8,42 \%$ y 7,83\% respectivamente. Estos valores superan al valor límite definido por la norma $(<7 \%)$, esto se debe a la falta de sinterización de los materiales lo que produce que queden poros abiertos que permiten que exista una alta superficie expuesta a la solución. Por este motivo, presentó menor porcentaje de solubilidad en ácido la muestra AG5, la cual tuvo menor porosidad abierta medida por intrusión con mercurio (Figuras 6.14 y 6.15).

En la Figura 6.14 se muestra la distribución de tamaño de los macroporos y en la Figura 6.15 la distribución de los mesoporos para ambos materiales. El volumen total de macroporos de los agentes de sostén AG4 es considerablemente mayor que el volumen total de los macroporos de los agentes de sostén AG5. El primero presentó un volumen total de macroporos de $120 \mathrm{~mm}^{3 / g}$ versus $30 \mathrm{~mm}^{3} / \mathrm{g}$ para la muestra AG5.

En el caso de la distribución de los mesoporos se observó que los agentes de sostén AG5 casi no presentaron poros en este rango de tamaño y el volumen total fue menor a $0,5 \mathrm{~mm}^{3} / \mathrm{g}$. 
Estas diferencias entre las distribuciones de poro para ambos materiales se puede correlacionar con la diferencia en el porcentaje de finos. Cuanto menor cantidad de poros tiene el material más compacto es el agente de sostén por lo cual mayor es su resistencia mecánica (menor porcentaje de finos en el test crush).

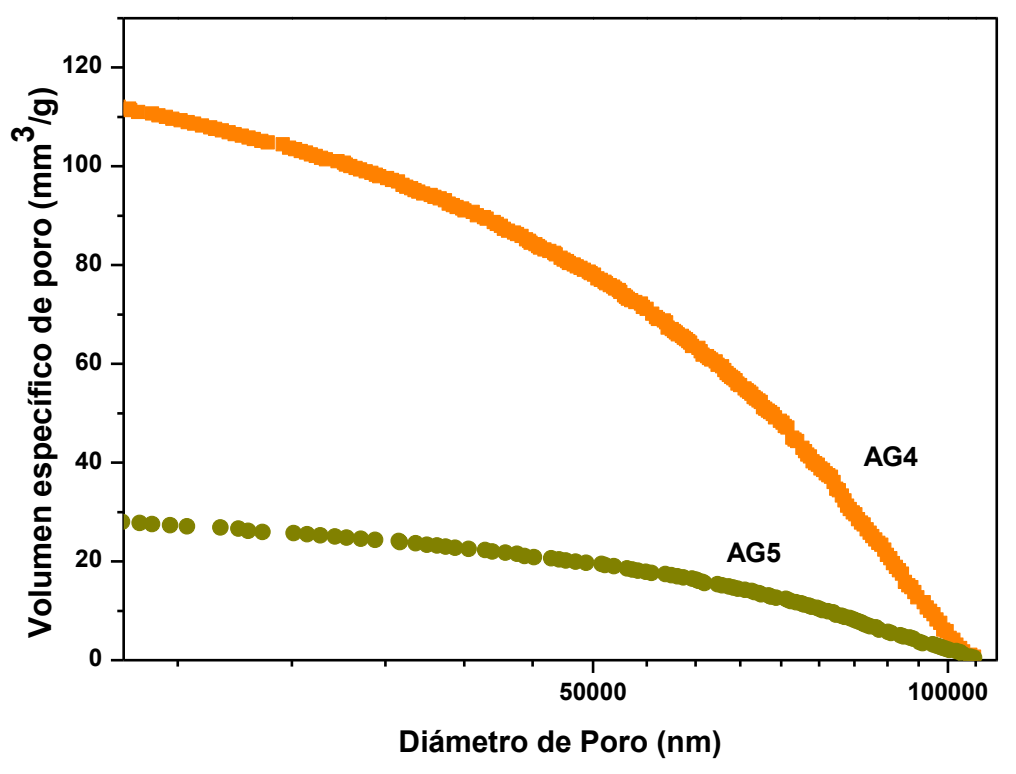

Figura 6.14. Distribución de tamaño de los macroporos de los agentes de sostén AG5 y AG4. 


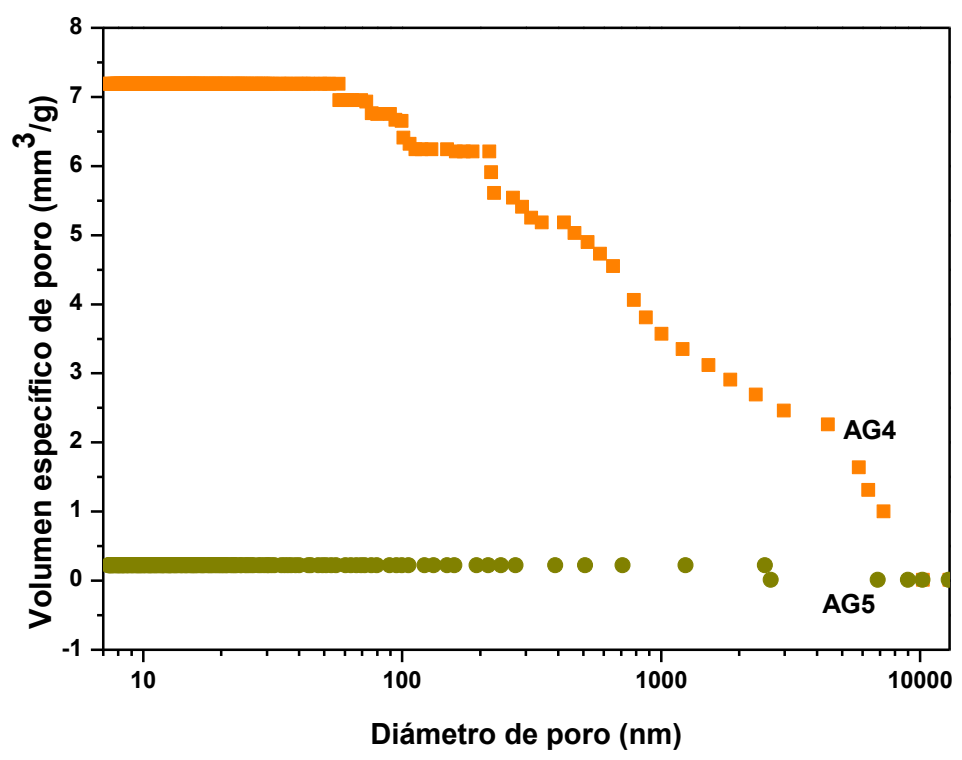

Figura 6.15. Distribución de tamaño de los mesoporos de los agentes de sostén AG5 y AG4.

Se midió la esfericidad y redondez de las muestras (Tabla 6.7 y Figuras 6.16). En cuanto a la esfericidad no presentaron diferencias significativas los materiales AG4 y los AG5, en cambio los AG4 presentaron menor redondez que los AG5. Esto se relaciona con la compactación de los materiales AG5 mencionada anteriormente provocado por el agregado de vinagre de alcohol en la pasta que le brindó mayor plasticidad a la mezcla.
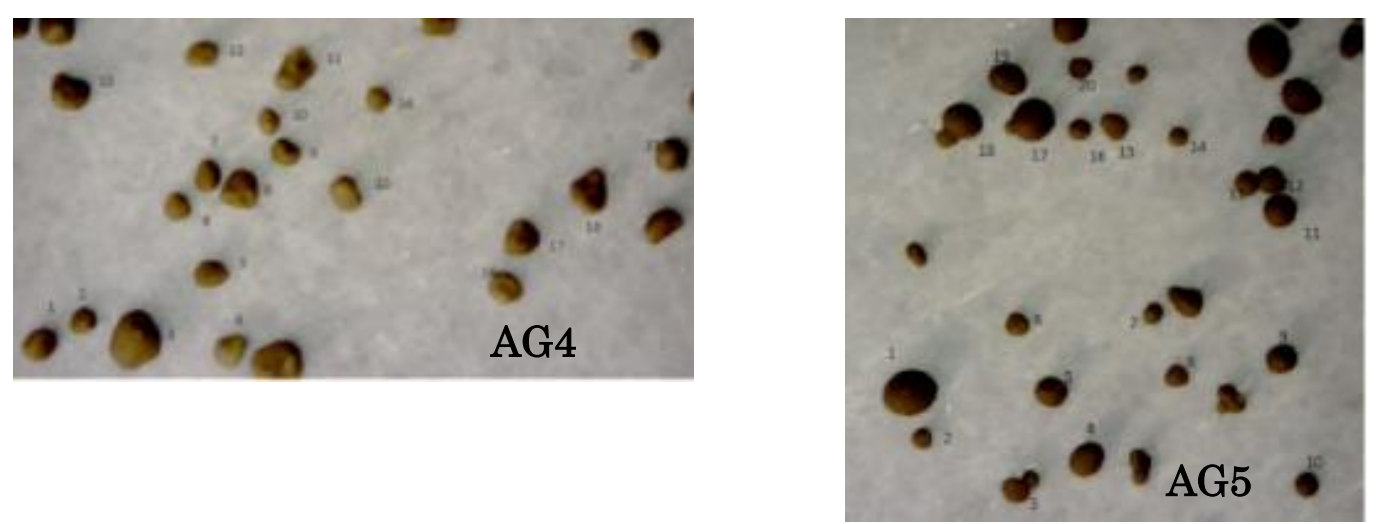

Figura 6.16. Fotografías de los agentes de sostén AG4 y AG5 para medir esfericidad y redondez. 
Tabla 6.7. Medidas de redondez (X) y esfericidad (Y) de los agentes de sostén AG4 y AG5.

\begin{tabular}{|c|c|c|}
\hline \multicolumn{3}{|c|}{ AG4 } \\
\hline Número & $\mathrm{X}$ & $\mathrm{Y}$ \\
\hline 1 & 0,8 & 0,9 \\
\hline 2 & 0,7 & 0,9 \\
\hline 3 & 0,6 & 0,9 \\
\hline 4 & 0,5 & 0,9 \\
\hline 5 & 0,4 & 0,7 \\
\hline 6 & 0,6 & 0,8 \\
\hline 7 & 0,7 & 0,9 \\
\hline 8 & 0,6 & 0,9 \\
\hline 9 & 0,5 & 0,9 \\
\hline 10 & 0,8 & 0,9 \\
\hline 11 & 0,3 & 0,7 \\
\hline 12 & 0,5 & 0,9 \\
\hline 13 & 0,5 & 0,9 \\
\hline 14 & 0,8 & 0,9 \\
\hline 15 & 0,6 & 0,9 \\
\hline 16 & 0,5 & 0,9 \\
\hline 17 & 0,7 & 0,9 \\
\hline 18 & 0,7 & 0,5 \\
\hline 19 & 0,8 & 0,9 \\
\hline 20 & 0,8 & 0,9 \\
\hline Promedio & 0,6 & 0,8 \\
\hline
\end{tabular}

\begin{tabular}{c|cc}
\multicolumn{3}{|c}{ AG5 } \\
Número & X & Y \\
\hline 1 & 0,9 & 0,5 \\
2 & 0,7 & 0,9 \\
3 & 0,5 & 0,9 \\
4 & 0,7 & 0,9 \\
5 & 0,7 & 0,9 \\
6 & 0,7 & 0,9 \\
7 & 0,5 & 0,9 \\
8 & 0,5 & 0,9 \\
9 & 0,7 & 0,9 \\
10 & 0,9 & 0,7 \\
11 & 0,9 & 0,9 \\
12 & 0,9 & 0,8 \\
13 & 0,8 & 0,9 \\
14 & 0,7 & 0,9 \\
15 & 0,5 & 0,8 \\
16 & 0,9 & 0,8 \\
17 & 0,7 & 0,9 \\
18 & 0,8 & 0,9 \\
19 & 0,8 & 0,7 \\
20 & 0,8 & 0,7 \\
\hline Promedio & 0,7 & 0,8 \\
& &
\end{tabular}

Los valores obtenidos de redondez y de esfericidad de los agentes de sostén AG5 fueron 0,7 y 0,8 respectivamente, por lo que estos materiales presentaron valores de acuerdo a lo establecido en norma.

En la Figura 6.17 se muestran los diagramas de rayos $\mathrm{X}$ de las muestras AG4 y AG5. En ambas muestras se observó la presencia de la fase 
mullita y cristobalita, en el caso de la muestra AG5 el pico característico de la mullita $(2 \theta=26,27)$ y el pico característico de la cristobalita $(2 \theta=21,762)$ presentaron mayor intensidad que en la muestra AG4. Esto refleja que los materiales AG5 tienen mayor cristalinidad que los materiales AG4.

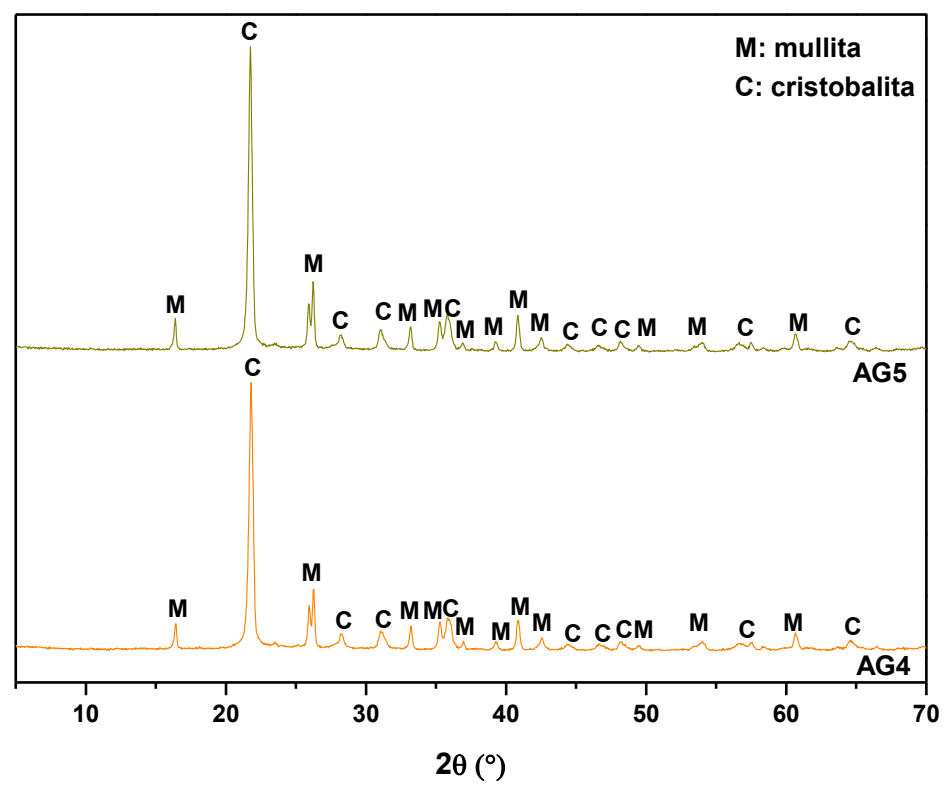

Figura 6.17. Diagrama de rayos X de los agentes de sostén AG5 y AG4.

En la Tabla 6.8 se presentan los valores de la cuantificación de las fases por el método de Rietvield y el método del patrón externo. Como se había observado en los DRX, el porcentaje de fase amorfa en la muestra AG4 $(13,38 \%)$ fue mayor que en la muestra AG5 (7,08\%).

El porcentaje de mullita esperado teniendo en cuenta la cantidad de alúmina presente en el sistema proveniente de la arcilla y de la bauxita (datos sacados de los análisis químicos de la bauxita y la arcilla Tabla 3.2), y que toda la alúmina presente contribuyó a la formación de la fase mullita es de $41,13 \%$. Esto corrobora los valores de esta fase cristalina obtenidos por cuantificación, siendo el caso de los agentes AG5 un valor muy parecido $(41,08 \%)$. 
Tabla 6.8. Porcentaje de cada fase de los agentes AG4 y AG5 calculadas por el método de Rietvield y el método del patrón externo.

\begin{tabular}{c|ccc} 
Muestra & \% mullita & \% cristobalita & \% fase amorfa \\
\hline AG4 & 37,78 & 48,84 & 13,38 \\
AG5 & 41,08 & 51,24 & 7,68
\end{tabular}

En las Figuras 6.18 y 6.19 se muestran las fotografías SEM de los agentes de sostén AG4 y AG5 respectivamente. Ambas muestras presentaron una distribución homogénea de poros de diversos tamaños, observándose en la muestra AG5 mayor cantidad de poros de menor tamaño corroborando lo determinado en la distribución de tamaño de poros por intrusión de mercurio (Figuras 6.14 y 6.15). A mayor magnificación se identificó, en ambos materiales, la presencia de las agujas de mullita embebidas en una matriz amorfa.
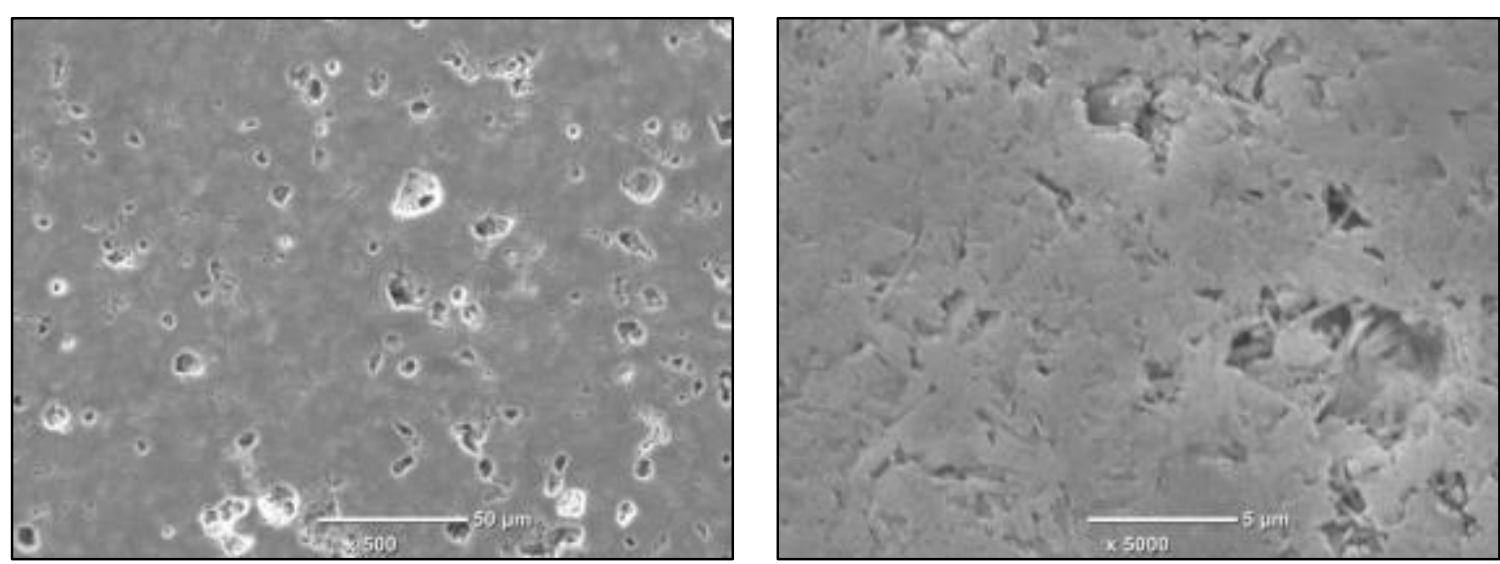

Figura 6.18. Fotografías SEM x500 y x5000 de los agentes de sostén AG4. 

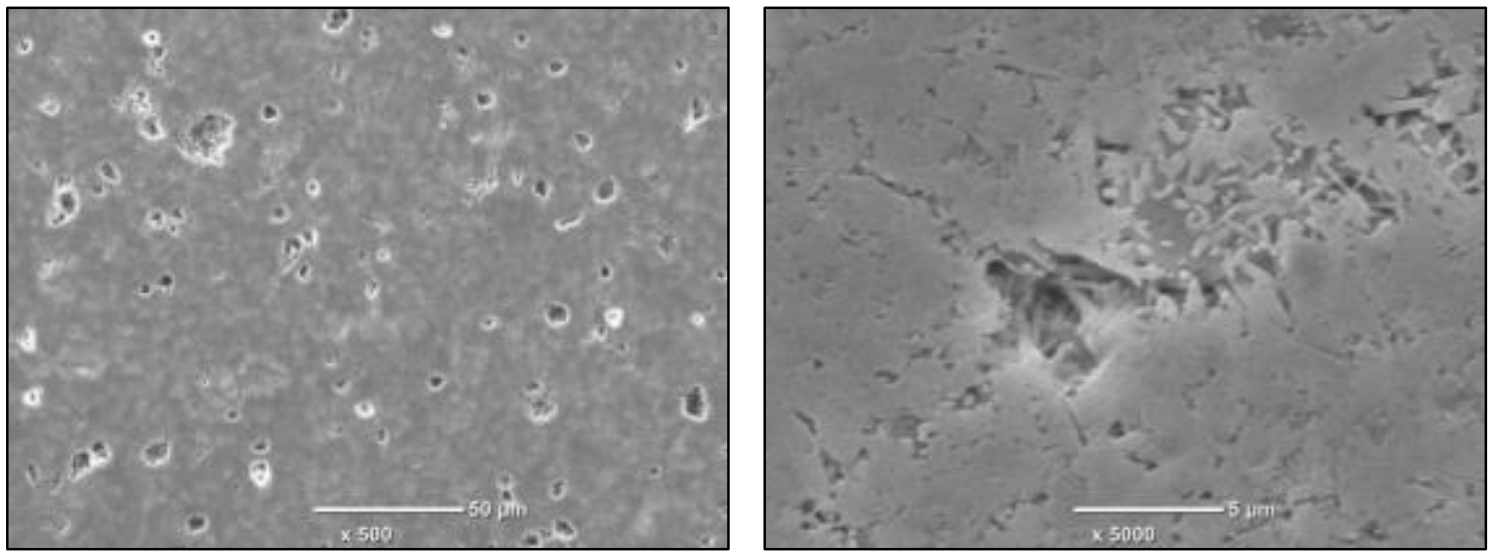

Figura 6.19. Fotografías SEM x500 y x5000 de los agentes de sostén AG5.

Para analizar la influencia del agregado de vinagre de alcohol en la conformación de los agentes de sostén se midió el potencial zeta de las materias primas sólidas. Las medidas se llevaron a cabo utilizando un equipo Brookhaven 90Plus/Bi-MAS con la función movilidad electroforética, que convierte directamente los valores de movilidad electroforética en valores de potencial zeta empleando la ecuación de HelmholtzSmoluchowski. Para lo cual $40 \mathrm{mg}$ de muestra (Tincar Super activada térmicamente-bauxita) se dispersaron en $40 \mathrm{~mL}$ de agua; la suspensión se agitó magnéticamente y el pH de la suspensión se ajustó agregando gotas de $\mathrm{HCl}$ o $\mathrm{KOH}$ de diferentes concentraciones hasta alcanzar el equilibrio (10 $\min )$.

En la Figura 6.20 se muestra el potencial zeta de la muestra arcilla Tincar Super activada térmicamente-bauxita molida en función del pH. Se observó que el punto isoeléctrico de la mezcla se encuentra a un pH de 3,5 aproximadamente; entonces al adicionar vinagre de alcohol (ácido acético al $5 \%$ ), que tiene un $\mathrm{pH}$ de 2,79, durante el esferizado de los agentes de sostén la mezcla Tincar Super activada térmicamente-bauxita se desplaza a valores bajos de $\mathrm{pH}$. Este desplazamiento a valores más bajos de $\mathrm{pH}$ hace que el sistema se aproxime a su punto isoeléctrico, con lo cual las partículas 
tienden a disminuir su carga superficial (menor repulsión entre las partículas) por lo que mejora el conformado del agente de sostén.

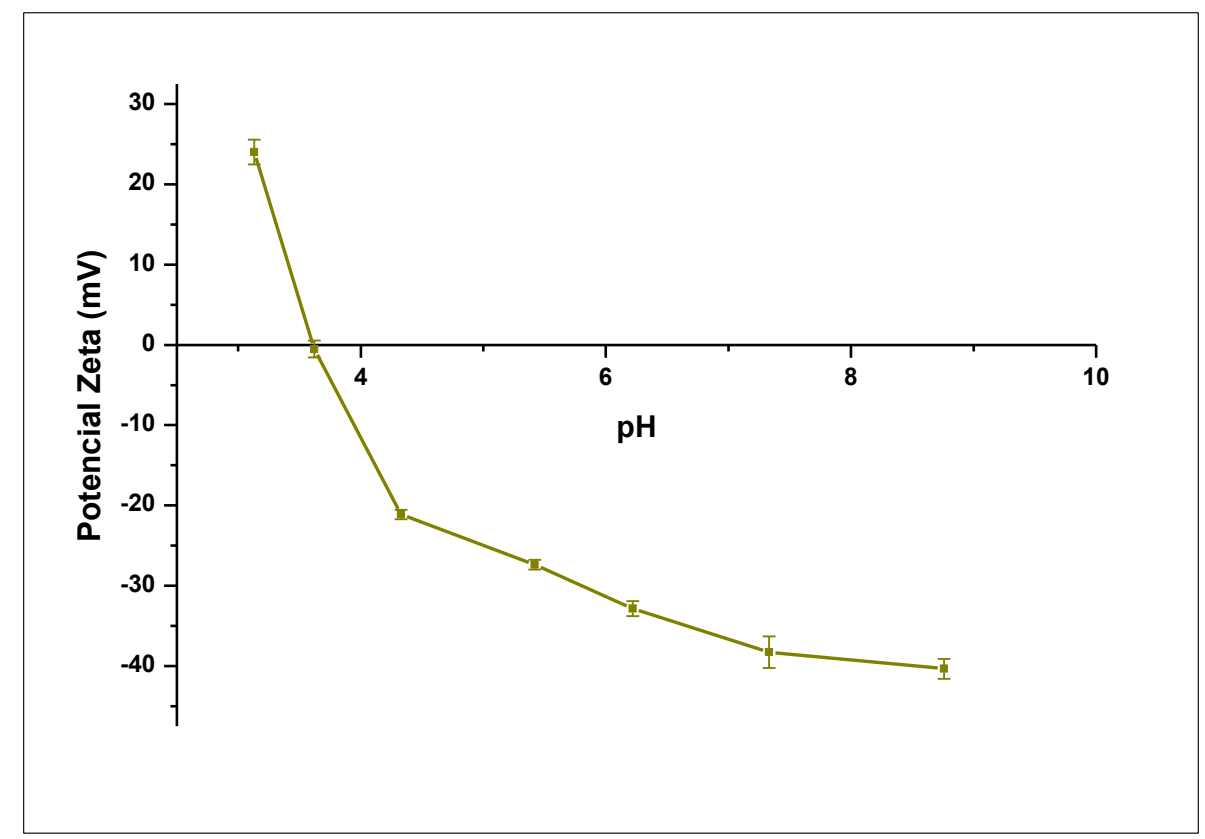

Figura 6.20. Potencial Zeta de las materias primas minerales de los AG5 en función del $\mathrm{pH}$.

\subsection{Agentes de sostén de Tincar Super con y sin MAP}

En esta sección se analizó cómo influye la adicción del MAP (precursor de liga fosfórica) en las propiedades de los agentes de sostén. Para ello se desarrollaron agentes de sostén de sostén con Tincar Super (AG6) y con arcilla Tincar Super-MAP (AG7). La cantidad de MAP adicionada fue del 10\% en base al peso de la arcilla. LaTincar Super se molió previamente durante 48 horas en molino con bolas de porcelana con la adicción de poliacrilato de sodio como dispersante.

Los agentes de sostén en ambos casos se realizaron a partir del programa detallado en la sección 6.1 agregando para el conformado $20 \%$ de 
agua para la mezcla AG6 y $12 \%$ de agua para la mezcla AG7. Esta diferencia en el porcentaje de agua radica a que el MAP es una solución al $40 \%$ por lo que ahí ya se adiciona agua al sistema para conformar los agentes de sostén. Una vez conformados las muestras se calcinaron a $1500^{\circ} \mathrm{C}$ durante una hora. La diferencia de temperatura de calcinación con los materiales desarrollados en las secciones anteriores se relaciona con los valores de CPE de la Tabla 3.3 (sección 3.2) en dónde la arcilla Tincar Super presentó mayor temperatura de ablandamiento que la mezcla Tincar Superbauxita debido a las impurezas presentes en la bauxita.

En este caso no se adicionó una fuente extra de alúmina (bauxita) por lo que el porcentaje de mullita final en los materiales será menor, entonces la resistencia mecánica de los materiales también lo será. En base a esto se decidió realizar el test crush a una presión de 34,5 MPa (5000 psi).

En la Figura 6.21 se muestra la distribución del tamaño de partícula de la arcilla Tincar Super molida durante 48 horas, los valores de los diámetros máximos del 10\%, 50\% y 90\% $\left(\mathrm{d}_{0,1}, \mathrm{~d}_{0,5} \mathrm{y}\right.$ d0,9 respectivamente $)$ de las partículas se muestran en la Tabla 6.9. Se obtuvo una distribución de partículas mono-modal con un $\mathrm{d}_{0,5}$ de $2,94 \mu \mathrm{m}$.

Tabla 6.9. Diámetro máximo $(\mu \mathrm{m})$ de partícula del 10\%, 50\% y 90\%.

\begin{tabular}{c|ccc} 
& $\mathrm{d}(0,1)$ & $\mathrm{d}(0,5)$ & $\mathrm{d}(0,9)$ \\
\hline $\begin{array}{c}\text { Tincar Super } \\
\text { molida }\end{array}$ & 1,39 & 2,94 & 6,24
\end{tabular}




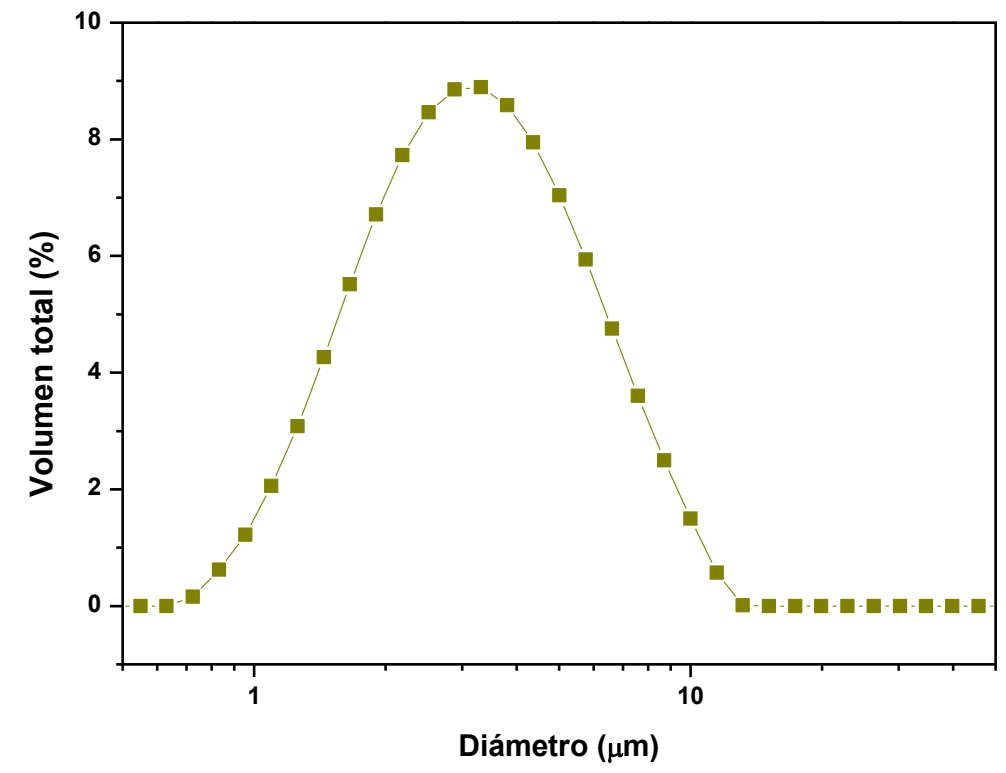

Figura 6.21. Distribución del tamaño de partícula de la arcilla Tincar Super molida.

La densidad aparente, la densidad bulk, la solubilidad en ácido y el porcentaje de finos que se generan luego del test crush de los agentes de sostén (AG6 y AG7) se muestran en la Tabla 6.10. Se observó que ambos materiales presentaron valores de densidad aparente menor que los valores definidos en la literatura para agentes de sostén cerámicos livianos $(\leq 2,65$ $\mathrm{g} / \mathrm{cm}^{3}$ ). Además, la muestra que no contiene el MAP (AG6) presentó menor densidad que la muestra AG7 y esta diferencia se acentúo en la densidad aparente de los agentes de sostén. Esto se debe a que la densidad aparente tiene en cuenta la porosidad del material, es decir que los AG6 son más porosos que los AG7. El porcentaje de finos, obtenido con el test crush, fue menor en la muestra AG7 que en la muestra AG6, esta diferencia también se relaciona con la porosidad del material debido a que una mayor porosidad influye en la resistencia mecánica del material disminuyéndola. 
Tabla 6.10. Densidades, solubilidad en ácido y porcentaje de finos del test crush de los agentes de sostén AG6 y AG7.

\begin{tabular}{|c|c|c|c|c|}
\hline Muestra & $\begin{array}{c}\text { Densidad } \\
\text { bulk }\left(\mathrm{g} / \mathrm{cm}^{3}\right)\end{array}$ & $\begin{array}{c}\text { Densidad } \\
\text { aparente }\left(\mathrm{g} / \mathrm{cm}^{3}\right)\end{array}$ & $\begin{array}{l}\text { Solubilidad } \\
\text { en ácido (\%) }\end{array}$ & $\begin{array}{l}\% \text { de finos } \\
(34,5 \mathrm{MPa})\end{array}$ \\
\hline AG6 & 1,30 & 2,15 & 5,57 & 8,33 \\
\hline AG7 & 1,35 & 2,37 & 6,22 & 7,98 \\
\hline
\end{tabular}

Los valores de solubilidad en ácido obtenidos para ambos materiales se encuentraron dentro del parámetro aconsejado por la norma $(\leq 7 \%)$, y entre los dos materiales el que contiene MAP presentó un mayor valor debido a la presencia de fósforo (óxido formador de vidrio) que produce mayor fase amorfa la cual es atacada por la solución ácida.

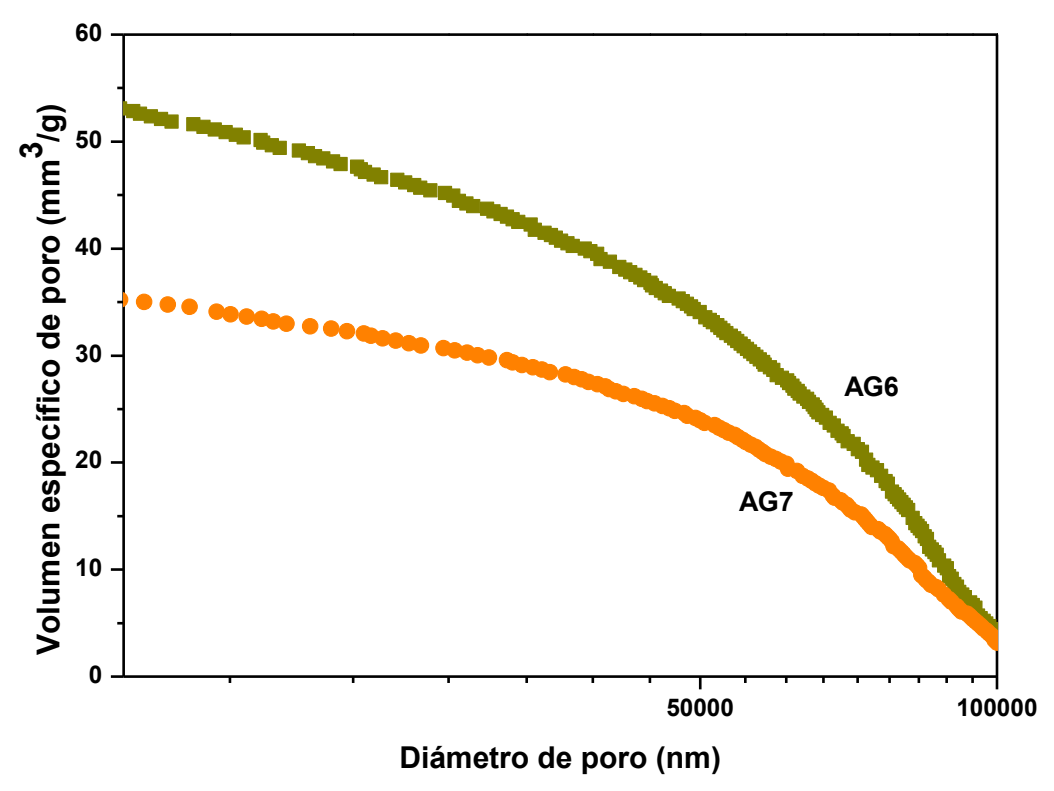

Figura 6.22. Distribución de tamaño de los macroporos de los agentes de sostén AG6 y AG7. 


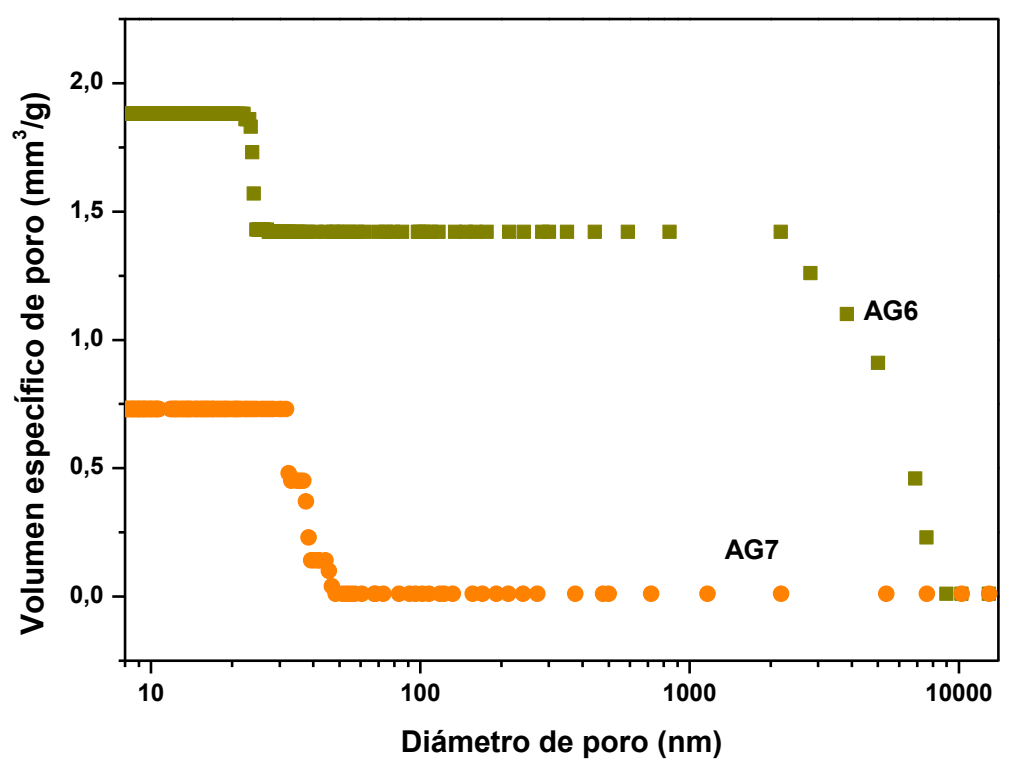

Figura 6.23. Distribución de tamaño de los mesoporos de los agentes de sostén AG6 y AG7.

Lo supuesto acerca de la menor porosidad de los agentes de sostén AG7 se verifica en la Figura 6.22 que muestra la distribución de tamaño de los macroporos y en la Figura 6.23 la distribución de tamaño de los mesoporos de los materiales AG6 y AG7. Efectivamente, la muestra AG7 presentó menor volumen total de poros tanto de los mesoporos como de los macroporos

En la Tabla 6.11 y la Figura 6.24 se muestra el ensayo de redondez y esfericidad de los materiales. Se observó una diferencia entre ambas propiedades siendo mayor la esfericidad de la muestra AG7. Sin embargo, los valores de esfericidad y redondez para ambos materiales se encuentran dentro de los aceptados por la norma para agentes de sostén cerámicos. 
Tabla 6.11. Medidas de redondez (X) y esfericidad (Y) de los agentes de sostén AG6 y AG7.

\begin{tabular}{|c|c|c|}
\hline \multicolumn{3}{|c|}{ AG6 } \\
\hline Número & $\mathrm{X}$ & $\mathrm{Y}$ \\
\hline 1 & 0,4 & 0,9 \\
\hline 2 & 0,5 & 0,9 \\
\hline 3 & 0,4 & 0,7 \\
\hline 4 & 0,6 & 0,6 \\
\hline 5 & 0,6 & 0,5 \\
\hline 6 & 0,7 & 0,9 \\
\hline 7 & 0,6 & 0,9 \\
\hline 8 & 0,4 & 0,7 \\
\hline 9 & 0,6 & 0,9 \\
\hline 10 & 0,9 & 0,7 \\
\hline 11 & 0,5 & 0,9 \\
\hline 12 & 0,5 & 0,5 \\
\hline 13 & 0,4 & 0,9 \\
\hline 14 & 0,6 & 0,7 \\
\hline 15 & 0,5 & 0,9 \\
\hline 16 & 0,4 & 0,9 \\
\hline 17 & 0,4 & 0,5 \\
\hline 18 & 0,7 & 0,9 \\
\hline 19 & 0,8 & 0,7 \\
\hline 20 & 0,5 & 0,9 \\
\hline Promedio & 0,7 & 0,8 \\
\hline
\end{tabular}

\begin{tabular}{c|cc}
\multicolumn{2}{c}{ AG7 } \\
Número & $\mathbf{X}$ & $\mathrm{Y}$ \\
\hline 1 & 0,7 & 0,9 \\
2 & 0,9 & 0,9 \\
3 & 0,8 & 0,9 \\
4 & 0,9 & 0,9 \\
5 & 0,7 & 0,9 \\
6 & 0,9 & 0,9 \\
7 & 0,5 & 0,6 \\
8 & 0,6 & 0,9 \\
9 & 0,6 & 0,9 \\
10 & 0,7 & 0,9 \\
11 & 0,8 & 0,9 \\
12 & 0,7 & 0,9 \\
13 & 0,9 & 0,9 \\
14 & 0,7 & 0,9 \\
15 & 0,8 & 0,9 \\
16 & 0,8 & 0,9 \\
17 & 0,7 & 0,9 \\
18 & 0,7 & 0,9 \\
19 & 0,6 & 0,9 \\
20 & 0,7 & 0,9 \\
\hline Promedio & 0,7 & 0,9 \\
& & \\
19 &
\end{tabular}



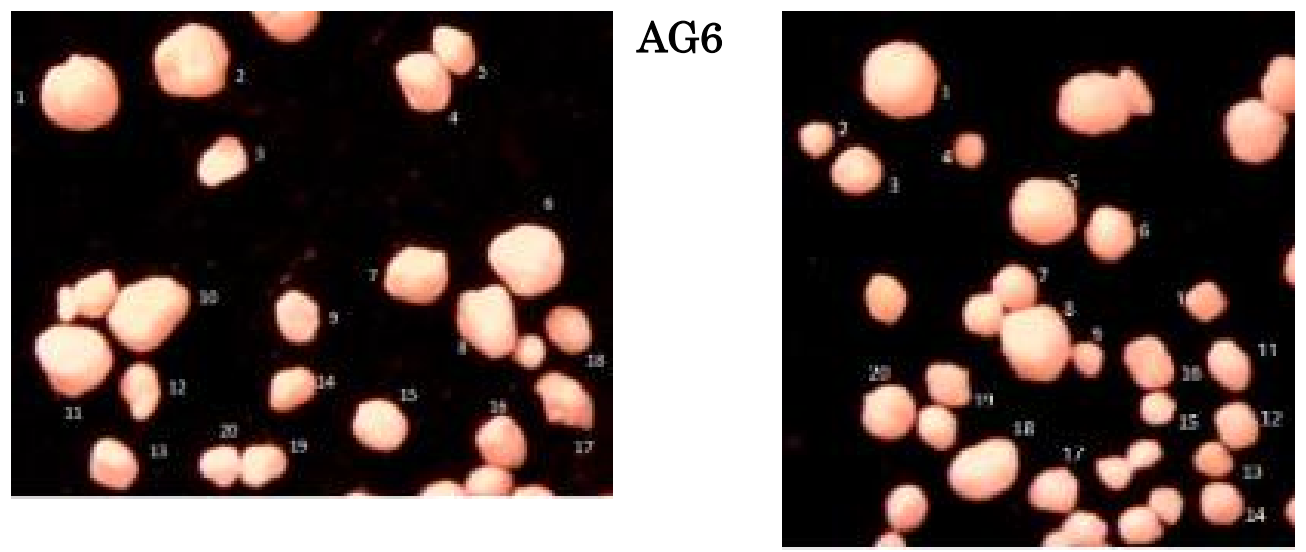

AG7

Figura 6.24. Fotografías de los agentes de sostén AG4 y AG5 para medir esfericidad y redondez.

Además como se ha mencionado con anterioridad en la producción de agentes de sostén en gran escala el sinterizado se realiza con un horno rotatorio, lo que permite continuar el proceso de redondeado y esferizado durante el tratamiento térmico.

La Figura 6.25 muestra los diagramas de rayos $\mathrm{X}$ de los materiales AG6 y AG7. En ambos materiales las fases cristalinas que se obtuvieron fueron cristobalita y mullita. La muestra AG6 presentó mayor intensidad en los picos que la muestra AG7, y a su vez ésta última exhibió una banda en valores de $2 \theta=21,80^{\circ}$, lo que evidencia la presencia de fase amorfa en el material. Esto se debe a la presencia del MAP, que cómo se mencionó anteriormente aporta fósforo al sistema, que sumado a la sílice proveniente de la arcilla forman la fase amorfa al ser ambos compuestos óxidos formadores de vidrio.

Por otro lado se observó que en los agentes de sostén AG7 las intensidades de los picos de la mullita son mayores y las intensidades de los picos de cristobalita menores que en los agentes de sostén AG6. Lo que evidencia la presencia de mayor cantidad de fase mullita en la muestra AG7. 


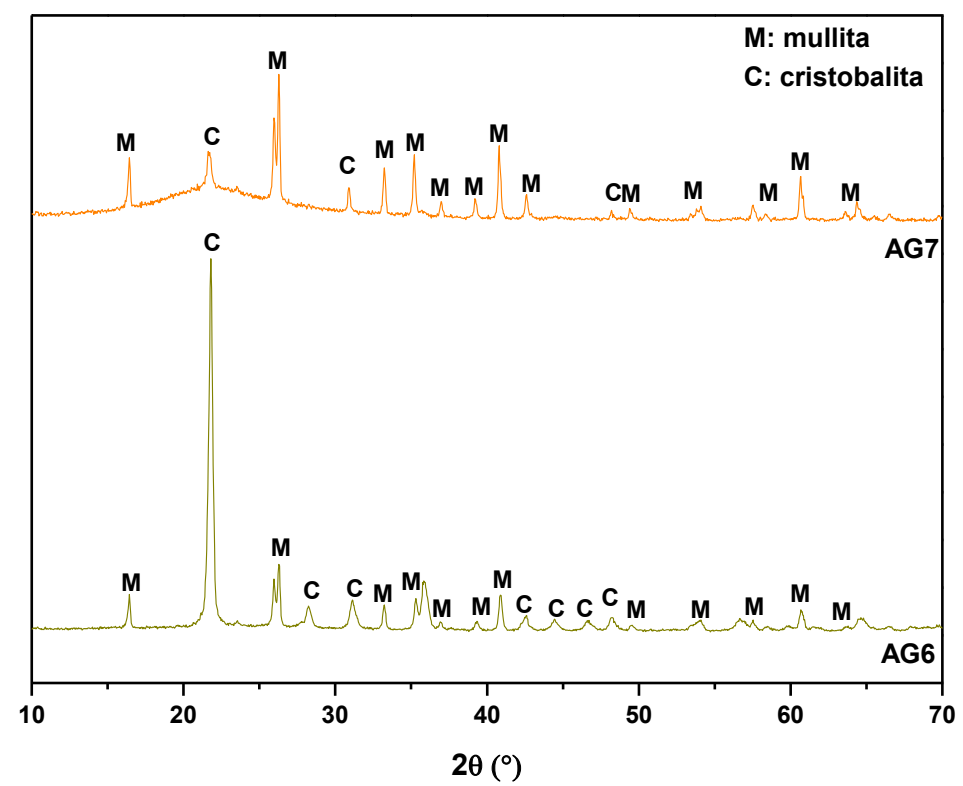

Figura 6.25. Diagrama de rayos X de los agentes de sostén AG6 y AG7.

En la Tabla 6.12 se presenta la cuantificación de las muestras AG6 y AG7 realizada con el método de Rietvield y el método del patrón externo. Se determinó que el porcentaje de fase amorfa en los agentes de sostén que contienen MAP (AG7) fue de 63,38\%, valor superior al determinado en los agentes de sostén AG6 (45,34\%). Como se observó en el DRX la muestra AG7 presentó mayor porcentaje de mullita y menor cantidad de cristobalita.

Tabla 6.12. Porcentaje de cada fase de los agentes AG6 y AG7 calculadas por el método de Rietvield y el método del patrón externo.

\begin{tabular}{c|ccc} 
Muestra & \% mullita & \% cristobalita & \% fase amorfa \\
\hline AG6 & 22,01 & 32,65 & 45,34 \\
AG7 & 33,40 & 2,92 & 63,68
\end{tabular}


En las fotografías SEM de los agentes de sostén AG6 y AG7 (Figuras 6.26 y 6.27 respectivamente) se observó la presencia de las agujas de mullita y fase amorfa. Como se había evidenciado en la distribución de poros por intrusión de mercurio (Figuras 6.22 y 6.23), la muestra AG6 presentó mayor porosidad que la muestra AG7 y a su vez esta última mayor cantidad de las agujas de mullita como se pudo cuantificar a partir de los DRX (Tabla 6.12).
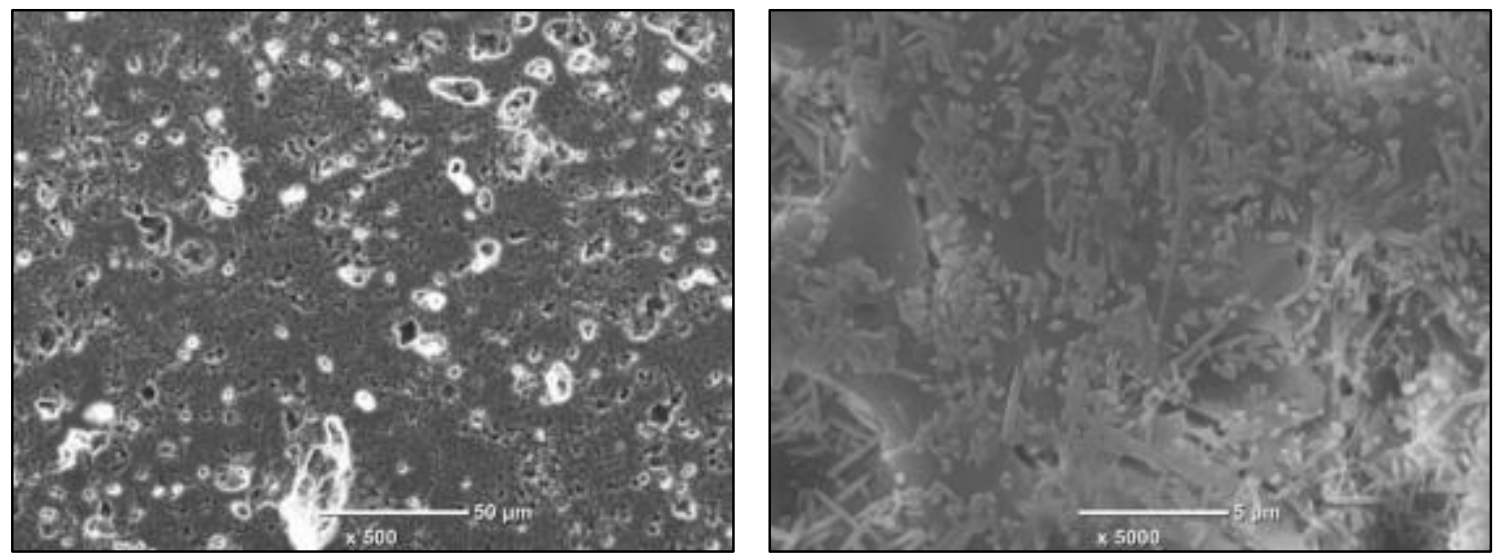

Figura 6.26. Fotografías SEM x500 y x5000 de los agentes de sostén AG6.
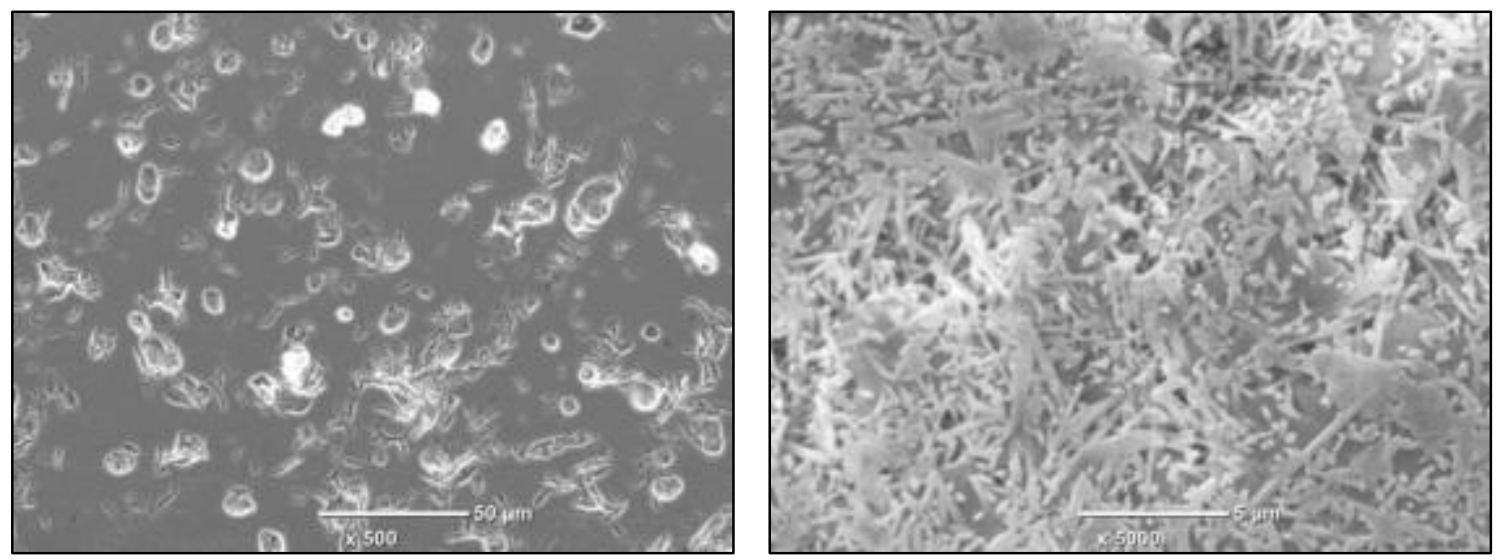

Figura 6.27. Fotografías SEM x500 y x5000 de los agentes de sostén AG7. 


\subsection{Comparación de los agentes de sostén desarrollados con los comerciales}

La performance obtenida de los agentes de sostén cerámicos desarrollados en las secciones anteriores (sección 6.2 y 6.3) a partir del sistema arcilla Tincar Super- bauxita-MAP (AG3 y AG5), se comparó con la performance de una arena y de agentes de sostén cerámicos comerciales.

En esta comparación no se incluyeron los agentes de sostén desarrollados sin bauxita (AG6 y AG7) debido a que si bien presentaron valores de densidad menores a $2,65 \mathrm{~g} / \mathrm{cm}^{3}$ lo que los incluiría en la categoría de agentes de sostén cerámicos de baja densidad, la presión máxima soportada en el test crush fue inferior a los valores de presión soportados por arenas con buena performance como la que se describe en esta sección.

La arena utilizada para comparar fue una proveniente de la Argentina ingresada al CETMIC para la evaluación de sus propiedades bajo norma Api 19C y los agentes de sostén cerámicos comerciales evaluados fueron los Carboeconoprop (CARBO Ceramics Inc.).

En la Tabla 6.13 se presentan la densidad bulk, la densidad aparente, la solubilidad en ácido, el porcentaje de finos del test crush, la redondez, la esfericidad y las fases cristalinas de cada material. El test crush se informa el porcentaje de finos obtenidos y entre paréntesis la presión máxima que el material soporta para que este porcentaje sea menor al 10\%, como lo requiere la norma.

Como se ha mencionado con anterioridad, la norma API 19C establece un valor de esfericidad y redondez para cada una $\geq 0,7$ en el caso de agentes de sostén cerámicos. En cambio, para las arenas el valor establecido de esfericidad y de redondez tiene que ser el promedio de cada una $\geq 0,6$. Los valores máximos de solubilidad en ácido también cambian según el material, para las arenas este porcentaje no debe superar el $3 \%$ y para los agentes de sostén cerámico el $7 \%$. 
Tabla 6.13. Propiedades de la arena y de los agentes de sostén Carboeconoprop, AG3 y AG5 según normas API 19C.

\begin{tabular}{|c|c|c|c|c|}
\hline & Arena & Carboeconoprop & AG3 & AG5 \\
\hline $\begin{array}{c}\text { Densidad } \\
\text { bulk }\left(\mathrm{g} / \mathrm{cm}^{3}\right)\end{array}$ & 1,50 & 1,64 & 1,33 & 1,40 \\
\hline $\begin{array}{c}\text { Densidad } \\
\text { aparente } \\
\left(\mathrm{g} / \mathrm{cm}^{3}\right)\end{array}$ & 2,64 & 2,84 & 2,40 & 2,50 \\
\hline $\begin{array}{l}\text { Solubilidad } \\
\text { en ácido (\%) }\end{array}$ & 0,56 & 2,80 & 8,47 & 7,83 \\
\hline$\%$ de finos & $9,00(48 \mathrm{MPa})$ & $3,4(51,7 \mathrm{MPa})$ & $9,61(64 \mathrm{MPa})$ & $6,22(64 \mathrm{MPa})$ \\
\hline $\begin{array}{l}\text { Redondez y } \\
\text { esfericidad }\end{array}$ & $0,40-0,70$ & $0,80-0,90$ & $0,6-0,9$ & $0,7-0,8$ \\
\hline $\begin{array}{c}\text { Fases } \\
\text { cristalinas }\end{array}$ & Cuarzo & $\begin{array}{c}\text { Cristobalita y } \\
\text { mullita }\end{array}$ & $\begin{array}{c}\text { Cristobalita y } \\
\text { mullita }\end{array}$ & $\begin{array}{c}\text { Cristobalita y } \\
\text { mullita }\end{array}$ \\
\hline
\end{tabular}

Los agentes de sostén desarrollados en este trabajo presentaron menor densidad tanto aparente como bulk, además el porcentaje de finos fue menor al valor límite especificado en la norma a una presión mayor (64 $\mathrm{MPa}$ ) que los otros materiales presentados en la Tabla 6.13.

En cuanto a la esfericidad y redondez los agentes de sostén Carboeconoprop presentaron los valores más elevados, y los AG3 ni las arenas alcanzaron el valor mínimo de redondez establecido en norma.

El único punto desfavorable de los agentes de sostén AG3 y AG5 en comparación con los otros materiales comparados es el porcentaje de solubilidad en ácido, el cual es superior al valor límite dispuesto en la norma. Este sería un parámetro a mejorar para que los agentes de sostén 
AG3 y AG5 superen en todas las propiedades a las arenas y a los Carboeconoporp.

\subsection{Consideraciones parciales}

Se observó que el tamaño de partícula de las materias primas influye en algunas propiedades de los agentes de sostén desarrollados, específicamente en la porosidad abierta de los materiales y en su resistencia mecánica evaluada por el test crush.

La distribución más estrecha de la porosidad abierta y el menor volumen total de poros abiertos se obtuvo a partir de las materias primas con menor tamaño de partícula $\left(\mathrm{d}_{50}=3,08 \mu \mathrm{m}\right)$ que corresponden a una molienda de 48 horas con adición de poliacrilato de sodio como dispersante. Además se advirtió que influyó en mayor grado la adición del dispersante para evitar aglomeración en la molienda que el tiempo que dura este proceso.

El menor tamaño de partícula de las materias primas mejoró el rendimiento del test crush a $64 \mathrm{MPa}$ dando como resultado un menor porcentaje de finos, siendo estos agentes de sostén (AG3) los únicos bajo esta formulación que arrojaron un porcentaje de finos menor al 10\% como lo requiere la norma API 19C.

Las densidades aparentes de los agentes de sostén cerámicos elaborados a partir del sistema Tincar Super-10\% bauxita- 10\% MAP varió entre 2,32-2,40 g/ $\mathrm{cm}^{3}$. Encontrándose estos valores dentro de los definidos como agentes de sostén cerámicos de baja densidad.

Se desarrollaron agentes de sostén del sistema arcilla Tincar Super activada térmicamente y sin activar, 20\% de bauxita y 10\% de MAP. La distribución del tamaño de partícula de la mezcla Tincar Super activada térmicamente-bauxita (AG5) molida fue menor que del sistema Tincar 
Super-bauxita por lo que la distribución de los macro y mesoporos de los materiales finales es notablemente menor.

Los agentes de sostén realizados a partir de arcilla Tincar Super activada térmicamente (AG5) presentaron mejores valores de porcentaje de finos del test crush de $6,22 \%$ a diferencia de cuando se utilizó arcilla sin activar (AG4) que el porcentaje de finos generados fue de 11,30\%. Esto se relaciona directamente con el volumen de poros abiertos de los agentes de sostén siendo que a mayor volumen de poros menor es la resistencia mecánica.

También se observó que la activación térmica de la arcilla influyó en los materiales finales obteniéndose agentes de sostén con mayor cristalinidad (mayor intensidad en los picos) con mayor porcentaje de mullita y cristobalita como se cuantificó con el método de Rietveld y el método del patrón externo.

Además se desarrollaron agentes de sostén cerámicos livianos con valores de densidad aparente de 2,37 y $2,15 \mathrm{~g} / \mathrm{cm}^{3}$ utilizando arcilla Tincar Super y arcilla Tincar Super-MAP. Estos agentes de sostén al no tener una fuente de alúmina extra contienen mayor cantidad de fase amorfa y presentaron una menor resistencia mecánica siendo su máximo valor de presión en el test crush estudiado de 34,5 $\mathrm{MPa}$.

Los agentes de sostén del sistema Tincar Super-MAP exhibieron mayor densidad aparente y menor porcentaje de finos generados en el test crush que los agentes de sostén de Tincar Super, esto se debe a que los primeros presentaron menor porosidad abierta por la presencia del MAP que ayuda en la sinterización del material. Se observó que la presencia de MAP en el sistema influyó en la porosidad abierta obteniendo materiales con menor volumen de poro

Se observó que la solubilidad en ácido para los agentes de sostén que contienen bauxita en su composición fue superior al $7 \%$, lo cual hace que 
estos materiales no se encuentren dentro de lo especificado en la norma API 19C. En cambio en los agentes de sostén AG6 y AG7, que no contienen alúmina extra adicionada, el porcentaje obtenido de solubilidad en ácido es menor al 7\%. El porcentaje de fase amorfa en los agentes de sostén sin bauxita es superior al porcentaje de fase amorfa en los agentes de sostén con bauxita; por lo que la presencia de fase vítrea no sería la causante del elevado porcentaje de solubilidad en ácido sino la presencia de impurezas en esta fase provenientes de la bauxita. De acuerdo con la teoría de Lewis, óxidos básicos tienden a reducir la resistencia al ataque ácido y óxidos ácidos tienden a aumentar esa resistencia ( $\mathrm{Wu}$ and $\mathrm{Wu}, 2012)$ por lo que la presencia de 6,20\% óxido de hierro en la bauxita (composición química de las materias primas Tabla 3.2) favorece la solubilidad en ácido de los agentes de sostén.

Para disminuir la solubilidad en ácido de los agentes desarrollados existen diversos trabajos en los cuales se agregan ciertos aditivos como el óxido de titanio (Wu et al., 2013, 2015). El punto principal es obtener agentes de sostén compactos para disminuir el área a la que va a estar expuesto el material a la solución ácida, por lo cual la estrategia sería agregar un aditivo que ayude a la sinterización del material. También se obtendrían agentes de sostén más compactos si el tratamiento térmico se hubiese realizado en un horno rotario, en el cual se produce un talud de material que va girando y contribuye a que se cierren los poros abiertos y además mejore la redondez de los agentes de sostén.

Los agentes de sostén obtenidos en este trabajo con diferentes formulaciones presentaron menores valores de densidad que las arenas y los agentes de sostén cerámicos comerciales Carboeconoprop. A su vez los materiales AG3 y AG5 dieron como resultado en el test crush un porcentaje de finos menor al 10\% a mayor presión (64 MPa), lo que ubica a estos agentes de sostén desarrollados en este trabajo en una posición preferencial para su utilización en la extracción de petróleo y gas no convencional. 
Capítulo 7 
En este trabajo de tesis inicialmente se estudiaron diferentes formulaciones y se analizaron las propiedades mecánicas y texturales en post de obtener materiales cerámicos de baja densidad $\left(\leq 2,65 \mathrm{~g} / \mathrm{cm}^{3}\right)$, baja porosidad abierta y valores adecuados de resistencia mecánica para su aplicación como agentes de sostén en la explotación de gas y/o petróleo no convencional.

Primero se seleccionó la arcilla entre la arcilla Blend y la arcilla Tincar Super, ambas arcillas con caolinita en su composición. Se obtuvieron materiales con densidades menores o iguales a $2,00 \mathrm{~g} / \mathrm{cm}^{3}$, los materiales realizados a partir de Blend presentaron elevado porcentaje de porosidad abierta en comparación con los materiales que tenían Tincar Super como materia prima. Entonces considerando estos resultados de porosidad y teniendo en cuenta que la arcilla Tincar Super posee mayor disponibilidad en el mercado se decidió continuar con el trabajo con esta última arcilla. 
Para disminuir la densidad de los materiales se utilizaron agentes formadores de poro, los cuales crean una matriz porosa durante el tratamiento térmico del material. Para esto se evaluaron tres fuentes de carbón como agente formador de poro (carbón vegetal, negro de humo y carbón residual de petróleo). Se obtuvieron materiales con baja densidad $\left(1,93-2,00 \mathrm{~g} / \mathrm{cm}^{3}\right)$ debido a una elevada porosidad cerrada pero con bajos valores de resistencia mecánica $(15,98-22,36 \mathrm{MPa})$ por lo que se descartó el uso de agentes formadores de poro en este trabajo.

También, se estudiaron dos tipos de precursores de liga química: fosfato de monoaluminio (MAP) y sílice coloidal. Entre estos dos precursores cuando se adicionó MAP entre las materias primas los materiales obtenidos presentaron mayores valores de resistencia mecánica con lo cual se optó por este precursor de liga química.

Luego del estudio de diferentes formulaciones se realizaron agentes de sostén cerámicos a partir de un procesamiento desarrollado en el marco de este trabajo, utilizando una mezcladora de alta energía y se evaluaron sus propiedades mecánicas y texturales según lo establecido en la norma API 19C.

Se observó que a menor tamaño de partícula de las materias primas los agentes de sostén tratados térmicamente tuvieron menor porosidad abierta y como consecuencia de esto mayor resistencia mecánica. Para el molino y el arreglo de bolas de porcelana utilizado se obtuvieron los menores tamaños de partícula $\left(\mathrm{d}_{0,5}=3,08 \mu \mathrm{m}\right)$ cuando se molieron las materias primas durante 48 horas con la adición de un dispersante para que la molienda sea homogénea.

Se realizaron agentes de sostén a partir de arcilla Tincar Super activada térmicamente y sin activar, 20\% de bauxita y 10\% de MAP. Cuando se utilizó la arcilla activada térmicamente se debió agregar durante el proceso de conformado vinagre de alcohol para mejora la plasticidad de la 
pasta. Esto provocó un cambio en el pH de la mezcla que hace que se aproxime al punto isoeléctrico de la misma, en consecuencia las partículas disminuyen su carga superficial y entonces disminuyen sus repulsiones.

En este caso se obtuvo agentes de sostén con los menores valores de porcentaje de finos del test crush (evaluados a $64 \mathrm{MPa}$ ), baja densidad aparente $\left(2,50 \mathrm{~g} / \mathrm{cm}^{3}\right)$, baja porosidad abierta y altos porcentajes de mullita y cristobalita.

También se desarrollaron agentes de sostén de menor resistencia mecánica (evaluados a 34,5 MPa en el test crush) con los sistemas: Tincar Super-MAP y Tincar Super. Se observó que el MAP ayuda en la sinterización del material disminuyendo la porosidad abierta, la cual influye en la resistencia mecánica del material; obteniéndose menor porcentaje de finos en el test crush de los agentes de sostén del sistema Tincar SuperMAP.

Los valores de esfericidad y redondez de los agentes de sostén obtenidos, en su mayoría, cumplen con los valores establecidos en la norma $(\geq 0,7)$ y éstos pueden ser mejorados si en lugar de calcinar los materiales en horno batch hubiesen sido calcinados en un horno giratorio, como es en el proceso industrial, lo que permite durante el tratamiento térmico mejorar estas propiedades debido al talud de material que se forma dentro del horno.

Las solubilidades en ácido de los agentes de sostén desarrollados con bauxita como materia prima no cumplieron el valor establecido por la norma API 19C $(\leq 7 \%)$. En cambio, los agentes de sostén que no contienen bauxita en su formulación tuvieron un porcentaje de solubilidad en ácido menor al 7\%. Estos últimos materiales presentaron mayor porcentaje de fase amorfa cuantificada con el método de Rietvield y el método del patrón externo que los materiales con bauxita, por lo que se concluyó que el óxido de hierro presente en la bauxita es el que se disuelve en la solución ácida. Para mejorar esta propiedad podrían utilizarse ciertos aditivos $\left(\mathrm{TiO}_{2}, \mathrm{BaCO}_{3}\right.$, etc.) 
que favorecen el proceso de sinterización del material. El objetivo es obtener agentes de sostén compactos con la menor área posible de exposición a la solución ácida.

Se compararon los agentes de sostén cerámicos realizados en este trabajo que presentaron las mejores propiedades con agentes de sostén cerámicos comerciales (Carboeconoprop) y arenas utilizadas en la actualidad en pozos no conveniconales de la Argentina. Los agentes de sostén desarrollados en el marco de esta tesis obtuvieron la menor densidad aparente y un porcentaje de finos con valores dentro de lo definido por norma a mayores presiones.

Se cumplió con el objetivo principal de esta tesis, desarrollar agentes de sostén cerámicos de baja densidad con propiedades acordes a la definido en la norma API 19C. Las propiedades de los agentes de sostén realizados ubican a estos materiales en una posición competitiva respecto a los agentes de sostén y arenas utilizadas actualmente en la fractura hidráulica. 


\section{Referencias}

Abdel-Baki, M., El-Diasty, F., 2011. Role of oxygen on the optical properties of borate glass doped with ZnO. J. Solid State Chem. 184, 2762-2769. https://doi.org/10.1016/j.jssc.2011.08.015

Ahmad, R., Anwar, M.S., Kim, J., Song, I.-H., Abbas, S.Z., Ali, S.A., Ali, F., Ahmad, J., Bin Awais, H., Mehmood, M., 2016. Porosity features and gas permeability analysis of bi-modal porous alumina and mullite for filtration applications. Ceram. Int. 42, 18711-18717. https://doi.org/10.1016/j.ceramint.2016.09.009

Aksay, I.A., Dabbs, D.M., Sarikaya, M., 1991. Mullite for Structural, Electronic, and Optical Applications. J. Am. Ceram. Soc. 74, 23432358. https://doi.org/10.1111/j.1151-2916.1991.tb06768.x

Almond, S.W., Penny, G.S., Conway, M.W., 1995. Factors Affecting Proppant Flowback with Resin Coated Proppants. Presented at the SPE European Formation Damage Conference, Society of Petroleum Engineers. https://doi.org/10.2118/30096-MS

Álvarez-Pinazo, G., Cuesta, A., García-Maté, M., Santacruz, I., Losilla, E.R., la Torre, A.G.D., León-Reina, L., Aranda, M.A.G., 2012. Rietveld quantitative phase analysis of Yeelimite-containing cements. Cem. Concr. Res. 42, 960-971. https://doi.org/10.1016/j.cemconres.2012.03.018

An, D., Li, Y., Lian, X., Zou, Y., Deng, G., 2014. Synthesis of porous ZnO structure for gas sensor and photocatalytic applications. Colloids Surf. Physicochem. Eng. Asp. 447, 81-87. https://doi.org/10.1016/j.colsurfa.2014.01.060

Angel, R.J. (University C., McMullan, R.K. (Brookhaven N.L., Prewitt, C.T. (Carnegie I. of W., 1991. Substructure and Superstructure of Mullite by Neutron Diffraction. Am. Mineral. U. S. 76:3-4.

Aranda, M.A.G., Torre, Á.G.D. la, León-Reina, L., 2012. Rietveld Quantitative Phase Analysis of OPC Clinkers, Cements and Hydration Products. Rev. Mineral. Geochem. 74, 169-209. https://doi.org/10.2138/rmg.2012.74.5

Bartonickova, E., Ptacek, P., Opravil, T., Soukal, F., Masilko, J., Novotny, R., Svec, J., Havlica, J., 2015. Mullite-based refractories fabricated by foam casting. Ceram. Int. 41, 14116-14123. https://doi.org/10.1016/j.ceramint.2015.07.032 
Bengisu, M., 2001. Engineering Ceramics, Engineering Materials. Springer Berlin Heidelberg, Berlin, Heidelberg. https://doi.org/10.1007/978-3662-04350-9

Bergna, H.E., 1994. Colloid Chemistry of Silica, in: The Colloid Chemistry of Silica, Advances in Chemistry. American Chemical Society, pp. 1-47. https://doi.org/10.1021/ba-1994-0234.ch001

Bouzerara, F., Boulanacer, S., Harabi, A., Boudaira, B., Achour, S., Condom, S., 2009. Preparation and characterization of macroporous ceramic supports for membranes. Phys. Procedia 2, 1449-1453. https://doi.org/10.1016/j.phpro.2009.11.115

Bruni, Y., Booth, F., Garrido, L., Aglietti, E., 2016. Densification and mechanical properties of $\mathrm{ZrO}_{2}-\mathrm{CaAl}_{4} \mathrm{O}_{7}$ composites obtained by reaction sintering. Int. J. Mater. Res. 107, 851-859. https://doi.org/10.3139/146.111404

Camerucci, M.A., Urretavizcaya, G., Castro, M.S., Cavalieri, A.L., 2001. Electrical properties and thermal expansion of cordierite and cordierite-mullite materials. J. Eur. Ceram. Soc. 21, 2917-2923. https://doi.org/10.1016/S0955-2219(01)00219-9

Campos, A.L., Silva, N.T., Melo, F.C.L., Oliveira, M.A.S., Thim, G.P., 2002. Crystallization kinetics of orthorhombic mullite from diphasic gels. J. Non-Cryst. Solids 304, 19-24. https://doi.org/10.1016/S00223093(02)00998-5

Cannan, C.D., Palamara, T.C., 2006. Low density proppant. US7036591 B2.

Cao, J., Dong, X., Li, L., Dong, Y., Hampshire, S., 2014. Recycling of waste fly ash for production of porous mullite ceramic membrane supports with increased porosity. J. Eur. Ceram. Soc. 34, 3181-3194. https://doi.org/10.1016/j.jeurceramsoc.2014.04.011

Chen, C.Y., Lan, G.S., Tuan, W.H., 2000. Preparation of mullite by the reaction sintering of kaolinite and alumina. J. Eur. Ceram. Soc. 20, 2519-2525. https://doi.org/10.1016/S0955-2219(00)00125-4

Chen, D., He, L., Shang, S., 2003. Study on aluminum phosphate binder and related Al2O3-SiC ceramic coating. Mater. Sci. Eng. A 348, 29-35. https://doi.org/10.1016/S0921-5093(02)00643-3

Chen, X., Gu, L., 2009a. Spinnablity and structure characterization of mullite fibers via sol-gel-ceramic route. J. Non-Cryst. Solids 355, 2415-2421. https://doi.org/10.1016/j.jnoncrysol.2009.06.030

Chen, X., Gu, L., 2009b. Sol-gel dry spinning of mullite fibers from AN/TEOS/AIP system. Mater. Res. Bull. 44, 865-873. https://doi.org/10.1016/j.materresbull.2008.09.011 
Chiou, J.-M., Chung, D.D.L., 1993. Improvement of the temperature resistance of aluminium-matrix composites using an acid phosphate binder. J. Mater. Sci. 28, 1435-1446. https://doi.org/10.1007/BF00363335

Chung, D.D.L., 2003. Acid aluminum phosphate for the binding and coating of materials. J. Mater. Sci. 38, 2785-2791. https://doi.org/10.1023/A:1024446014334

Cividanes, L.S., Campos, T.M.B., Rodrigues, L.A., Brunelli, D.D., Thim, G.P., 2010. Review of mullite synthesis routes by sol-gel method. J. Sol-Gel Sci. Technol. 55, 111-125. https://doi.org/10.1007/s10971-0102222-9

Colombo, P., 2006. Conventional and novel processing methods for cellular ceramics. Philos. Trans. R. Soc. Math. Phys. Eng. Sci. 364, 109-124. https://doi.org/10.1098/rsta.2005.1683

Conconi, M.S., Rendtorff, N.M., Aglietti, E.F., 2011. Evaluation of Non Crystalline Phase in AZS Refractories by XRD Methods. New J. Glass Ceram. 01, 28-33. https://doi.org/10.4236/njgc.2011.12005

da Silva, V.J., Da Silva, M.F., Gonçalves, W.P., de Menezes, R.R., Araújo Neves, G. de, Lucena Lira, H. de, de Lima Santana, L.N., 2016. Porous mullite blocks with compositions containing kaolin and alumina waste. Ceram. Int. 42, 15471-15478. https://doi.org/10.1016/j.ceramint.2016.06.199

de Sousa, L.L., Salomão, R., Arantes, V.L., 2017. Development and characterization of porous moldable refractory structures of the alumina-mullite-quartz system. Ceram. Int. 43, 1362-1370. https://doi.org/10.1016/j.ceramint.2016.10.093

Dewprashad, B., Abass, H.H., Meadows, D.L., Weaver, J.D., Bennett, B.J., 1993. A Method To Select Resin-Coated Proppants. Presented at the SPE Annual Technical Conference and Exhibition, Society of Petroleum Engineers. https://doi.org/10.2118/26523-MS

Domínguez, E., Dondi, M., Etcheverry, R., Recio, C., Iglesias, C., 2016. Genesis and mining potential of kaolin deposits in Patagonia (Argentina). Appl. Clay Sci. 131, 44-47. https://doi.org/10.1016/j.clay.2015.12.031

dos Anjos, R.D., Ismael, M.R., de Oliveira, I.R., Pandolfelli, V.C., 2008. Workability and setting parameters evaluation of colloidal silica bonded refractory suspensions. Ceram. Int. 34, 165-171. https://doi.org/10.1016/j.ceramint.2006.09.004 
Duval, D.J., Risbud, S.H., Shackelford, J.F., 2008. Mullite, in: Ceramic and Glass Materials. Springer, Boston, MA, pp. 27-39. https://doi.org/10.1007/978-0-387-73362-3_2

Elssner G, Hoven H, Kiessler G, Wellner P, 1999. Ceramics and Ceramic Composites: Materialographic Preparation, 1 st. ed. Elservier Science, New York.

Fitzgibbon, J.J, Lafayette, L., n.d. Sintered spherical pellets containing clay as mayor component useful for gas and oil well proppants. US 4427068.

Giskow, R., Lind, J., Schmidt, E., 2004. The variety of phosphates for refractory and technical applications by the example of aluminium phosphates. CFI Ceram. Forum Int. 81, E27-E32.

Gonzalez, F.J., Halloran, J.W., 1980. Reaction of orthophosphoric acid with several formas of aluminum oxide.

Guo, H., Li, W., Ye, F., 2016. Low-cost porous mullite ceramic membrane supports fabricated from kyanite by casting and reaction sintering. Ceram. Int. 42, 4819-4826. https://doi.org/10.1016/j.ceramint.2015.11.167

Gupta, T.K., Jean, J.-H., 1994. Origin of cristobalite formation during sintering of a binary mixture of borosilicate glass and high silica glass. J. Mater. Res. 9, 999-1005. https://doi.org/10.1557/JMR.1994.0999

Han, H.-J., Kim, D.-P., 2003. Studies on Curing Chemistry of AluminumChromium-Phosphates as Low Temperature Curable Binders. J. SolGel Sci. Technol. 26, 223-228. https://doi.org/10.1023/A:1020799015594

Han, L., Li, F., Deng, X., Wang, J., Zhang, H., Zhang, S., 2017. Foamgelcasting preparation, microstructure and thermal insulation performance of porous diatomite ceramics with hierarchical pore structures. J. Eur. Ceram. Soc. 37, 2717-2725. https://doi.org/10.1016/j.jeurceramsoc.2017.02.032

Hipedinger, N.E., Scian, A.N., Aglietti, E.F., 2002. Magnesia-phosphate bond for cold-setting cordierite-based refractories. Cem. Concr. Res. 32, 675-682. https://doi.org/10.1016/S0008-8846(01)00725-6

Ismael, M.R., Anjos, R.D., Salomão, R., Pandolfelli, V.C., 2006. Colloidal silica as a nanostructured binder for refractory castables. Refract Appl News 11, 16-20.

Jayasankar, M., Anilkumar, G.M., Smitha, V.S., Mukundan, P., Madhusoodana, C.D., Warrier, K.G.K., 2011. Low temperature needle 
like mullite grain formation in sol-gel precursors coated on $\mathrm{SiC}$ porous substrates. Thin Solid Films 519, 7672-7676. https://doi.org/10.1016/j.tsf.2011.05.053

Juettner, T., Moertel, H., Svinka, V., Svinka, R., 2007. Structure of kaolinealumina based foam ceramics for high temperature applications. J. Eur. Ceram. Soc., Refereed Reports IX Conference \& Exhibition of the European Ceramic Society 27, 1435-1441. https://doi.org/10.1016/j.jeurceramsoc.2006.04.029

Kazlauskas, S., Kazakevičius, E., Kežionis, A., 2017. Electrical properties of scandia- and ceria-stabilized zirconia ceramics. Solid State Ion. 310, 143-147. https://doi.org/10.1016/j.ssi.2017.08.008

Khaund, A., 1987. Sintered low density gas and oil well proppants from a low cost unblended clay material of selected composition. US 4668645 .

Kingery, W.D., 1950. Fundamental Study of Phosphate Bonding in Refractories: I, Literature Review. J. Am. Ceram. Soc. 33, 239-241. https://doi.org/10.1111/j.1151-2916.1950.tb14171.x

Krumbein W. C, Sloss L. L, 1963. Stratigraphy and Sedimentation, 2nd ed. ed. W. H. Freeman and Company, San Francisco.

Kulkarni, M.C., Ochoa, O.O., 2012. Mechanics of light weight proppants: A discrete approach. Compos. Sci. Technol. 72, 879-885. https://doi.org/10.1016/j.compscitech.2012.02.017

Kumar, P., Tiwari, A.N., Bhargava, P., 2013. Effect of Process Parameters and Binder Concentration on Mechanical Properties of Phosphate Bonded Alumina. Trans. Indian Ceram. Soc. 72, 130-135. https://doi.org/10.1080/0371750X.2013.817602

Laskou, M., Margomenou-Leonidopoulou, G., Balek, V., 2006. Thermal characterization of bauxite samples. J. Therm. Anal. Calorim. 84, 141-146. https://doi.org/10.1007/s10973-005-7126-5

Lee, S., Kim, Y.J., Moon, H.-S., 1999. Phase Transformation Sequence from Kaolinite to Mullite Investigated by an Energy-Filtering Transmission Electron Microscope. J. Am. Ceram. Soc. 82, 28412848. https://doi.org/10.1111/j.1151-2916.1999.tb02165.x

Lee, W.E., Souza, G.P., McConville, C.J., Tarvornpanich, T., Iqbal, Y., 2008. Mullite formation in clays and clay-derived vitreous ceramics. J. Eur. Ceram. Soc., Papers Presented at the International Workshop Mullite 2006. Hartmut Schneider: An Appreciation.Mullite 2006 28, 465-471. https://doi.org/10.1016/j.jeurceramsoc.2007.03.009 
Liang, F., Sayed, M., Al-Muntasheri, G.A., Chang, F.F., Li, L., 2016. A comprehensive review on proppant technologies. Petroleum 2, 26-39. https://doi.org/10.1016/j.petlm.2015.11.001

Liu, K.-C., Thomas, G., Caballero, A., Moya, J.S., De Aza, S., 1994. Mullite formation in kaolinite-a-alumina. Acta Metall. Mater. 42, 489-495. https://doi.org/10.1016/0956-7151(94)90503-7

Liu, P., Guo, S., Lian, M., Li, X., Zhang, Z., 2015. Improving water-injection performance of quartz sand proppant by surface modification with surface-modified nanosilica. Colloids Surf. Physicochem. Eng. Asp. 470, 114-119. https://doi.org/10.1016/j.colsurfa.2015.01.073

Liu, P., Zhu, Y., Ma, J., Yang, S., Gong, J., Jian, X., 2013. Effect of boehmite sol on the crystallization behavior and densification of mullite formed from a sol-gel precursor. Prog. Nat. Sci. Mater. Int. 23, 145-151. https://doi.org/10.1016/j.pnsc.2013.02.004

Liu, P.S., Chen, G.F., 2014. Fabricating Porous Ceramics, in: Porous Materials. Elsevier, pp. 221-302. https://doi.org/10.1016/B978-0-12407788-1.00005-8

Liu, Z., Zhao, J., Li, Y., Zeng, Z., Mao, J., Peng, Y., He, Y., 2016. Lowtemperature sintering of bauxite-based fracturing proppants containing $\mathrm{CaO}$ and $\mathrm{MnO} 2$ additives. Mater. Lett. 171, 300-303. https://doi.org/10.1016/j.matlet.2016.02.090

López Anadón Ernesto, Casalotti Victor, Masarik Guisela, Halperin Fernando, 2013. El abecé de los hidrocarburos en reservorios no convencionales, 3 ra. ed. Instituto Argentino de Petróleo y Gas, Buenos Aires.

Lunghofer, E.P., 1992. Hydraulic fracturing propping agent. US5120455 A.

Luz, A.P., Gomes, D.T., Pandolfelli, V.C., 2015. High-alumina phosphatebonded refractory castables: $\mathrm{Al}(\mathrm{OH}) 3$ sources and their effects. Ceram. Int. 41, 9041-9050. https://doi.org/10.1016/j.ceramint.2015.03.276

Luz, A.P., Oliveira, G.R., Gomes, D.T., Pandolfelli, V.C., 2016. Monoaluminum phosphate-bonded refractory castables for petrochemical application. Ceram. Int. 42, 8331-8337. https://doi.org/10.1016/j.ceramint.2016.02.047

Luz, A.P., Silva Neto, A.B., Santos, T., Medeiros, J., Pandolfelli, V.C., 2013. Mullite-based refractory castable engineering for the petrochemical industry. Ceram. Int. 39, 9063-9070. https://doi.org/10.1016/j.ceramint.2013.05.001 
Ma, X., Tian, Y., Zhou, Y., Wang, K., Chai, Y., Li, Z., 2016. Sintering temperature dependence of low-cost, low-density ceramic proppant with high breakage resistance. Mater. Lett. 180, 127-129. https://doi.org/10.1016/j.matlet.2016.04.080

Marghussian, V., 2015. Magnetic Properties of Nano-Glass Ceramics, in: Nano-Glass Ceramics. Elsevier, pp. 181-223. https://doi.org/10.1016/B978-0-323-35386-1.00004-9

Moore, D.M., Reynolds, R.C., 1997. X-Ray Diffraction and the Identification and Analysis of Clay Minerals, 2 edition. ed. Oxford University Press, Oxford; New York.

Morris, J.H., Perkins, P.G., Rose, A.E.A., Smith, W.E., 1977. The chemistry and binding properties of aluminium phosphates. Chem. Soc. Rev. 6, 173-194. https://doi.org/10.1039/CS9770600173

Morris, J.H., Perkins, P.G., Rose, A.E.A., Smith, W.E., 1976. Interaction between aluminium dihydrogen phosphate and quartz. J. Appl. Chem. Biotechnol. 26, 385-390. https://doi.org/10.1002/jctb.5020260157

Neto, J., T, A., Prata, F.G.M., Gomez, J., Pedroso, C.A., Martins, M., Silva, D.N., 2012. Ultralightweight Proppants: An Effective Approach To Address Problems in Long Horizontal Gravel Packs Offshore Brazil. SPE Drill. Complet. 27, 613-624. https://doi.org/10.2118/150581-PA

Nouri-Khezrabad, M., Braulio, M.A.L., Pandolfelli, V.C., Golestani-Fard, F., Rezaie, H.R., 2013. Nano-bonded refractory castables. Ceram. Int. 39, 3479-3497. https://doi.org/10.1016/j.ceramint.2012.11.028

Ohlberg, S.M., Strickler, D.W., 1962. Determination of Percent Crystallinity of Partly Devitrified Glass by X-Ray Diffraction. J. Am. Ceram. Soc. 45, 170-171. https://doi.org/10.1111/j.1151-2916.1962.tb11114.x

Pagliari, L., Dapiaggi, M., Pavese, A., Francescon, F., 2013. A kinetic study of the quartz-cristobalite phase transition. J. Eur. Ceram. Soc. 33, 3403-3410. https://doi.org/10.1016/j.jeurceramsoc.2013.06.014

Pangilinan, K.D., de Leon, A.C.C., Advincula, R.C., 2016. Polymers for proppants used in hydraulic fracturing. J. Pet. Sci. Eng. 145, 154160. https://doi.org/10.1016/j.petrol.2016.03.022

Petrotecnia, 2012. Las elección de la arena es una de las desiciones más importantes en la etapa exploratoria.

Ptáček, P., Šoukal, F., Opravil, T., Nosková, M., Havlica, J., Brandštetr, J., 2010. The kinetics of Al-Si spinel phase crystallization from calcined kaolin. J. Solid State Chem. 183, 2565-2569. https://doi.org/10.1016/j.jssc.2010.08.030 
Quan, C., Gao, N., Wu, C., 2017. Utilization of NiO/porous ceramic monolithic catalyst for upgrading biomass fuel gas. J. Energy Inst. https://doi.org/10.1016/j.joei.2017.02.008

Ren, L., Fu, Z., Wang, Y., Zhang, F., Zhang, J., Wang, W., Wang, H., 2015. Fabrication of transparent mullite ceramic by spark plasma sintering from powders synthesized via sol-gel process combined with pulse current heating. Mater. Des. 83, 753-759. https://doi.org/10.1016/j.matdes.2015.06.046

Rendtorff, N., Garrido, L., Aglietti, E., 2009. Mullite-zirconia-zircon composites: Properties and thermal shock resistance. Ceram. Int. 35, 779-786. https://doi.org/10.1016/j.ceramint.2008.02.015

Ribero, D., Restrepo, R., Paucar, C., García, C., 2009. Highly refractory mullite obtained through the route of hydroxyhydrogels. J. Mater. Process. Technol. 209, 986-990. https://doi.org/10.1016/j.jmatprotec.2008.03.028

Rietveld, H.M., 1969. A profile refinement method for nuclear and magnetic structures. J. Appl. Crystallogr. 2, 65-71. https://doi.org/10.1107/S0021889869006558

Roy, D., Bagchi, B., Das, S., Nandy, P., 2013. Electrical and dielectric properties of sol-gel derived mullite doped with transition metals. Mater. Chem. Phys. 138, 375-383. https://doi.org/10.1016/j.matchemphys.2012.11.070

Sahnoun, R.D., Bouaziz, J., 2012. Sintering characteristics of kaolin in the presence of phosphoric acid binder. Ceram. Int. 38, 1-7. https://doi.org/10.1016/j.ceramint.2011.06.058

Sahraoui, T., Belhouchet, H., Heraiz, M., Brihi, N., Guermat, A., 2016. The effects of mechanical activation on the sintering of mullite produced from kaolin and aluminum powder. Ceram. Int. 42, 12185-12193. https://doi.org/10.1016/j.ceramint.2016.04.157

Saikia, N.J., Bharali, D.J., Sengupta, P., Bordoloi, D., Goswamee, R.L., Saikia, P.C., Borthakur, P.C., 2003. Characterization, beneficiation and utilization of a kaolinite clay from Assam, India. Appl. Clay Sci. 24, 93-103. https://doi.org/10.1016/S0169-1317(03)00151-0

Santana, L.N.L., Gomes, J., Menezes, R.R., Neves, G.A., Lira, H.L., Segadães, A.M., 2017. Microstructure development in clays upon heat treatment: Kinetics and equilibrium. Appl. Clay Sci. 135, 325-332. https://doi.org/10.1016/j.clay.2016.10.014

Schaafhausen, S., Yazhenskikh, E., Walch, A., Heidenreich, S., Müller, M., 2013. Corrosion of alumina and mullite hot gas filter candles in 
gasification environment. J. Eur. Ceram. Soc. 33, 3301-3312. https://doi.org/10.1016/j.jeurceramsoc.2013.05.024

Schneider, H., Schreuer, J., Hildmann, B., 2008. Structure and properties of mullite-A review. J. Eur. Ceram. Soc., Papers Presented at the International Workshop Mullite 2006. Hartmut Schneider: An Appreciation.Mullite $2006 \quad 28, \quad 329-344$. https://doi.org/10.1016/j.jeurceramsoc.2007.03.017

Scian, A.N., Pereira, E., 1994. Mechanochemical activation of high alumina cements - hydration and thermomechanic behaviour. II. Cem. Concr. Res. 24, 937-947. https://doi.org/10.1016/0008-8846(94)90014-0

Sen, S., Thiagarajan, S., 1988. Phase-transformations in amorphous 3Al2O3-2SiO2 system prepared by sol-gel method. Ceram. Int. 14, $77-86$.

Sergey Shmotev, Sergey Pliner, 2009. Ceramic proppant with low specific weight. US7521389 B2.

Srivastava, M., Muniprakash, M., Singh, S.K., 2014. Synthesis of fused mullite and its use in multifunctional nickel based composite coating. Surf. Coat. Technol. 245, 148-155. https://doi.org/10.1016/j.surfcoat.2014.02.053

Stabile, F.M., 2016. Effects of Incorporating Natural Minerals on Production and Bioactivity of Bioactive Glass Ceramics. Ceram. - Silik. 1-9. https://doi.org/10.13168/cs.2016.0028

Studart, A.R., Gonzenbach, U.T., Tervoort, E., Gauckler, L.J., 2006. Processing Routes to Macroporous Ceramics: A Review. J. Am. Ceram. Soc. 89, 1771-1789. https://doi.org/10.1111/j.15512916.2006.01044.x

Takahara, H., 1994. The sound absorption characteristics of particulate porous ceramic materials. Appl. Acoust. 41, 265-274. https://doi.org/10.1016/0003-682X(94)90076-0

Tang, Q., Xue, G., Yang, S., Wang, K., Cui, X., 2017. Study on the preparation of a free-sintered inorganic polymer-based proppant using the suspensions solidification method. J. Clean. Prod. 148, 276282. https://doi.org/10.1016/j.jclepro.2017.02.001

Taslicukur, Z., Balaban, C., Kuskonmaz, N., 2007. Production of ceramic foam filters for molten metal filtration using expanded polystyrene. J. Eur. Ceram. Soc., Refereed Reports IX Conference \& Exhibition of the European Ceramic Society 27, 637-640. https://doi.org/10.1016/j.jeurceramsoc.2006.04.129 
Uchisawa, J., Obuchi, A., Ohi, A., Nanba, T., Nakayama, N., 2008. Activity of catalysts supported on heat-resistant ceramic cloth for diesel soot oxidation. Powder Technol. 180, 39-44. https://doi.org/10.1016/j.powtec.2007.05.019

U.S. Energy Information Administration, 2013. EIA/AIR Technically Recoverable Shale Gas and Shale Oil Resources: An Assessment of 137 Shale Formations in 41 Countries Outside the United States. U.S. Energy Information Administration U.S. Department of Energy.

Vallés Jorge M., 2011. Arcillas caolníticas del jurásico, in: Relatorio Del XVIII Congreso Geológico Argentino. Neuquén, pp. 763-766.

Vippola, M., Keränen, J., Zou, X., Hovmöller, S., Lepistö, T., Mäntylä, T., 2000. Structural Characterization of Aluminum Phosphate Binder. J. Am. Ceram. Soc. 83, 1834-1836. https://doi.org/10.1111/j.11512916.2000.tb01477.x

Viswabaskaran, V., Gnanam, F.D., Balasubramanian, M., 2004. Mullite from clay-reactive alumina for insulating substrate application. Appl. Clay Sci. 25, 29-35. https://doi.org/10.1016/j.clay.2003.08.001

Wagh, A.S., 2016. Chapter 12 - Iron Phosphate Ceramics, in: Chemically Bonded Phosphate Ceramics (Second Edition). Elsevier, pp. 157-164. https://doi.org/10.1016/B978-0-08-100380-0.00012-9

Wagh, A.S., 2013. Recent Progress in Chemically Bonded Phosphate Ceramics [WWW Document]. Int. Sch. Res. Not. https://doi.org/10.1155/2013/983731

Wagh, A.S., Jeong, S.Y., 2003. Chemically Bonded Phosphate Ceramics: I, A Dissolution Model of Formation. J. Am. Ceram. Soc. 86, 1838-1844. https://doi.org/10.1111/j.1151-2916.2003.tb03569.x

Wu, P., Du, N., Zhang, H., Zhai, C., Yang, D., 2011. Self-templating synthesis of SnO2-carbon hybrid hollow spheres for superior reversible lithium ion storage. ACS Appl. Mater. Interfaces 3, 19461952. https://doi.org/10.1021/am200168w

$\mathrm{Wu}, \mathrm{T} ., \mathrm{Wu}, \mathrm{B} ., 2012$. Corrosion resistance of ceramic proppant in BaOCaO-P2O5-Al2O3 system. Corros. Sci. 63, 399-403. https://doi.org/10.1016/j.corsci.2012.06.025

Wu, T., Wu, B., Zhao, S., 2013. Acid resistance of silicon-free ceramic proppant. Mater. $\quad$ Lett. $210-212$. https://doi.org/10.1016/j.matlet.2012.10.124

Wu, T., Zhou, J., Wu, B., 2015. Effect of TiO2 content on the acid resistance of a ceramic proppant. Corros. Sci. 98, 716-724. https://doi.org/10.1016/j.corsci.2015.06.012 
Wu, X., Huo, Z., Ren, Q., Li, H., Lin, F., Wei, T., 2017. Preparation and characterization of ceramic proppants with low density and high strength using fly ash. J. Alloys Compd. 702, 442-448. https://doi.org/10.1016/j.jallcom.2017.01.262

Xiong, J.Q., Peng, Y.T., Xie, D.Y., Mao, X.S., 2012. The Characteristics of Silica-Sol Combining Refractories. Adv. Mater. Res. 396-398, 288291. https://doi.org/10.4028/www.scientific.net/AMR.396-398.288

Xu, G., Ma, Y., Ruan, G., Cui, H., Zhang, Z., Bai, B., 2013. Preparation of porous Al2TiO5 ceramics reinforced by in situ formation of mullite whiskers. Mater. Des. 47, 57-60. https://doi.org/10.1016/j.matdes.2012.12.028

Yang, H.X., Qian, J.F., Chen, Z.X., Ai, X.P., Cao, Y.L., 2007. Multilayered nanocrystalline $\mathrm{SnO} 2$ hollow microspheres synthesized by chemically induced self-assembly in the hydrothermal environment. J. Phys. Chem. C 111, 14067-14071. https://doi.org/10.1021/jp074159a

Yuan, K., Jin, X., Yu, Z., Gan, X., Wang, X., Zhang, G., Zhu, L., Xu, D., 2018. Electrospun mesoporous zirconia ceramic fibers for catalyst supporting applications. Ceram. Int. 44, 282-289. https://doi.org/10.1016/j.ceramint.2017.09.171

Żbik, M.S., Raftery, N.A., Smart, R.S.C., Frost, R.L., 2010. Kaolinite platelet orientation for XRD and AFM applications. Appl. Clay Sci. 50, 299304. https://doi.org/10.1016/j.clay.2010.08.010

Zhang, J., Liu, K., Cao, M., 2017. Experimental study on modified polyacrylamide coated self-suspending proppant. Fuel 199, 185-190. https://doi.org/10.1016/j.fuel.2017.02.103

Zhao, J., Liu, Z., Li, Y., 2015. Preparation and characterization of lowdensity mullite-based ceramic proppant by a dynamic sintering method. Mater. Lett. 152, 72-75. https://doi.org/10.1016/j.matlet.2015.03.060

Zhao, X., Cong, Y., Lv, F., Li, L., Wang, X., Zhang, T., 2010. Mullitesupported Rh catalyst: a promising catalyst for the decomposition of N2O propellant. Chem. Commun. 46, 3028. https://doi.org/10.1039/b925085a

Zhu, B., Fang, B., Li, X., 2010. Dehydration reactions and kinetic parameters of gibbsite. Ceram. Int. 36, 2493-2498. https://doi.org/10.1016/j.ceramint.2010.07.007

Zoveidavianpoor, M., Gharibi, A., 2015. Application of polymers for coating of proppant in hydraulic fracturing of subterraneous formations: A comprehensive review. J. Nat. Gas Sci. Eng. 24, 197-209. https://doi.org/10.1016/j.jngse.2015.03.024 



\section{Anexo I}

Métodos de cuantificación basados en $D R X$

\section{Método de Rietveld}

El método de Rietveld es un método cuantitativo desarrollado en 1969 para refinar estructuras cristalinas a partir de datos obtenidos por medio de difracción de electrones (Rietveld, 1969); se ha ido extendiendo su uso y en la actualidad se lo utiliza para la realización de análisis estructurales, determinación de defectos cristalinos, medición de parámetros reticulares y análisis cuantitativo en difractometría de polvos por rayos $\mathrm{X}$.

La técnica consiste en ajustar punto a punto las intensidades experimentales ( $\mathrm{y}_{\mathrm{i}}$ obs) con las intensidades calculadas ( $\mathrm{y}_{\mathrm{i}}^{\mathrm{cal}}$ ) en base a un 
modelo de estructura cristalino determinado, el cual considera los efectos ópticos de difracción, los factores instrumentales y otras características de la muestra. Los parámetros que se incluyen en la ecuación del modelos son refinados hasta obtener el mejor ajuste de cuadrados minimos para los $\mathrm{y}_{\mathrm{i}}$ pertenecientes al difractograma. La cantidad a minimizar es el residual Ry que se encuentra definido en la ec a.1.

$$
\mathrm{Ry}=\sum_{\mathrm{i}} \mathrm{w}_{\mathrm{i}}\left(\mathrm{y}_{\mathrm{i}}^{\mathrm{obs}}-\mathrm{y}_{\mathrm{i}}^{\mathrm{cal}}\right)^{2}
$$

Con el peso estadístico $\mathrm{w}_{\mathrm{i}}=1 / \mathrm{y}_{\mathrm{i}}$ obs

Las intensidades calculadas $\left(\mathrm{y}_{\mathrm{i}}\right.$ cal) para cada punto del difractograma se obtienen a partir de la suma de la contribución de todas las reflexiones $(\mathrm{k})$ que dan intensidad a ese punto i por encima del fondo, ybi (ec. a.2).

$$
y_{i}^{\text {cal }}=\sum_{\mathrm{p}} \mathrm{S}_{\mathrm{p}} \sum_{\mathrm{K}} \mathrm{L}_{\mathrm{k}}\left|\mathrm{F}_{\mathrm{k}}\right|^{2} \varphi\left(2 \theta_{\mathrm{i}}-2 \theta_{\mathrm{k}}\right) \mathrm{P}_{\mathrm{k}} \mathrm{A}+\mathrm{y}_{\mathrm{bi}} \quad \text { ec. } \mathbf{a} .2
$$

Donde $\mathrm{S}_{\mathrm{p}}$ es el factor de escala de la fase $\mathrm{p}$; $\mathrm{K}$ representa los índices de Miller para una reflexión de Bragg; $\mathrm{L}_{\mathrm{K}}$ contiene los factores de Lorentz, polarización y multiplicidad; $\varphi_{K}$ es la función del perfil de la reflexión, $P_{K}$ es la función de orientación preferencial; A es un factor de absorción; $\mathrm{F}_{\mathrm{K}}$ es el factor de estructura de la K-ésima reflexión de Bragg e ybi, como se mencionó anteriormente, es la intensidad del fondo en el punto i.

El análisis cuantitativo se realiza a partir de los factores de escala refinados para cada fase $\left(\mathrm{S}_{\mathrm{i}}\right)$ de acuerdo con la siguiente ec. a.3.

$$
W_{i}=\frac{S_{i}(Z M V)_{i}}{\sum_{p} S_{p}(Z M V)_{p}} \quad \text { ec. a.3 }
$$


Dónde: $\mathrm{W}_{\mathrm{i}}, \mathrm{S}_{\mathrm{i}}, \mathrm{Z}_{\mathrm{i}}, \mathrm{M}_{\mathrm{i}} \mathrm{y} \mathrm{V}_{\mathrm{i}}$ es la fracción en peso, el factor de escala, el número de moléculas por celda unidad, el peso molecular y el volumen de la para la fase i, respectivamente. La suma se encuentra normalizada y se realiza sobre todas las fases presentes (sumatoria en el denominador).

Para realizar la cuantificación de las fases por el método de Rietveld, los difractogramas obtenidos como se mencionó en la sección 3.1 se analizaron con el programa FULL-PROF. Los datos cristalográficos de inicio de cada fase fueron extraídos de la literatura y de los datos cristalográficos obtenidos de las tarjetas de rayos X (Anexo II).

Para utilizar el método de Rietveld se debe conocer la estructura cristalina de cada fase presente en la muestra, por lo cual este método no nos permite cuantificar la fase amorfa o no cristalina. Entonces en los casos donde existe un contenido considerable de fase amorfa, la cuantificación de las fases cristalinas presentes será errónea, ya que el método normaliza al $100 \%$ sólo a las fases que se están teniendo en cuenta. Por este motivo, varios autores han desarrollado técnicas complementarias al método Rietvield como son el método de Ohlberg y el método del patrón externo que se explican a continuación.

\section{Método de Ohlberg}

El metodo desarrollado por Ohlberg en 1962 es un método semicuantitativo que permite determinar el porcentaje de fase cristalina en vidrios parcialmente desvitrificados a partir de la interpolación de la línea de base del difractograma entre las correspondientes a una sílice amorfa y a una sílice completamente cristalina (cuarzo) (Ohlberg and Strickler, 1962). El porcentaje de fase cristalina se calcula a partir de la ec. a.4 en la cual $\mathrm{I}_{\mathrm{v}}$ 
es la intensidad de la fase $100 \%$ amorfa, $\mathrm{I}_{\mathrm{m}}$ es la intensidad de la muestra parcialmente cristalina e $I_{c}$ es la intensidad de la muestra $100 \%$ cristalina. Todas las intensidades medidas en $2 \theta=22,5^{\circ}$.

$$
\% \mathrm{C}=\frac{\left(\mathrm{I}_{\mathrm{v}}-\mathrm{I}_{\mathrm{m}}\right)}{\left(\mathrm{I}_{\mathrm{v}}-\mathrm{I}_{\mathrm{C}}\right)} \times 100
$$

ec. a.4

A partir de esta ecuación es válido definir el porcentaje de fase amorfa (\%NC) como el complementario de la fase cristalina (ec. a.5) (Conconi et al., 2011).

$$
\% N C=100-\% C=100 \times\left[1-\frac{\left(I_{v}-I_{m}\right)}{\left(I_{v}-I_{c}\right)}\right]=100 \times \frac{\left(I_{m}-I_{c}\right)}{\left(I_{v}-I_{c}\right)} \quad \text { ec.a.5 }
$$

En este trabajo para determinar el porcentaje de fase amorfa a partir del método de Ohlberg, se utilizó vidrio de sílice como fase 100\% amorfa y cuarzo como fase $100 \%$ cristalina.

\section{Método del patrón externo}

El método del patrón externo se utiliza para determinar el porcentaje de fases cristalinas presentes en una muestra a partir de los datos obtenidos por difracción de rayos X y utilizando el método de Rietveld (Álvarez-Pinazo et al., 2012; Aranda et al., 2012). La ventaja de esta técnica es que no se necesita contaminar y/o diluir la muestra con una muestra estándar. 
La técnica consiste en determinar la constante del difractómetro (G) con los datos del difractograma de la muestra estándar (en este caso se utilizó alúmina cristalina de 99,9\% de pureza) a partir de la ec. a.6.

$$
\mathrm{G}=\mathrm{S}_{\mathrm{st}} \frac{\rho_{\mathrm{st}} \mathrm{V}_{\mathrm{st}}^{2} \mu_{\mathrm{st}}}{\mathrm{W}_{\mathrm{st}}} \quad \text { ec. } \mathbf{a} \cdot 6
$$

Donde $\mathrm{S}_{\text {st }}$ es el factor de escala, $\rho_{\text {st }}$ es la densidad, $V_{\text {st }}$ es el volumen de la celda unidad y $\mathrm{W}_{\text {st }}$ es el porcentaje en peso de la fase cristalina (en este caso 100) en la muestra estándar. Todos estos parámetros son obtenidos a partir del refinamiento del difractograma del patrón estándar con el método de Rietvield, el cual fue realizado bajo las mismas condiciones de barrido (adquisición de datos) que las muestras en cuestión. Por otro lado, $\mu_{\text {st }}$ es el coeficiente de absorción másica de la muestra cuyo valor fue sacado de la literatura (Álvarez-Pinazo et al., 2012).

El factor G calculado con la ec. a.6 representa un factor de calibración para toda la configuración experimental que comprende el difractómetro usado, la radiación, la óptica y todas las condiciones de adquisición de datos, (configuración del detector, tiempo de integración, etc.). Luego este factor G es utilizado para obtener el porcentaje de cada fase cristalina $\left(\mathrm{W}_{\alpha}\right)$ (ec. a.7).

$$
\mathrm{W}_{\alpha}=\mathrm{S}_{\alpha} \frac{\rho_{\alpha} \mathrm{V}_{\alpha}{ }^{2} \mu_{\alpha}}{\mathrm{G}} \quad \text { ec. } \mathbf{a} .7
$$

Donde $\mathrm{S}_{\alpha}$ es el factor de escala, $\rho_{\alpha}$ es la densidad y $\mathrm{V}_{\alpha}$ es el volumen de la celda unidad de la fase a determinados a partir del refinamiento del diagrama de rayos $\mathrm{X}$ de la muestra con el método de Rietveld; y $\mu_{\alpha}$ es el coeficiente de absorción másica obtenido de la literatura. 
El porcentaje de fase amorfa o no cristalina (\%NC) deriva de restarle a 100 la suma de los porcentajes de todas las fases cristalinas presentes en la muestra (ec. a.8). Dónde $\mathrm{W}_{\mathrm{a}}$ es el porcentaje de las a fases cristalinas que componen la muestra.

$$
\% \mathrm{NC}=100-\sum_{\alpha} \mathrm{W}_{\alpha} \quad \text { ec. a.8 }
$$




\title{
Anexo II
}

\author{
Tarjetas de rayos $X$ utilizadas en el método de \\ Rietveld
}

\begin{tabular}{|c|c|}
\hline Reference Pattern: 01-083-2384 & \\
\hline Name and formula & \\
\hline Reference code: & 01-083-2384 \\
\hline $\begin{array}{l}\text { Mineral name: } \\
\text { ICSD name: }\end{array}$ & $\begin{array}{l}\text { Boehmite } \\
\text { Aluminum Oxid }\end{array}$ \\
\hline $\begin{array}{l}\text { Empirical formula: } \\
\text { Chemical formula: }\end{array}$ & $\begin{array}{l}\mathrm{AlHO} \\
\mathrm{AlO}(\mathrm{OH})\end{array}$ \\
\hline Crystallographic parar & ters \\
\hline $\begin{array}{l}\text { Crystal system: } \\
\text { Space group: } \\
\text { Space group number: }\end{array}$ & $\begin{array}{l}\text { Orthorhombic } \\
\text { Amam } \\
63\end{array}$ \\
\hline$a(A):$ & 3,6936 \\
\hline$b(A):$ & 12,2140 \\
\hline$c(A)$ & 2,8679 \\
\hline Alpha (\%): & 90,0000 \\
\hline Beta (\%): & 90,0000 \\
\hline Gamma (): & 90,0000 \\
\hline Calculated density $\left(\mathrm{g} / \mathrm{cm}^{\wedge} 3\right)$ : & 3,08 \\
\hline Volume of cell $\left(10^{\wedge} 6 \mathrm{pm}^{\wedge} 3\right)$ : & 129,38 \\
\hline $\mathrm{Z}:$ & 4,00 \\
\hline RIR: & 2,25 \\
\hline
\end{tabular}

Reference Pattern: 01-079-1570

\section{Name and formula}

$\begin{array}{ll}\text { Reference code: } & 01-079-1570 \\ \text { Mineral name: } & \text { Kaolinite } \\ \text { ICSD name: } & \text { Aluminum Silicate Hydrate } \\ \text { Empirical formula: } & \mathrm{Al}_{2} \mathrm{H}_{4} \mathrm{O}_{9} \mathrm{Si}_{2} \\ \text { Chemical formula: } & \mathrm{Al}_{2}\left(\mathrm{Si}_{2} \mathrm{O}_{5}\right)(\mathrm{OH})_{4}\end{array}$

\section{Crystallographic parameters}

\begin{tabular}{|c|c|}
\hline $\begin{array}{l}\text { Crystal system: } \\
\text { Space group: }\end{array}$ & $\begin{array}{l}\text { Anorthic } \\
\mathrm{C} 1\end{array}$ \\
\hline$a(\hat{A}):$ & 5,1554 \\
\hline$b(A):$ & 8,9448 \\
\hline$c(A):$ & 7,4048 \\
\hline Alpha (\%): & 91,7000 \\
\hline Beta (): & 104,8620 \\
\hline Gamma ("): & 89,8220 \\
\hline Calculated density $\left(\mathrm{g} / \mathrm{cm}^{\wedge} 3\right)$ : & 2,60 \\
\hline Volume of cell $\left(10^{\wedge} 6 \mathrm{pm}^{\wedge} 3\right)$ : & 164,95 \\
\hline z: & 2,00 \\
\hline RIR: & 0,98 \\
\hline
\end{tabular}


Reference Pattern: 01-083-0539

Name and formula

Reference code:

01-083-0539

Mineral name:

Quartz

ICSD name:

Silicon Oxide

Empirical formula:

$\mathrm{O}_{2} \mathrm{Si}$

Chemical formula:

$\mathrm{SiO}_{2}$

\section{Crystallographic parameters}

Crystal system:

Space group:

Space group number:

Hexagonal

P3121

152

$a(A)$ :

b (A):

4,9210

4,9210

5,4163

Alpha (): $\quad 90,0000$

Beta (): $\quad 90,0000$

Gamma ("): $\quad 120,0000$

Calculated density $\left(\mathrm{g} / \mathrm{cm}^{\wedge} 3\right): \quad 2,63$

Volume of cell $\left(10^{\wedge} 6 \mathrm{pm}^{\wedge} 3\right)$ : $\quad 113,59$

Z:

3,00

RIR:

3,07

Reference Pattern: 01-074-1775

Name and formula

$\begin{array}{ll}\text { Reference code: } & \text { 01-074-1775 } \\ \text { Mineral name: } & \text { Gibbsite } \\ \text { ICSD name: } & \text { Aluminum Hydroxide } \\ \text { Empirical formula: } & \mathrm{AlH}_{3} \mathrm{O}_{3} \\ \text { Chemical formula: } & \mathrm{Al}(\mathrm{OH})_{3}\end{array}$

\section{Crystallographic parameters}

\begin{tabular}{|c|c|}
\hline $\begin{array}{l}\text { Crystal system: } \\
\text { Space group: } \\
\text { Space group number: }\end{array}$ & $\begin{array}{l}\text { Monoclinic } \\
\text { P21/n } \\
14\end{array}$ \\
\hline $\mathrm{a}(\mathrm{A})$ : & 8,6760 \\
\hline$b(A):$ & 5,0700 \\
\hline$c(A)$ & 9,7210 \\
\hline Alpha (): & 90,0000 \\
\hline Beta (): & 94,5700 \\
\hline Gamma ("): & 90,0000 \\
\hline Calculated density $\left(\mathrm{g} / \mathrm{cm}^{\wedge} 3\right)$ : & 2,43 \\
\hline Measured density $\left(\mathrm{g} / \mathrm{cm}^{\wedge} 3\right)$ : & 2,42 \\
\hline Volume of cell $\left(10^{\wedge} 6 \mathrm{pm}^{\wedge} 3\right)$ : & 426,24 \\
\hline$z:$ & 8,00 \\
\hline
\end{tabular}


Reference Pattern: 00-002-0272

\section{Name and formula}

$\begin{array}{ll}\text { Reference code: } & 00-002-0272 \\ \text { Mineral name: } & \text { Goethite } \\ \text { POF index name: } & \text { Iron Oxide Hydrate } \\ \text { Empirical formula: } & \mathrm{Fe}_{2} \mathrm{H}_{2} \mathrm{O}_{4} \\ \text { Chemicol formula: } & \mathrm{Fe}_{2} \mathrm{O}_{3} \cdot \mathrm{H}_{2} \mathrm{O}\end{array}$

\section{Crystallographic parameters}

\begin{tabular}{|c|c|}
\hline $\begin{array}{l}\text { Orystal system: } \\
\text { Space group: } \\
\text { Space group number. }\end{array}$ & $\begin{array}{l}\text { Orthorhombic } \\
\text { Pbnm } \\
62\end{array}$ \\
\hline$a(A):$ & 4,5870 \\
\hline$b(A):$ & 9,9370 \\
\hline$c(A):$ & 3,0150 \\
\hline Alpha (): & 90,0000 \\
\hline Beta (): & 90,0000 \\
\hline Gomma ( $):$ & 90,0000 \\
\hline Meosured density $\left(\mathrm{g} / \mathrm{cm}^{\wedge} 3\right)$ : & 4,28 \\
\hline Volume of cell $\left(10^{\circ} 6 \mathrm{pm} \cap 3\right)$ : & 137,43 \\
\hline $\mathrm{Z}$ & 4,00 \\
\hline RIR: & $=$ \\
\hline
\end{tabular}

Reference Pattern: 00-034-0180

\section{Name and formula}

$\begin{array}{ll}\text { Reference code: } & 00-034-0180 \\ \text { Mineral name: } & \text { Rutile, syn } \\ \text { PDF index name: } & \text { Titanium Oxide } \\ \text { Empirical formula: } & \mathrm{O}_{2} \mathrm{Ti} \\ \text { Chemical formula: } & \mathrm{TiO}_{2}\end{array}$

\section{Crystallographic parameters}

\begin{tabular}{|c|c|}
\hline $\begin{array}{l}\text { Crystal system: } \\
\text { Space group: } \\
\text { Space group number: }\end{array}$ & $\begin{array}{l}\text { Tetragonal } \\
\mathrm{P} 42 / \mathrm{mnm} \\
136\end{array}$ \\
\hline$a(A):$ & 4,5930 \\
\hline$b(A):$ & 4,5930 \\
\hline$c(A):$ & 2,9590 \\
\hline Alpha (0): & 90,0000 \\
\hline Beta (): & 90,0000 \\
\hline Gamma (): & 90,0000 \\
\hline Calculated density $\left(\mathrm{g} / \mathrm{cm}^{\wedge} 3\right)$ : & 4,25 \\
\hline Volume of cell $\left(10^{\wedge} 6 \mathrm{pm}^{\wedge} 3\right)$ : & 62,42 \\
\hline z: & 2,00 \\
\hline RIR: & 9,96 \\
\hline
\end{tabular}


Reference Pattern: 00-003-0849

\section{Name and formula}

$\begin{array}{ll}\text { Reference code: } & 00-003-0849 \\ \text { Mineral name: } & \text { Muscovite } \\ \text { PDF index name: } & \text { Hydrogen Potassium Aluminum Silicate } \\ \text { Empirical formula: } & \mathrm{Al}_{6} \mathrm{H}_{4} \mathrm{~K}_{2} \mathrm{O}_{24} \mathrm{Si}_{6} \\ \text { Chemical formula: } & \mathrm{H}_{4} \mathrm{~K}_{2}(\mathrm{Al}, \mathrm{Fe})_{6} \mathrm{Si}_{6} \mathrm{O}_{24}\end{array}$

\section{Crystallographic parameters}

Crystal system:

Space group:

Space group number:

Monoclinic

$\mathrm{C} 2 / \mathrm{C}$

$\begin{array}{lr}\text { a }(\hat{A}): & 5,1800 \\ \text { b (A): } & 9,0200 \\ \text { c( }(\hat{A}): & 20,0400 \\ \text { Alpha ( }): & 90,0000 \\ \text { Beta }(): & 95,5000 \\ \text { Gamma ( }): & 90,0000 \\ & \\ \text { Measured density }\left(\mathrm{g} / \mathrm{cm}^{\wedge} 3\right): & 2,88 \\ \text { Volume of cell }\left(10^{\wedge} 6 \mathrm{pm}^{\wedge} 3\right): & 932,03 \\ \text { Z: } & 4,00 \\ & \end{array}$

RIR:

Reference Pattern: 01-079-1275

Name and formula

$\begin{array}{ll}\text { Reference code: } & 01-079-1275 \\ \text { Mineral name: } & \text { Mullite } \\ \text { ICSD name: } & \text { Aluminum Silicon Oxide } \\ \text { Empirical formula: } & \mathrm{Al}_{4.80} \mathrm{O}_{9.60} \mathrm{Si}_{1.20} \\ \text { Chemical formula: } & \mathrm{Al}_{2}\left(\mathrm{Al}_{2.8} \mathrm{Si}_{1.2}\right) \mathrm{O}_{9.6}\end{array}$

\section{Crystallographic parameters}

\begin{tabular}{|c|c|}
\hline $\begin{array}{l}\text { Crystal system: } \\
\text { Space group: } \\
\text { Space group number: }\end{array}$ & $\begin{array}{l}\text { Orthorhombic } \\
\text { Pbam } \\
55\end{array}$ \\
\hline$a(A):$ & 7,5880 \\
\hline$b(\hat{A}):$ & 7,6880 \\
\hline$c(A):$ & 2,8895 \\
\hline Alpha (): & 90,0000 \\
\hline Beta (\%): & 90,0000 \\
\hline Gamma (): & 90,0000 \\
\hline Calculated density $\left(\mathrm{g} / \mathrm{cm}^{\wedge} 3\right)$ : & 3,12 \\
\hline Volume of cell $\left(10^{\wedge} 6 \mathrm{pm}^{\wedge} 3\right)$ : & 168,56 \\
\hline Z: & 1,00 \\
\hline RIR: & 0,75 \\
\hline
\end{tabular}


Reference Pattern: 01-082-0512

$\begin{array}{ll}\text { Name and formula } & \\ \text { Reference code: } & 01-082-0512 \\ \text { Mineral name: } & \text { Cristobalite } \\ \text { ICSD name: } & \text { Silicon Oxide } \\ \text { Empirical formula: } & \mathrm{O}_{2} \mathrm{Si} \\ \text { Chemical formula: } & \mathrm{SiO}_{2}\end{array}$

\section{Crystallographic parameters}

\begin{tabular}{|c|c|}
\hline $\begin{array}{l}\text { Crystal system: } \\
\text { Space group: } \\
\text { Space group number: }\end{array}$ & $\begin{array}{l}\text { Tetragonal } \\
\text { P41212 } \\
92\end{array}$ \\
\hline $\mathrm{a}(\hat{A}):$ & 4,9970 \\
\hline$b(A):$ & 4,9970 \\
\hline$c(A):$ & 7,0700 \\
\hline Alpha (\%): & 90,0000 \\
\hline Beta ( ): & 90,0000 \\
\hline Gamma (): & 90,0000 \\
\hline Calculated density $\left(\mathrm{g} / \mathrm{cm}^{\wedge} 3\right)$ : & 2,26 \\
\hline Volume of cell $\left(10^{\wedge} 6 \mathrm{pm} \wedge 3\right)$ : & 176,54 \\
\hline $\mathrm{z}$ & 4,00 \\
\hline RIR: & 5,35 \\
\hline
\end{tabular}




\section{Anexo III}

\section{Publicaciones científicas y técnicas generadas en el marco de la tesis}

\section{Publicaciones en revistas científicas}

Mocciaro A; Lombardi M.B; Scian A. N. Effect of raw material milling on ceramic proppants properties. Applied Clay Science. Marzo 2018. N ${ }^{\circ} 153$ pp.90-94. DOI:10.1016/j.clay.2017.12.009

Mocciaro A; Lombardi M.B; Scian A. N. Ceramic Material Porous Structure Prepared Using Pore-Forming Additives. Refractories and Industrial Ceramics. Julio 2017. Translated from Novye Ogneupory, $\mathrm{N}^{\circ} 1$, pp. 54 - 57, January, 2017. DOI: 10.1007/s11148-017-0055-6

Mocciaro A; Lombardi M.B; Scian A. N. Desarrollo de materiales cerámicos refractarios de baja densidad a partir de agentes ligantes nanoestructurados y carbón. Boletín de la Sociedad Española de Cerámica y Vidrio. Noviembre- diciembre 2017. $\mathrm{N}^{\circ} 56$ (6) pp. 243-248. DOI: 10.1016/j.bsecv.2017.05.003 
Publicaciones en actas de congresos

Mocciaro A; Lombardi M.B; Scian A. N. Desarrollo de agentes de sostén cerámicos de baja densidad y comparación con los disponibles en el mercado. $3^{\text {a }}$ Jornada Nacional de Investigación Cerámica. JONICER 2017. ATAC-INTEMA-CONICET. Mar del Plata, Octubre 2017.

Mocciaro A; Lombardi M.B; Scian A. N. Elaboración y caracterización de materiales silicoaluminosos ligados con fosfato de aluminio. $16^{\circ}$ Congreso Internacional de Metalurgia y Materiales SAM-CONAMET. Córdoba, 22 al 25 de noviembre de 2016.

Mocciaro A; Lombardi M.B; Scian A. N. Liga fósforica a alta temperatura en arcilla caolinítica. XIII Jornadas Argentinas de Tratamiento de Minerales. Mendoza, 5, 6 y 7 de octubre de 2016.

Mocciaro A; Cipollone M; Lombardi M.B; Scian A. N. Estudio de la Textura Porosa de un Cerámico Elaborado con Tres Agentes Formadores de Poro. $15^{\circ}$ Congreso Internacional de Metalurgia y Materiales. CONAMETSAM. Noviembre 2015Concepción, Chile.

Mocciaro A; Lombardi M.B; Scian A. N. Desarrollo de materiales cerámicos con liga nanoestructurada de potencial uso en la extracción de shale gas/oil. VIII Congreso Argentino de Ingeniería Química. Asociación Argentina de Ingeniería Química (AAIQ). Agosto 2015 Buenos Aires, Argentina.

Mocciaro A; Lombardi M.B; Scian A. N. Obtención de cerámicos de baja densidad y alta resistencia mecánica utilizando el sistema arcillaMAP- carbón. Jornada Nacional de Investigación Cerámica. JONICER 2015. ATAC-CETMIC. Buenos Aires, Abril 2015. 


\section{Informes técnicos}

A. Mocciaro, M. Bárbara Lombardi, Alberto N. Scian. Fonarsec 2012. Desarrollo de Nanoproductos para la Industria Petrolera. Nano Agentes de Sostén - Nanofluídos - Nanosensores 454/2012. Informe técnico CAPP. ITI 06-17. Junio-Diciembre 2017.

A. Mocciaro, M. Bárbara Lombardi, Alberto N. Scian. Fonarsec 2012. Desarrollo de Nanoproductos para la Industria Petrolera. Nano Agentes de Sostén - Nanofluídos - Nanosensores 454/2012. Informe técnico CAPP. ITI 05-17. Junio-Diciembre 2017.

A. Mocciaro, M. Bárbara Lombardi, Alberto N. Scian. Fonarsec 2012. Desarrollo de Nanoproductos para la Industria Petrolera. Nano Agentes de Sostén - Nanofluídos - Nanosensores 454/2012. Informe técnico CAPP. ITI 04-17.Enero-Junio 2017.

A. Mocciaro, M. Bárbara Lombardi, Alberto N. Scian Fonarsec 2012. Desarrollo de Nanoproductos para la Industria Petrolera. Nano Agentes de Sostén - Nanofluídos - Nanosensores 454/2012. Informe técnico CAPP. ITI C001-16, Abril-Noviembre 2016.

A. Mocciaro, M. Bárbara Lombardi, Alberto N. Scian Fonarsec 2012. Desarrollo de Nanoproductos para la Industria Petrolera. Nano Agentes de Sostén - Nanofluídos - Nanosensores 454/2012. Informe técnico CAPP. ITI C002-16, Abril-Noviembre 2016.

A. Mocciaro, M. Bárbara Lombardi, Alberto N. Scian Fonarsec 2012. Desarrollo de Nanoproductos para la Industria Petrolera. Nano Agentes de Sostén - Nanofluídos - Nanosensores 454/2012. Informe técnico CAPP. Junio-Diciembre 2015. 